\title{
TECHNICAL AREA STATUS REPORT FOR WASTE DESTRUCTION AND STABILIZATION
}

\author{
J. D. Dalton \\ T. L. Harris \\ L. M. DeWitt \\ Science Application International Corporation \\ 545 Shoup Avenue \\ Post Office Box 50697 \\ Idaho Falls, ID 83405-0697
}

August 1993

Prepared for the

Waste Destruction and Stabilization Technical Support Group Mixed Waste Integrated Program

U.S. Department of Energy

Office of Technology Development

Washington, D.C. 20585

under contract DE-AC01-92EW30030

\section{DISCLAIMER}

This report was prepared as an account of work sponsored by an agency of the United States Government. Neither the United States Government nor any agency thereof, nor any of their employees, makes any warranty, express or implied, or assumes any legal liability or responsibility for the accuracy, completeness, or usefulness of any information, apparatus, product, or process disclosed, or represents that its use would not infringe privately owned rights. Reference herein to any specific commercial product, process, or service by trade name, trademark, manufacturer, or otherwise does nr, necessarily constitute or imply its endorsement, recommendation, or favoring by the United States Government or any agency thereof. The views and opinions of authors expressed herein do not necessarily state or reflect those of the United States Government or any agency thereof. 


\section{CONTENTS}

ACRONYMS AND ABBREVIATIONS $\ldots \ldots \ldots \ldots \ldots \ldots \ldots$

1. INTRODUCTION $\ldots \ldots \ldots \ldots \ldots \ldots \ldots \ldots \ldots \ldots \ldots \ldots$

1.1 TECHNICAL SUPPORT GROUP RESPONSIBILITIES $\ldots \ldots \ldots 2$

1.2 WASTE DESTRUCTION AND STABILIZATION TECHNICAL

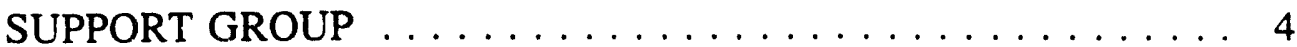

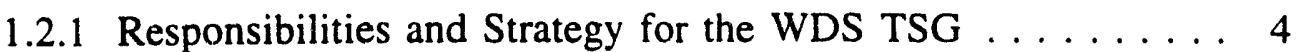

1.2.2 Surrogate Waste Streams for Testing . . . . . . . . . 6

1.2.3 Definitions of Current and Emerging Treatment Tecinologies . . . . . . . . . . . . . . . . . 6

1.2.4 Determination of Treatment Technology Requirements . . . . 6

1.2.5 Technology Evaluation Criteria .............. 7

1.2.6 Selection of Development Projects to be Funded . . . . . 11

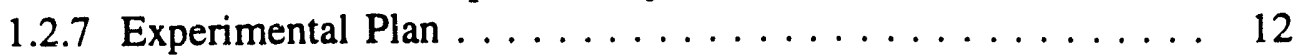

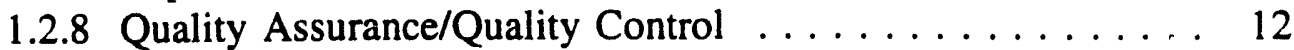

1.2.9 Project Deliverables .................. 13

1.3 SCOPE OF TECHNICAL AREA STATUS REPORT $\ldots \ldots \ldots \ldots 13$

2. DOE WASTE STREAM IDENTIFICATION $\ldots \ldots \ldots \ldots \ldots \ldots \ldots$

3. SUMMARY OF PREVIOUS EFFORTS $\ldots \ldots \ldots \ldots \ldots \ldots \ldots \ldots$ 21

3.1 HAZARDOUS WASTE REMEDIAL ACTIONS PROGRAM

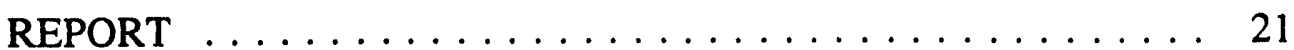

3.2 THERMAL TREATMENT WORKING GROUP REPORT $\ldots \ldots, 22$

3.3 RESEARCH AND DEVELOPMENT PROJECTS .......... 23

4. SUMMARY OF WDS TREATMENT TECHNOLOGIES $\ldots \ldots \ldots \ldots 25$

4.1 INNOVATIVE WASTE DESTRUCTION AND STABILIZATION TECHNOLOGIES . . . . . . . . . . . 26

4.1.1 Thermal Waste Destruction and Stabilization Technologies . 26

4.1.2 Chemical Waste Destruction and Stabilization Technologies . . . . . . . . . . . . . . . . . . 28

4.1.3 Electrochemical Waste Destruction and Stabilization Technologies . . . . . . . . . . . . . . . . . 28

4.1.4 Radiolytic Waste Destruction and Stabilization

Technologies . . . . . . . . . . . . . . . . . . . . . . . 28

4.2 CURRENTLY AVAILABLE WASTE DESTRUCTION AND

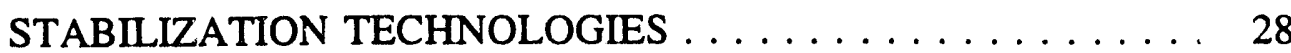

4.2.1 Thermal Waste Destruction and Stabilization Technologies . 30

4.2.2 Chemical Waste Destruction and Stabilization

Technologies . . . . . . . . . . . . . . . 31 
4.2.3 Biological Organic Destruction and Stabilization Technologies 32

4.3 ALTERNATIVES TO INCINERATION . . . . . . . . . . . 32

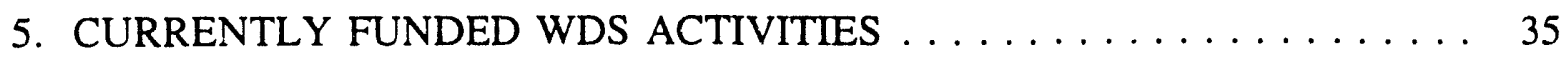

6. RECOMMENDATIONS FOR FUTURE ACTIVITIES $\ldots \ldots \ldots \ldots \ldots \ldots$

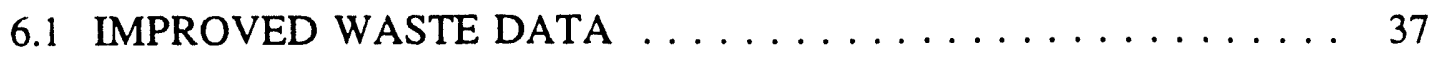

6.2 COMMUNICATIONS IN TECHNOLOGY DEVELOPMENT . . . . 37

6.3 FUTURE DEVELOPMENT ACTIVITIES . . . . . . . . . . . 38

7. REFERENCES ........................... 39

Appendix A: MIXED WASTE CHARACIERIZATION CODE DESCRIPTIONS A-1 Appendix B: DEPARTMENT OF ENERGY'S LOW-LEVEL MIXED WASTE

INVENTORY .......................

Appendix C: THERMAL TREATMENT TECHNOLOGIES . . . . . . . . . . C-1

Appendix D: ADDITIONAL THERMAL TREATMENT TECHNOLOGIES $\ldots \ldots$ D- 1

Appendix E: ADDITIONAL FURNACE TECHNOLOGIES . . . . . . . . . . E-1

Appendix F: MIXED WASTE INTEGRATION PROGRAM TECHNOLOGY NEEDS

STATEMENT AND CALL FOR PROPOSALS FY94 . . . . . . . F F-1 


\section{FIGURES}

1.1 Mixed Waste Integrated Program Technology Areas $\ldots \ldots \ldots \ldots \ldots \ldots$

1.2 MWTP Flow Sheet -. Thermal Treatment Baseline $\ldots \ldots \ldots \ldots \ldots \ldots \ldots$

2.1 Mixed Waste Categories Figure $\ldots \ldots \ldots \ldots \ldots \ldots \ldots \ldots \ldots \ldots \ldots$

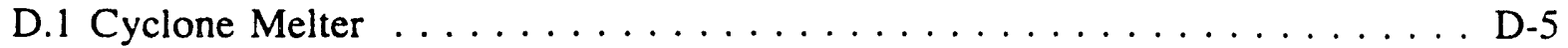

D.2 Graphite Electrode Hearth Melter $\ldots \ldots \ldots \ldots \ldots \ldots \ldots \ldots \ldots \ldots$ D-7

D.3 Fossil Fuel Shaft Furnace $\ldots \ldots \ldots \ldots \ldots \ldots \ldots \ldots \ldots \ldots \ldots$ D-9

D.4 Plasma Torch-Fired Shaft Furnace $\ldots \ldots \ldots \ldots \ldots \ldots \ldots \ldots \ldots$ D-11

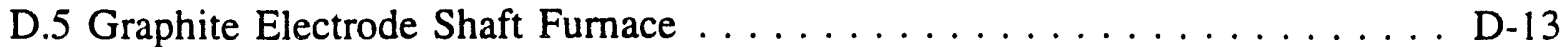

E.1 Simplified Flow Diagram for Catalytic Extraction Process . . . . . . . . . E-3

E.2 Graphical Representation of Mass Flows for a Simplified Molten Metal Bath

Process with Inert Feed $(\mathrm{HHV}=0.0 \mathrm{Btu} / \mathrm{lb}) \ldots \ldots \ldots \ldots \ldots \ldots$ E-6

E.3 Graphical Representation of Energy Flows for a Simplified Molten Metal Bath Process with Inert Feed $(\mathrm{HHV}=0.0 \mathrm{Btu} / \mathrm{lb}) \ldots \ldots \ldots \ldots \ldots \ldots$ E-7

\section{TABLES}

1.1 Mixed Waste Integrated Program Work Breakdown Structure $\ldots . . \ldots \ldots \ldots .2$

4.1 Thermal Treatment Technologies Advantages and Disadvantages . . . . . . . 29

5.1 Summary of FY93 Funded TTP Activities $\ldots \ldots \ldots \ldots \ldots \ldots \ldots$ 


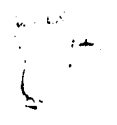




\section{ACRONYMS AND ABBREVIATIONS}

ALARA

as low as reasonably achievable

Ag

Silver

As

Arsenic

ATI

Alternative to Incineration

$\mathrm{Ba}$ barium

BDAT

Best Demonstrated Available Technology

$\mathrm{Br}$ bromine

$\mathrm{C}$

${ }^{\circ} \mathrm{C}$ carbon

$\mathrm{Cd}$ degrees Celsius

CEP cadmium CEPOD Catalytic Extract Process

$\mathrm{Cl}$ chlorine

$\mathrm{CO}$ carbon monoxide

$\mathrm{CO}_{2}$ carbon dioxide

$\mathrm{Cr}$ chromium

D\&D decontamination and decommissioning

DOE Department of Energy

DRE Destruction and Removal Efficiency

EM Office of Environmental Restoration and Waste Management EM-10 Office of Planning and Resource Management

EM-20 .... . Office of Environmental Quality Assurance \& Resource Management

EM-30 Office of Waste Operations

EM-40 Office of Environmental Restoration

EM-50 Office of Technology and Development EPA Environmentai Protection Agency

ER Environmental Restoration ETCAP Environmental Technology Cost Savings Analysis Project $\mathrm{F}$ fluorine ${ }^{\circ} \mathrm{F}$ FFCA degrees Fahrenheit F\&ORs $\ldots \ldots \ldots \ldots \ldots$ Functional and Operational Requirements $\mathrm{ft}$ FY HAZWRAP fiscal year $\mathrm{H}_{2}$ Hazardous Waste Remedial Ar tions Program hydrogen $\mathrm{H}_{2} \mathrm{O}$ water

$\mathrm{HCl}$ hydrogen chloride HEPA high efficiency particulate air

$\mathrm{Hg}$

HOC Halogenated Organic Compounds

INEL

$\therefore$

. . mercury Idaho National Engineering Laboratory 
LAINL

Los Alamos National Laboratory

LDR Land Disposal Restrictions

MEO Mediated Electrochemical Oxidation

MIT

Massachusetts Institute of Technology

MLLW mixed low-level waste

$\mathrm{mm}$ MMT millimeter

MS Molten Metal Technology MSW municipal solid waste

MWIP Mixed Waste Integrated Program

MWTP Mixed Waste Treatment Project

$\mathrm{Na}_{2} \mathrm{CO}_{3}$ NEPA sodium carbonate NESHAP National Environmental Policy Act NOx NRC

ORNI

OTD National Emissions Standards for Hazardous Air Pollutants $\mathrm{Pb}$ Nuclear Regulatory Commission Oak Ridge National Laboratory Office of Technology Development

PCB polychlorinated bi-phenols $\mathrm{pH}$ measure of acidity

PI principal investigator PIC Products of Incomplete Combustion

PINL Pacific Northwest Laboratory POHC Principal Organic Hazardous Constituents ppm parts per million

PVC polyvinyl chloride

QA Quality Assurance QA/QC

QAMS . Quality Assurance/Quality Control RCRA Quality Assurance Management System

R\&D Resource Conservation and Recovery Act RDDT\&E Research and Development RFP Research, Development, Demonstration, Testing and Evaluation RFP $\mathrm{Se}$ SOx TASR TCLP TRU TSCA TSG TTP TTTDP TTWG

$\ldots \ldots$ Rocky Flats Plant
$\ldots \ldots$ sulfated compounds
$\ldots \ldots$ selenium
Technical Area Status Report

$\ldots \ldots$ Rocky Flats Plant
$\ldots \ldots$ sulfated compounds
$\ldots \ldots$ selenium
Technical Area Status Report
cteristic Leaching Procedure

$\ldots \ldots$ Rocky Flats Plant
$\ldots \ldots$ sulfated compounds
$\ldots \ldots$ selenium
Technical Area Status Report
cteristic Leaching Procedure

$\ldots \ldots$ Rocky Flats Plant
$\ldots \ldots$ sulfated compounds
$\ldots \ldots$ selenium
Technical Area Status Report
cteristic Leaching Procedure Toxicity Characteristic Leaching Procedure Toxic Substance Control Act . Technical Support Group . . Technical Task Plan Thermal Treatment Technology Development Program Thermal Treatment Working Group 


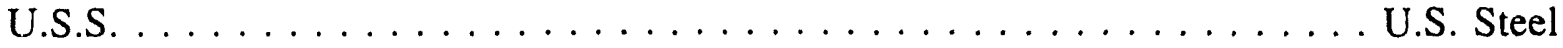
UV $\ldots \ldots \ldots \ldots \ldots \ldots \ldots \ldots \ldots \ldots \ldots \ldots \ldots \ldots \ldots \ldots \ldots \ldots \ldots \ldots$ ultraviolet

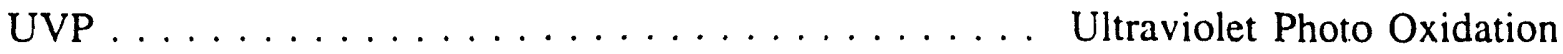
WDS $\ldots \ldots \ldots \ldots \ldots$ Waste Destruction and Stabilization WMIS $\ldots \ldots \ldots \ldots \ldots \ldots$ Waste Management Information System 


\section{TECHNICAL AREA STATUS REPORT FOR WASTE DESTRUCTION AND STABILIZATION}

\section{INTRODUCTION}

The Office of Environmental Restoration and Waste Management (EM) was established by the Department of Energy (DOE) to direct and coordinate waste management and site remediation programs/activities throughout the DOE complex. In order to successfully achieve the goal of properly managing waste and the cleanup of the DOE sites, the EM was divided into five organizations: the Office of Planning and Resource Management (EM-10); the Office of Environmental Quality Assurance and Resource Management (EM-20); the Office of Waste Operations (EM-30); the Office of Environmental Restoration (EM-40); and the Office of Technology and Development (EM-50).

The mission of the Office of Technology Development (OTD) is to develop treatment technologies for DOE's operational and environmental restoration wastes where current treatment technologies are inadequate or not available. The Mixed Waste Integrated Program (MWIP) was created by OTD to assist in the development of treatment technologies for the DOE mixed low-level wastes (MLLW). Throughout the DOE complex, mixed waste is a problem because definitive treatment standards and capacity have not been established and few disposal facilities are available. Currently, DOE sites are storing mixed waste for future disposal, despite the fact that regulations governing the hazardous constituents of the mixed waste requires treatment by specific deadlines.

Statutory requirements which provide the driving force for the development of mixed waste treatment technologies are the Land Disposal Restrictions (LDR) within the Resource Conservation and Recovery Act (RCRA) and the new Federal Facility Compliance Act of 1992 (FFCA). The LDR regulations have mandated schedules for treatment regardless of whether treatment standards and applicable treatinent technologies exist. The FFCA requires that plans for technologies and treatment be agreed to by the states. There is a clear need for technologies designed to meet the unique requirements for mixed waste processing and for a system-wide integrated strategy to develop treatment technology and deploy the cafability to treat mixed waste (Reference 1).

The mission of the MWIP is to plan and manage the national Research, Development, Demonstration, Testing and Evaluation (RDDT\&E) program qualifying emerging and existing technologies on a systems basis for waste treatment and disposal of MLLW, in coordination with the Office of Waste Management's needs and schedules. The MWIP is developing a unified approach for the treatment of all DOE MLLW presently in inventory and that which is being generated. Only a small percentage of DOE's MLLW can be treated by available DOE treatment facilities. The development of integrated process systems capable of effectively treating all of the various types of DOE wastes is the ultimate goal of the MWIP. The treatment facility must include capabilities for front end viaste handling, physical and chemical pre- 
treatment as required, offgas treatment, and the generation of stable final waste forms suitable for disposal.

The DOE has established general criteria that successful treatment technologies must achieve. The treatment technologies must be socially and politically acceptable. They must be cost effective, and air emissions, any liquid effluents, and final waste forms must meet or exceed all applicable DOE, EPA, and state regulatory requirements. In addition, the treatment technologies developed must allow the DOE to meet the requirements in the Federal Facility Compliance Agreements (FFCAs). Finally, these process systems must be developed and demonstrated within a time frame that allows the DOE to meet their goal of remediation of all DOE sites within 30 years.

\subsection{TECHNICAL SUPPORT GROUP RESPONSIBIIIIIES}

The MWIP has established five Technical Support Groups (TSGs) whose purpose is to identify, evaluate, and develop treatment technologies within five general technical areas representing waste treatment functions from initial waste handling through generation of final waste forms (Figure 1.1). These TSGs are: (1) Front-End Waste Handling, (2) Physical/Chemical Treatment, (3) Waste Destruction and Stabilization, (4) Second-Stage Destruction and Offgas Treatment, and (5) Final Waste Forms. Each TSG consists of a team of experts in the particular technical area covered by the TSG (Table 1.1). These experts come from the DOE sites, contractors,

Table 1.1. Mired Waste Integrated Program Work Breakdown Structure

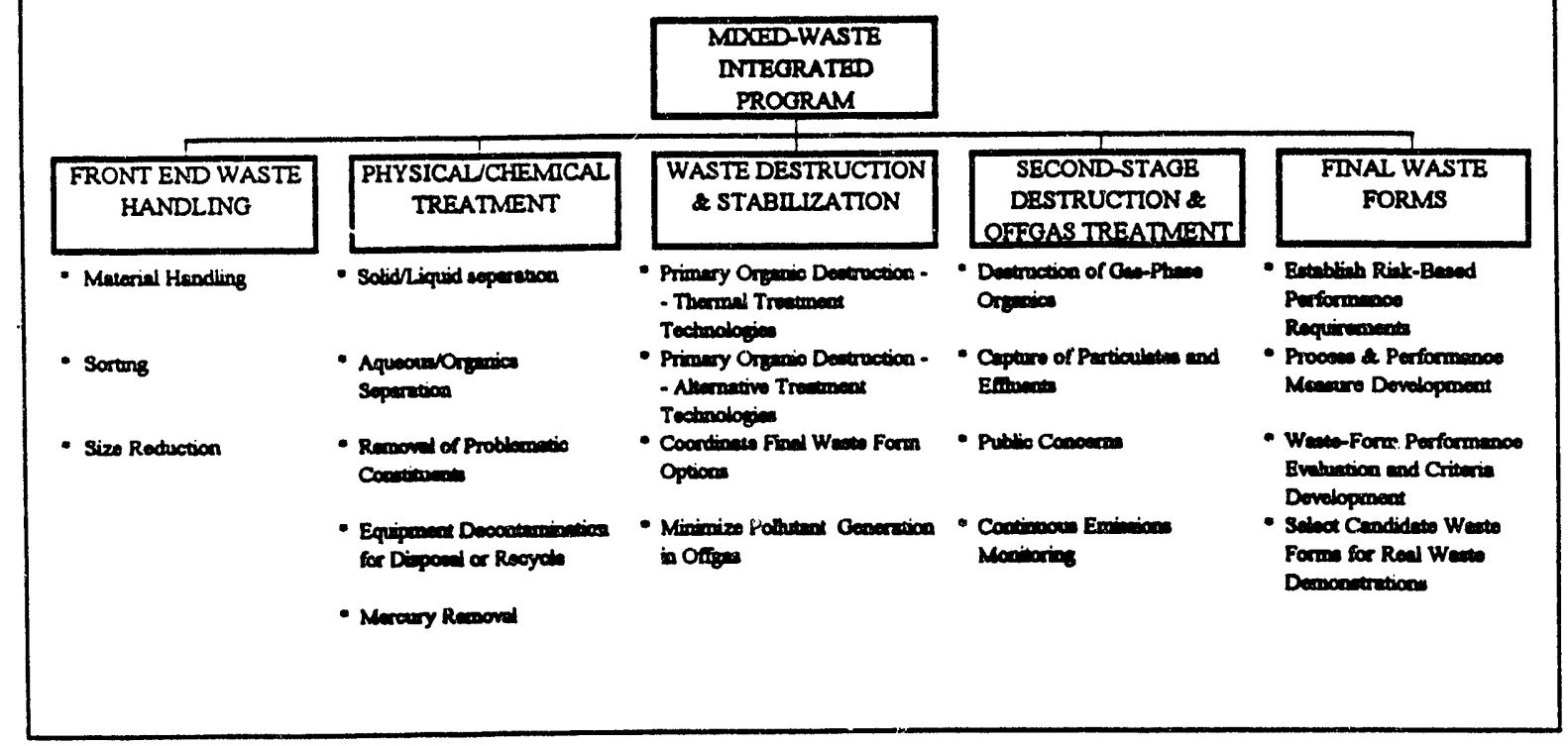




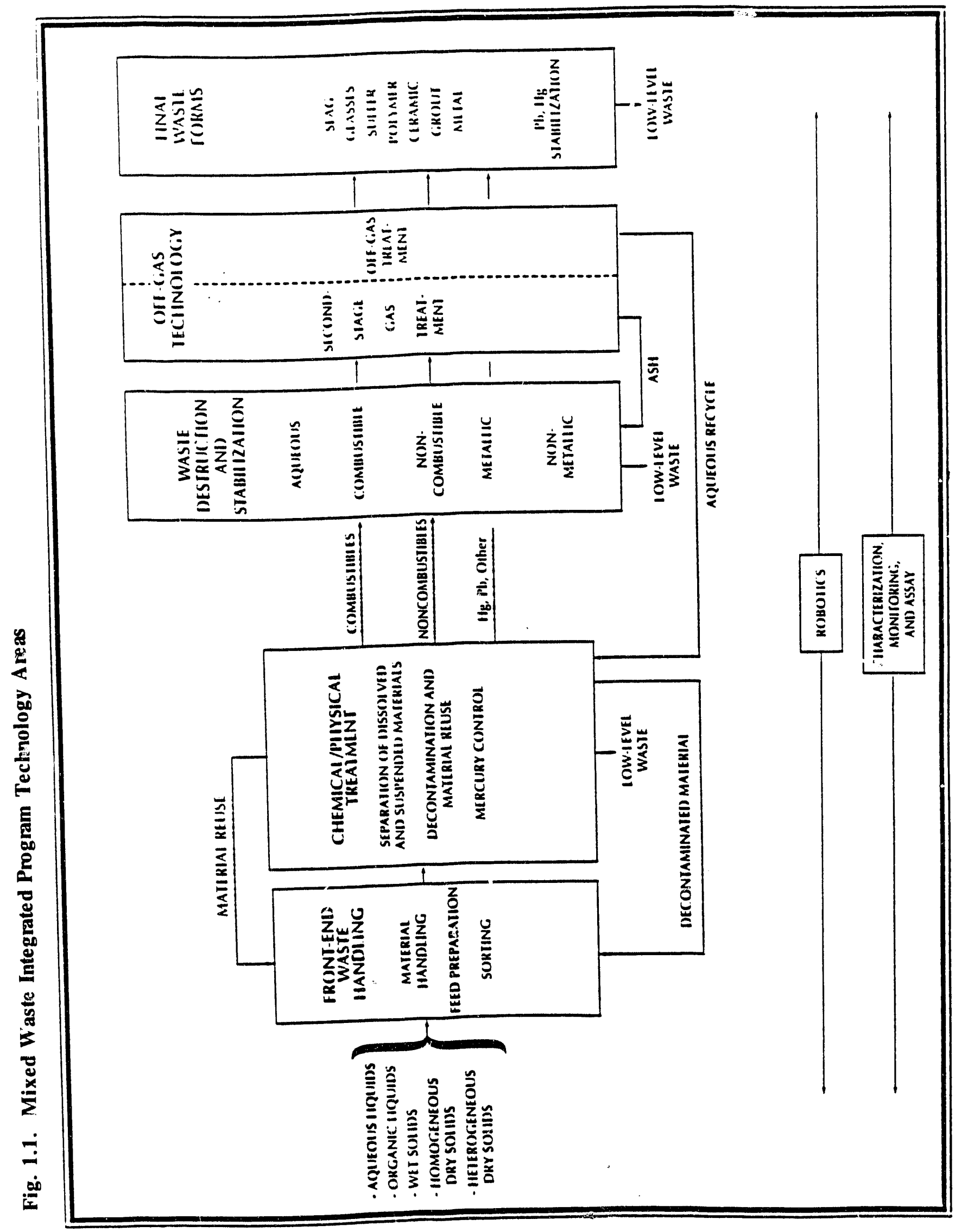


EPA, and the NRC. Each TSG must communicate and work closely with the other TSGs to insure that development efforts result in technically successful integrated process systems for the DOE's waste streams.

The MWIP is responsible for issuing solicitations for Technical Task Plans (TTPs). The TTP process is the mechanism that allows researchers to submit proposals and receive funding for the development and/or improvement of treatment technologies as determined to be needed by the Office of Waste Management (EM-30). The function of the TSGs is to identify technology development needs for these solicitations, review the TTPs submitted as a result of the solicitation, prioritize them, and make recommendations for fulding. The intent of this process is to identify the range of options proposed to address the MLLW ireatment needs and to judge the relative ability of these options to meet the needs of the DOE, including schedule constraints. If any needs are not addressed by submitted TTPs, the TSGs are responsible for follow-up solicitation of proposals, within the DOE or from the commercial sector, to fill the unaddressed needs.

Once selected TTPs are funded, the TSGs are responsible to evaluate development progress and ensure that quality data is generated. With quality data, MWIP can then select the technologies with the greatest potential for successfully treating DOE MLLW. Pilot-scale demonstrations of these technologies will determine necessary design and operational parameters. Finally, MWIP will assist Waste Operations (EM30) and Environmental Restoration (EM-40) in applying these technologies at fullsco.e, providing technical support throughout the design, construction, start-up, and operation of the treatment systems. The end result of this work will be to develop and demonstrate technologies that are safe, cost effective, $a r^{\circ}$-an adequately treat the DOE MLLW to meet all appropriate requirements.

\subsection{WASTE DESTRUCTION AND STABILIZATION TECHNICAL SUPPORT GROUP}

The Waste Destruction and Stabilization (WDS) TSG is responsible for MWIP technology development for mixed waste destruction, reduction, and stabilization as identified in Table 1.1.

\subsubsection{Responsibilities and Strategy for the WDS TSG}

The responsibilities and strategy of the WDS TSG consist of the following key elements. These elements are further discussed in Sections 1.2.4, 1.2.5, and 1.2.6.

- Formulate specific technology requirements for mixed waste destruction and stabilization in support of EM-30 treatment needs as identified by such organizations as the Mixed Waste Treatment Project (MWTP) or by individual sites.

- Identify gaps or deficiencies in existing potentially applicable technologies. 
- Evaluate emerging innovative technologies for application to DOE mixed waste treatment.

- Develop a set of commonly accepted standards and criteria by which all technologies can be evaluated.

- Identify similar work in progress and establish a means of sharing information with other similar projects to avoid duplication of effort and avoid funding of specific dedicated development projects.

- Identify at an early stage those technologies that offer the greatest potential for rapid deployment ( 2 year time frame) versus promising emerging technologies that offer potential improvements over existing technologies for the longer term by using the systems analysis task as a tool.

- Prepare and issue requests for technical proposals that include statements of work for specific technology development areas that focus on identified EM30 needs.

- Evaluate all proposals and recommend for funding those projects whose proposals are most responsive to the statements of work and which the WDS TSG judges to offer the highest potential for success in the particuiar application evaluation criteria.

- Review/approve test plans for individual TTPs. Authorize work to be initiated based on test acceptability.

- Assure that all development projects generate quality data.

- Monitor funded development projects and periodically, based on a consensus judgment of the TSG, determine if funding of the project should continue based on the probability of the technology's success within the MWTP flowsheet. The potential for project success will be determined by evaluation of performance, cost, and risk by the MWIP systems analysis.

- Communicate closely with other TSGs to ensure that the candidate waste destruction and stabilization technologies interface acceptably with front end waste handling, chemical/physical treatment, generation of final waste forms, and second stage destruction/offgas treatment to form an integrated process system.

- Develop specifications for deployment of the chosen technologies in the field or pilot plant applications.. 
Projects that are proposed as cooperative efforts with the private sector are encouraged by the WDS TSG. Such cooperative efforts generally lower costs both through cost sharing and by leveraging the technical expertise found outside the DOE laboratories. Close ties with the private sector reduce the likelihood that an individual project is reinventing an already developed process. Finally, technology developers may have a limited perspective of issues like manufacturability, cost containment, operability, materials of construction, and ultimate market for the technology of which commercial entities must be highly conscious.

Engineering modeling of proposed WDS technologies should be an integral part of a selected technology development program from project incepiun. A clear methodology for chemical and process engineering evaluation, cost/benefit analysis, and risk analysis is being conducted by MWIP. These analysis are conducted by the System Analysis Group of MWIP. Such efforts will allow MWIP to make definitive comparisons of alternative technologies to the baseline technologies.

\subsubsection{Surrogate Waste Streams for Testing}

The ability to evaluate candidate treatment technologies on a common basis is of utmost importance to the success of the MWIP. The key to achieving a common test basis is establishment of a standard set of waste streams. A list of candidate waste feed streams of concern to the WDS task area will be produced in collaboration with the Final Waste Forms TSG waste stream effort.

From this list, an effort is underway within the MWIP to define a set of surrogate waste compositions in the form of "recipes" to be used in all future treatment technology development activities. The surrogate waste compositions for each major waste category address the quantities of bulk matrix components, hazardous organic constituents, metals, and surrogate radionuclides. When finalized, these surrogate waste recipes will be included in the requests for proposals as the waste streams on which the development work must focus. Efforts related to DOE waste characterization and the establishment of surrogate waste streams are described in Section 2.0.

\subsubsection{Definitions of Current and Emerging Treatment Technologies}

With the assistance of TSG members, consultants, and other experts in the field, the WDS TSG will compile and maintain a list of current and emerging technologies for addressing the applicable waste streams. Current technologies include those that are currently in use in the commercial sector and within the DOE. Emerging technologies are those that are under development and have shown promise for implementation by DOE

\subsubsection{Determination of Treatment Technology Requirements}

WDS technologies cannot be fully evaluated except as part of a complete 
treatment system that considers waste input and oulput requirements. For purposes of developing a straw man process flowsheet and providing a basis for technology comparisons, the Functional and Operational Requirements (F\&ORs) document developed by EM-30's MWTP has made an initial selection of existing waste destruction and stabilization technologies for specific waste streams (Figure 1.2). This selection currently serves as a technology baseline for the MWIP. The current technology baseline will continue to be updated and expanded upon via sources within the DOE, EPA, commercial sector, and from international experience on treatment of similar waste strearns.

Technology development requirements will be evaluated based on deficiencies in current options due to baseline technology flowsheet incompatibility or concerns related to safety, performance, permittability, or cost. The treatment technology evaluation and selection process is described in the next two sections.

\subsubsection{Technology Evaluation Criteria}

The technology evaluation criteria will address two key activities. The first activity is evaluating proposed technologies for their ability to conform to minimum performance requirements and to improve on baseline technologies for determination of initial funding. The second activity is establishing a basis for correlating progress on funded technology projects with recommendations for continued funding.

The degree to which the criteria are applied will clearly depend upon where the proposed project stands on a maturity scale ranging from proof-of-principal validation to prototype demonstration. The application of these criteria is intended to allow timely decisions on which projects to fund and then to push funded projects as rapidly as possible toward demonstration and subsequent down-selection.

Those R\&D projects proposed for DOE funding that fall within the mission of the MWIP and are recommended for funding by the Waste Destruction and Stabilization TSG should incorporate the criteria listed below as a major part of their work scope. The deliverables for each project will specify the degree to which each criterion is satisfied.

1) Waste Feed Acceptance Criteria: What are the feed compositions and forms that can be accepted by this process and what fraction of the total mixed waste stream does that represent? A detailed inventory of the applicable DOE waste streams collected into waste forms by physical form and matrix composition will be supplied by the MWIP. Standardized surrogate matrix and hazardous compositions for each waste will also be supplied by the MWIP to the WDS. The Principal Investigator (PI) shall incorporate into his scope of work the full range of waste forms which his process will potentially address, and the test plan shall use the surrogate waste description as the test base for each waste form addressed. Feasibility tests must be conducted early in the project to determine the validity of the postulated waste feed capability. Difficulties anticipated or encountered in handling the surrogate waste in a test 


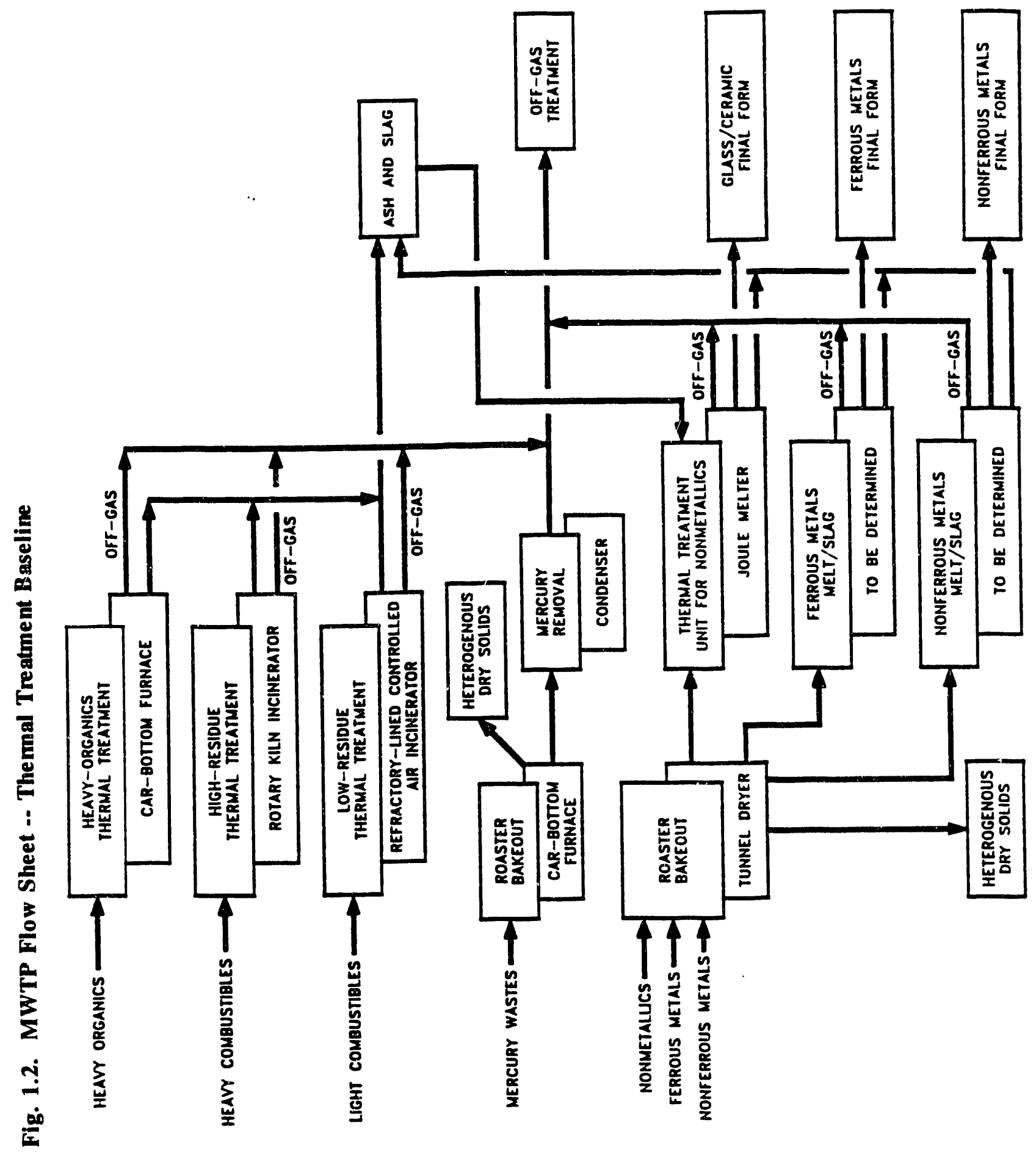


will be discussed with the WDS TSG and modifications to the test base will be considered. It must be recognized that deletion of any components from the surrogate matrix or hazardous components list will imply a narrower scope for the application of the technology. The TSG will ascertain whether the narrower waste scope adequately addresses a DOE waste stream and whether the volume and uniqueness of that stream represents a sufficient problem that the cost versus benefit derived justifies the investment in the technology development.

2) Process Effectiveness: The key questions are how well does the technology perform and what are the anticipated advantages over existing alternatives. Feasibility studies with key waste constituents should be conducted early in the project to define expected process effectiveness. For the primary treatment unit under development, characterization of the treatment environment as to the range of pressures, temperatures, temperature profiles, and flow rates is required. The DREs for the POHCs in the surrogate will be measured at the exit to the last destruction stage of the process, as will the identity and concentration of all PICs and the concentration, composition, and size distribution of particles in the offgases. For some technologies, the TSG may deem it important to measure some or all of the above parameters at the exit to the primary destruction chamber as well. Mass and energy balances will be developed for all constituents in the waste feed. In particular, nonorganic hazardous components in the secondary waste will be determined. Although any appropriate methods for characterization and analysis for the above determinations may be employed, the standard EPA approved methods will be the baseline and will be used to verify the accuracy and reliability of any nonstandard method. The MWIP will provide direction to the PIs regarding the characterization protocol to be used.

3) Secondary Waste: At the earliest possible project stage, the nature and quantity of any secondary wastes generated should be determined on the basis of the experimental test results. This will serve as an important point of comparison with alternate technologies and will be used as a justification for further funding of the development project. Strategies for controlling the composition of secondary waste streams will be an integral part of each project.

4) Offgas Composition: The nature and quantity of offgas produced by the primary technology and any secondary units is of paramount importance because this is often the primary issue for public and environmental impact. Toxic and radioactive constituents should be determined at an early stage to assure that an assessment of cleanup needs is made and that regulatory/public concerns are addressed as early as possible.

5) ALARA Concems: Any potential concerns associated with maintaining 
operator exposure to radioactivity and toxic substances as low as reasonably achievable (ALARA) should be addressed at an early stage. Such fastors translate to the reliability and maintainability of the technology while treating potentially highly radioactive and toxic waste streams. The technology should a) minimize buildup of such materials in the process, b) require minimum personnel access into the process internals for any purpose, and c) be potentially adaptable to remote operation in the case of penetrating radiation and to secondary containment in the case of treatment of alpha-contaminated wastes.

6) Permittability: One of the major issues for implementing technology is the extensive and often exhaustive permitting process. The permitting requirements for all technologies being developed must consider, but not be limited to, requirements under RCRA, TSCA, NEPA, NESHAPs, DOE Orders, as well as state and local requirements. This is a time-consuming and costly process and, since the outcome or time frame cannot be readily predicted, pursuit of an alternate technology that may offer regulatory and public acceptance advantages in addition to technical advantages is justified. Many proposals submitted for consideration tout regulatory or public acceptance advantages without substantiating documentation. The WDS TSG intends to have an EPA representative with extensive experience in permitting as a member of its advisory team. Other advisory team members have extensive experience in permitting as well as technology development. A review of the claims by the PI on these issues will be accomplished as early in the development process as is practical to attempt to substantiate any claims to easier permitting. Additional requirements for deliverables may become necessary to accomplish this review and these will determined as experience in the review process is gained.

7) Risk Assessment: A risk assessment protocol will be developed based on input from the MWIP Risk Assessment team. This analysis will determine the risks associated with implementing and operating facilities incorporating a given technology. Early risk and/or hazards assessments will focus on basic operating parameters and obvious concerns regarding those parameters. Information on how a tecinology would integrate into a treatment plant will be requested as the technology matures. Flow sheets and the specification of full scale equipment designs will be accomplished as early in the development process as practical to allow timely risk assessments and to identify potential show-stoppers early in the development process. Input information required to perform risk assessments for a technology will be specified by the Risk Assessment team.

8) Cost/Benefit Analysis: A major concern is how a technology compares to other options in cost of implementation and operation, including treatment 
costs, costs associated with the management of generated secondary waste, and the cost of meeting regulatory and permitting squirements. A life cycle cost breakdown will be performed, the depth of the analysis dependent on the maturity of the technology development and the level of uncertainty in key elements of the analysis. The analysis will be performed by the MWIP Cost/Benefit team with input from the TSG. Specific information requirements for accomplishing these analyses, and how uncertainties in the values of parameters which are dependent on technology maturity will be treated, will be provided by the Cost/Benefit team.

9) Compatibility in an Integrated Process System: During the development process, a waste destruction or stabilization technology should focus on the ultimate requirement to interface acceptably with front end waste handling, generation of final waste forms, and second stage destruction and offgas treatment to form an integrated process system. This interface will be analyzed by the MWIP performance assessment team. Specific requirements for data necessary to complete the performance assessment will be provided by the performance assessment team.

\subsubsection{Selection of Development Projects to be Funded}

The most important single mission of the WDS TSG is to match specific technology requirements identified by the TSG with proper selection of development projects to be funded. The criteria by which treatment technologies will be evaluated were presented in the previous section. For each particular application within the technical area, a screening of existing applicable technologies versus promising emerging technologies will be made. The technology selection process should follow a two-tiered approach. At an early stage, those technologies that offer the highest pot ential for rapid deployment in the field will receive highest initial emphasis. Concurrently, those emerging technologies judged by the TSG to offer clear potential for improvement over existing technologies in the longer term will be funded for further development. To avoid duplication of effort and unnecessary funding of work, any similar work in progress both within and outside the DOE will be identified and arrangements made to share the information generated from that project with the WDS TSG.

For technology areas that are identified by the TSG to require development, requests for technical proposals will be prepared and issued by the TSG that include a very specific statement of work. The request for proposal package will include a questionnaire called the WDS Technology Proposal Fact Sheet, to assist in providing a common basis for proposal evaluation. The fact sheet will address the issues upon which the evaluation criteria are based (Section 1.2.5). Proposals received by the TSG will be evaluated and projects will be recommended for funding on the following basis: 1) responsiveness to the proposal's statement of work, ana 2) highest potential for success as judged by the WDS TSG using the evaluation criteria outlined in 
Section 1.2.5.

\subsubsection{Experimental Plan}

The PI for a project funded in the MWIP WDS technical area shall develop an experimental plan for the project. The experimental plan is a document which outlines planned tests, the objectives of the tests, a schedule for testing, the technical approach and major parameters for each test, and the criteria to be used to evaluate the outcome of a test in terms of demonstrating success. The intent of the experimental plan is to ensure that the PI's planned experiments support the specific goals of the project and provide a logical means of evaluating the results of tests relative to established WDS criteria. Administrative controls will be developed to ensure that the test plan is approved by the TSG before experimental/development work is conducted. The experimental plan should include the following sections:

- Objectives

- Background

- Schedule

- Description of:

- Technical Approach/Problems

- Major Parameters

- Surrogate(s) to be Tested

- $\quad$ Success Criteria

- References

\subsubsection{Quality Assurance/Quality Control}

The QA/QC program for any funded TTP shall describe the provisions that will be implemented to provide confidence that a development project activity will be performed in an acceptable and consistent manner. The experimental plan submitted with any funded TTP must satisfy all applicable and relevant QA requirements established by codes, standards, and regulations governing waste treatment development efforts imposed by federal, state and local authorities. The plan must follow DOE Order $5700.6 \mathrm{C}$ for all experimental operations. It is recommended that the EPA document QAMS 004, "Guidelines and Specifications for Preparing QA Program Plans" be followed for WDS projects. A plan for verifying and documenting appropriate operation and calibration of all measuring instrumentation will be completed by the PI and submitted to the MWIP. Adequate recording and documentation of the performance of each experiment shall be provided and shall follow general QA procedures. Proposed data analysis methods shall describe, as a minimum, the following requiremints:

- Acceptance and implementation of general QA/QC principals by the personnel and facility performing the work. 
- The PIs and their management accepts responsibility for the implementation, assessment, and improvement of a Quality Assurance Program. They also accept responsibility for the accomplishinent of the experimental plan.

- Performance readiness evaluation should be performed prior to major scheduled or planned work to verify at least the following characteristics sufficient for the type and level of development:

-- Work prerequisites have been satisfied;

-- Technical and QA procedures have been reviewed for adequacy and completeness;

-- Personnel have been suitably trained and qualified;

-- The proper equipment, materials, and resources are available;

-- A system for test control, inspection, and equipment calibration exists;

-- A QA record system exists.

Technical expert(s) from applicable Technical Support Groups (TSGs) may be selected to participate in the Performance Readiness Evaluation Process (Reference 2).

\subsubsection{Project Deliverables}

The following are examples of deliverables to which each funded project may be required to commit:

- A list that defines DOE waste streams applicable to the technology;

- Descriptions of surrogate wastes to be used by the project for evaluating the technology;

- Success criteria for evaluating performance of proposed demonstrations;

- A comprehensive list of competing technologies;

- Test reports of completed demonstrations;

- Detailed project schedules;

- Periodic status reports; and

- Technology specifications for the deployment of the technology in a waste treatment system.

\subsection{Scope of Technical Area Status Report}

Technical Area Status Reports (TASR) will be prepared and updated annually by each MWIP TSG. The purpose of this Technical Area Status Report is to detail the responsibilities and to document the efforts of the Waste Destruction and Stabilization TSG. Because the comerstone for this program is the accurate identification and description of DOE mixed waste streams, the current status of waste characterization efforts will be reviewed. This review will identify EM-30 and EM-40 waste treatment needs. The current state-of-the-art in treatment technologies for waste destruction and 
stabilization will be defined, existing industrial treatment technologies that can be applied to DOF waste streams will be identified and described, and the advantages and disadvantages of these technologies will be reviewed. New or emerging technologies will be discussed and the current stage of development of these technologies will be examined. Previous endeavors in identifying and evaluating thermal treatment technologies will also be reviewed to ensure that OTD-sponsored RDDT\&E is not duplicating technologies developed elsewhere and that on-going RDDT\&E builds upon the work of others. A comparison of waste treatment needs with treatment technologies will identify technology development needs. Based upon the resulting conclusions, recommendations for future actions will be made. 


\section{DOE WASTE STREAM IDENTIFICATION}

The basic precondition for the efficient and economical processing and disposal of the DOE MLLW is a thorough knowledge of the quantities and compositions of the waste streams. The MWTP recognized the importance of accurate waste characterization information for technology evaluations and therefore funded the MWTP date-gathering activities. The objective of this group was to expand upon the waste volume reports and data bases that had been previously prepared (References 36). More detailed waste characterization information was obtained by visiting all the major DOE sites. The following information was desired for each waste stream:

- Waste location;

- Description of how the waste was generated;

- $\quad$ RCRA information (LDR category and EPA waste codes);

- Hazardous constituents;

- Chemical matrix and concentration of major components;

- Radionuclide types, activities, and handling category;

- Physical form and size, container sizes, special packaging information;

- Waste inventory volumes, locations, and expected generation rates.

All new information obtained from these visits were used to update the DOE Waste Management Information System (WMIS) data base. However, much of the desired information was not available for many waste streams.

The waste descriptions are divided into nine classes as can be noted in the Mixed Waste Categories Figure 2.1. The major categories are aqueous liquid wastes, organic liquids, solid process residues, soils, debris materials, special wastes, inherently hazardous wastes, unknown wastes and treated materials. Most liquid wastes (1000's and 2000 's) and solid process residues (3000's) are generated in a routine manner from process operations and are subject to full RCRA regulations. They are generally homogeneous within a specific waste stream; however, it has been regularly reported that other foreign materials such as a failed pump may have been included within the process waste drums. Soils (4000's) are to be the subject of a future regulation and will likely be further subdivided at that time.

Debris materials (5000's), as classified by the EPA, do not need characterization before processing because of their heterogeneity and the difficulty in characterization. The debris materials only require treatment by an appropriate technology with the process residues being included in the appropriate process residue categories. The regulations state that debris must be solid materials with an average particle size larger than $60 \mathrm{~mm}$. Debris are materials that:

1) have been originally manufactured or processed (specific examples include tanks, pipes, valves, appliances, scrap metal, paper, plastic, rubber, glass, concrete, brick and crushed drums);

2) are plant or animal matter; or 
3)

are natural geologic materials.

Debris can be an inseparable mixture (by simple mechanical removal processes) of such materials with soil, liquid, sludge, or other solid waste materials, but the debris must be more the $50 \%$ of the total material. Debris cannot be process residuals (1000's and 200n's as described above).

Special wastes (6000's) are those that need specific treatments or are not currently considered in the Mixed Waste Treatment Project because of safety or regulatory concerns. Inherently hazardous wastes (7000's) are those waste streams that cannot by treated to remove the hazardous contamination. The first objective is for the recycle of these material within the DOE or general commerce if very low level radioactive materials become releasable for general use. Unknown wastes (8000's) are those wastes that cannot reasonably be included into a specific waste category because of a lack of information on that stream. The treated wastes (9000's) will result from treatment processes and should be suitable for disposal. A more detailed description of the subcategories making up a waste category and the constituents of those waste streams is included in Appendix A.

In addition to the matrix category defined in this document, the wastes need to be defined as to radioactive content as either contact handled, alpha wastes, or remote handled. Contaminants will also be defined for each of the streams and will be hazardous organic or toxic metals with appropriate subdivisions. EPA codes provide one method for identifying the hazardous contents.

The last category for each of the groups is an uncategorized group. These groups represent the presence of either multiple waste types or the lack of sufficient information to adequately classify the wastes into a more specific group. It is anticipated that, as this categorization matrix is utilized by the sites, additional waste types will be identified. Therefore open categorizes remain within the matrix and will be defined as needed.

Waste data gathering activities are continuing and updates to this waste stream information will be published in FY93. The quality of waste data is expected to improve as the sites complete characterization, classification, and treatment activities. However, improvements in data quality and consistency are needed. The waste data would be improved with uniformity in definitions of waste streams and classification of specific streams for each site. Currently, there are differences with respect to classification of high-level waste, transuranic waste, low-level waste, and PCB waste streams. Resolution of these differences would further improve the waste information.

Although the DOE mixed waste information is not sufficient for design purposes, it can be used on a general basis to determine what type of treatment processes are needed and which waste streams have a high priority. Once this determination is made, the TSGs will assess the performance of currently developed technologies to 


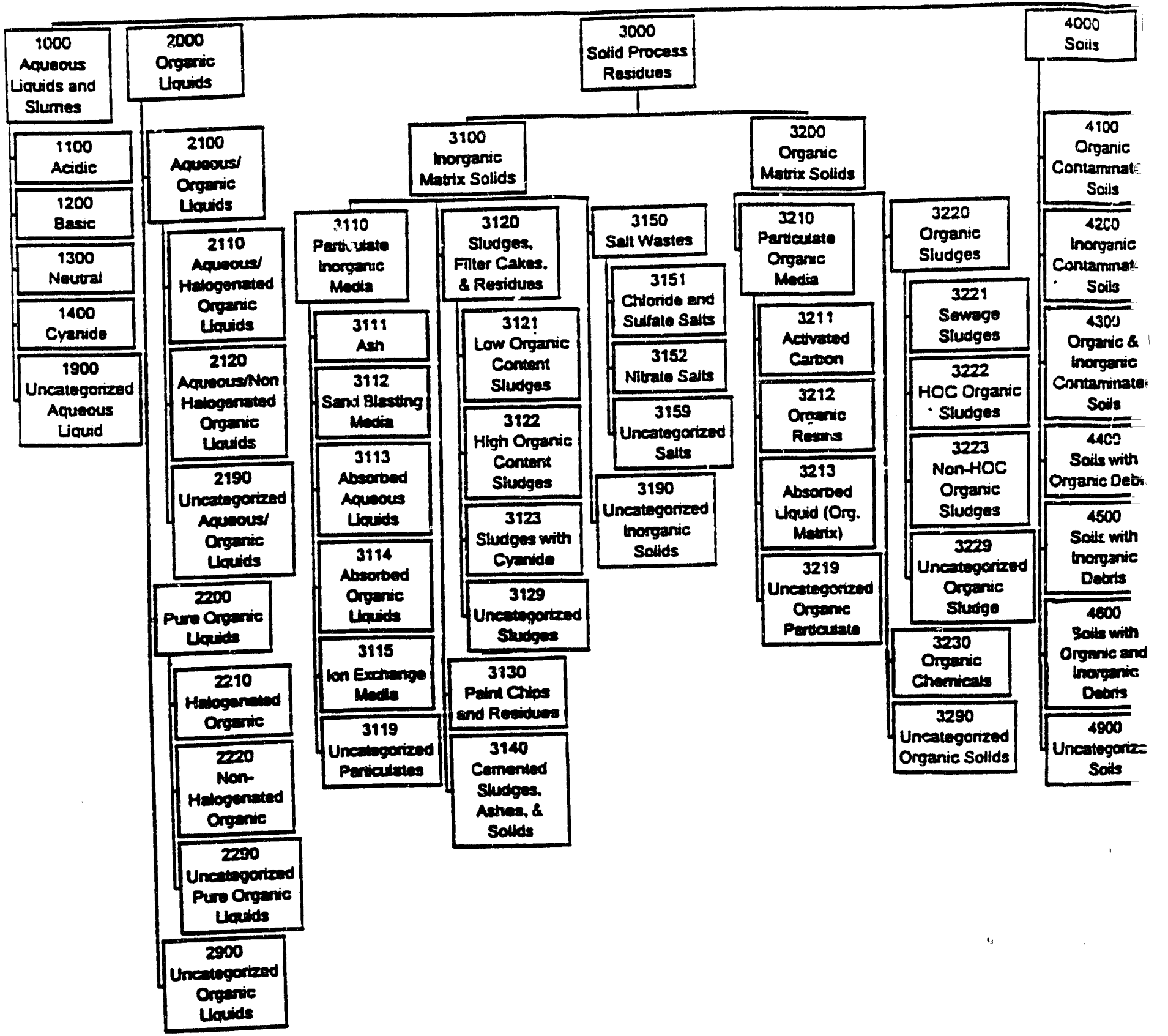

Fig. 2.1. Mixed Waste Categories Figure 


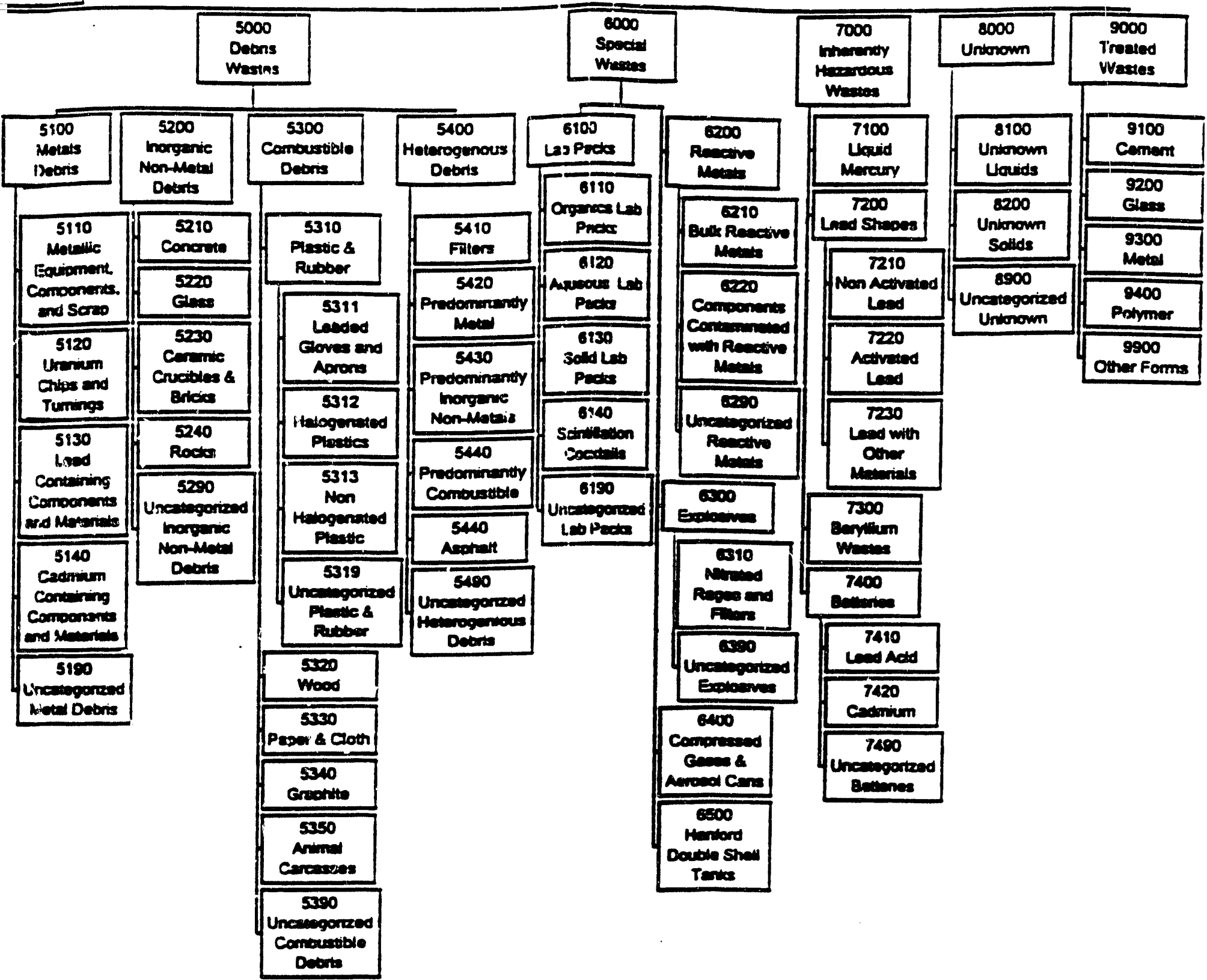


identify which waste streams can adequately be treated with currently available treatment technologies. By matching up the treatment needs with currently available technologies, the TSGs are able to identify those waste streams where treatment technologies have not yet been developed or where existing technologies are inadequate so that improvements or alternatives are warranted.

Several of the DOE waste categories are identified as problematic. This means that treatment technologies have not been identified for these waste streams due to constituents contained within the waste stream or because of their physical waste form. Treatment of these problematic waste streams to render them compliant with land disposal restrictions is the responsibility of the WDS. Detailed waste stream descriptions, hazardous waste components, and quantity information for these problematic waste streams listed below can be found in Appendix B. These problematic waste streams include:

- $\quad$ Cemented sludges;

- Beryllium wastes;

- Reactive metals;

- Tritium contaminated wastes;

- Compressed gases; and

- Chlorine containing wastes.

The DOE has large quantities of mixed cemented wastes. Since these mixed cemented waste streams are listed for both the radioactive and hazardous components of the waste, it is assumed that the cementation process did not adequately stabilize the hazardous component. Therefore, these waste streams will require treatment since they currently do not pass TCLP tests. Since the cement mixed with these waste streams will not burn, very high temperatures will need to be obtained if a thermal treatinent process is selected for reprocessing.

Beryllium fines were also identified as a problematic waste stream. Since beryllium is a listed carcinogen, the Clean Air Act has set very restrictive feed and emission limits on any thermal treatment of beryllium containing wastes. In fact, these limits are so low that the thermal treatment of high concentrations of beryllium waste is prohibited. The V'aste Destruction and Stabilization TSG will need to identify possible treatment technologies for this waste stream.

Additional problematic waste streams identified are those which contain reactive metals. The use of a thermal treatment process for treating this waste stream creates some problems, since reactive metals can cause extensive damage to the refractories. These waste streams not only create problems in the treatment process, but also posse a waste hancling problem due to the ignitability of the reactive metals.

The addition of tritium contaminated wastes to the problematic waste list is due to the fact that this waste stream creates an offgas problem (creates tritiated water which will pass through pollution control systems to the environment). Compressed gases were added because currently the MWTP has not identified a treatment system that 
can handle this waste stream. Chlorine-containing wastes are included because these materials create problems in offgas treatment and waste form stability.

Environmental restoration wastes, particularly those resulting from the decontamination and decommissioning of many DOE facilities, are anticipated to be of a large volume, although very little data are available. Specific information about many of these wastes is needed so that more comprehensive evaluations and plans can be completed.

Conclus:ons drawn from the MWTP Data-Gathering Activities indicates several important factors:

- Most wastes are stored/generated at only a few of the $30 \mathrm{DOE}$ sites. Some of the major DOE facilities are listed below:

-- Fernald Environmental Management Project

-. Hanford

-- Idaho National Engineering Laboratory

-. K-25 Site

-- Los Alamos National Laboratory

-- Oak Ridge National Laboratory

-- Paducah Gaseous Diffusion Plant

-- Pantex Plant

-- $\quad$ Portsmouth Gaseous Diffusion Plant

-- $\quad$ Rock Flats Plant

-- Sandia National Laboratory Albuquerque

-- Savannah River Site

-- Y-12 Plant;

- The most significant waste volumes for treatment considerations are the inorganic solids and the aqueous waste streams.

- The types of waste being stored and being generated at each site are different. Flexible processes are needed to minimize the number of treatment processes required by EM-30 and EM-40.

The WDS TSG and the MWIP staff are establishing waste feed streams that represent a significant portion of the mixed waste in the DOE Complex and will provide a first cut determination of the ability of new technologies to meet destruction and stabilization guidelines. Two surrogate sludges and one bulk combustible surrogate waste form have been specified to present a first cut at a standard waste description for a significant portion of the DOE Complex's waste streams. The description of these waste forms follows:

1) Inorganic Sludge (MWTP 3100 Series): Matrix is $20 \%$ vermiculite, $20 \%$ diatomaceous earth, $20 \%$ ion exchange resin, $25 \%$ ferrous hydroxide sludge, 15 $20 \%$ dry portland cement, and up to $5 \%$ water. Sludge will contain $5 \%$ to $10 \%$ 
sulfate and chloride salts and will be contaminated with up to $1 \%$ hazardous organics, including halogenated hydrocarbons and toxic metals. EPA waste codes that should be exhibited or contained are: D002, D006, D007, D008, D009, D019, D022, D040, F001, F003, F004.

2) Organic Sludge (MWTP 3200 Series): Matrix is $25 \%$ activated carbon from filters, $25 \%$ organic resins, $25 \%$ absorbed organics on cellulosic materials (i.e. pulverized corn cobs) and $15-20 \%$ dry portland cement. Sludge will contain $5 \%$ to $10 \%$ sulfate and chloride salts and will be contaminated with up to $1 \%$ hazardous organics, including halogenated hydrocarbons, and toxic metals. EPA waste codes that should be exhibited or contained are: D001, D002, D006, D007, D008, D009, D019, D022, D040, F001, F003, F004.

3) Bulk Combustible Waste (MWTP 5440 Series -- Heterogeneous debris): Matrix is $30 \%$ low density cellulosic materials and wood, $20 \%$ polyethylene plastic and sheeting, benelex, and polyvinyl chloride plastic, $10 \%$ rubber, and $20-50 \%$ tramp metal and glass. Waste will be contaminated with up to $1 \%$ hazardous organics, including halogenated hydrocarbons and toxic metals. EPA waste codes that should be exhibited or contained are: D001, D002, D006, D007, D008, D009, D019, D022, D040, F001, F003, F004.

Percentages of each waste constituent are approximate and should be adjusted as constituents such as portland cement, inorganic salts, water, and tramp metal and glass are varied. All waste streams will contain surrogate materials to represent the expected behavior of plutonium, uranium, and/or fission products in concentrations expected for low level waste streams. The concentrations of chlorides that may appear as hydrogen chloride in the emissions, and the hazardous organic and toxic metals concentrations will be adjusted to meet the current regulatory constraints on the system's emissions. 


\section{SUMMARY OF PREVIOUS EFFORTS}

There have been several previous studies to identify, review, and assess thermal treatment technologies for MLLW. Of these studies, two in particular have provided significant assistance in the various tasks assigned to the Waste Destruction and Stabilization TSG. Both of these studies involve treatment technologies that can be used to thermally treat DOE MLLW. In addition to these reports, there have been numerous research and development projects involving waste treatment technologies. The results of these study projects can have a major impact on the decisions and recommendations of the Waste Destruction and Stabilization TSG.

\subsection{HAZARDOUS WASTE REMEDIAL ACTIONS PROGRAM REPORT}

Reference 7, the Hazardous Waste Remedial Actions Program (HAZWRAP) documents a study conducted for the OTD addressing the thermal treatment of DOE waste streams. The report is $0_{i}$ anized into two volumes. Volume 1 identifies several important issues related to the therinal treatment of waste. A summary of the DOE MLLW quantities and characteristics was assembled. Six generic waste categories were defined and utilized to assess the processing capabilities of the technologies identified. A discussion on the appropriate regulations concerning the thermal treatment of MLLW was also included. The report identifies 35 thermal treatment technologies and gives a brief description of each. All technologies listed in this report were evaluated and ranked according to LDR compliance, operability, applicability, radioactive contamination control, and cost.

Volume 2 contains much more detailed information concerning each treatment technology (including descriptions, the theory of operation, advantages and deficiencies, process support requirements, cost data, developmental status, and reference information). The thermal treatment technologies reviewed encompass operational conventional and unique incinerators, industrial process co-firing units, municipal waste treatment technologies, and emerging treatment technologies.

There are four significant conclusions that are reached in this report and restated here:

- None of the evaluated technologies ranked high in treating all of the general waste categories. This fact illustrates one reason why additional research and development is needed.

- The technologies with the highest ratings were fluidized bed incinerators, rotary kiln incinerators, plasma arc furnaces, and glass furnaces (this is due to the versatility of these treatment technologies). It is not surprising that these are the technologies that are currently used by the DOE, are under construction or are planned for construction in the near future, and/or have significant demonstrations in progress. 
- The third important conclusion discussed in the HAZWRAP report concerns an overall approach to treating the waste. Instead of trying to process all of the various combustible waste streams in one thermal treatment unit, a more effective facility would result if at least two thermal processes are utilized. For example, a facility employing a controlled air incinerator and a plasma arc furnace would be highly effective at treating all of the general waste categories. This facility would likely have a lower life-cycle cost, would be more effective at destroying all of the waste types, and would produce very stable final waste form(s).

- The report points out that the evaluations of the waste technologies are highly dependent on the actual circumstances involved. Care must be taken not to overextend the results from a general analysis to a more specific situation or from one specific situation to another.

\subsection{Thermal Treatment Working Group Report}

The second report (Reference 8) is a product of the MWIP's Thermal Treatment Working Group (TTWG). The TTWG was comprised of a group of thermal treatment experts from throughout the DOE system. The TTWG was tasked with assisting the MWIP in the evaluation and prioritization of thermal treatment options. In addition, this group assisted in developing strategies to expedite the development of technologies that were recommended for further investigation.

The purpose of the TTWG report was to establish DOE mixed waste treatment needs, describe the approach of the TTWG to meet these needs, prioritize DOE mixed waste streams, identify candidate thermal treatment technologies and their associated requirements for near term application. This report covers several important concepts that can aid the Waste Destruction and Stabilization TSG in their efforts to develop waste treatment technologies. Several important issues related to determining a strategy for developing thermal technologies were discussed.

In content, this report is very similar to the HAZWRAP Report (Reference 7). Regulatory issues and public acceptance issues were discussed. Several sources of information concerning DOE mixed waste quantities and characteristic were reviewed. Based upon this information, the waste was grouped into general categories according to similar characteristics that affect how the waste is to be treated. A methodology to prioritize the waste streams was developed and 21 waste streams were ranked accordingly. Thermal treatment technologies were evaluated against applicable DOE needs. The technologies were then ranked according to their ability to treat the general waste categories. The report finishes with information concerning the developmental needs of the treatment technologies and provides several recommendations and conclusions. Ranking of near term technologies in this study based on the criteria of maintainability, safety risk, operability, flexibility, effluent, and maturity, differed from those developed in the HAZWRAP report. Such discrepancies demonstrate that, until operating and performance data are obtained for technologies 
on a common basis including treatment of standardized waste streams, clear choices for down-selection cannot be made with sufficient reliability.

It should be noted that although both of these OTD reports identify waste streams that were grouped into general categories, there are still significant efforts needed in characterizing the waste streams throughout the DOE system. More detailed chemical and physical characterization of waste feed streams will be required before ultimate selection of treatment technologies for the MWTP flowsheet can be made. For example, transport properties, such as density and viscosity are needed for liquid wastes. Likewise, to process solid waste, the size of the solids and how they are packaged must be determined. Properties that pertain to waste destruction and stabilization, such as heat of combustion (or heat of reaction) and elemental and chemical analyses must be determined. However, the information that is presented in these reports is an excellent starting point in the efforts to develop and improve treatment technologies.

\subsection{RESEARCH AND DEVELOPMEN'T PROJECTS}

For several years, many sites throughout the DOE complex have been conducting research and development of treatment technologies to provide solutions to waste management problems. Demonstrations of many of these technologies have led to successful applications of waste destruction facilities at various DOE sites. These facilities can effectively treat several different types of wastes, thereby reducing the waste volume. Unfortunately, many waste streams are still unable to be treated. Consequently, research and development efforts for these waste streams is continuing at both the individual sites and the DOE complex wide MLLW. The status and results of each of these efforts are too voluminous to be discussed in this report; however, the status of many of the technologies currently being considered are discussed in Section 4. 


\section{SUMMARY OF WDS TREATMENT TECHNOLOGIES}

This section contains descriptions of both innovative and demonstrated commercial treatment technologies that may be applicable to DOE MLLW. The technologies presented in this section are not meant to be inclusive of all waste destruction and stabilization technologies, but rather only to highlight some of the more promising technologies for application to DOE waste streams. Appendices C-E contains a more exhaustive, but still not complete, listing of waste destruction technologies. These technologies include those that are currently being researched or considered for research as TTPs, as well as those that are now commercially available. In many cases, the available technologies will adequately treat a large percentage of DOE MLLW; however, it may still be desirable to expend research funds on these technologies to improve upon them, especially in terms of applying them to radioactive service.

The technologies presented here are divided into two groups, innovative and conventional. These groups are then further divided by similar principles of operation. On first appearance, it would seem that by separating the technologies on the basis of principal of operation that the technologies are also separated on the basis of the types of waste that the technologies can effectively treat. However, this is not the case. In all cases, there are multiple principles of operation that can be used to treat one particular waste stream. For example, organic liquids can be destroyed by using thermal, biological, chemical, and electrochemical treatment processes.

It should be mentioned here that thermal treatment technologies whose primary application is production of a stable vitreous waste form (such as joule melters and microwave melters) rather than waste destruction come under the purview of the Final Waste Forms TSG. These technologies are also being pursued by the MWIP, and overlapping of functions is addressed by close coordination between the two TSGs.

A sub-Technical Support Group has been formed as part of the WDS TSG to focus on technology alternatives to incineration (ATI). This entity is called the ATI sub-TSG. Section 4.3 lists the currently identified altematives to incineration, some of which are described in Sections 4.1 and 4.2, as well as a discussion of the issues associated with arriving at a clear definition of "alternatives to incineration."

A few research projects were started prior to the organization of the Waste Destruction and Stabilization TSG. These have been considered by the WDS TSG and been determined as technology development that should continue but, in a few cases, with a refocus of their mission. An example is the development of aqueous based organic destruction technology. This effort should primarily focus on aqueous waste clean-up and only secondarily on bulk organic waste destruction. These projects include the following topics:

- Testing of a centrifugal plasma furnace;

- $\quad$ Plasma arc furnace treatment of compacted wastes;

- Catalytic destruction of organics;

- $\quad$ Catalyzed Electrochemical Production Devices (CEPOD); 
- Supercritical water oxidation;

- $\quad$ High temperature packed-bed reactor;

- $\quad$ Silent discharge plasma;

- Studies on the volatility of actinides species.

Descriptions, current status, and other information concerning these technologies, as well as other treatment technologies, are included in this section or can be found in References 7 and 8.

\subsection{INNOV ATIVE WASTE DESTRUCTION AND STABILIZATION TECHNOLOGIES}

Innovative technologies are loosely defined as those technologies that are not currently being used on a large scale to treat wastes. These technologies are generally in the development stage. In some cases, there are technologies that have been utilized on a large scale for many years for purposes other than waste treatment. These technologies are still classified as innovative as they have not been effectively demonstrated for waste destruction and stabilization and/or there are several issues still remaining to he worked out before they can be used in full-scale applications.

\subsubsection{Themal Waste Destruction and Stabilization Technologies}

Rather than reiterating all of the information contained in References 7 and 8, only a brief discussion of thermal processing is presented here. These references include extensive listing of thermal treatment technologies, detailed information concerning these technologies, additional references where more information can be obtained, and a listing of commercial companies and DOE facilities investigating each thermal treatment technology. These companies and laboratories can be excellent sources of information. Appendices C-E provide summary information on several thermal technologies.

Current WDS TTP activities involving thermal treatment processes include: metal melting technologies and plasma arc incineration. Joule melter technologies and other thermal technologies whose primary function is generation of a final waste form are being addressed by the Final Waste Forms TSG. The metal melting technologies are basically adapted from the metals industry (e.g., induction furnaces and plasma arc melters) and the glass industry (e.g., fuel-fired and joule heated melters). There are also a few new melting processes that are being researched as a waste management tool (e.g., the microwave melter). Although most metal melting technologies are not considered new, these technologies are discussed in the innovative technology section because they have only limited operational experience in the radioactive waste management area.

Melter technologies are currently receiving attention because they offer the potential for requiring no additional treatment of the generated inorganic residues. The waste forms resulting from metal melting of the input waste streams tested so far 
appear to meet the identified final waste form standards. Because of the high temperature of the melting operations, melters can be used to destroy organics, although for highly contaminated waste streams an incineration system will likely be more efficient. The use of melters for the destruction of organics are likely to require significant process modifications.

Melters are ideally suited for inorganic waste streams such as inorganic oxides and elemental metals. Furthermore, the chemistry in the melt can be reducing or oxidizing depending on the type of waste form desired. When processing oxides, the final waste form will be a glass or a ceramic, depending on the rate of cooling as well as other parameters. When processing metals, the melt will form a top layer of slag and a bottom layer of molten metal. The slag can then be separated from the molten metal, allowing for recycle of the molten metal. Depending on how the melter is operated, it is possible to oxidize the majority of the radionuclides in the waste so that they will become part of the slag, thereby decontaminating the molten metal. The Waste Destruction and Stabilization TSG will evaluate molten metal technologies to determine their applicability to DOE MLLW.

Many thermal treatment devices share similar research needs. The common needs for some of the more promising thermal devices are shown in Table 4.1. This table identifies both the advantages and disadvantages for each technology. Many of the disadvantages can be eliminated with additional research. In terms of melters, there are several research requirements that need to be resolved and disadvantages that need to be overcome to ensure safe and proper operation in a radioactive environment. In general, these research needs can be classified as requiring more operational experience, better materials of construction, improved materials handling techniques, less waste pretreatment, control of chemistry in the process, and detailed analysis of the resulting residue and off-gas to determine the constituents that are in these effluents.

Innovative thermal treatment technologies are primarily directed towards the destruction of organics and producing a stable final waste form. In addition to these waste streams, thermal technologies can be used to destroy other compounds such as nitrates and cyanides. At the current time, the majority of funded development in innovative thermal treatment is associated with plasma systems. Based on the conclusions of the HAZWRAP report (Reference 7), this technology was selected as a high priority for research, development, demonstration, testing and evaluation for four main reasons. First, previous efforts to identify and evaluate thermal treatment technologies rated plasma treatment as a strong candidate for its application to many of the DOE waste streams. Second, a plasma system has demonstrated the ability to treat drums of some types of waste without first removing the waste. This capability can be beneficial to the DOE because there is currently a large portion of DOE wastes that are stored in drums, and it is undesirable to remove this waste from the drums and sort through the waste because of the associated hazards and costs. Another important benefit of the plasma technology may be its ability to simultaneously treat organics, metals, and inorganic oxides which also precludes the need to remove waste from drum for sorting. Another element that led to the decision to concentrate at this 
time on plasma technology was the fact that there are already ongoing efforts in other DOE organizations to investigate other melters such as joule heated melters and arc melters.

There are several variations in plasma systems that can be utilized for waste treatment. One of the significant variations is in how the plasma is generated. There are different methods that can be used to create a plasma, and therefore there are various proposed TTPs to investigate these different types of plasmas. There has also been significant work in the type of chamber used for the plasma system. At this point, one of the important TTPs that has been approved for funding is to build a fixed hearth plasma system using a transferred arc plasma. This system will be used to test various subsystems and to verify the treatment of various types of waste.

\subsubsection{Chemical Waste Destruction and Stabilization Technologies}

There are no studies identified by the WDS TSG that investigate the applicabilities of innovative chemical destruction technologies to DOE MLLW.

\subsubsection{Electrochemical Waste Destruction and Stabilization Technologies}

Two TTPs were recommended by the TSG for FY93 funding on a lower priority. These TTPs investigate the feasibility of treating DOE MLLW streams with electrochemical destruction technologies. The Mediated Electrochemical Oxidation (MEO) process is designed to convert organic materials to $\mathrm{CO}_{2}, \mathrm{H}_{2} \mathrm{O}$, and inorganic nontoxic ions. The CEPOD system uses a powerful regenerated oxidative catalyst to dissolve, destroy, or decontaminate organic and inorganic materials. Due to funding constraints, these two electrochemical treatment technologies were not supported.

\subsubsection{Radiolytic Waste Destruction and Stabilization Technologies}

There are no studies identified by the WDS TSG that investigate the applicabilities of innovative radiolytic waste destruction technologies to DOE MLLW.

\subsection{CURRENTLY AVAILABLE WASTE DESTRUCTION AND STABILIZATION TECHNOLOGIES}

These technologies are loosely defined as those technologies with significant waste treatment experience. As a result of this experience, these processes are well understood, the types of waste that can be treated with these process is known, and the limitations are clearly established. Consequently, once a waste stream is characterized, it can be determined if these processes are appropriate and can adequately treat the waste streams without a significant amount of research and development. In addition, these processes can normally be designed and operated without a great deal of testing. However, this definition does not imply that improvements to these technologies are not needed for successful MLLW service. 
Table 4.1. Thermal Treatment Technologies Advantages and Disadvantages

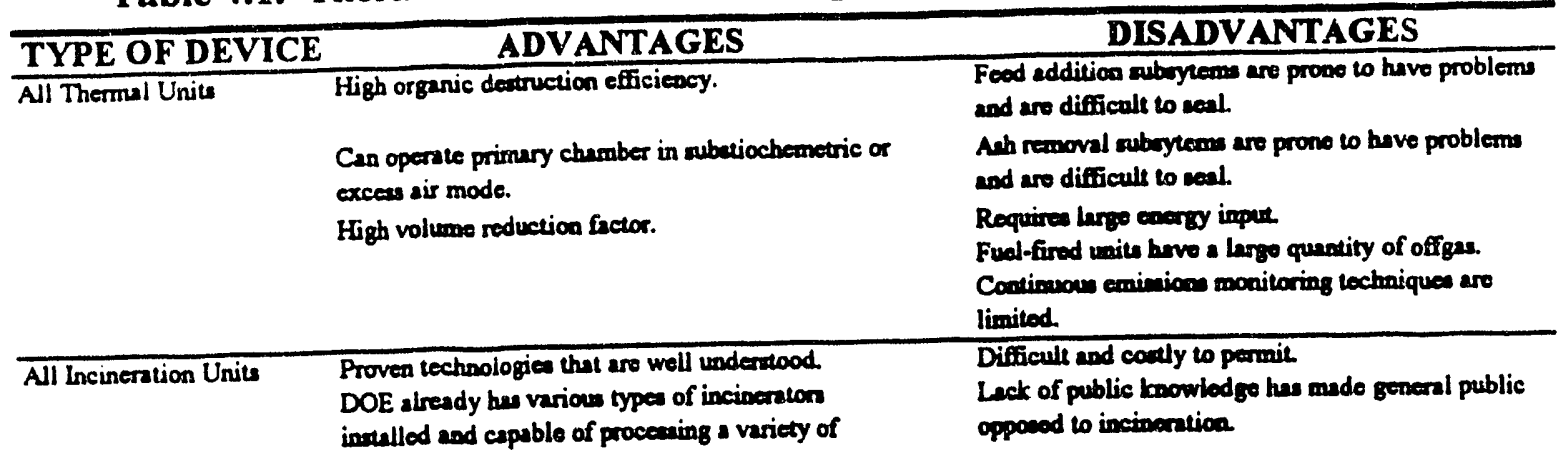

wastea.

Mandated dectruction lechnology by EPA for many

Ash reaidue may comain leachuble beavy metale. types of watee.

Can have large wate feed changea

Can have varition is waste composition.

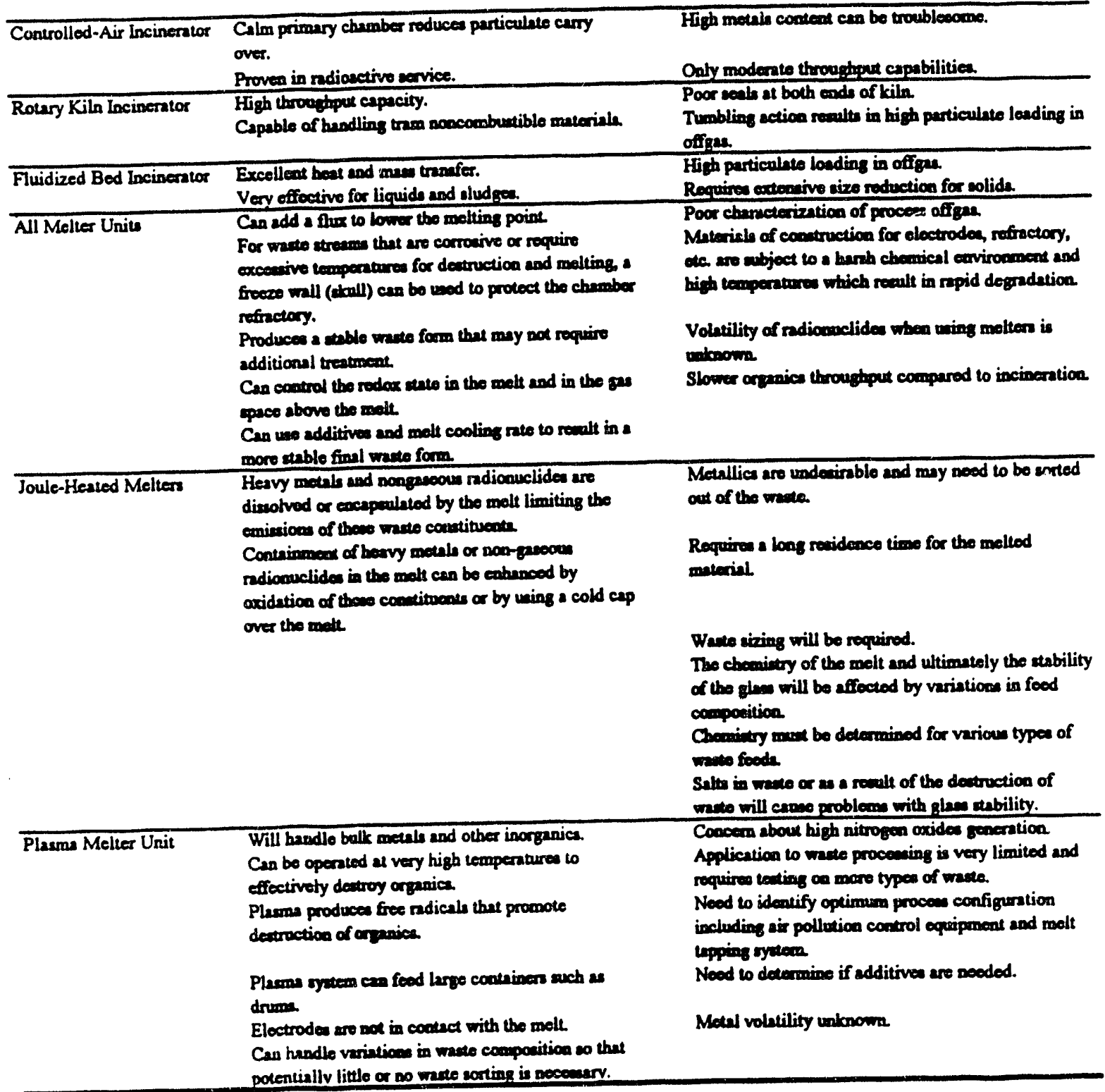


The EPA has been developing and tracking technologies for hazardous waste treatment. The EPA also encourages development in the private sector. Many of these activities are directed toward Environmental Restoration (ER) problems at Superfund sites. Some of these technologies can be used to clean up DOE ER problems but, since their primary function is the destruction of hazardous organic constituents, they may also have applications in MLLW treatment.

\subsubsection{Thermal Waste Destruction and Stabilization Technologies}

As was previously stated, the conventional thermal treatment technologies are incinerators or processes that are very similar to incineration. Waste incineration is well established and has been in use for over 100 years. With the recent concern about the environment and waste management, many improvements have been made in this technology. Currently, incineration is one of the best waste management tools available. Destruction and removal efficiencies of hazardous constituents in excess of 99.9999\% can be obtained. High quality turnkey systems are available that can be tailored to a specific situation. Radioactive waste incineration has been successfully utilized in the U.S. and in many other countries.

The large incineration experience base allows for the successful use of this technology on a wide variety of waste streams. A variety of incinerator types and configurations have been developed to accept specific combustible waste types. Three of the most commonly used incinerator types for waste treatment applications have been controlled air, rotary kiln, and fluidized bed incinerators. Controlled air incinerators are typically used for low density packaged waste streams but have been adapted to other applications such as medical waste treatment, cremation, and liquid waste combustion. Rotary kiln incinerators are considered the workhorse of the hazardous waste incineration industry due to their ability to accept a wide variety of waste physical forms and sizes. Fluidized bed incinerators have been adapted to accept liquid and slurry waste, sludges, and solids that have been reduced in size.

In addition to the above mentioned incinerator types, other incinerator configurations are available to treat more specific waste streams. Multiple hearth incinerators are primarily used for treatment of sludges containing organics. Liquid injection incinerators are generally designed to accept liquids and slurries, and with some modification gaseous wastes also. Large (> 1000 Ton/day) incinerators are used for municipal solid waste combustion. Industrial combustion processes originally developed for other applications are now also being used for waste treatment. Such systems include waste heat boilers, furnaces, and kilns and each takes advantage of the heat content of organic waste for their primary process application. References 7 and 8 provide more detailed lists and descriptions of these incineration technologies.

The disadvantages for waste incineration that could be addressed by research are tabulated in Table 4.1. Specific research needs for the individual types of incinerators are detailed in Reference 8. In addition to these research needs, there are a few other issues to consider. 
For some waste streams, more than one treatment technology may be required in scries to effectively destroy the waste's organic fraction, stabilize the inorganic fraction, and minımize overall offgas emissions. For example, it may be more cost effective and result $i n$ a better system if waste with a high organic content is first processed in an incint rator and the resulting ash is then processed in a melter. Incinerators are more efti $i$ ient at processing wastes with a high organic content and will likely result in a higher waste r.ocessing rate. The small volume of resulting ash can then easily be handled in a small melter to produce a stable final waste form. In addition, the chemistry in the melt and in the offgas is much easier to control in this scenario and may, therefore, result in a better final waste form and fewer emissions in the offgas.

Likewise, an aqueous waste that has a high nitrate and dissolved metals content could be first treated in a fluid-bed calciner. The calciner converts the nitrates to nitroger: oxides, which leave as a gas that can be treated in the pollution control system. Simultaneous to destroying the nitrates, the calciner converts the dissolved metals to metal oxides which can then be vitrified in a melter. This two step process is more efficient than using the melter alone as calciners can oxidize the metals much more afficient'ly than other technologies and can also evaporate off the moisture at a rapid rate and in a controlled manner. There may be other benefits as well, such as easier temporary storage because of the resulting volume reduction and safer form of the waste. There are limitations to calcination such as the presence of certain species, e.g. sodium nitrates, makes the process unacceptable because the calcined waste forms a viscous material.

Thermal treatment technologies have been instrumental in DOE's current waste management practices for two main reasons. First, thermal treatment is a very effective method for waste destruction and stabilization. In fact, for many types of wastes, the EPA has determined that incineration is the Best Demonstrated Available Technology (BDAT), and therefore federal regulations require that these wastes be treated by incineration. Secondly, the DOE presently has incinerators (many more are under construction or are planned for construction, and/or in the permitting stage). These future facilities will have a major impact on DOE waste management strategy and practices but there will continue to be many required technology improvements and other issues to be resolved.

It has been suggested, particularly by some developers of alternative technologies, that incinerators are not permittable and that, only by substituting such alternative technologies, will treatment of MLLW be allowed. However, the commercial sector has demonstrated the permittability of incinerators. A key to implementation of incineration and alternative technologies for treatment of MLLW will be the involvement of the public and regulatory agencies at an early stage in the process.

\subsubsection{Chemical Waste Destruction and Stabilization Technologies}

Chemical treatment destruction technologies are processes in which hazardous wastes are altered by chemical reactions. These chemical reactions can destroy the 
hazardous components. In other cases, the resulting product can still be hazardous, although in a more convenient form for further processing or disposal. Possible chemical treatment processes includes oxidation, reduction, ozonation, and electrolysis. Limitations in the use of chemical treatment processes are the low solubilities of some metals, impurities in the waste that can inhibit reactions, and the potential for generating equally hazardous byproducts.

The Waste Destruction and Stabilization TSG will evaluate the applicability of these waste treatment technologies to DOE MLLW streams.

A determination needs to be made between the Waste Destruction and Stabilization and the Chemical/Physical Treatment TSGs as to which technical area these technologies should reside in, on a case-by-case basis.

\subsubsection{Biological Organic Destruction and Stabilization Technologies}

A discussion on organic waste destruction technologies would not be complete without including biological treatment processes. Biological processcs have been successfully used by industrial wastewater treatment facilities for years. Oil, chlorinated hydrocarbons, and heavy metals can be reduced within a biological treatment facility. Limitations of this technology include sensitivity to changes in waste stream concentration, metal salts concentration, and $\mathrm{pH}$ changes. The available information from development efforts to date must be reviewed by the WDS TSG to evaluate the applicability of biological treatment technologies to the DOE's waste streams.

A determination needs to be made between the Waste Destruction and Stabilization and the Chemical/Physical Treatment TSGs as to which technical area these technologies should reside in, on a case-by-case basis.

\subsection{ALTERNATIVES TO INCINERATION}

As previously mentioned, the WDS TSG has created a sub-TSG to focus on technology alternatives to incineration in support of the DOE's waste management efforts. The ATI sub- TSG has identified alternatives to incineration and broadly characterized these technologies as either thermal or non- thermal in nature.

Following is a current list of technology alternatives to incineration assembled by the ATI sub-TSG:

Thermal Treatments:

Wet Air Oxidation - Catalyzed

Wet Air Oxidation - Non-catalyzed

Calcination

Supercritical Water Oxidation

Steam Reforming

Microwave Processing 
Metal Melting and Recycle

Non-Thermal Treatments ${ }^{1}$ :

Biotreatments

Electrochemical Oxidation

Electron Beam and Other Radiolytic methods

Silent Discharge Plasma or other ozonation

Corona Discharge

UV Mediated Oxidation

Sonochemical Destruction

Supercritical $\mathrm{CO}_{2}$

Extraction

The general types of wastes streams for which the above listed technologies will focus are as follows. It is not assumed that all the listed technologies will be applicable to all of these waste types.

- Nitrates

- Chlorides

- Radioactively contaminated

- $\quad$ Tritium contaminated mixed wastes

- $\quad$ PCB contaminated materials

- Ion Exchange resins

- Plastics and other room trash (primarily cellulosics)

A significant challenge to the ATI sub-TSG is to arrive at a consensus concerning what technologies should be identified as an "alternative to incineration" and the justification for their inclusion as such. For example, is a technology an alternative because it will address a waste stream that is not amenable to incineration or is it an alternative to the process of incineration? An example of the latter is the treatment of vermiculite which is non-combustible and therefore does not burn at typical incinerator conditions.

To be considered an altemative to incineration a prospective technology could show an advantage in one or more of the following areas and be equal in those areas not exceeded:

- handle wastes not handled by incineration, or handle a wide range of waste equal to those handled by incineration;

1 A determination needs to be made between the Waste Destruction and Stabilization and the Chemical/Physical Treatment TSGs as to which technical area these technologies should reside in, on a case-by-case basis. 
- $\quad$ applicable to small problematic waste streams;

- technically surpass incineration capabilities;

- $\quad$ produce more benign wastes, smaller volumes, or no secondary waste;

- $\quad$ reduce or eliminate fugitive emissions;

- $\quad$ operate at lower costs; and

- meet or exceed all regulatory requirements. 


\section{CURRENTLY FUNDED WDS ACTIV ITIES}

The current efforts in the Waste Destruction and Stabilization TSG are focused on the TTPs funded in FY93. These activities are summarized in Table 5.1. Two thermal treatment technology categories have been funded in FY-93, the plasma hearth furnace and molten metal/slagging technologies.

Table 5.1. Summary of FY 93 Funded TTP Activities

\begin{tabular}{|lll|}
\hline \multicolumn{1}{|c}{ TITLE } & \multicolumn{1}{c|}{ RESPONSIBLE } & TTP NO. \\
ORGANIZATION & \\
The Plasma Hearth Process & MSE/SAIC & PE021202 \\
The Plasma Hearth Process & ORNL/SAIC & OR132020 \\
Liquid Metal Recycle and Waste Treatment & LANL & AL132001 \\
$\begin{array}{l}\text { Magnetic and Nonmagnetic MeltSlag } \\
\text { Treatment of Mixed Waste }\end{array}$ & PNL & RL332014 \\
$\begin{array}{l}\text { Waste Stream Diagnostics and Control for } \\
\text { Treatment }\end{array}$ & ORNL & OR-NEW \\
$\begin{array}{l}\text { Control of Metal Emissions from Mixed Waste } \\
\text { Incinerators }\end{array}$ & ORNL & OR132006 \\
\hline
\end{tabular}

The plasma hearth development program has been funded by various EM-50 organizations since FY -91. The plasma hearth process is perceived as a highly versatile WDS technology that could treat a wide variety of DOE's mixed wastes. Demonstrations have been performed on simulated compacted mixed waste and on buried mixed waste. This project will demonstrate processing of as many of the surrogate waste streams as possible, using the existing plasma hearth unit, and will also upgrade the system to more closely represent a full-scale production unit.

Molten metal/slagging technologies are being investigated for their potential to treat high metal- content mixed waste streams without requiring significant feed segregation. Metals processed could be recycled for limited uses within the DOE, and the non-metallics will be destroyed or bound up in the slag for subsequent disposal. FY-93 efforts will investigate the technology options, select a preferred molten metal process, and perform limited demonstrations on selected surrogate waste streams. The effort will include significant involvement by a commercial partner.

Two TTPs have been funded to investigate the characteristics of thermal treatment device effluents to aid in proper sampling and analysis of effluents. An effort to characterize the spectrum of effluents from thermal treatment devices, beginning with the plasma arc furnace, is being managed by ORNL. This task will define the surrogate formulations for MWIP-identified waste streams, sampling and analysis 
requirements, identify standardized sampling and analysis protocols, and established QA/QC requirements for measurements to be taken for all thermal treatment demonstrations. A second effluent activity will investigate the control of metal emissions from mixed waste thermal treatment units. 


\section{RECOMMENDATIONS FOR FUTURE ACTIVITIES}

\subsection{Improved Waste Data}

The WDS TSG will continue to direct and develop waste treatment technologies in support of DOE EM-30 needs. There are numerous efforts currently in progress and planned for the near future that are directed at solving the DOE waste management problems. One area that is currently being worked is the identification of waste streams; however, significant efforts in obtaining more detailed chemical and physical characteristics is necessary for the detailed design of full-scale treatment systems. With the waste information that is now being gathered, it is possible to determine which existing technologies can be used, where improvements to existing technologies are needed, and where altogether new technologies must be developed.

It is important to continue working on identifying waste streams where existing treatments are not sufficient to meet DOE needs. This information will serve as the basis for the developments and improvements that are required. It is also important to identify where DOE facilities may already exist. Efforts to identify currently available technologies that can be used to treat DOE waste should continue. Likewise, it would be beneficial to identify the commercial organizations that are processing wastes similar to DOE wastes. These commercial organizations may be able to provide valuable information about various technologies and possibly even process DOE waste at an accelerated schedule.

\subsection{Communications in Technology Development}

One of the critical elements that must be incorporated in this process is communications. In order to eliminate redundant efforts, ensure effective use of resources, and to make sure that there are no technology gaps, each of the TSGs must communicate with the each other. Coordination as to which TSG should deal with a particular technology is not always straightforward as there is some overlap of the functions for the TSGs. For example, metal melting technologies can be used to destroy organic wastes, to produce an enhanced final waste form, or to recycle metals by producing shielding block, etc. Consequently, a decision must be made as to which technologies and tasks will be covered by the Destruction and Stabilization TSG, the Final Waste Form TSG, and the Physical/Chemical Treatment TSG. Likewise, vitrification technologies can be used to destroy organics and to produce an enhanced final waste form. Therefore, it is important to maintain communications to prevent the duplication of efforts.

It is equally important to make sure that no development needs are overlooked. Without active communications between all TSGs, there is a concern that some areas that require research and development will not be addressed. For example, for certain waste streams the Waste Destruction and Stabilization TSG must specify to the 
Physical/Chemical Treatment TSG what pretreatment is required for the destruction and stabilization processes that are being considered. Likewise, the Second-Stage Destruction and Off-Gas Treatment TSG and the Final Waste Form TSG are affected by the processes selected by the Waste Destruction and Stabilization TSG. Therefore, different air pollution control capabilities may be required, and different performance standards may need to be developed for the final waste form. This interaction between the TSGs is particularly important in developing a systems approach to waste management rather than concentrating only on the individual technologies. In addition to the communications between the TSGs, there are other Integrated Programs and Integrated Demonstrations in the DOE that are related to or can use the information gained from the MWIP. The MWIP should also maintain communications with these organizations.

\subsection{Future Development Activities}

The MWIP's FY-94 Call for Proposals was issued to the field in February 1993 (Reference 9). The specific needs identified by the WDS TSG are contained in this call, portions of which are reproduced as Appendix F. 


\section{REFERENCES}

1. Mixed Waste Integrated Program Technology Needs Statement and Call for Proposals, Mixed Waste Integrated Program, FY-94.

2. Guidance for Conducting a DT\&E Demonstration Performance Readiness Evaluation, EM-55, January 1993.

3. Land Disposal Restrictions Case-by-Case Extension A pplication for Radioactive Mixed Wastes, U.S. Department of Energy, Washington D.C., 1991.

4. Integrated Data base for 1991: U.S. Spent Fuel and Radioactive Waste Inventories, Projections, and Characteristics, DOE/RW-0006, Rev. 7, U.S. Department of Energy, Washington D.C., 1991.

5. Waste Management Information System Data Base (WMIS), maintained by HAZWRAP, Oak Ridge, TN.

6. W.A. Ross, C.L. Warner, et al, Locations, Volumes, and Characteristics of DOE's Mixed Low-Level Wastes, Waste Management '92, March 1-5, 1992, Tucson, Arizona.

7. An A ssessment of Thermal Destruction Technologies for Application to Department of Energy Mixed Wastes Volume 1 \& 2, DOE/HWP-106, Hazardous Waste Remedial Actions Program, Oak Ridge, TN., August 1991.

8. Mixed Waste Integrated Program Interim Evaluation Report on Thermal Treatment Technologies, DOE/MWIP-2, U.S. Department of Energy, September 1992.

9. G. Coyle, EM-542, to TPOs and TPMs, Subject: Requests for FY -94 Short Form Technical Task Plan Proposals for the Department of Energy Mixed Waste Integrated Program, February 2, 1993. 


\section{APPENDIX A}

Mixed Waste Characterization Code Descriptions:

! Information contained in Appendix A was obtained from the following document: Ross, W., Warner, C., et al, Locations, Volumes, and Characteristics of DOE's Mixed LowLevel Wastes, Waste Management '92, March 1-5, 1992, Tucson, Arizona. 


\section{MIXED WASTE CHARACTERIZATION CODE DESCRIPTIONS}

Code

Number

1000

1100

1200

1300

1400

1900
Title

Aqueous Liquids and Slurries

Acidic

Basic

Neutral

Cyanide

Uncategorized Aqueous Liquids

\section{Description}

Aqueous solutions or slurries that have less than $1 \%$ organic content. Solids must be pumpable, but can be up to about $35-40 \%$ of the mass.

These solutions have a $\mathrm{pH}$ of less than 2 and a RCRA code of D002. They are typically general waste waters, plating line solutions, and electropolishing activities.

The acid may be of any type. Most common acid types are nitric, sulfuric, and hydrochloric.

These are solutions with a $\mathrm{pH}$ of greater than 12.5 and a RCRA code of D002. They are generated from a variety of activities. They can result from neutralization of acidic streams.

Solutions with a pH from 2 to 12.5. One source is condensate from evaporators.

Any stream that contains cyanide as a significant component. Solutions will generally be basic.

Aqueous liquid streams for which insufficient information is available to further characterize or streams that contain mixtures of waste categories.
Treatment

Concern

The acid nature of the wastes.
The basic nature of the wastes.

Cyanide gas generation. 
Code

Number

2000

2100

2110

2120

2190

2200 $\underline{\text { Title }}$

Organic Liquids

Aqueous/Organic

Liquids

Aqueous/

Halogenated

Organic Liquids

Aqueous/Non-

Halogenated

Organic Liquids

Uncategorized

Aqueous/Organic

Liquids

Pure Organic

Liquids
Description

Treatment

Concern

Liquid steams that are elther essentially a pure organic stream or those streams that contain both aqueous and organic materials. Solids must be pumpable but can be up to $35-40 \%$ of the mass.

Liquid streams that contain mixtures of aqueous and organic liquids with contents of $1 \%$ or more of organic liquids but less than about $99 \%$ organic.

Liquid streams that contain mixtures of aqueous and halogenated organic liquids with contents of $1 \%$ or more of organic liquids but less than about $99 \%$ organic.

Liquid streams that contain mixtures of aqueous and nonhalogenated organic liquids with contents of $1 \%$ or more of organic liquids but less than about $99 \%$ organic.

Liquid streams that contain mixtures of aqueous and uncategorized organic liquids

Liquids with only organic materials 
Code

Number

2210

2220

2290

2900

3000 $\underline{\text { Title }}$

Halogenated

Organic

Non-Halogenated

Organic

Uncategorized

Organic Liquids

Solid Process

Resides Organic Liquids
Treatment

Description

Concern

Nearly pure organic liquids containing more than trace $(-1000 \mathrm{ppm})$ levels of halogens (e.g., $\mathrm{F}, \mathrm{Cl}, \mathrm{Br}$, etc.). Contaminated freon is one specific stream. High level PCB wastes are also a potential stream.

Nearly pure organic liquids free of more than trace $(-1000$ ppm) levels of halogens (e.g., $\mathrm{F}, \mathrm{Cl}, \mathrm{Br}$, etc.). Oils, hexon. and methanol are typical streams.

Uncategorized Pure Organic liquids that can not be categorized as halogenated or non-halogenated.

Organic liquids for which insufficient information is available to determine the aqueous content and whether the stream is more than trace halogenated.

These materials are typically residues from process operations such as waste water clean up or process operations, or are listed wastes.
Treatment must provide for

PCB

destruction. 
Code

Number

3100

3110

3111

3112

3113
Title

Inorganic Matrix

Solids

Particulate

Inorganic Media

Ash

Sand Blasting

Media

Absorbed Aqueous Liquids
Treatment

Description

Concern

These are materials that have an inorganic matrix or content such that they would have a high residue from incineration. They may contain both hazardous organics and metals. They may also contain either aqueous or organic interstitial liquids.

Fine particulate wastes. Typical sources are ash from incinerators, dusts, sand blasting residue, vermiculite, and ion exchange media.

Materials generated from the incineration of radioactive wastes. It includes both bottom ash, fly ash, and other solid residues.

Destruction or removal of organics in solids and immobilization of toxic metals.

Dispersibility

of the wastes.

May contain residual carbon, heavy metals in a very dispersible form.

Particulate material (generally course sand or glass) used to decontaminate or clean radioactively contaminated materials.

Inorganic materials such as clay, vermiculite, or diatomaceous earth added to absorb aqueous liquids or placed in drums to absorb liquids if internal containers leak. 
Code

vumber

3114

3115

3119

3120

3121

3122
Title

Absorbed Organic Liquids

Ion Exchange

Media

Uncategorized

Particulates

Sludges, Filter

Cakes and

Residues

\section{Low Organic \\ Content Sludges}

High Organic

Content Sludges
Description

Treatment

Concern

Inorganic materials such as clay, vermiculite, or diatomaceous earth used to absorb organic liquids or placed in drum to absorb liquids if internal containers leak.

Inorganic materials that have been used to remove ions from liquid streams.

Particulate materials that can not be assigned to any of the above categories or is a mixture of such materials including absorbed liquids or materials that have some trap materials.

These materials are generally from waste water cleanup or from settling ponds. They

Identification of foreign may contain organic materials items in drums. in limited quantities from laundry or other sources. Heavy metals are present in some sludges. Equipment, filters, and other materials have occasionally been included with some drums.

Sludges with less than $1 \%$ of hazardous organic materials.

Sludges with greater then $1 \%$ hazardous organic material. The organics can be either halogenated or nonhalogenated materials. 
Code

Number

3123

3129

3130

3140

3150

3151

3152
Title

Sludges with

Cyanide

Uncategorized

Sludges

Paint Chips \&

Residues
Description

Sludges such as those in 211 that contain cyanide as more than a trace concentration.

Sludges with unknown levels of organic content nr sludges with other components such as paper filter media.

New or removed paint. The paint may have some liquids content either as original paint or as a paint stripper; it may also be paint chips

Painting equipment would be a debris waste.

Cemented Sludges, Ashes, and Solids

Salt Wastes

Chloride and Sulfate Salts

Nitrate Salts absorber or that are mixed with cement or solidifying agents to produce a homogenous solid waste, but do not yet met disposal requirements. Final treated cemented materials are a 9100 waste.

\section{Salt Wastes}

Evaporated or process salt that may contain more than trace concentrations of sulfate and chlorides or other halogens.

Evaporated or process slats
Treatment

Concern

Destruction of cyanide.

It will likely have a high residue after incineration.

Residuaì or free water in waste.

The corrosion potential for process equipment and the limited solubility in glass waste forms. that are predominantly nitrate Destruction of salts.

NOx. 
Code

Number

3159

3190

3200

3210

3211

3212

3213
Title

Uncategorized Salt

Wastes

Uncategorized

Inorganic Solids

Organic Matrix

Solids

Particulate Organic Media

Activated Carbon

Organic Resins

Absorbed Liquids (Organic Matrix)
Treatment

Description

Concern

Salt wastes with unknown salts, a combination of 3151 and 312 salts, or are non chloride, sulfate, or nitrate.

Inorganic solid waste streams that can not be further

Insufficient characterization characterized or is a mixture of 211 to 217 materials.

These are materials that have an organic matrix or base structure. They may have some liquid present, but will not leave a large residue when incinerated.

Particulate organic media including spent organic resins. spent carbon filters used in waste water cleanup, or particulate organic material used to absorb organic aqueous liquids.

information

Destruction of the organic content.

Destruction of the organic content. Some resins are not compatible with cement or grout systems.

Particulate activated carbon that has often been used for removal of organic materials from off-gas streams or liquid streams.

Organic based resins that have been used in waste water treatment or other applications.

Liquids absorbed on a particulate organic matrix such as cellose or pulverized corn cobs. 
Code

Number

3219

3220

3221

3222

3229

3230

3290
Title

Uncategorized Organic Particulate

Organic Sludges

Sewage Sludges

HOC Organic

Sludges

Uncategorized

Organic Sludges

Organic Chemicals

Uncategorized

Organic Solids
Description

Treatment

Concern
Particulate materials or media that can not be categorized above or that is a mixture of the above materials.

Organic based sludges of various types.

Sludges generated in treating waste water from animals or people.

Halogenated organic containing materials that can not be poured from a drum at room temperature for treatment as an organic liquid

Organic sludges which could not be categorized as a 3221 , 322 , or 3223 because of it being a combination of materials or because of its unknown chemistry.

Drums of unused organic chemicals.

Materials that can not be included into any of the above organic solid categories or is a combination of categories.
Streams may contain PCB's

Transfer of contents from containers. 
Code

Number

4000

4100

4200

4300

4400
Title

Soils

Organic

Contaminated Soils

Inorganic

Contaminated Soils

Organic and

Inorganic

Contaminated Soils

Soils with Organic Debris
Description

Soils contaminated with hazardous materials and radioactivity. Codes 4100 to 4300 may contain up to $5 \%$ debris materials. Codes 4400 to 4600 may have 5 to $50 \%$ debris. Streams with more than $50 \%$ debris would be a debris waste $(5000)$. This group is subdivided as noted below however it may be modified when specific EPA regulations are promulgated.

Soils contaminated with hazardous organics from activities such as spills, drains, and waste water treatment.

Soils contaminated with hazardous inorganics from activities such as spills, drains, anid waste water treatment.

Soils contaminated with both hazardous organic and inorganic materials from activities such as spills, drains, and waste water treatment.

Soils contaminated with more than $5 \%$ hazardous organics debris from activities such as spills, drains, D\&D, and previous waste disposal actions. These streams may also contain organic or inorganic hazardous materials.
Treatment Concern
Rernoval or destruction of the hazardous organic materials.

Removal or immobilization of the hazardous inorganic materials. 
Code

Number

4500

4600

4900

5000

Debris Wastes

Uncategorized

Soils

Soils with Both Inorganic and

Organic Debris

Soils with Inorganic Debris
Treatment

Description

Concern

Soils contaminated with more than $5 \%$ hazardous inorganics debris from actıvities such as spills, drains, D\&D, and previous waste disposal actions. These streams may also contain organic or inorganic hazardous materials.

Soils contaminated with more than $5 \%$ of either or both hazardous organic and inorganic debris from activities such as spills, drains, D\&D, and previous waste disposal actions. These streams may also contain organic or inorganic hazardous materials.

Soils contaminated with unknown materials or with a combination of 4000 series waste categories.

Wastes that meet the EPA criteria for Debris. Debris materials are divided into four groups as either metal, inorganic non-metal, combustible, or mixtures of materials (heterogeneous). If the wastes is dominate in one type of material it should be classed as that material otherwise it is heterogeneous.

Streams that generally have a metal content greater than about $95 \%$. 


\section{A-13}

Code

Number

Title

Description

Treatment

5110

Metallic

Equipment,

Components, and

Scrap.

General metallic items that

have been used in process

operations or maintenance.

Typical items include piping, pumps, metal filters, traps, wire, and fixtures. It is anticipated that the metal content is greater than about $95 \%$.

$5120 \quad$ Uranium Chips and Turnings

Uranium metal components or particulate materials with other types of materials to reduce uranium reactivity.

$5130 \quad$ Lead Containing Components and Metallic lead containing materials, including Materials gloveboxes, lead wool, lead base solder materials, or lead components used in radioactive processes. It also includes lead shapes mixed with other materials or lead encapsulated in other metals. This stream does not include lead acid batteries which are a 7410 waste or pure lead shapes used as shielding (7200).

5140

Cadmium

Containing

Components formed from cadmium or contain a

Components and significant fraction of Materials cadmium. This stream does not include cadmium batteries which are a 7420 waste.

Metallic components that can not be classed as a specific 5100 waste stream because of lack of knowledge or because it contents multiple categories. 
Code

Number

5200

5210

5220

5230

5240

5290

5300

5310
Title

Inorganic Non-

Metal Debris

Concrete

Glass

Ceramic Crucibles and Bricks

Rocks

Uncategorized

Inorganic Non-

Metal Debris

Combustible

Debris

Plastic and Rubber
Description

Treatment

Concern
Debris streams composed of about $95 \%$ inorganic nonmetal materials.

Concrete materials removed from buildings or roadways.

Items composed primarily of glass. It may be process equipment, laboratory equipment, window materials, vessels, bottles, or light bulbs if metallic components are removed. This stream may include leaded glass. The glass may contain small amounts of organic, metal, or other inorganic materials.

Crystalline or glass materials used as crucibles or refractories.

Rocks and gravel that have a particle size greater than 60 $\mathrm{mm}$.

Non-Metallic items that can not be classed as a specific 5200 waste stream because of lack of knowledge or because it contents multiple categories.

Specific waste streams that contain more than $95 \%$ combustible materials.

Plastic and rubber such as sheeting, containers, gloves, gaskets, and components of benelex or plexiglass.
Glass from florescent bulbs may contain some $\mathrm{Hg}$ or PCB contamination.
The halogen content during combustion. 
Code

Number

5311

5312

5313

5319

5320

5330

5340

5350
Title

Leaded Gloves and Aprons

Halogenated

Plastics

Non-Halogenated

Plastics

Uncategorized Plastic and Rubber Materials

Wood

Paper and Cloth

Graphite

Animal Carcasses
Description

Treatment

Concern

Rubber materials that contain

a high fraction of lead and lead compounds.

Plastics, such as PVC, that contain halogens as part of their chemical structure.

The halogen content during combustion.

Plastics, such as polyethylene. that are free of halogenated materials.

Materials that can not be separated into any of the above categories or that contain a mixture of such materials types.

Wood items such as structural timbers, boxes, or pallets.

Residence time required for complete combustion.

Paper and cloth items such as Nitrate contain protective clothing, and items used to wipe up rags and rapid combustion contamination or absorb rates. liquids. Wipes may contain some absorbed organic and aqueous liquids.

Crucibles or components of graphite or carbon.

Sufficient residence time to totally oxidized.

Dead animals or parts of Biological animals. Most animals will have been used in testing and may contain chemical agents such as lime or formaldehyde to stabilize them. hazards may be present. May have a high residue from stabilizing agents. 
Code

Number

5390

5400

5410

5420

5430

5440

5450
Title

Uncategorized

Combustible

Debris

Heterogeneous

Debris

Filters

Predominantly Metal

Predominantly Inorganic NonMetal

Predominantly

Combustible

Debris

Asphalt
Description

Treatment

Concern

Uncharacterized combustible

or mixtures of combustible

materials in the above

categories

Mixtures of metals, non-

Sorting of metals, combustibles, soils, and process residues that can be classified as debris.

HEPA filters, and other process filters. Filters are contaminated with fine particulate. HEPA filters may be either wood or metal frame. Particulate filter media would be process residues.

Debris materials that contain more than about $50 \%$ but less than $95 \%$ metals with other debris.

Debris materials that contain more than about $50 \%$ but less than about $95 \%$ inorganic non-metals with other debris

Debris materials that contain more than about $50 \%$ but less than $95 \%$ combustible materials with other noncombustible debris.

Asphalt materials from roadways or other sources and contain both tar and gravel. these materials may be necessary for treatment.

Mixtures of materials that can not be easily separated. 
Code

Number

5490

6000

6100

6110

6120

6130
Title

Uncategorized

Heterogeneous

Debris

Special Wastes

Lab Packs

Organic Lab Packs

Aqueous Lab

Packs

Solid Lab Packs
Description

Treatment

Concern

Heterogeneous debris that can not be further characterized. or does not contain a dominance of metals, nonmetals, or combustible debris

These waste streams will require specific treatment methods that are not expected to be common with other waste types. It also includes wastes streams for which treatment capacity may not be initially established as part of the Mixed Waste Treatment Project.

This category includes more than just the conventionally identified lab packs. It includes all wastes that contain liquids in container with surrounding packing materials such as vermiculite. Lab packs contain mixtures of chemicals in drums.

Chemicals are mostly solid but can contain liquids in bottles.

Lab packed materials that contain organic liquids.

Lab packed materials that contain aqueous liquids.

Lab packed materials that do not contain liquid materials.
Sorting of materials. Wide variety of chemicals.

Ability to characterize. 


\section{A-18}

Code

Number

6140

Scintillation

Cocktails

6190

6200

6210

6220

6290 Packs Metals
Title

Description

Solutions used for scintillation counting. Solutions are most often in the original glass or plastic analysis bottles.

Uncategorized Lab

Reactive Metals

Bulk Reactive

Components

Contaminated with Reactive Metals

Uncategorized

Reactive Metals
Lab packed materials that could be classified as more than one waste code from 6100 series or that have insufficient information available to further classify

Reactive metals are typically sodium metal or alkali metal alloys, but can also be particulate fines of aluminum, uranium, zirconium, or other pyrophoric materials and may be mixed with stabilizing materials.

Nearly pure reactive metals in Same as above. containers. They may have various types of impurities, but the bulk of materials is reactive metal and can be treated in a bulk processing system.

Piping, pumps, and other materials that have reactive metal contamination. The bulk of the material is not reactive metals, but the reactive metals require treatment before disposal.

Non alkali metal reactives or mixtures of reactives.
Treatment

Concern

Removal of the solutions from the bottles and containers and subsequent treatment of the containers

Reactive nature of materials and potential for hydrogen gas generation.

Some of the reactive materials may not be readily accessible to chemical reaction. 
Code

Number

6300

6310

6390

6400

6500

7000

7100

7200
Title

Explosive

Nitrated Rags \&

Filters

Uncategorized

Explosives

Compressed Gases

and Aerosol Cans
Any material that may explode during normal or extreme handling.

Rags that have absorbed nitric acid and then been left in storage.

Materials that may be explosive that are not nitrated rags or filters.

Aerosol cans and gas cylinders with gases of any composition. It is expected that the containers will be pressurized. Non-pressurized containers would be a debris waste.

Hanford Double Shell Tanks

Inherently

Hazardous

Materials

Liquid Mercury

Lead Shapes
Treatment

Concern

Serious

handling

problem and

worker safety

problem.

During storage nitrocellulose may form which is explosive.

Rapid gas release from container failure during processing.
Wastes in Hanford Double Shell Tanks.

Materials that are composed of inherently hazardous materials.

Liquid mercury pourable from containers. Will include drums of waste that contain elemental mercury within a container.

Bulk Lead materials that are separable from other wastes in the form of bricks, sheets, or unique components.
Separation of $\mathrm{Hg}$ from other waste materials. 
Code

Number

7210

7220

7230

7300

7400

7410

7420

7490
Title

Non-Acrivated

Lead

Activated Lead

Lead with Other Materials

Beryllium Wastes

Batteries

Lead Acid

Cadmium

Uncategorized

Batteries
Description

Treatment

Concern

Lead bricks, shipping casks. Recycle of the or shielding materials. The materials lead should only be surface contaminated.

Lead activated from it's use in radiations fields such as in reactors or accelerators where it can be activated.

\section{Radiation} levels are generally sufficient to require shielding and remote handling.

Lead bricks or shapes in drums of waste with other inorganic or organic type materials. The lead should be a shape that can be decontaminated and can be easily separated from the other wastes.

Beryllium metal chips or materials contaminated with more than trace levels of beryllium. It should be a P014 RCRA waste.

These are generally lead, and cadmium-type batteries, but will include other types as well.

BDAT specifies recycle.

The BDAT specifies recycle of the metals.

Lead Acid batteries.

Cadmium type batteries.

Other types of batteries or unclassifiable batteries. 
Code

Number

8000

8100

8200

8900

9000

9100

9200

9300

9400
Title

Unknowr

Unknown Liquids

Unknown Solids

Uncategorized

Unknown

Treated Wastes

Cement

Glass

Metal

Polymer
Treatment

Description

Waste materials that can not reasonable be classified into one of the other categories based on available information or streams for which the available iniormation is conflicting.

Liquid wastes that can not be categorized as aqueous or organic liquids.

Solid Materials that can be categorized.

Materials that can not be categorized.

Wastes that have been treated to meet the Land Disposal Restriction.

Cement type waste forms including grouts and cements of various types.

Wastes that have been converted to a vitreous type waste form.

Metal waste forms that have been consolidated or decontaminated and are ready for disposal or recycle.

Organic type waste forms including polyethylene, bitumen, resins, and other organic binders.
Inadequate information to allow classification. 


\section{A-22}

Code

Number

9900
Title

Other Forms

\section{Description}

Final waste forms that are not classed as either a cement. glass, metal, or polymer. It would include amalgamated mercury and microencapsulated lead.
Treatment

Concern 


\begin{abstract}
APPENDIX B
Department of Energy's Low-Level Mixed Waste Inventory
\end{abstract}

1 Information contained in Appendix B was obtained from the following document: Ross, W., Warner, C., et al, Locations. Volumes, and Characteristics of DOE's Mixed LowLevel Wastes, Waste Management '92, March 1-5, 1992, Tucson, Arizona. 
B-3

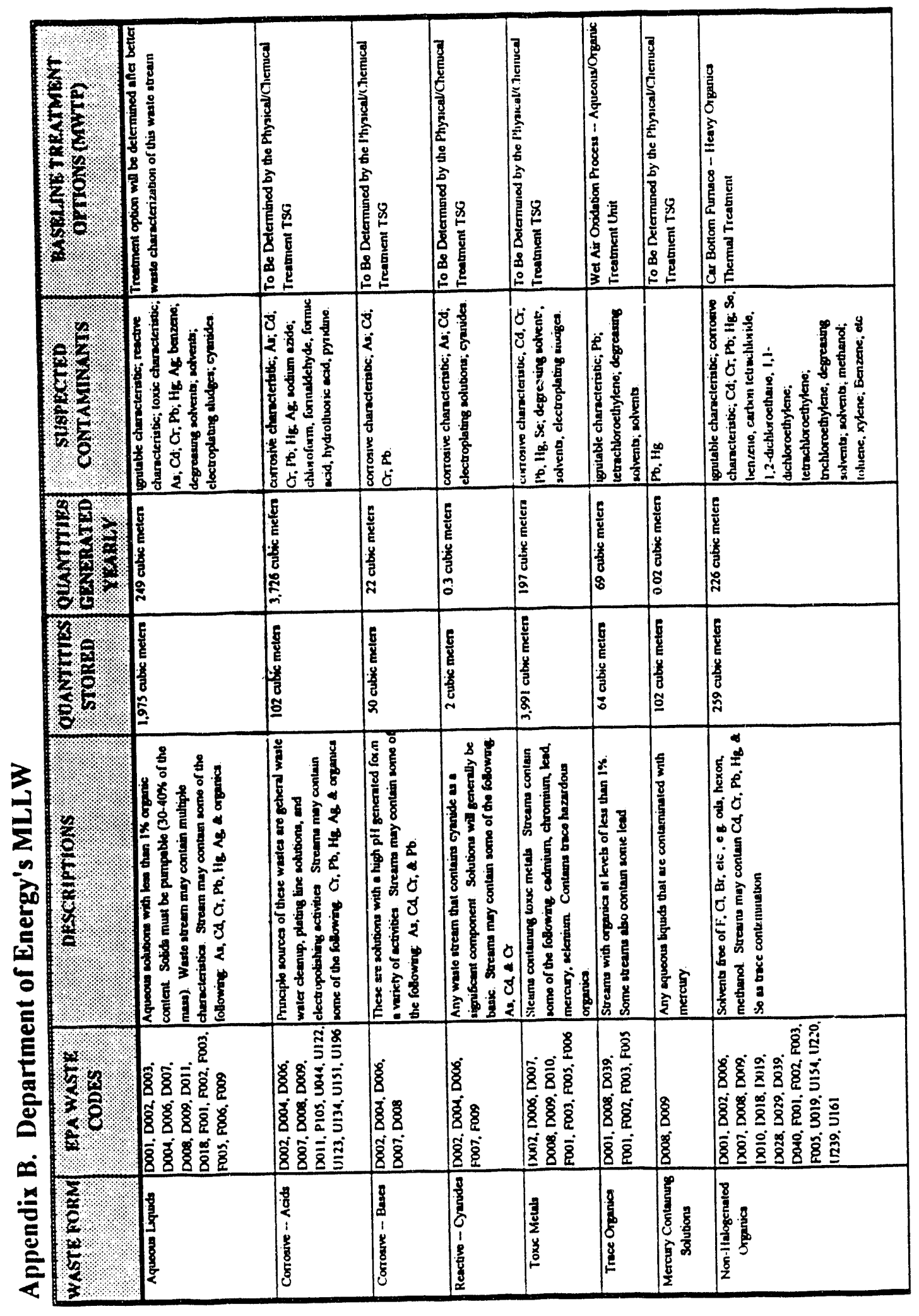




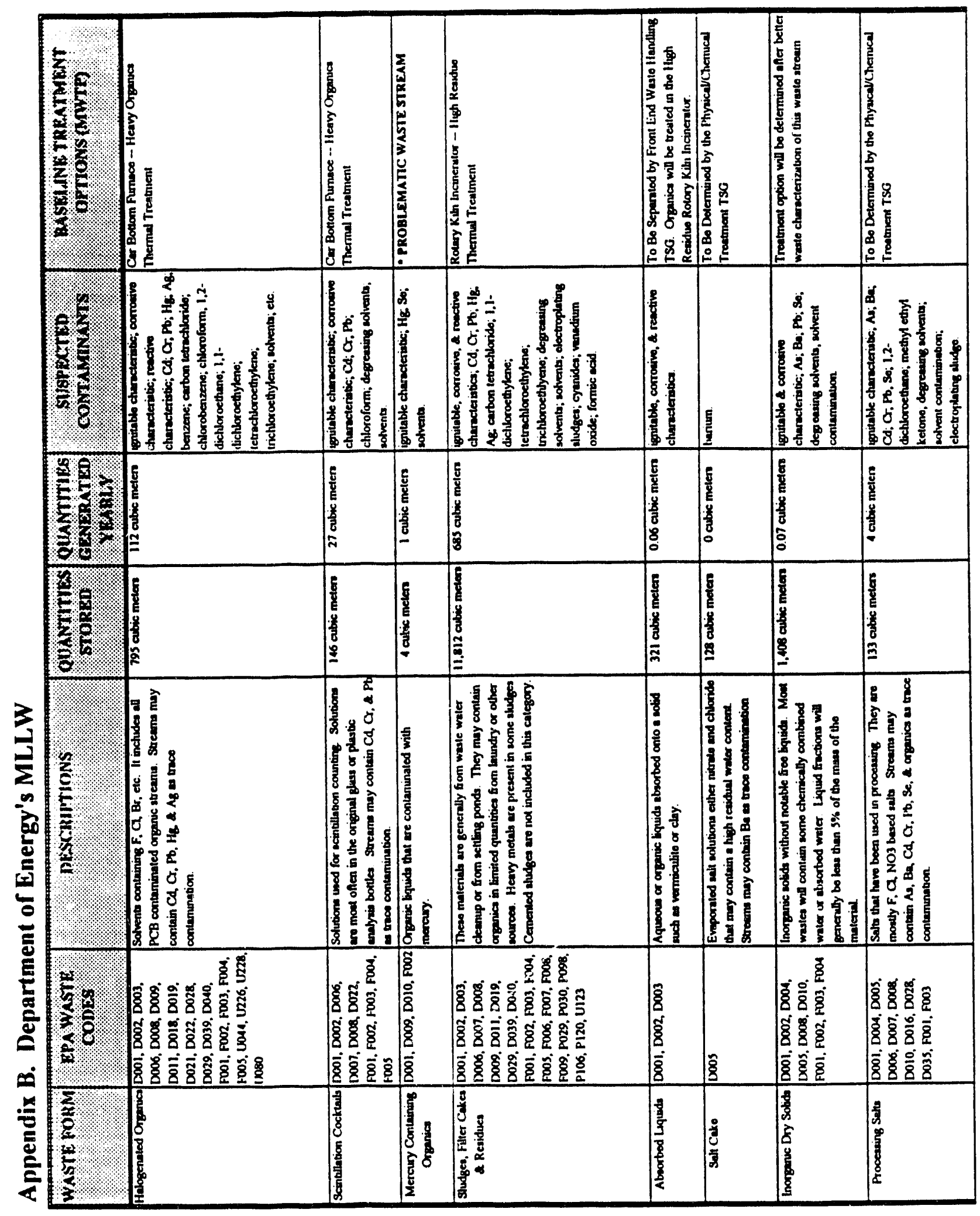


B-5

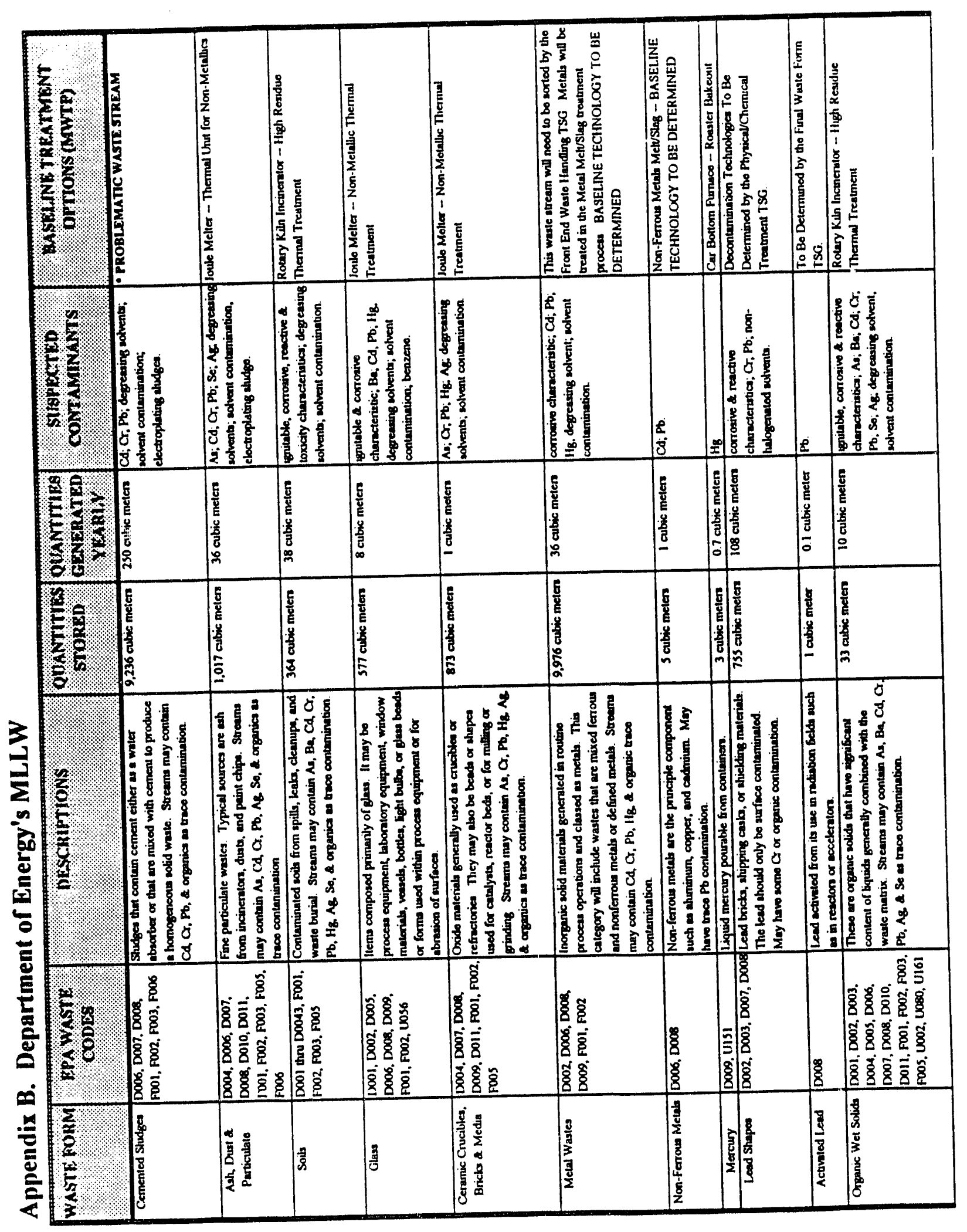




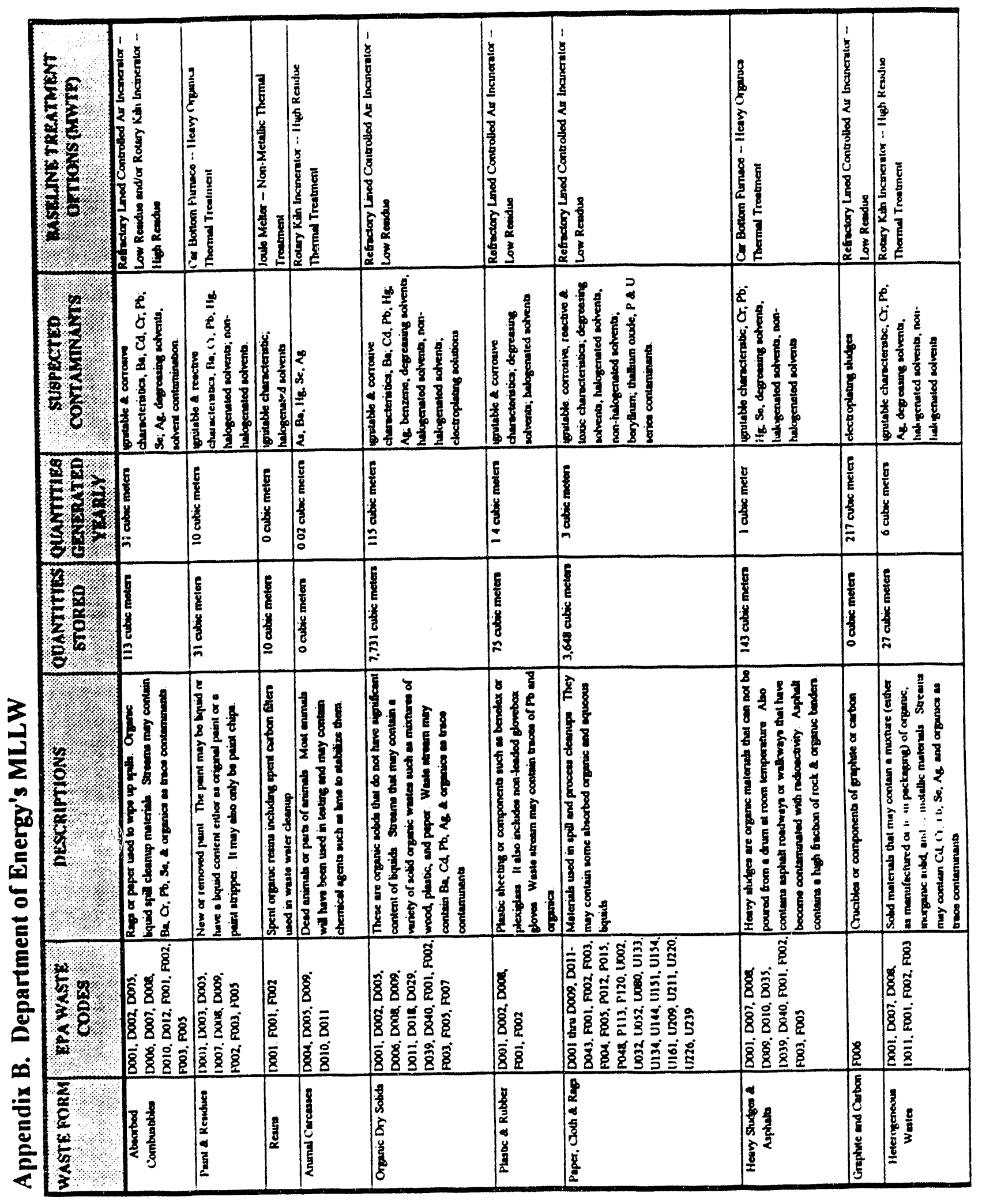




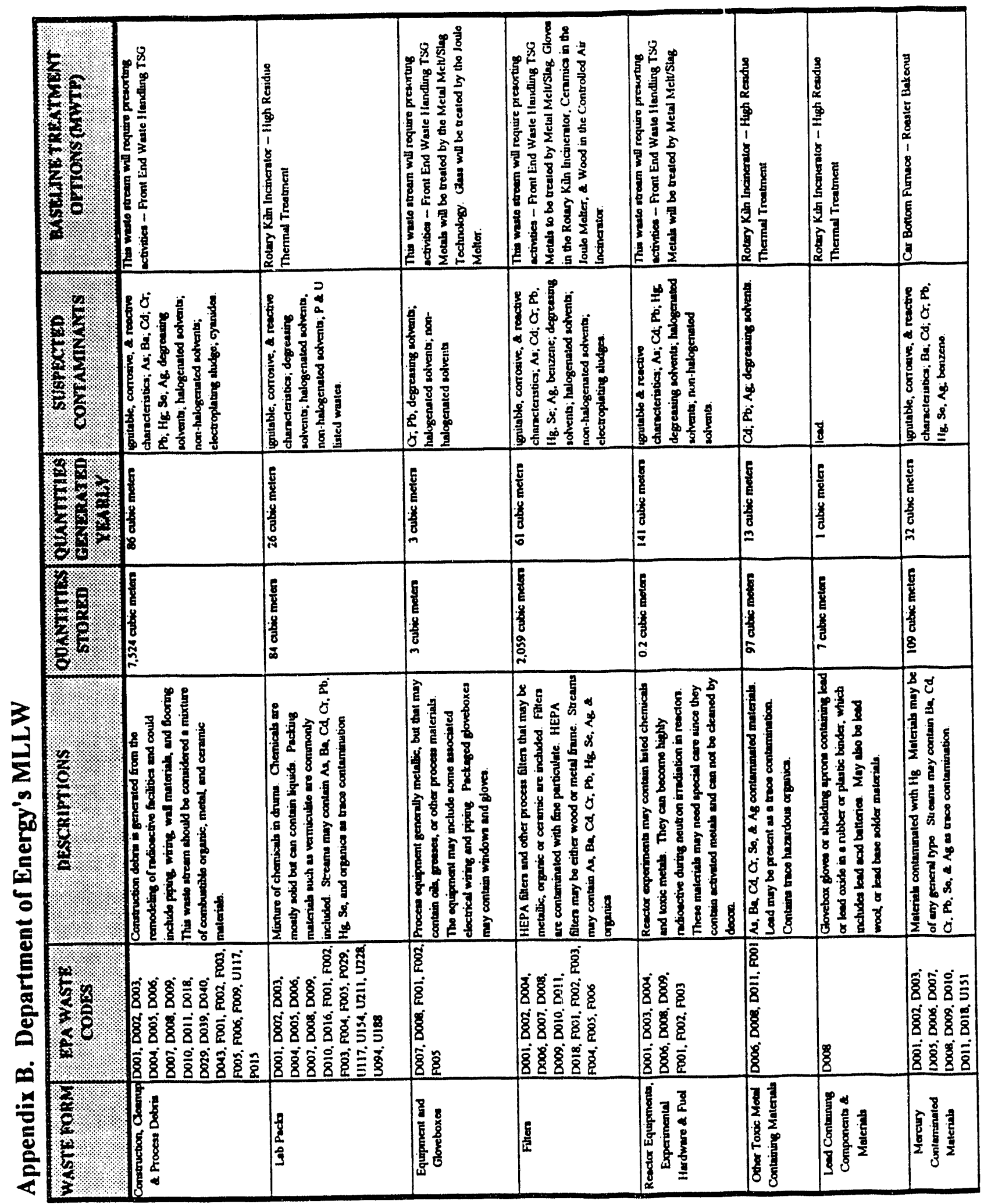




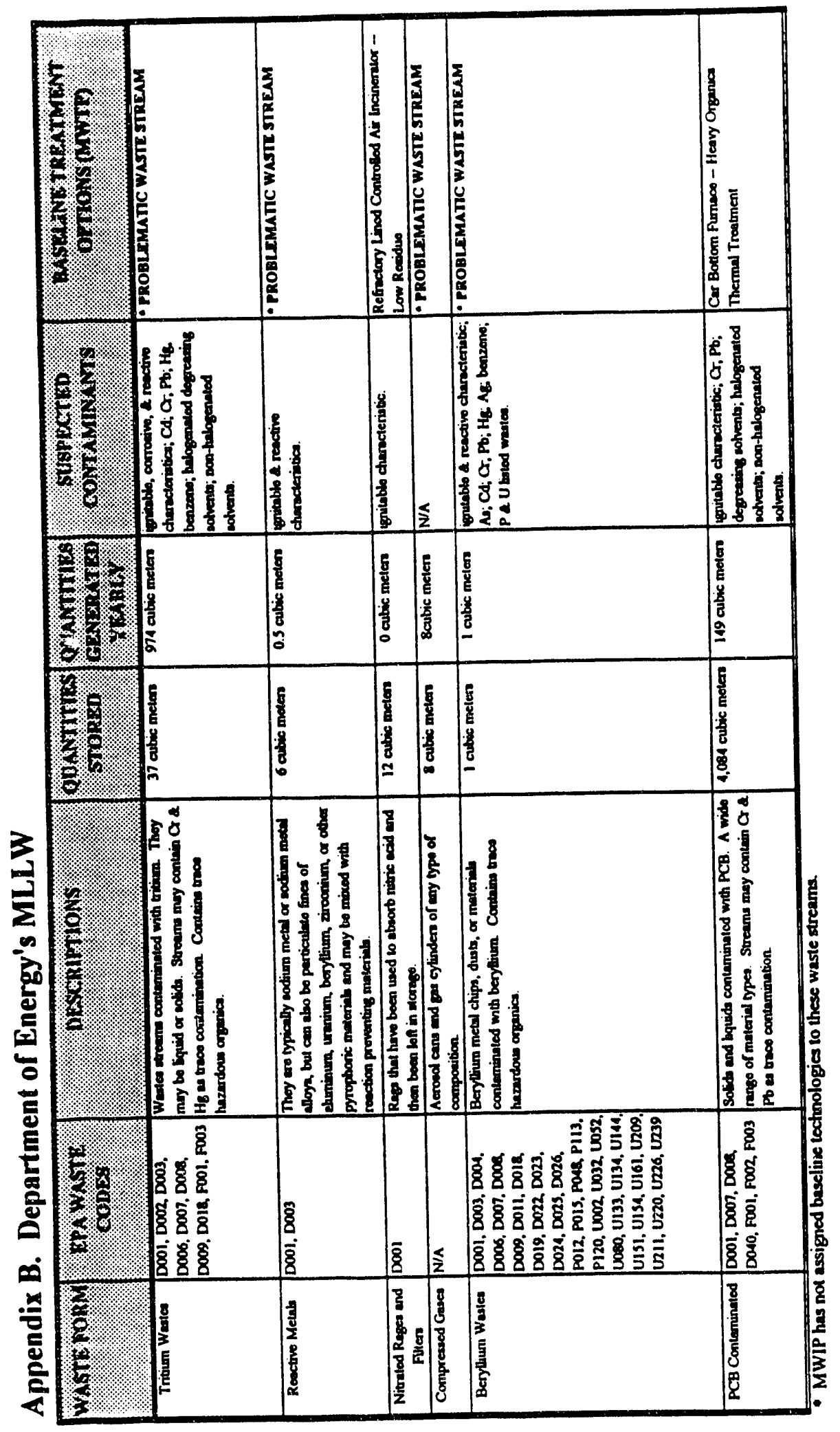




\section{APPENDIX C}

Thermal Treatment Technologies:

1 Information contained in Appendix $\mathrm{C}$ was obtained from the Mixed Waste Integrated Program Interim Evaluation Report on Thermal Treatment Technologies, DOE/MWIP-2, U.S. Department of Energy, September 1992. Additional information was supplied by the Waste Destruction and Stabilization Technical Support Group. 


\section{TABLE OF CONTENTS}

Preface

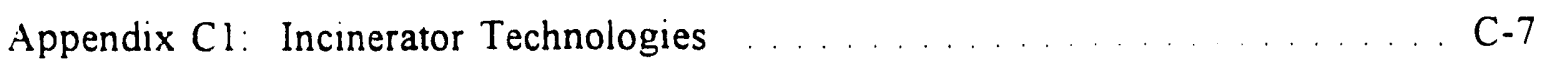

Rotary Kiln Incinerator . . . . . . . . . . . . . . . . . . . . . . C C-8

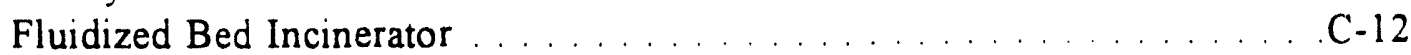

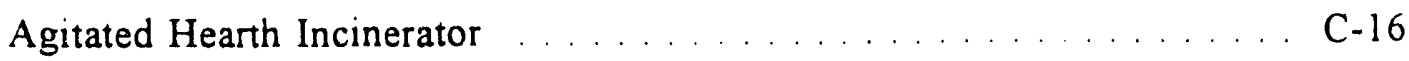

Multiple-Hearth Incinerator . . . . . . . . . . . . . . . . C C 19

KFK Excess Air Incinerator . . . . . . . . . . . . . . . . . C-22

Liquid Injection Incinerator $\ldots \ldots \ldots \ldots \ldots \ldots \ldots . \ldots \ldots$. . . . . . . . . . . . .

Controlled Air Incinerator . . . . . . . . . . . . . . . . . . . C-29

Cyclone Incinerator . . . . . . . . . . . . . . . . . . . C-33

Indirect Fired Pyrolysis Incinerator . . . . . . . . . . . . C-36

Appendix C2: Miscellaneous Technologies . . . . . . . . . . . . . C -40

Infrared Furnace . . . . . . . . . . . . . . . . . . . . C-41

Wet Air Oxidation . . . . . . . . . . . . . . . . . . . C-45

Steam Gasification Detoxifier . . . . . . . . . . . . . . . . C

Supercritical Water Oxidation . . . . . . . . . . . . . . . C-52

Ultraviolet Photo-Oxidation . . . . . . . . . . . . . . . . C-56

Plasma Pyrolysis Reactor . . . . . . . . . . . . . . . . . . C C-60

Appendix C3: Melter Technologies .................. C-63

Molten Salt Furnace ... . . . . . . . . . . . . . . . . . . . C-64

Joule Heated Melter . . . . . . . . . . . . . . . . . . . . . . . . . . . . C-68

Plasma-Arc Furnace $\ldots \ldots \ldots \ldots \ldots$. . . . . . . . . . . . . . . . . . . . . .

Microwave Melter . . . . . . . . . . . . . . . . . . C-78

Slagging Kiln . . . . . . . . . . . . . . . . . . . . . . C-82

Electric Furnace Melter . . . . . . . . . . . . . . . . . . . . C-86

Fuel-Fired Melter . . . . . . . . . . . . . . . . . . . . . . . . . . . C-89

High Temperature Joule Melter . . . . . . . . . . . . . . . . . . . . . C C-92

In-Can Resistance Melter . . . . . . . . . . . . . . . . . . . . . . . . . . . . . . . C-96

Stirred Joule Melter . . . . . . . . . . . . . . . . . . . . . . . . . . . . . . . C-99

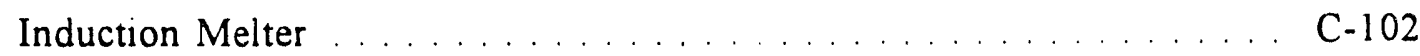




\section{PREFACE}

Appendix $C$ presents additional information on each technology discussed in the text of this report. This appendix is divided into three parts: $\mathrm{Cl}$ - Incinerator Technologies: C2 - Miscellaneous Technologies; and C3 - Melter Technologies. Descriptions, waste applicability, advantages, disadvantages, and development needs are given for each technology. In addition, DOE laboratories involved in the technologies are listed, as well as commercial vendors. References used to assemble information for each technology are also listed.

A functional process diagram is given for each technology, which gives a general illustration of the waste sort/processing/treatment train for each technology. Additional clarifications to be considered when reviewing the functional process diagrams are discussed below. The portion on each functional process diagram listing nontreatable waste categories should not be taken as absolute information; rather, it should be reviewed along with the attached waste applicability section, as well as Tables 4.2 and 7.1 . Waste streams with low applicability to a given technology were listed in the nontreatable category since they are, in general, ineffectively treated by that technology. In most cases, there are exceptions within each waste stream which are applicable to a given technology.

\section{C1 - Incinerator Technologies}

In general, incinerator technologies are not applicable to aqueous liquids, noncombustibles, or solids which are large in size. However, some incinerators are amenable to limited amounts of these waste types.

Most incinerators would be equipped with a shredder for large dry waste types. Incinerators, in general, produce an ash or ash-like residue which would require further treatment if produced from mixed waste processing. Therefore, an ash treatment step is included. Many of the incinerator processes will also produce an offgas residue resulting from offgas scrubbing, which would also require treatment.

\section{C2 - Miscellaneous Technologies}

Most of the technologies in this category are highly applicable to one or two waste types, rather than a variety of waste types. For example, five of the technologies are applicable only to aqueous liquids, two are highly applicable to dry homogeneous solids, and one is highly applicable to combustible liquids or solids only.

The high temperature reactor/furnace technologies produce ash residues which would require a treatment step to stabilize the leachable species. The three technologies which serve to oxidize organics from aqueous solutions produce not only an ash-like precipitate, but also the treated water stream which would require conversion to a solid form, in most cases, before disposal. 


\section{C3 - Melter Technologies}

These technologies are applicable to a wide variety of waste streams. However. most of them would require a shredder for some of the larger solids, since they do not have the capability of accepting, for a variety of reasons, large waste constituents. Generally, melters are not amenable to large heterogeneous solids due to the metal content, with the exception of those melters that are operated at very high temperatures, such as the electric arc furnace, plasma arc furnace, and slagging kiln technologies. Since the melter technologies produce a molten slag which then solidifies to a glassy matrix, it will not be necessary, in most cases, to include an additional treatment step. However, if the glass matrix does not pass leach tests, the matrix will require further treatment, most likely including remelting. 
C-7

APPENDIX C1

\section{INCINERATOR TECHNOLOGIES}


Technology Name: $\quad$ Rotary Kiln Incinerator

Maturity: Operational - Conventional

\section{Description:}

The rotary kiln is a cylindrical refractory-lined shell mounted on a slight incline. Rotation of the kiln provides for movement of waste through the kiln as well as for enhancement of waste mixing. Rotary kilns normally require a secondary combustion chamber to assure complete destruction of hazardous constituents. The primary chamber functions to pyrolyze or combust solid waste to gases. The gas-phase combustion reaction is completed in the secondary. Both primary and secondary chambers are generally supplied with auxiliary fuel systems. An extensive offgas system is generally required to control the high volume of emissions.

\section{Waste Applicability:}

Aqueous Liquids:

Organic Liquids:

Wet Solids:

Dry Homogeneous

Solids:

Dry Heterogeneous

Solids (Small):

Dry Heterogeneous

(Large):
Low applicability to aqueous liquids.

High applicability to both sludge and pumpable organic liquid waste streams.

High applicability to all subcategories of wet solids.

High applicability to dry solids, especially soils.

High applicability to both the combustible and noncombustible fractions of heterogeneous solid wastes.

High applicability to large wood items and low Solids applicability to non-combustibles such as equipment and gloveboxes.

\section{Advantages:}

The rotary kiln incinerator is the most versatile type of conventional incinerator. It can handle a wide variety of solid and liquid waste types, and is capable of a wide range of physical waste feed configurations. Ash is removed continuously and does not interfere with waste oxidation. A rotary kiln incinerator can be operated at very high temperatures to handle difficult to destroy constituents, and has a good turndown ratio. 


\section{Disadvantages:}

Rotary kiln incinerators generally have high capital costs for installation. High particulate loadings are often experienced. Drying of some aqueous sludge waste or melting of some solid wastes can result in clinker or ring formation on refractory walls. Spherical or cylindrical objects may roll through the kiln before complete combustion. Rotary kiln incinerators are not very thermally efficient, and cannot be thermally cycled often (shutdown/startup cycle). The large volumes of air required for combustion give rise to large costly offgas treatment systems.

\section{Development Needs:}

Better kiln seal design, advanced offgas systems, better stack monitoring and other real-time performance assurance capabilities; control of heavy metal emissions; combustion by-product formation: sub-micron particulate emissions.

\section{Vendor List:}

ABB Raymon

ABB Environmental Services

AMETEK Process Systems

Allis Chalmers

Anderson 2000 Inc.

Aqua-Guard Technologies

Bigelow-Liptak

Brule CE\&E Inc.

Cleansoils

Cleever Brooks Div.

College Research Corp.

Combustion Engineering

Combustion Technologies

Conservtherm Systems

DRE Technologies

Ford-Bacon-Davis

Fuller Power
Harper Electric Furnace

International Waste Energy Systems

International Energy System

Joy Energy Systems

Kennedy Van Saun Corp.

Lurgi Corp.

M\&S Engineering \& Manufacturing Co.

McGill Pollution Control Systems

Soil Purification Inc.

Surface Combustion

Texcel Environmental Systems

Thermali Inc.

Thermal Process Construction

Trofe Inc.

Von Roll

Vulcan Waste Systems

Westinghouse Resource Energy Systems

Williams Environmental Services

John Zinc 
DOE Laboratories Involved in Technology:

Rocky Flats Plant

Oak Ridge K-25 Plant

Savannah River Site

Idaho National Engineering Laboratory

\section{References:}

C.C. Lee, G.L. Huffman, D.A. Oberacker, "An Overview of Hazardous/Toxic Waste Incineration", Hazardous Waste Management, Vol. 36, No. 8, August 1986, pp.922-931.

H.M. Freeman et al., "Thermal Destruction of Hazardous Waste -A State-of-the-Art Review", Journal of Hazardous Materials, Vol. 14, 1987, pp. 103-117.

G. Rich and K. Cherry, Hazardous Waste Treatment Technologies, Pudvan Publishing Co., 1987.

R.J. McCormick et al., Costs for Hazardous Waste Incineration, Noyes Publications, Park Ridge, NJ, 1985.

J. Frankel, N. Sanders, G. Vogel, "Profile of the Hazardous Waste Incinerator Industry", MITRE Corp. report, 1982. 


\section{C-11}

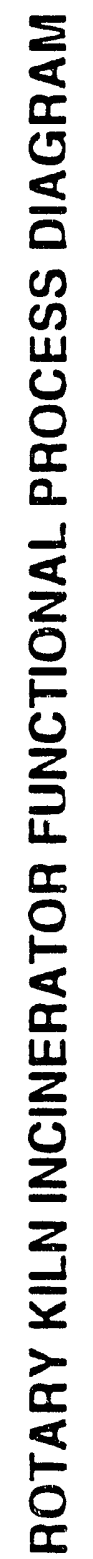

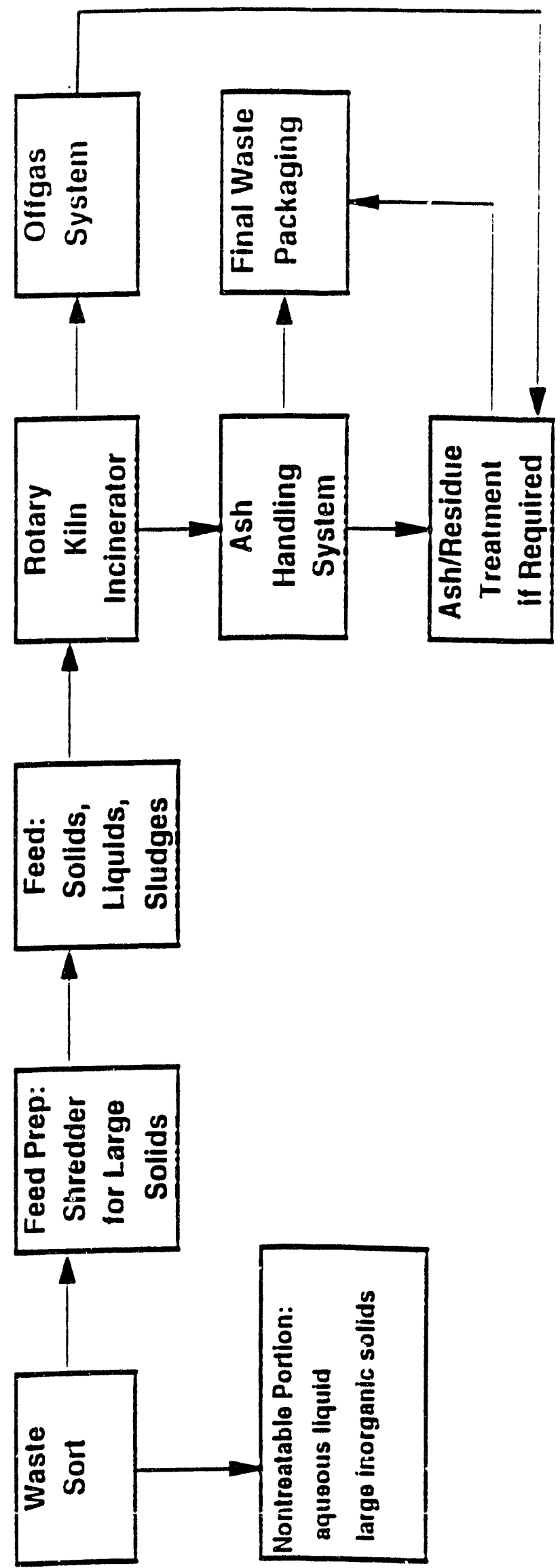




\section{C -12}

Technology Name: $\quad$ Fluidized Bed Incinerator

Maturity: $\quad$ Operational-Conventional

\section{Description:}

A vertical refractory lined vessel containing a bed of an inert granular material. The bed is "fluidized" by passing air, which serves as combustion air, through a perforated plate at the bottom of the vessel. Waste is fed to the hot bed for combustion where the high thermal mass and turbulent mixing action of the bed material rapidly transfers the heat to the waste. Auxiliary fuel is often used to maintain bed temperature. A secondary chamber may be required to ensure complete combustion for hazardous wastes. Limestone is usually added to the bed to provide capability for in-bed acid gas scrubbing capability (no scrubber required). Offgas particulate removal is required. A variation of fluidized bed technology is a circulating bed system where higher air velocities cause high carryover rates. The carryover material is recovered and returned to the system.

\section{Waste Applicability:}

Aqueous Liquids:

Organic Liquids:

Wet Solids:

Dry Homogeneous Solids:

Dry Heterogeneous Solids (Small):

Dry Heterogeneous Solids (Large)
Low applicability to aqueous liquids.

Medium applicability to organic liquid sludges and high applicability to pumpable organic liquids.

High applicability to resins with only moderate to low applicability to sludges, absorbed liquids, and cemented sludges respectively.

Medium applicability to homogeneous dry solids.

High applicability to combustible wastes within this category and low applicability to non-combustible wastes.

Medium applicability to wood waste (with size reduction).

\section{Advantages:}

The fluidized bed incinerator is relatively simple in design, as it has few moving parts. Its capital and maintenance costs are relatively low, and the incinerator is longlived. A fluidized bed incinerator is simple to operate, and has ease of process control and high thermal efficiency. Lower operating temperatures lead to lower $\mathrm{NO}_{\mathrm{x}}$ formation and metal emission rates, and the capability for in-bed scrubbing eliminates the need for 


\section{C-13}

an offgas scrubber system. Fluidized bed incinerators are versatile in that they can accept solids. liquids, sludges, and gases.

\section{Disardvantages:}

Fluidized bed incinerators have a relatively low throughput capacity, and it is difficult to remove residuals from the bed. Operating costs of fluidized bed incinerators are relatively high. Solid wastes will likely have to be pre-treated (shredded or sized) prior to introduction. Residence times are non-uniform, and particulate entrainment rates are high. The vessel and related components are subject to erosion. Low melting point materials in the bed may cause the bed material to fuse.

\section{Development Needs:}

Advanced offgas systems capable of removing higher percentages of the radioactive constituents; better stack monitoring and other real-time performance assurance capabilities; control of heavy metal emissions; combustion by-product formation; sub-micron particulate emissions.

\section{Vendor List:}

ARI Technologies

AWT Systems

Aerojet Energy Conversion

Anderson 2000 Inc.

Combustion Power company

Conversion Technologies

Copeland Associates

Fuller Company
GA Technologies

Hankin Environmental Systems Inc.

Keeler/Dorr Oliver

Lurgi Corp.

Niro Atomizer Inc.

Process Combustion Corp.

Texcel Environmental Systems Co.

Waste Tech Services, Inc.

Zimpro/Passavant Inc.

DOE Laboratories Involved in Technology:

Rocky Flats Plant 


\section{References:}

H.M. Freeman et al., "Thermal Destruction of Hazardous Waste -A State-of-the-Art Review", Journal of Hazardous Materıals, vol. 14 (1987), pp. 103-117.

R.W. Benedict and F.R. Weitz, "Thermal Oxidation of Hazardous Waste in a Fluidized Bed Combustor", Waste Tech Services Inc.,

Gerald Rich and Kenneth Cherry, Hazardous Waste Treatment Technologies, Pudvan Publishing Co., 1987.

R.A. Koenig, J. McFee, J.S. Vavruska, "Incineration Systems", Incineration Conference 1990, San Diego, CA, May 1990. 
C- 15

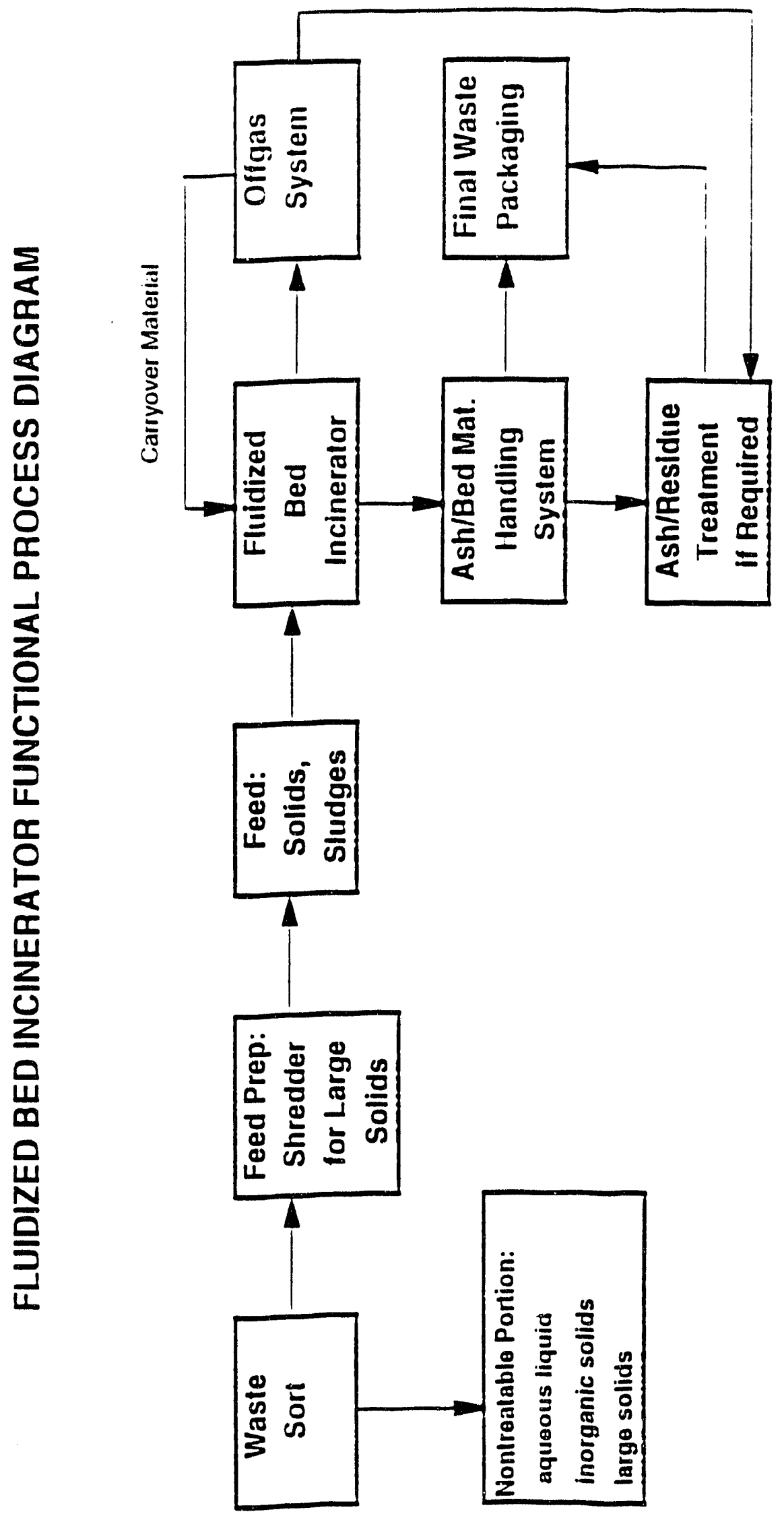


Technology Name: Agitated Hearth Incinerator

Maturity: $\quad$ Operational-Unique

\section{Description:}

The agitated hearth incinerator is a vertical, cylindrical chamber with a rabble arm that is rotated around the incinerator hearth to slowly agitate the waste pile, spreading out the waste material and exposing unburned material to the combustion air supply. The shaft for the rabble arm penetrates up through the bottom of the incinerator in the center of the hearth. Solid waste is fed in from the side through a ram feeder. Multiple burners are located at approximately mid-height in the cylindrical walls for start-up and auxiliary heat input. These burners could also be used for liquid waste disposal. Combustion gases pass from the primary chamber to the secondary chamber for extended residence time. In operation, waste is slowly fed into the chamber over a period of time. During this period, the rabble arm continually mixes the burning waste. Eventually, the waste pile builds up and waste feeding is stopped. The incinerator goes through a burn-out cycle where the rabble arm continues to mix the waste and stir the ashes until all combustible material is consumed. As the heat input from the burning waste begins to fall, the burners are ignited to maintain the temperature in the primary chamber at approximately $800^{\circ} \mathrm{C}$. When the waste is completely consumed, an ash discharge door in the floor of the hearth is opened and the ash is raked out of the chamber by the rabble arm. When the ashes have been removed, the ash discharge door is closed, the feeding cycle begins, and the process is repeated.

\section{Waste Applicability:}

Aqueous Liquids: Low applicability.

Organic Liquids: High applicability.

Wet Solids: High applicability.

Dry Homogeneous Medium applicability.

Solids:

Dry Heterogeneous High applicability for combustible waste components.

Solids (Small):

Dry Heterogeneous Not applicable.

Soliá (Large): 


\section{C -17}

\section{Advantages:}

This is a simple system that can achieve an excellent burn-out of combustible matter because of the long solids retention time and the mixing of the waste. The process is easy to monitor and control, and can incinerate a wide range of combustible waste types including solids, liquids, and sludges.

\section{Disadvantages:}

Proper operation depends on movement of the rabble arm, which is subject to mechanical, chemical, and thermal stresses. Operation is also limited by the size of waste constituents that are too heavy to be moved by the rabble arm or which could jam the rabble arm.

\section{Development Needs:}

Conversion and long-term operation tests on radioactive waste. Characterization of offgas, especially in terms of toxic metals and fine particulate. Better stack monitoring and other real-time performance assurance capabilities.

\section{Vendor List:}

Environmental Tech (it is unknown if this company still exists)

\section{DOE Laboratories Involved in Technology:}

Rocky Flats Plant

\section{Refirences:}

D. L. Ziegler, "Incineration Process Fire and Explosion Protection", presented at the 13 th AEC Air Cleaning Conference, San Francisco, California, August 1974. 


\section{C-18}

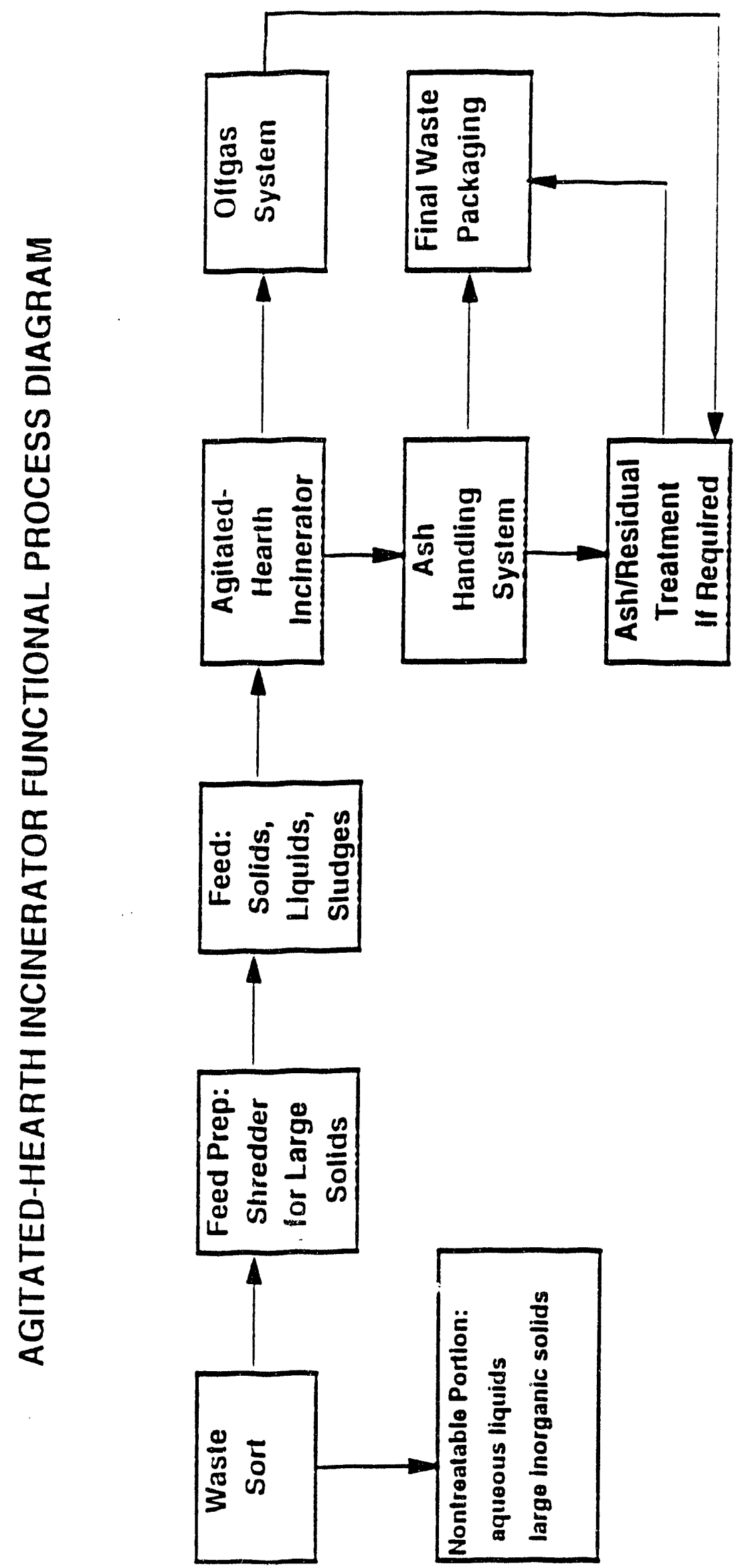




\section{C-19}

\section{Technology Name:}

Maturity:
Multiple-Hearth Incinerator

Operational-Conventional

\section{Description:}

A multiple-hearth incinerator consists of a refractory-lined steel shell with a series of circular hearths arranged in a vertical design. A series of rotating, air-cooled rabble arms conveys the solid waste from upper to lower hearths. As the waste is conveyed down through the incinerator the successive hearths are used for drying, heating, combustion, burnout, and cooling of the waste. Fuel burners are mounted on the side of the vessel in the hearths where combustion and burnout occur. These burners can be used for high heat value hazardous liquids if desired. A secondary chamber may be required for complete destruction of hazardous wastes. Some form of air pollution control equipment will be required, and will vary with the waste being processed. This type of incinerator has been used principally for sludges, tars, or other low-heat value solids requiring long solids retention times, and has been commonly used for disposal of dewatered activated waste-water treatment sludges. Use of this type of incinerator has been largely abandoned.

\section{Waste Applicability:}

Aqueous Liquids:

Low applicability to aqueous liquids.

Organic Liquids:

Medium applicability to organic liquid sludges and high applicability to pumpable organic liquids.

Wet Solids:

High applicability to all subcategories of wet solids waste with the exception of medium applicability to cemented sludges.

Dry Homogeneous

Low to medium applicability to homogeneous dry solids Solids: and soils respectively.

Dry Heterogeneous Medium applicability to combustible wastes within this Solids (Small): category and low applicability to non-combustible wastes.

Dry Heterogeneous Solids (Large):

Low applicability to wood waste only, not applicable to remainder of category.

\section{Advantages:}

The long solids retention times achieved in multiple hearth incinerators increase the complete destruction of waste materials. Multiple hearth incinerators can handle a wide 
range of wastes. including solids. sludges. liquids, and gases, and are capable of evaporating large amounts of water. A wide range of fuels mav be utilized to operate multiple hearth incinerators.

\section{Disadvantages:}

Multiple hearth incinerators cannot handle wastes that fuse into large chunks during incineration, and are not good for wastes requiring high destruction temperatures. The incinerators are susceptible to thermal shock. The large volumes of air required for combustion give rise to large, costly, and difficult-to-operate offgas treatment systems. Solid wastes may have to be pre-treated (shredded) before processing.

\section{Development Needs:}

Advanced offgas systems adapted to remove high percentages of radioactive constituents; better stack monitoring and other real-time performance assurance capabilities; control of heavy metal emissions; combustion by-product formation; sub-micron particulate emissions.

\section{Vendor List:}

Bethleham Corp.

BSP Thermal Systems

Hankin Environmental Systems Inc.

Kennedy Van Saun Corp.
Texcel Environmental Systems Co. Thermal Process Construction Zimpro/Passavant Inc.

\section{DOE Laboratories Involved in Technology:}

None

\section{References:}

C.W. Modres, "Waste-to-Energy '87: Exploring the Total Market", Badger Engineers, Inc. report, 1987.

W.E. Sweet, R.D. Ross, G.V. Velde, "Hazardous Waste Incineration: A Progress Report", Journal of the Air Pollution Control Association, Vol. 35, No. 2, February 1985.

G. Rich and K. Cherry, Hazardous Waste Treatment Technologies, Pudvan Publishing Co., Northbrook, IL, 1987

J. Cudahy, T. Eicher, "Hazardous Waste Incineration Course", prepared by IT Corp., August, 1988. 


\section{C-21}

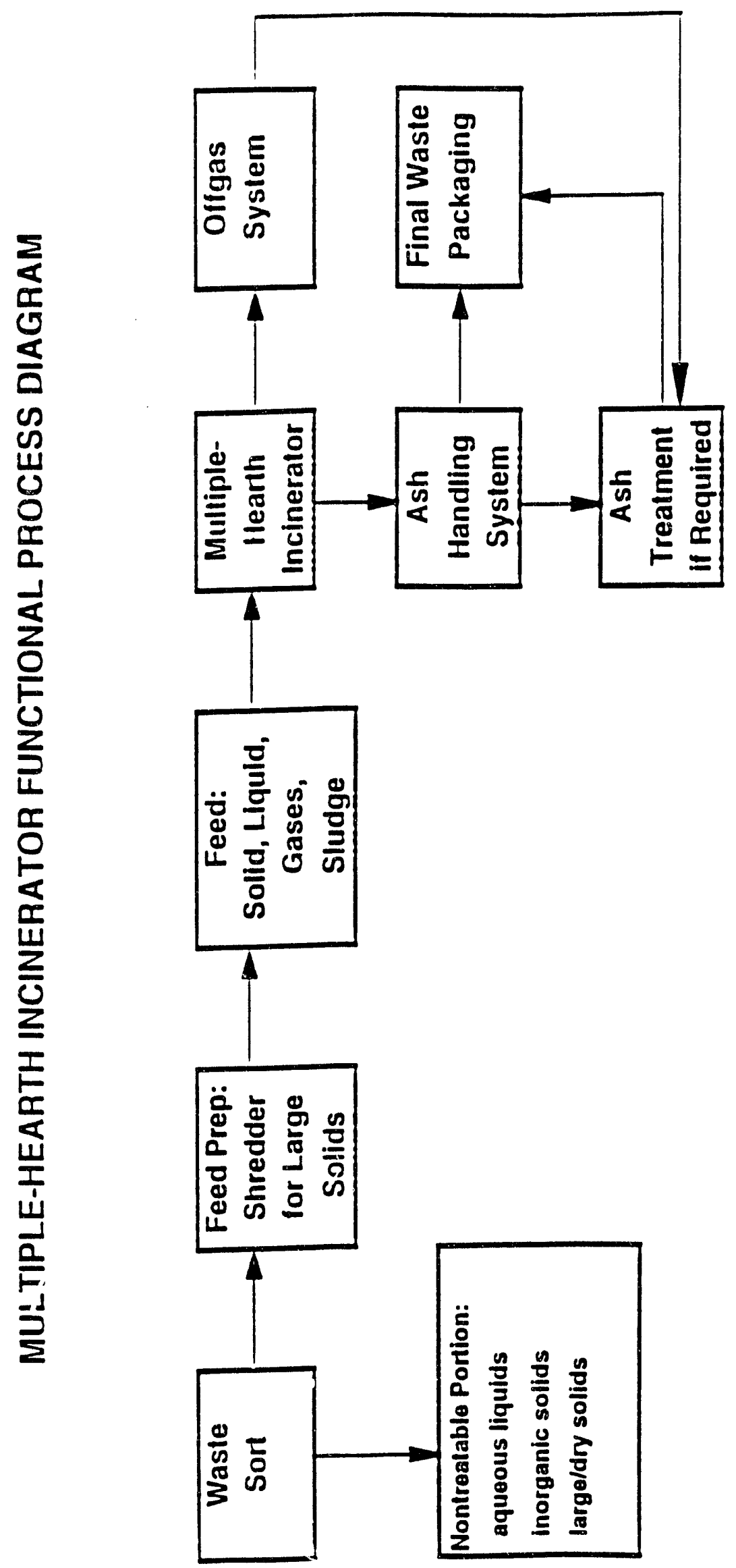


Technology Name:

Maturity:

Description:
KFK Excess Air Incinerator

Operational-Conventional

The KFK Incinerator is a vertical shaft excess air incinerator. The incinerator consists of a cylindrical shaft furnace with a refractory lining. The bottom section of the furnace is constructed in a cone shape. An afterburning chamber, two hot gas filters and a two-stage flue gas scrubbing system are located downstream of the furnace. The scrubbing system consists of a jet scrubber, a Venturi scrubber, a HEPA filter, and an exhaust fan. Charging of the waste takes place via a feeding system which is accommodated in glove boxes. The furnace is charged automatically, depending on the $\mathrm{O}_{2}$ content as well as on the furnace temperature. A double closure serves to ensure the contamination-free supply of waste from the drums. The cylindrical shaft furnace is operated at a temperature of at least $850^{\circ} \mathrm{C}$. The minimum temperature is attained by means of a propane burner. For incineration, air is supplied in a controlled manner via several inlets oriented tangentially to the furnace walls. The temperature of the ash bed in the cone-shaped bottom part of the furnace is maintained at $5800^{\circ} \mathrm{C}$ by means of steam addition. As a result, heat is removed from the ash bed and the slag is prevented from adhering to the furnace. Ash discharge also takes place within a glovebox system which is equipped with a double closure to avoid contamination.

\section{Waste Applicability:}

Aqueous Liquids: Low applicability.

Organic Liquids: High applicability.

Wet Solids:

High applicability, except possibly for resin wastes.

Dry Homogeneous

Solids:

Low to medium applicability to homogeneous dry solids and soils respectively.

Dry Heterogeneous

High applicability to combustible wastes in this category, Solids (Small): low applicability to non-combustible wastes.

Dry Heterogeneous Solids (Large):

Low applicability to wood waste only.

\section{Advantages:}

This technology has over 20 years operating experience in Germany and Japan, incinerating both beta and alpha contaminated wastes (liquid wastes since 1988). 


\section{$C-23$}

Disadvantages:

Large volumes of combustion air result in complex, costly offgas treatment systems High particulate carryover will entrain radioactive components into downstream components.

Development Needs:

Advanced offgas systems. combustion by-product formation, and determination of optimal secondary chamber operating points.

Vendor List:

Fahrholf (Denmark)

NGC (Japan)

NUKEM (Germany)

DOE Laboratories Involved in Technology:

None identified

\section{References:}

F. Dirks, W. Hempelmann, W. Pfeifer, G. Steinhaus, "Incineration of Radioactive Residues Further Development of KFK Incineration Plants, Plant Performance and Test Results", presented at 1991 Incineration Conference, May 1991. 
C- 24

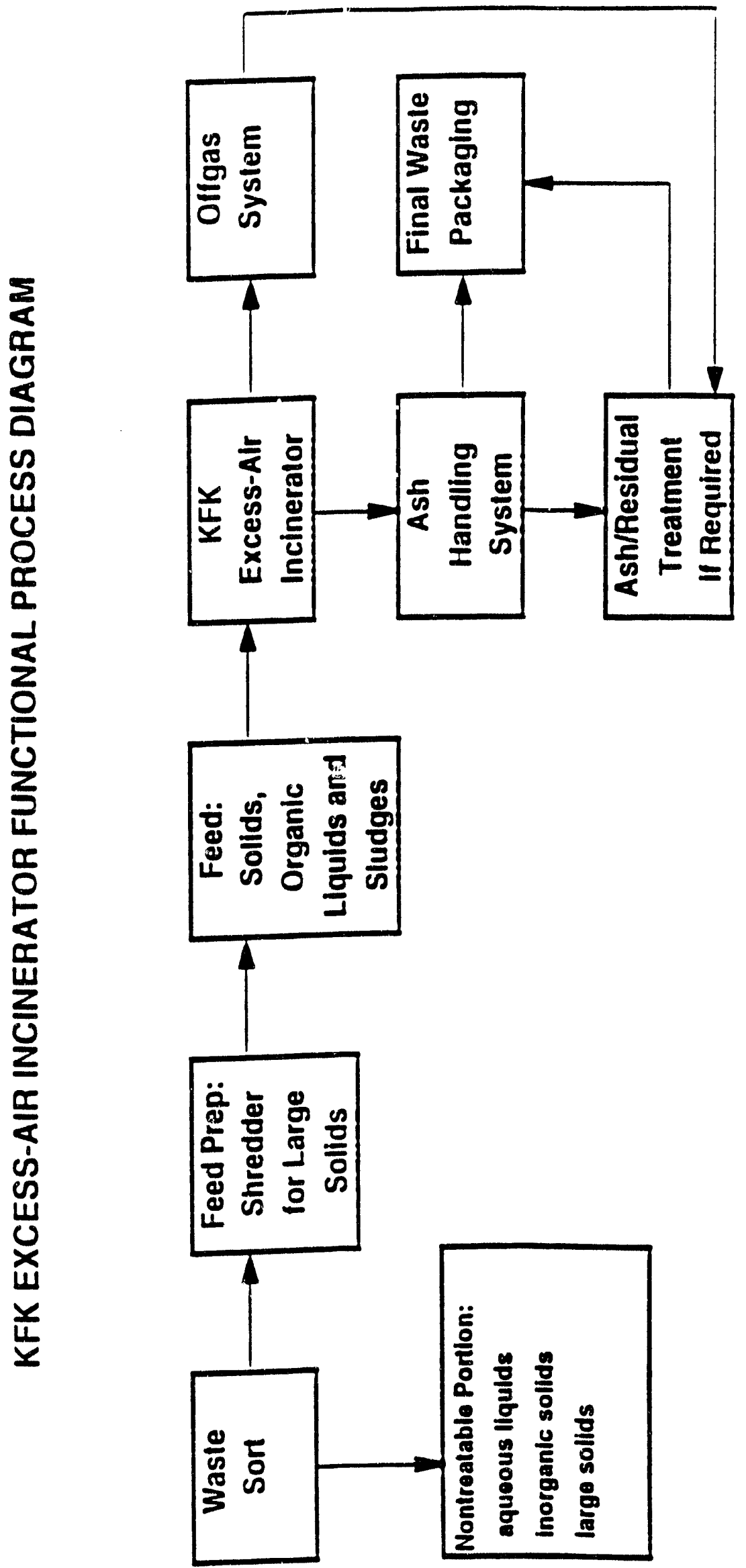




\section{C -25}

Technology Name: Liquid Injection Incinerator

Maturity: Operational-Conventional

\section{Description:}

A type of incinerator designed to process liquid wastes only. They are usually simple, refractory-lined cylinders equipped with one or more waste burners. Only one combustion chamber is generally used (secondary chamber not necessary for proper destruction). An offgas treatment system may be required depending on the application, and will vary in design based on the types of waste being processed. Most commercial type liquid injection incinerators do not use offgas equipment; however, a liquid injection incinerator for radioactive waste will likely require some type of offgas particulate filter. Sometimes used as a secondary chamber for other incinerator types.

\section{Waste Applicability:}

Aqueous Liquids:

Organic Liquids:

Wet Solids:

Dry Homogeneous

Solids:

Dry Heteroger eous

Solids (Small):

Dry Heterogeneous

Solids (Large):
Low applicability to aqueous liquids.

High applicability to organic liquids that are pumpable only.

Not applicable to any wet solid subcategories with the exception of low applicability to resin wastes.

Not applicable.

Not applicable.

Not applicable.

\section{Advantages:}

No secondary combustion chamber is needed if the primary combustor has enough residence time. Liquid injection incinerators can incinerate a wide range of liquid hazardous waste. No continuous ash removal system is required other than for downstream air pollution control systems. Their simple design is thermally efficient, entails virtually no moving parts, and enables fairly high turndown ratios. Maintenance costs for liquid injection incinerators are low. 


\section{Disadvantages:}

Wastes which can be accepted in a liquid injection incinerator are restricted to only those that can be atomized through a burner nozzle (liquids with low or no solids content, and no sludges or solids). The incinerator system is sensitive to waste composition changes. The incinerator burners may be susceptible to plugging. The offgas systems necessary for a liquid injection incinerator generate secondary byproduct wastes that are often difficult to handle.

\section{Development Needs:}

Advanced offgas systems capable of removing a higher percentage of radioactive constituents; better stack monitoring and other real-time performance assurance capabilities; control of heavy metal emissions; combustion by-product formation; sub-micron particulate emissions.

\section{Vendor List:}

Anderson 2000 Inc.

Bayco Industries

Bedford Industries Inc.

Bigelow-Liptak

Brule CE\&E

Burn-Zol

$\mathrm{B} \& \mathrm{~W}$

Combustion Technologies

Copen

Durr Engineering \& Management

Entech

Energy Development Assoc.

Epscon Industrial Systems Inc.

Fuel \& Combustion Technology Inc.

Hirt Combustion Engineers

John Zink

Kelly

Liquid Injection

Lotepro Corp.
Lurgi Corp.

McGill Pollution Control Sys.

Met-Pro

NOA Inc.

North American Manufact. Co.

Peabody

Prenco

Process Combustion

Product Recovery and Energy Co.

Pyro Industries Inc.

Texcel Env. Systems Inc.

T-Thermal Inc.

Trecan Combustion Inc.

Selas Fluid Processing Corp.

Smith Eng. \& Environmental

Sure-Life

Surface Combustion Inc.

United

UPO Solid Waste Systems

\section{DOE Laboratories Involved in Technology:}

Savannah River Site 


\section{References:}

C.C. Lee, G.L. Huffman. P.A. Oberacker, "An Overview of Hazardous Waste - A Stateof-the-Art Review". Journal of Hazardous Materials, Vol. 14, 1987. pp. 103-117.

G. Rich and K. Cherry, Hazardous Waste Treatment Technologies, Pudvan Publishing Co., 1987.

R.J. McCormick et al., Costs for Hazardous Waste Incineration, Noyes Publications, Park Ridge, NJ, 1985.

I. Frankel, et al, "Profile of the Hazardous Waste Incinerator Manufacturing Industry", MITRE Corp. report, 1982. 


\section{C-28}
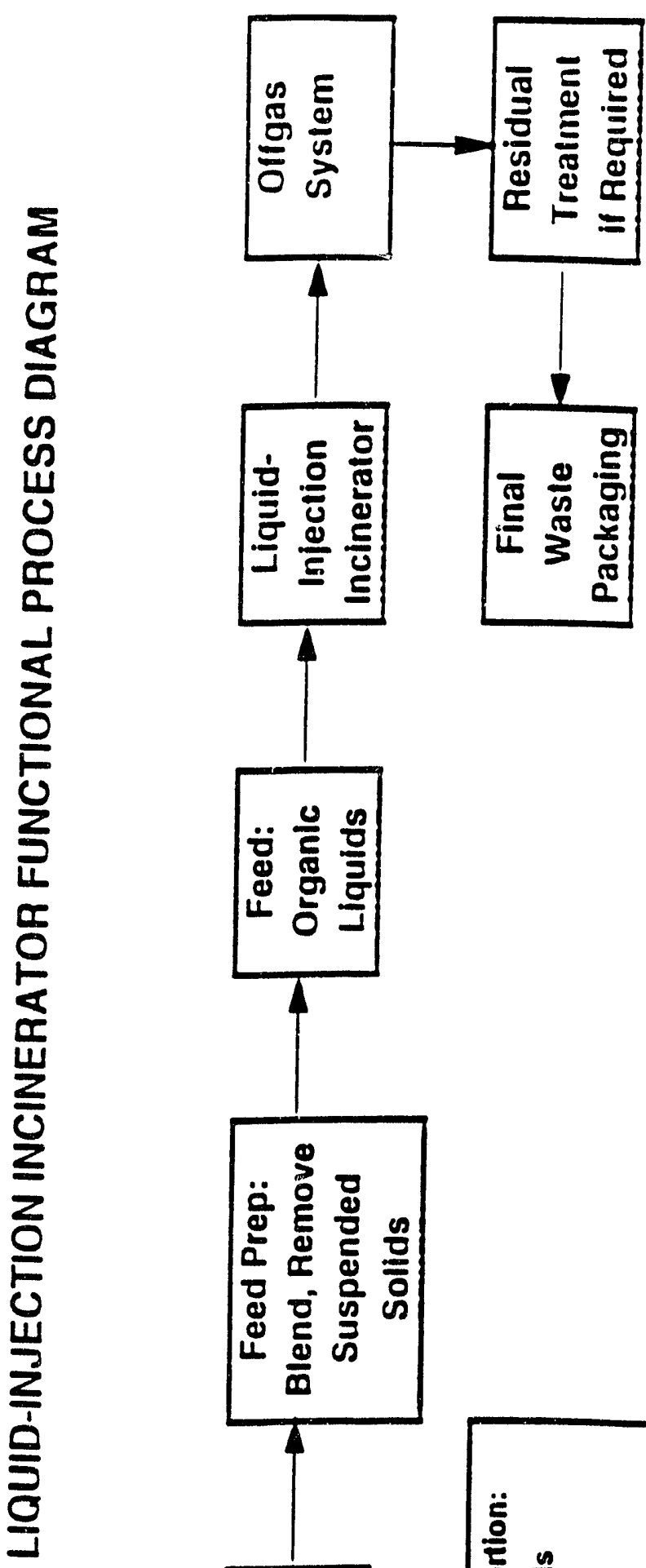

농 독
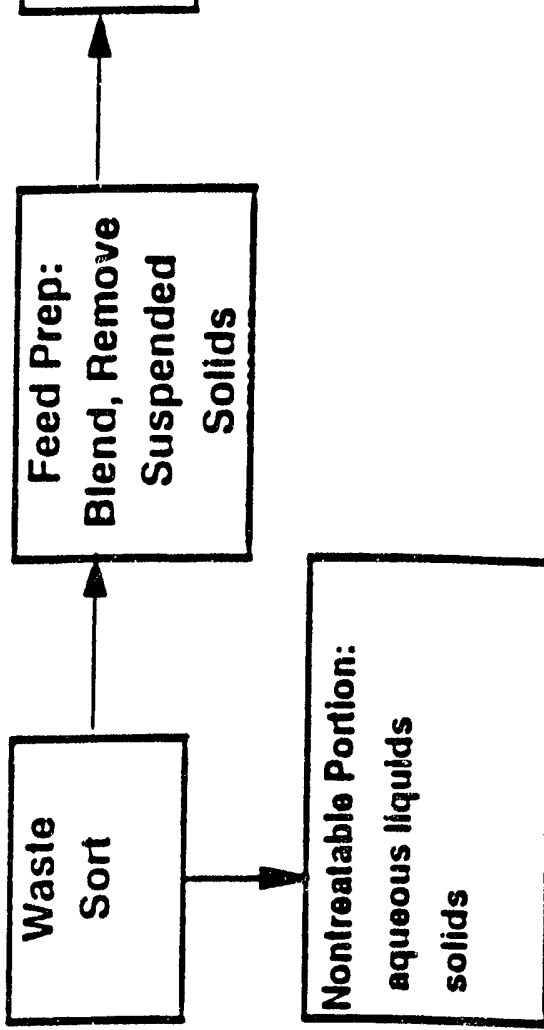
Technology Name: Controlled Air Incinerator

Maturity: Operational - Conventional

\section{Description:}

A controlled air incinerator is the name often used for the stationary hearth class of incinerator. This type of incinerator is usually designed as a two-stage combustion process with some systems using three chambers. Solid waste is fed into the primary chamber and burned at roughly 50 to $80 \%$ of the stoichiometric air requirement (starved air condition). This pyrolyzes the waste, thus emitting a volatile fraction with the required heat supplied by partial combustion and oxidation of the fixed carbon. The resultant smoke and pyrolytic products, consisting primarily of volatile hydrocarbons and carbon monoxide along with some combustion products, pass to the secondary chamber. Excess air is provided in the secondary chamber to assure complete combustion. Liquid waste can be incinerated in either the primary or secondary chambers. An offgas treatment system is required to provide emission control, dependent on the application and waste type.

\section{Waste Applicability:}

Aqueous Liquids: Low applicability to aquecus liquids.

Organic Liquids: $\quad$ High applicability to organic liquids that are pumpable and medium applicability to sludges.

Wet Solids: $\quad$ Low applicability to sludges and medium applicability to the remaining wet solids subcategories.

Dry Homogeneous Low applicability.

Solids:

Dry Heterogeneous

Solids (Small):

Dry Heterogeneous

Solids (Large):
High applicability to combustible heterogeneous solids and low applicability to noncombustible solids.

Medium applicability to wood waste and not applicable to noncombustible equipment and metal type wastes.

\section{Advantages:}

The starved air condition in the primary chamber leads to a lower air velocity, thus minimizing particulate entrainment and carryover. Controlled air incinerators can be used to process a wide variety of wastes including solids, liquids, and sludges, and can handle 
wastes with high water content. These incinerators have a low cost modular design, can utilize a wide range of supplementary fuels, and are easy to contro!

\section{Disadvantages:}

Solid wastes generally have to be pre-treated or packaged in some fashion before they can be fed to the incinerator. Controlled air incinerators are not well suited for wastes containing fusible ash, large bulky solid wastes, or large quantities of essentially non-combustible materials (i.e. metal and glass). Batch feeding of waste can lead to pressure spikes in the primary chamber. The large volumes of air required for secondary combustion give rise to large, costly, and difficult to operate offgas treatment systems. Offgas systems generate secondary byproduct wastes that are often difficult to handle.

\section{Development Needs:}

Advanced offgas systems capable of retaining a higher percentage of radioactive constituents, better stack monitoring and other real-time performance assurance capabilities; control of heavy metal emissions; combustion by-product formation; sub-micron particulate emissions.

\section{Vendor List:}

AER

Aerojet Energy Conversion

American Energy Waste System

Anderson 2000 Inc.

Basic Environmental Engineering

Besser-Wasteco Corp.

Burney The Burner

Cil Incineration Systems

Cleever-Brooks Div.

Consumat Systems

Econo-Therm Energy Systems Corp.

International Waste Energy Systems

Fuller Company
Joy Energy Systems Inc.

Kennedy Van Saun Corp.

Koch Process Systems Inc.

Simonds Manufacturing Corp.

Stock Equipment Co.

Thermall Inc.

Thermal Process Constr. Co.

Trecan Combustion Ltd.

Vent-O-Matic Incineration Corp.

Vulcan Waste Systems Inc.

John Zink Co.

DOE Laboratories Involved in Technology:

Brookhaven National Laboratory

Idaho National Engineering Laboratory

Lawrence Livermore National Laboratory

Los Alamos National Laboratory

Oak Ridge Y-12 Plant

Oak Ridge K-25 Site

\section{PANTEX}

Rocky Flats Plant

Savannah River Site 


\section{References:}

C.C. Lee, G.L. Huffman, D.A. Oberacker, "An Overview of Hazardous/Toxic Waste Incineration", Hazardous Waste Management, Vol. 36, No. 8. August 1986. pp. 922-931.

R.J. McCormick et al., Costs for Hazardous Waste Incineration, Noyes Publications, Park Ridge, NJ, 1985.

R. A. Koenig, L. C. Borduin. D. A. Hutchins, J. S. Vavruska, C. L. Warner, "The Los Alamos Controlled Air Incinerator for Radioactive Waste", Vols. I-III, LA-9427, 19821987.

R. E. McRee, "Operation of Controlled Air Incinerators and Design Considerations for Controlled Air Incinerators Treating Radioactive Wastes", presented to the Conference on Incineration of LLRW, Tucson, AZ, March 1985.

R. L. Gillins, H. A. Bohrer, "Progress Report on Contaminated Solid Waste Incineration at the Waste Experimental Reduction Facility", prepared for the U.S. DOE, EGG-WM7162, February 1986 

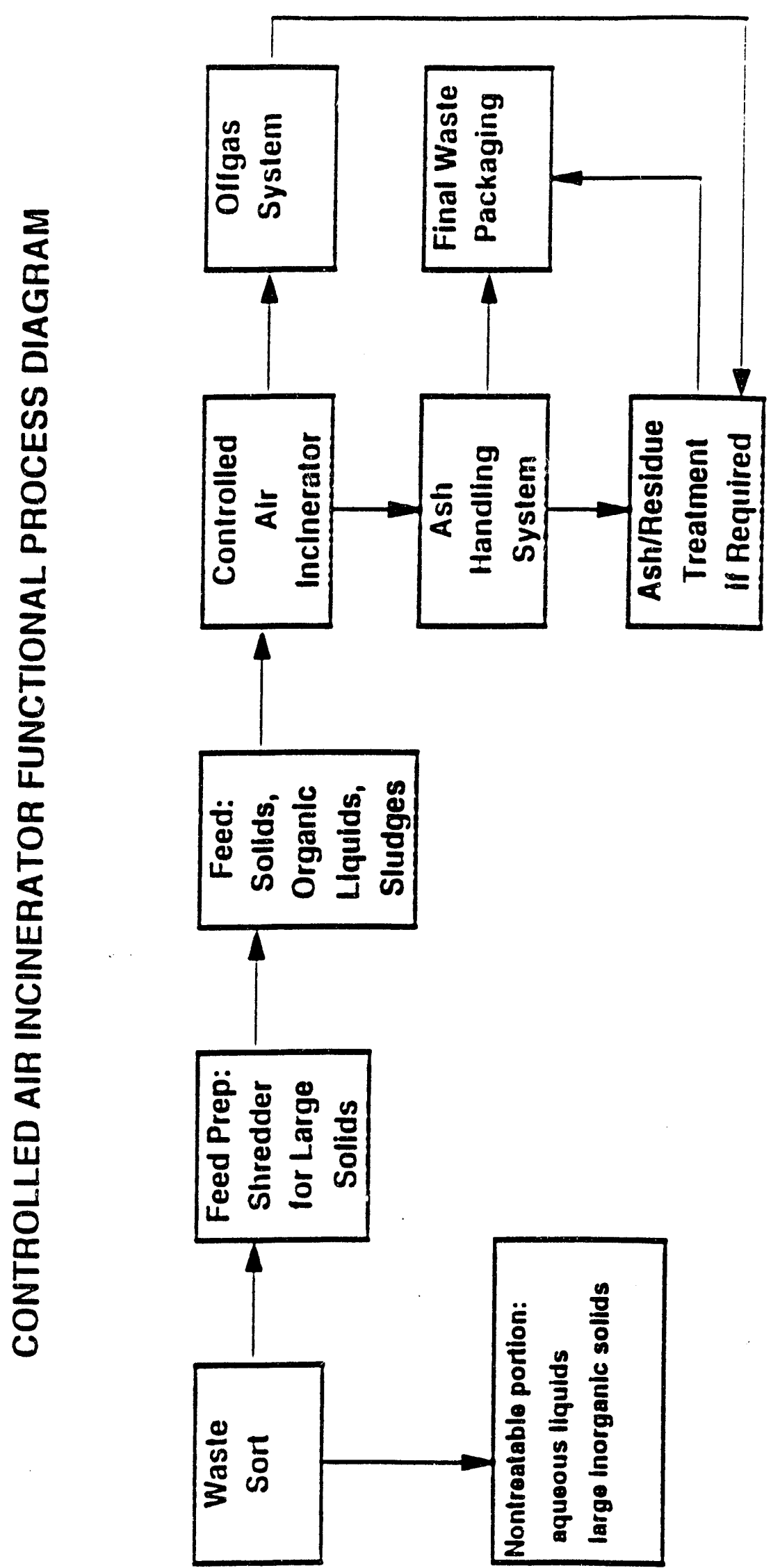


\section{$C-33$}

Technology Name:

Cyclone Incinerator

Maturity:

Operational-Linique

\section{Description:}

The cyclone incinerator is a single hearth, vertical cylindrical vessel in which cyclonic flow is induced through the tangential introduction of fuel and air. The highshear cyclonic flow provides intense mixing and complete combustion. Cyclone incinerators are primarily used for solid fines and dried sludges, but special furnaces have also been designed for gases or liquids. Typically, the hearth rotates with stationary rabble teeth for moving ash to a center discharge. Horizontal cyclone furnaces without hearths are also employed. These units carry the ash away with the offgas for downstream collection.

\section{Waste Applicability:}

Aqueous Liquids:

Organic Liquids:

Wet Solids:

Dry Homogeneous Solids:

Dry Heterogeneous Solids (Small):

Dry Heterogeneous Solids (Large):
Low applicability to aqueous liquids.

High applicability to organic liquids that are pumpable and medium applicability to sludges.

Medium applicability to sludges, absorbed liquids, and resins and low applicability to cemented sludges.

Low applicabiiity to soils and not applicable to other dry solids waste such as concrete, bricks, and salts.

Medium applicability to combustible heterogeneous solids and low applicability to noncombustible solids.

Medium applicability to wood waste (size reduced) and not applicable to noncombustible equipment and metal type wastes.

\section{Advantages:}

Cyclone incinerators are inexpensive and mechanically simple. The low temperature requirements allow for fast startup and cool down. The combustion in cyclone incinerators is stable and efficient, and the combustion volume is small. The refractory is long-lived. The offgas and particulate loading are separated centrifugally. The high energy density of the process results in high destruction efficiencies at moderate temperatures. 


$$
\text { C }-34
$$

Disadvantages:

Cyclone incinerators are limited to processing gaseous. liquid. and sludge wastes.

Development Needs:

Destruction and removal efficiency determination.

\section{Vendor List:}

Babcock \& Wilcox

International Gas Technology

York-Shipley Inc.

DOE Laboratories Involved in Technology:

Mound

References:

H.M. Freeman, "Innovative Thermal Hazardous Waste Treatment Processes", PB85192847, April 1985

C.R. Brunner, "Incineration Systems", Incinerator Consultants Inc., Reston, VA, 1988.

Contact: Institute of Gas Technology (Headquarters), 3424 South State Street, Chicago, IL, 60616, (312) 567-3650. 


\section{C-35}

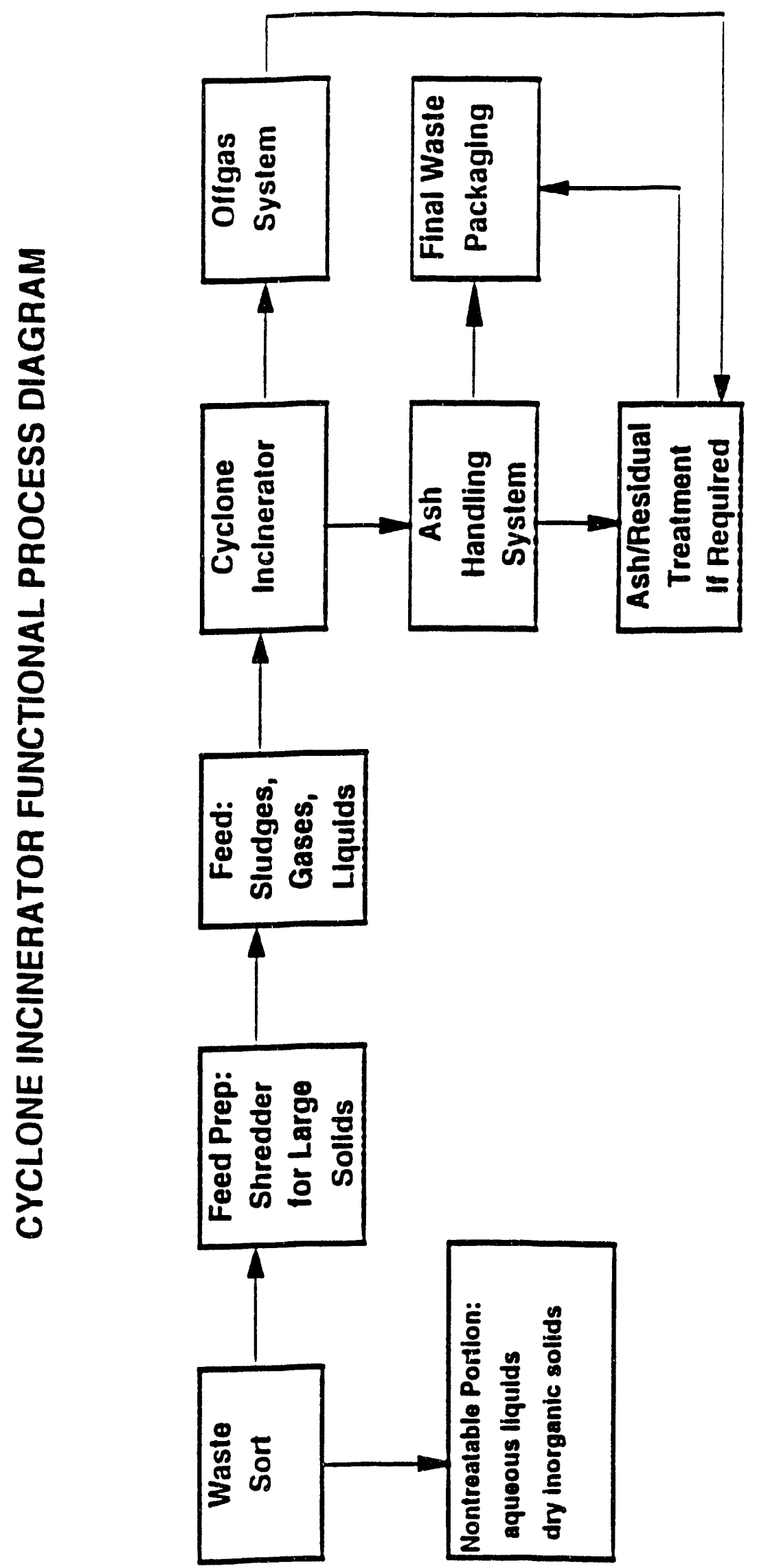




\section{C-36}

Technology Name: Indirect Fired Pyrolysis Incinerator

Maturity: $\quad$ Operational-Unique

\section{Description:}

A thermal treatment process consisting of a low temperature, indirect-fired furnace for pyrolyzing waste followed by a rich fume reactor to complete combustion and destruction. The pyrolysis process achieves chemical decomposition of waste materials by applying heat in the absence of oxygen resulting in high DREs and low NOx levels and particulate carryover. The process is available in continuous feed for granular or liquid materials, or batch feed for liquids, solids, or sludges in open containers. Wastes are pyrolyzed at relatively low temperatures $\left(1000^{\circ} \cdot 1600^{\circ} \mathrm{F}\right)$ for $15-30$ minutes for the continuous system and 4-6 hours for the batch system. The resulting fumes are then completely combusted in a rich-fume reactor chamber at $1800^{\circ}-2200^{\circ} \mathrm{F}$ for $1-2$ seconds Heating in the pyrolyzing chamber is provided by natural gas or fuel oil. A widely used commercial application is the destruction of organic contamination on metals and equipment. One application would collect the pyrolysis fumes for utilization as a fuel gas.

Waste Applicability:

Aqueous Liquids: Low applicability to aqueous liquids.

Organic Liquids:

High applicability to organic liquid sludges and low applicability to pumpable liquids.

Wet Solids:

Medium applicability to sludges and absorbed liquids, high applicability to resins, and low applicability to cemented sludges.

Dry Homogeneous

Low applicability to soils and other dry solids waste such Solids: as concrete, bricks, and salts.

Dry Heterogeneous Solids (Small):

Medium applicability to combustible heterogeneous solids and high applicability to noncombustible solids (removal of organic contamination).

Dry Heterogeneous

High applicability to noncombustible equipment and metal Solids (Large): type wastes (removal of organic contamination). 


\section{Advantages:}

Inert materials are not melted or vaporized. The indirect heating and pyrolyzing mode of indirect fired pyrolysis incinerators minimizes particulate carryover. These incinerators produce low volumes of offgas with low NOx concentrations. Excellent control of thermal rates can be achieved.

\section{Disadvantages:}

Indirect fired pyrolysis incinerators are inefficient for processing high Btu liquid wastes, and the process is not applicable for inert solids, except to remove organic contamination. Batch system process rates are low. Removal of waste containers from batch system presents high contamination risk when processing radioactive wastes.

\section{Development Needs:}

Adaptation to radioactive service.

\section{Vendor List:}

Bryant Incinerator

Midland-Ross Corporation

\section{DOE Laboratories Involved in Technology:}

None

\section{References:}

Marc Breton et al., "Technical Resource Document: Treatment Technologies for Solvent Containing Wastes", U.S. Environmental Protection Agency, EPA/600/2-86/095, October 1986.

Harry Freeman, Innovative Thermal Hazardous Organic Waste Treatment, Noyes Publications, Park Ridge, NJ, 1985.

T.J. Schultz et al., "Pyrolytic Incineration of Hazardous and Toxic Wastes", American Institute of Chemical Engineers, Houston, TX, March 1989.

"Treatment Technology Briefs: Alternatives to Hazardous Waste Landfills", U.S. Environmental Protection Agency, EPA/600/8-86/017, July 1986.

J.C. Shah et al., "Thermal Treatment for Disposal of Containerized Hazardous Wastes", American Institute of Chemical Engineers 1988 Spring National Meeting, New Orleans, 


\section{C -38}

LA, March 1988

"A Background Paper on Pyrolytic Incineration, Surface Combustion". Inc., Maumee, $\mathrm{OH}$, August 1988

Contact: Tom Schultz, Surface Combustion, Inc., 1700 Indian Wood Circle. Maumee, Ohio, 43537-0428, (419) 891-7150. 
C-39
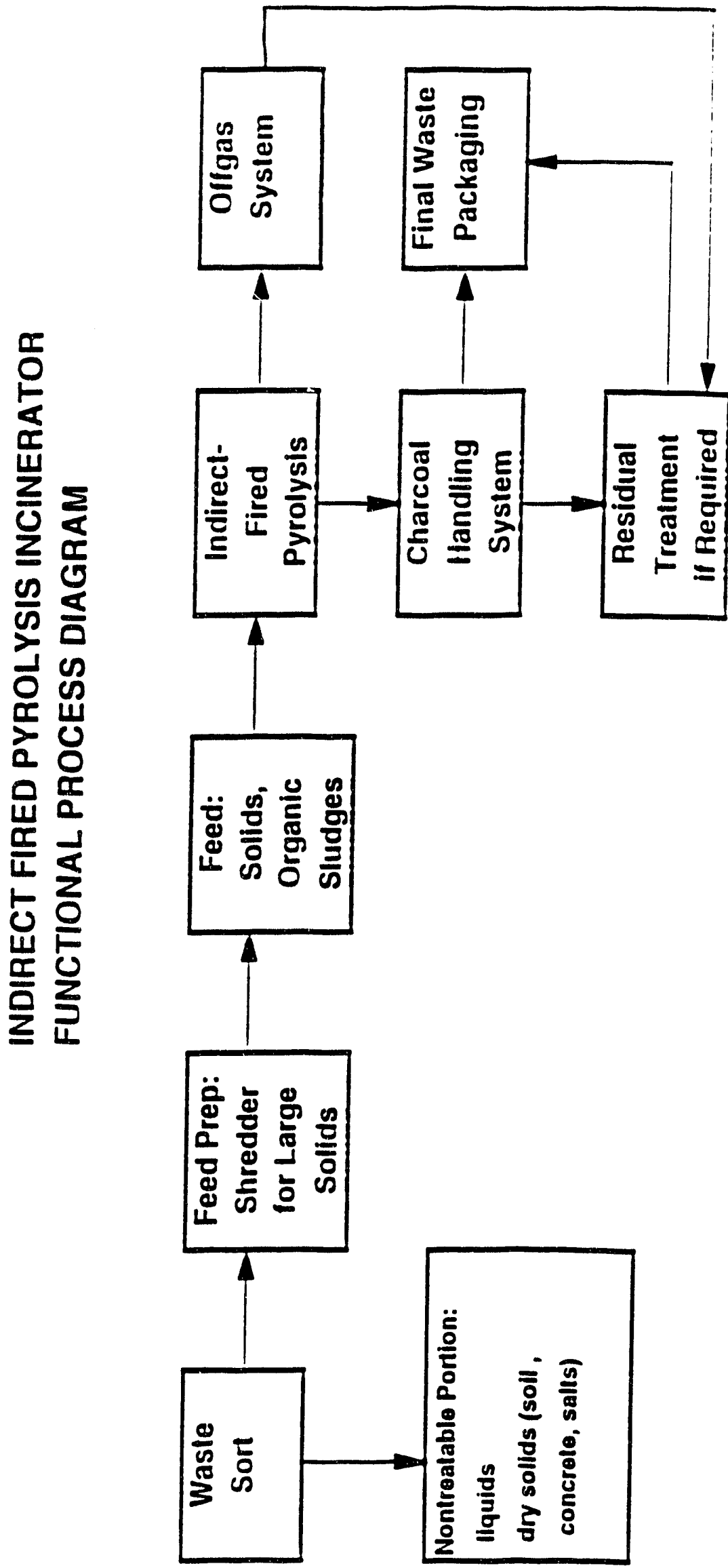
C -40

APPENDIX C2

MISCELLANEOUS TECHNOLOGIES 
Technology Name: Infrared Furnace

Maturity: Operatıonal-L::ique

\section{Description:}

A thermal waste processing unit emploving direct radiant (infrared) heat in a primary chamber to desorb organics from soils followed by fossil fuel fired secondary combustion chamber. The primary chamber has several heating zones with increasing temperatures to initially dry and finally combust the waste passing through. The primary chamber can be operated in a pyrolysis or combustion mode. Waste is transported through the primary chamber on a mesh metal alloy conveyor belt. Variable residence time is provided by adjusting the belt speed. The process is designed to treat organically contaminated soils and sludges. Most solid wastes require size reduction to insure maximum exposure to the radiant energy. Sludges require pretreatment drying before feeding to the incinerator. The waste is stirred by rotary rakes to ensure adequate exposure. The ash is quenched by water sprays. Available in stationary and mobile applications.

\section{Waste Applicability:}

Aqueous Liquids: Not applicable to aqueous liquids.

Organic Liquids: Not applicable to organic liquids.

Wet Solids:

Low applicability to wet sludges, absorbed liquids, resins, and cemented sludges.

Dry Homogeneous

High applicability to soils and other fine dry solid waste.

Solids:

Dry Heterogeneous

Not applicable to combustible solids or noncombustible

Solids (Small): wastes.

Dry Heterogeneous

Solids (Large):

Not applicable.

\section{Advantages:}

Infrared furnaces have high throughput capacities. They operate with non-flame combustion, and therefore have low NOx and PIC generation rates. Offgas requirements for such furnaces are minimal. Infrared furnaces are easy to operate, and can be purchased as mobile units (6 trailers). 


\section{Disadvantages:}

Wastes which can be processed with an infrared furnace are limited to solid fines and sludges, and drying and other pretreatment is usually required for sludges. Feed handling equipment is prone to clogging. Infrared furnaces are expensive. Sticky ash clinging to the conveyer belt can become a problem when the furnace is operated at high combustion temperatures.

\section{Development Needs:}

Optimization, effect of treatment on the leachability of metals in matrix; improved transport method through furnace (belt); and improved mixing mechanism.

\section{Vendor List:}

ECOVA

Harper Electric Furnace

National Applied Science Systems Inc.

OHM

Shirco Infrared Systems, Inc.

Westinghouse HazTech

\section{DOE Laboratories Involved in Technology:}

Savannah River Site

\section{References:}

Howard O. Wall et al., "The SITE Demonstration of the Shirco Electric Infrared Incinerator", Journal of the Air Pollution Control Association, Vol. 39, No. 6, June 1989.

"Technology Evaluation Report, SITE Program Demonstration Test", Shirco Infrared Incineration System, Peak Oil, Brandon, Florida, EPA/540/5-88/002a, September 1989.

"Technology Demonstration Summary SITE Program Demonstration Test", Shirco Infrared Incineration System at the Peak Oil Superfund Site, EPA/540/55-88/002, January 1989.

David Charlesworth and Mike Hill, "Electrically Fired Incineration of Combustible Radioactive Waste", 1985 National Conference on Environmental Engineering, Boston, July 1985.

Final Report, On Site Incineration Testing of Shirco Infrared Systems Portable Pilot Test Unit, Times Beach Dioxin Research Facility, Times Beach, MO, Shirco Report No. 815 85-2, November 1985. 


\section{C -43}

A. Judson Hill, "Hazardous Waste Treatment Capabilities of the Shirco Infrared Demonstration and Full Scale Mobile Waste Processing Systems". Ind National Symposium on the Leading Edge of Incineration, Washington. DC. October 1987.

Shirco Infrared Incineration System, Applications Analysis report, EP.A/540/A5-89/010, June 1989

Contact: Shirco Infrared Systems, Inc., 1195 Empire Central, Dallas. TX 75247, (214) 630-7511. 


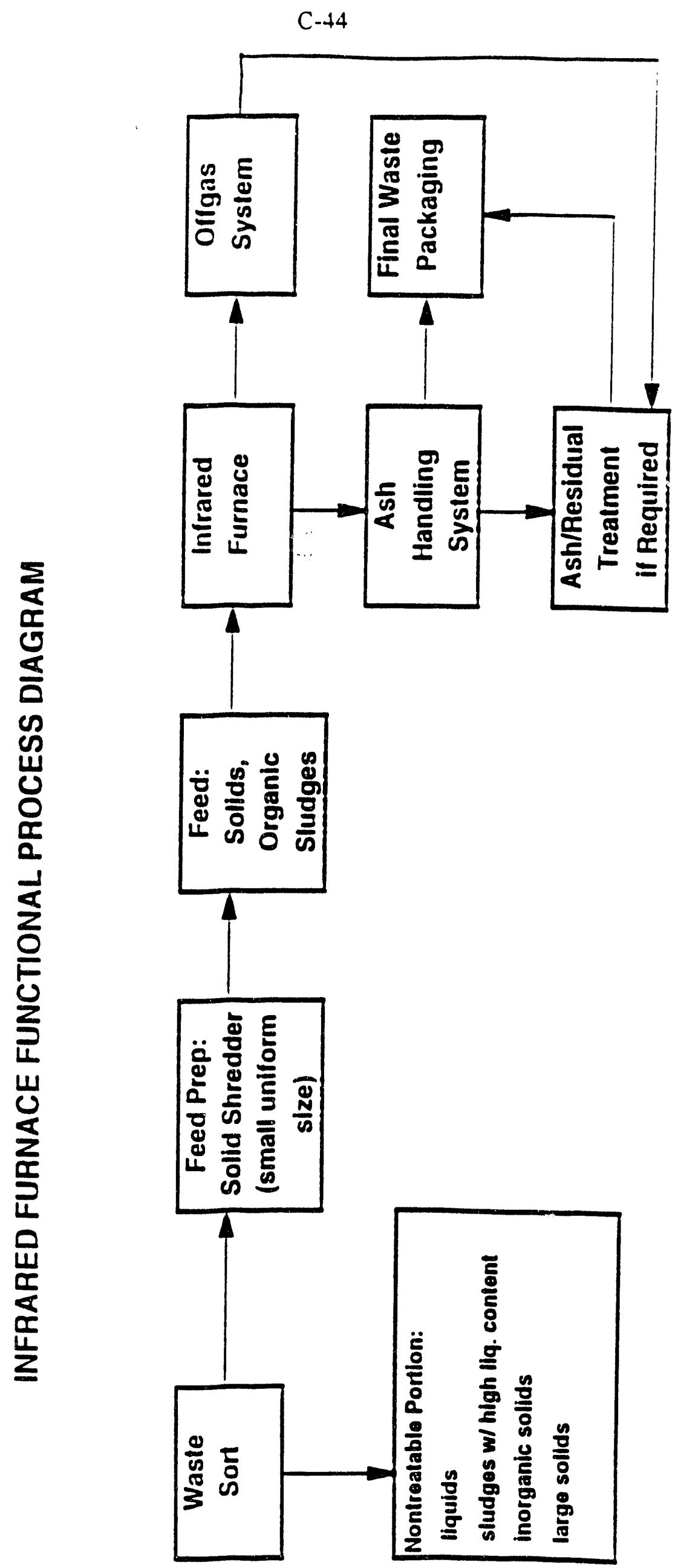




\section{C-45}

Technology Name: Wet Air Oxidation

Maturity: $\quad$ Operational-Unique

\section{Description:}

The aqueous phase oxidation of dissolved or suspended organic substances at elevated temperatures and pressures. Oxygen (air) and a dilute organic/water mixture are introduced into a reactor vessel at subcritical conditions $\left(350^{\circ}-650^{\circ} \mathrm{F}\right.$ and $20-200 \mathrm{~atm}$.) where oxidation of the organics occurs. The process, once started, is thermally selfsustaining and is maintained above the vapor pressure of water to minimize evaporation. The process reduces the organics to $\mathrm{H}_{2} \mathrm{O}, \mathrm{CO}_{2}$, and various biodegradable acids. Reaction times of 60 minutes are typical.

\section{Waste Applicability:}

Aqueous Liquids:

Organic Liquids:

Wet Solids:

Dry Homogeneous

Solids:

Dry Heterogeneous

Solids (Small):

Dry Heterogeneous

Solids (Large):
High applicability to aqueous liquids.

High applicability to organic liquids with $<10 \%$ organics.

\section{Advantages:}

The wet air oxidation process is thermally self-sustaining. It is suited for nonincinerable dilute wastes, and requires small equipment volumes. Its low off-gas volumes are free of $\mathrm{NO}_{x}, \mathrm{SO}_{x}, \mathrm{PICs}$, and particulate.

\section{Disadvantages:}

Since wet air oxidation does not generally meet EPA treatment standards, the process is predominantly used for pretreatment. The wet oxidation process is not highly predictable. Existing full-scale units are largely tailored to bench-scale results on specific compounds. Wastes which can be processed using wet air oxidation are limited to weak aqueous organic solutions. High-pressure system hardware is required. Offgas scrubbing 
is required. The wet air oxidation process is not effective on halogenated species.

\section{Development Needs:}

Impro:e systems corrosion and corrosion monitoring; evaluate oxyhydroxide formation with actunides; evaluate ash content limits; and adaptation to radioactive applications

\section{Vendor List:}

Zimpro/Passavant, Inc.

Oxidyne

Ver Tech

DOE Laboratories Involved in Technology:

None

\section{References:}

Marc Breton et al., "Technical Resource Document: Treatment Technologies for Solvent Containing Wastes", U.S. Environmental Protection Agency, EPA/600/2-86/095, October 1986.

Harry Freeman, Innovative Thermal Hazardous Organic Waste Treatment, Noyes Publications, Park Ridge, NJ, 1985.

H.M. Freeman et al., "Thermal Destruction of Hazardous Waste -A State-of-the-Art Review, Journal of Hazardous Materials, Vol. 14, 1987, pp. 103-117.

Gerald Rich and Kenneth Cherry, Hazardous Waste Treatment Technologies, Pudvan Publishing, Northbrook, IL, 1987

J.P. Wilks et al., "Wet Oxidation of Mixed Organic and Inorganic Radioactive Sludge Wastes from Water Reactor", The 1989 Incineration Conference, Knoxville, TN, May 1989.

Contact: William Copa, ZIMPRO, Inc., Military Road, Rothschild, Wisconsin, 54474, (715) 359-7211.

Contact: Gerald C. Rappe, Vertech Treatment Systems, 12000 Pecos-Third Floor, Denver, CO 80234, (303) 452-8800. 


\section{C -47}

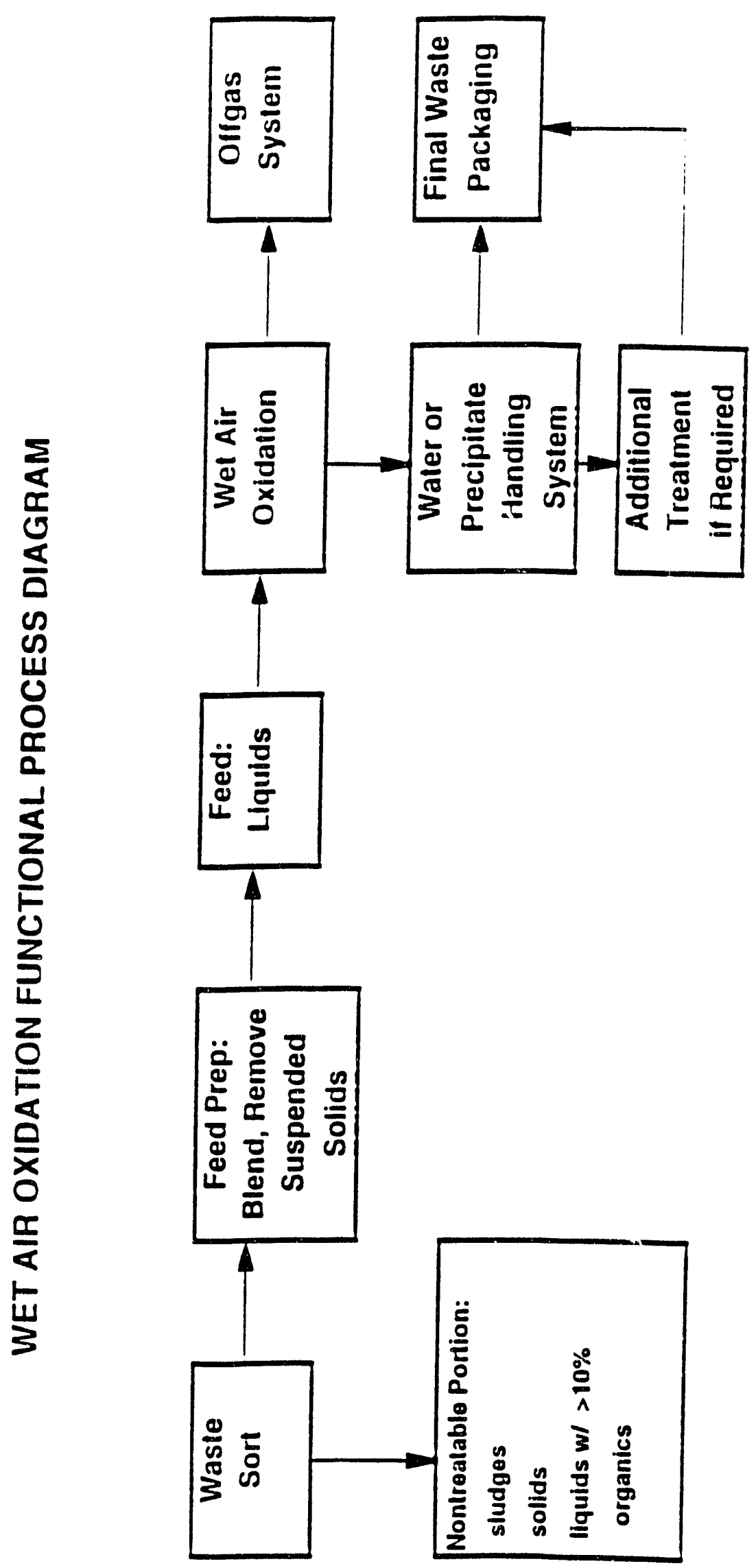


Technology Name:

Maturity:
Steam Gasificatıon Detoxifier

Operational-Unique

\section{Description:}

A two-stage thermal process in which hydrocarbons are vaporized at $700^{\circ}-1100^{\circ} \mathrm{F}$ in an autoclave, and then injected into a reaction chamber (detoxifier) with superheated steam where the organics are decomposed via steam hydrocarbon reforming chemistry. Typical detoxifier operating conditions are $2100^{\circ}-3000^{\circ} \mathrm{F}$ at a slightly negative pressure. Organics can be vaporized in-drum, minimizing waste handling requirements, or by pumping from large tanks. Non-volatiles remain behind in the drum for subsequent disposal. The system consists of two boxes, evaporator and gasifier, which are small enough ( $4 \mathrm{ft} \times 6 \mathrm{ft} \times 7 \mathrm{ft}$ ) to be located inside many existing building spaces. All process monitors and controls are located inside these boxes, and the system is designed for automatic, hands-off operation. The offgas is processed through halogen absorbers, carbon absorbers, and catalytic carbon monoxide converters to remo: : metals, methane, carbon monoxide, hydrogen, and $\mathrm{HCl}$, which are normal exhaust gas constituents from this process. The offgas from this process has potential value as a fuel gas. Process rates are 1-5 drums per 24-hour day. A number of these units were manufactured and sold.

\section{Waste Applicability:}

Aqueous Liquids:

Organic Liquids:

wet Solids

Dry Homogeneous

Solids:

Dry Heterogeneous

Solids (Small)

Dry Heterogeneous

Solids (Large)
Medium applicability to aqueous liquids.

High applicability to organic liquids.

Low applicability to sludges.

Not applicable.

Medium applicabiitity to combustible solids and not applicable to noncombustibles.

Not applicable.

\section{Advantages:}

Steam gasification detoxifiers can achieve a high DRE. Their low offgas volumes are free of NOx, SOx, PICs, and particulate. extremely small process equipment; remote and automatic operations; low waste handling requirements. 


\section{Disadvantages:}

Steam reforming detoxifiers are best for organic liquid wastes, but application for organically contaminated solids has also been demonstrated. The batch processing rate is $1-3$ drums/day.

\section{Development Needs:}

Demonstration of continuous feed; offgas-catalyst improvement; oxyhydroxide formation with actinides: Hydrogen gas buildup; radioactive contamination/exposure provisions.

\section{Vendor List:}

Synthetica Technologies, Inc.

\section{DOE Laboratories Involved in Technology:}

Hanford

Savannah River Site

Sandia National Laboratory

\section{References:}

Terry R. Galloway, "Destroying Hazardous Waste On Site Avoiding Incineration", Environmental Progress, Vol. 8, No. 3, August 1989

Charles A. Wentz and Terry R. Galloway, "Public Impact on Technical Research: The Dissimilar Fates of Two Waste Gasification Projects", Environmental Progress, Vol. 8. No. 3, August 1989

T. R. Galloway, "Renew Carbon On-site by Steam Reforming", Chem Eng, December 1991, p. 11.

T. R. Galloway and F. S.dney Howard, "On-site Reactivation of Granular Carbon with the Synthetica Detoxifier", Annual AIChE Meetıng, Los Angeles, November 17-22, 1991.

T. R. Galloway and Jerry L. Sprung, "Waste Destruction by Very High Temperature Steam Reforming", National Academy of Sciences/National Research Council. Committee on Potential Applications of Concentrated Solor Photons, Solar Energy Research Institute, November 7-8, 1990, Golden, Colorado.

T. R. Galloway, "Synthetica Detoxifier", The Hazardous Waste Consultant. McCoy \& Associates, Colorado, November/December 1990. 


\section{C- -50}

T. R. Galloway, "The Need for New Technical Approaches to Environmental Control \& Management", Annual Chemical Marketing Research Association Meetıng, San Francisco. conference vol. pp. 13-16, February 5-7, 1990

T. R. Galloway, "Destroying Hazardous Waste On-site .- Avoiding Incineration", Environmental Progress, $\underline{8}, 176-185$ (1989).

C. A. Wenti and T. R. Galloway, "Public Impact on Technical Research: The Dissimilar Fates of Two Waste Gasification Projects", $\underline{8}, 186-189$ (1989).

T. R. Galloway, "The Role of Steam in Lowering PICs in a Thermal Detoxifier", Annual AIChE Meeting, San Francisco, November 5-10, 1989.

T. R. Galloway, "The Destruction of Infectious Waste in the Thermolytica Detoxifier", Proceedings of the HazMat West 89 Conference and Exhibition, Long Beach. November 7-9, 1989.

T. R. Galloway, "Thermal Treatment with the Thermolytica Detoxifier", Chapter 8 in Book entitled: "Thermal Processes, Volume 1: Innovative Thermal Processes for Treating Hazardous Waste", pp. 77.93, Technomic Publishing Co., Lancaster, Pennsylvania, 1990.

T. R. Galloway, "Destroying Hazardous Waste On-Site", AIChE Annual Meeting, Pub. Symposium Vol., Washington, D.C., November 27-December 2, 1988.

T. R. Galloway, "Thermolytica Detoxifier", The Hazardous Waste Consultant, McCoy \& Associates, Colorado, May/June 1988.

T. R. Galloway, "Achieving Reduced Risk -- The Thermolytica Detoxifier Destroying Hazardous Waste On-Site", International Conference on Incineration of Hazardous/Radioactive Wastes, San Francisco, CA, May 3-6, 1988.

T. R. Galloway, "Economical On-Site Waste Detoxification: An Exercize in Heat Recovery", American Institute of Chemical Engineers Symposium Series No. 257, Vol. 83, pp. $418-424$ (1987), Presented at 1987 National Heat Transfer Conference, Pittsburgh, PA, August 9-12, 1987. 


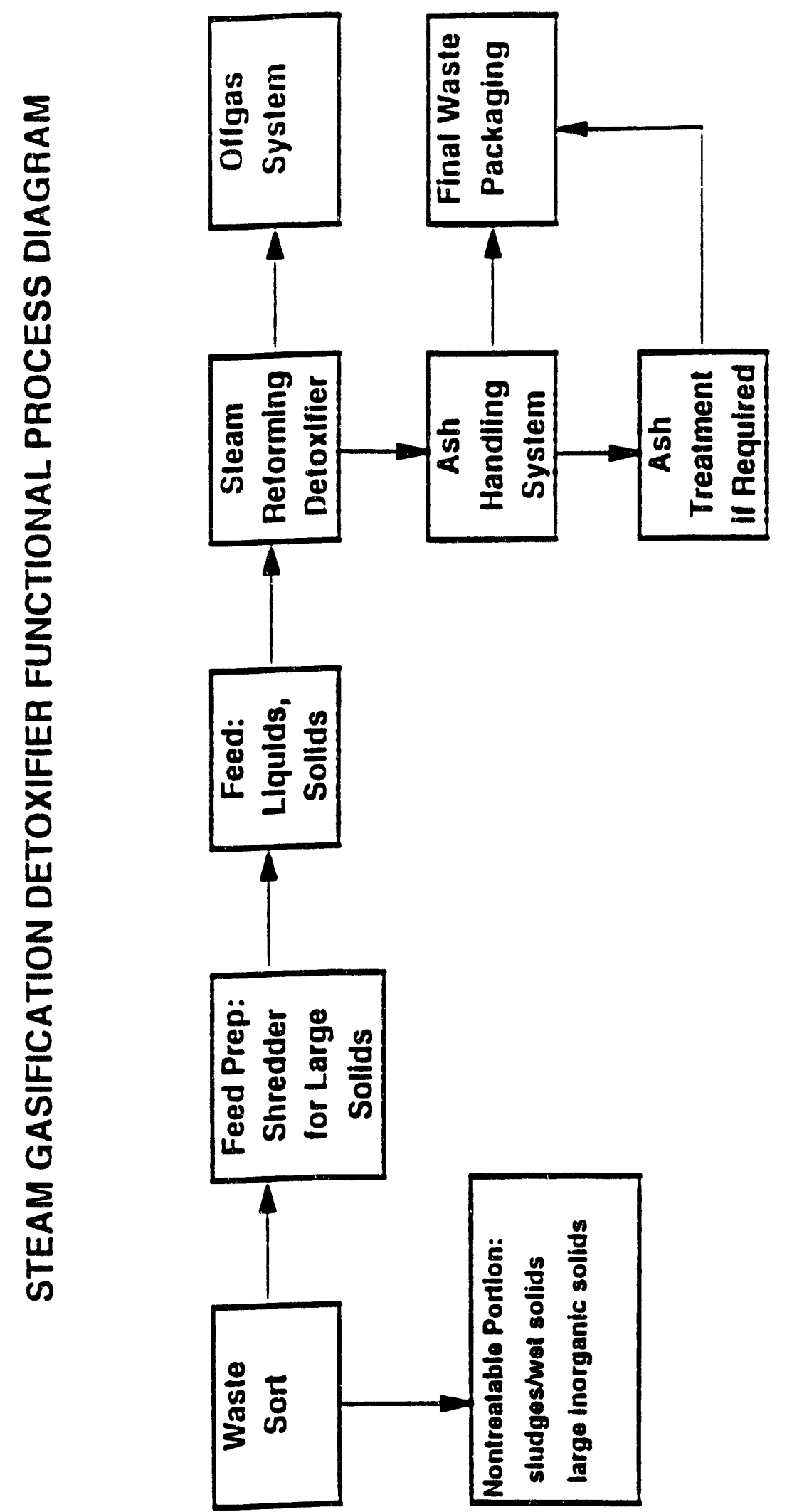




\section{C -52}

Technology Name: $\quad$ Supercritical Water Oxidation

Maturity: $\quad$ Emerging-Demonstration

\section{Description:}

The aqueous phase oxidation of dissolved or suspended organic contaminants at temperature and pressure conditions that are supercritical for water (above $705^{\circ} \mathrm{F}$ and 218 atm). Oxygen (air) and a dilute organic/water mixture are introduced into a reactor vessel where oxidation of the organics occurs. In supercritical water, oxygen and organics are totally miscible and oxidation proceeds rapidly and completely. Inorganic compounds are nearly insoluble and precipitate out. The process reduces the organics to $\mathrm{H}_{2} \mathrm{O}, \mathrm{CO}_{2}$, and various biodegradable acids. Reaction times of less than one minute are required. The process, once started, is thermally self-sustaining, as well as providing a source of hightemperature process heat. One application employs a deep well and static head to generate supercritical pressures.

Waste Applicability:

Aqueous Liquids:

Organic Liquids:

Wet Solids:

Dry Homogeneous

Solids:

Dry Heterogeneous

Solids (Small):

Dry Heterogeneous

Solids (Large):
High applicability to aqueous liquids.

High applicability to organic liquids with $<10 \%$ organics.

Not applicable to solids.

Not applicable to soils or other solids.

Not applicable.

Not applicable.

\section{Advantages:}

The super-critical water oxidation process is thermally self-sustaining. It is suited for processing non-incinerable dilute wastes. Its low off-gas volumes are free of $\mathrm{NO}_{\mathrm{x}}$, $\mathrm{SO}_{\mathrm{x}}$, PICs, and particulate. The super-critical water oxidation process can achieve complete oxidation of organics, and has a high DRE. Short (one minute) residence times allow a smaller reactor; hence, small equipment volumes are required. The process provides efficient precipitation of inorganics. Offgas scrubbing is not required. Process provides a source of high temperature process heat. 


\section{Disadvantages:}

This technology has high cost and potential equipment limitations due to stringent temperature and pressure requirements. The technology is limited to weak aqueous organic solutions. There may be equipment fouling problems, especially with pumps fouling from particulate matter. Precipitated salts are difficult to remove. The supercritical water oxidation technology has not been demonstrated for solid content wastes.

\section{Development Needs:}

Materials of construction for high temperature/pressure conditions and abrasion problems; high pressure pumps which are not susceptible to fouling; corrosion control and monitoring; scale-up; solid effluent handling; investigate phase behavior-precipitation.

\section{Vendor List:}

ABB Lummus Crest

A. H. Halff Associates

Ecowaste
Genesyst Inc.

Modar Inc.

Modell Development Corp.

\section{DOE Laboratories Involved in Technology:}

Los Alamos National Laboratory

Sandia National Laboratory

NIST

Idaho National Engineering Laboratory

Rocky Flats Plant

Westinghouse Hanford Company

\section{References:}

Tester, J. W., Holgate, H. R., Armellini, F. J., Welbey, P. A., Killilea, W. R., Hong, G. T., and Barner, H. E., "Supercritical Water Oxidation Technology: A Review of Process Development and Fundamental Research", 1991 ACS Symposium Series, Emerging Technologies for Hazardous Waste Management, Atlanta, Georgia, October 1991.

Modell, M., "Supercritical Water Oxidation", Standard Handbook of Hazardous Waste Treatment and Disposal, H. M. Freeman, ed., New York: McGraw Hill, pp. 8.153-8.168 (1989).

"Phase II Final Report: Oxidation of Hydrocarbons and Oxygenates in Supercritical 


$$
\text { C }-54
$$

Water", HAZWRAP report No. DOE/HWP-90, September 1989

Contact: Prof. Jeff Tester, Energy Laboratory, MIT. 77 Massachusetts Ave., Room E4045, Cambridge, MA 02139-4307, (617) 253-3401.

Contact: Dr. Michael Modell, MODEC, 39 Loring Drive, Framingham. MA 01701, (508)820-09213. 


\section{C. -55}

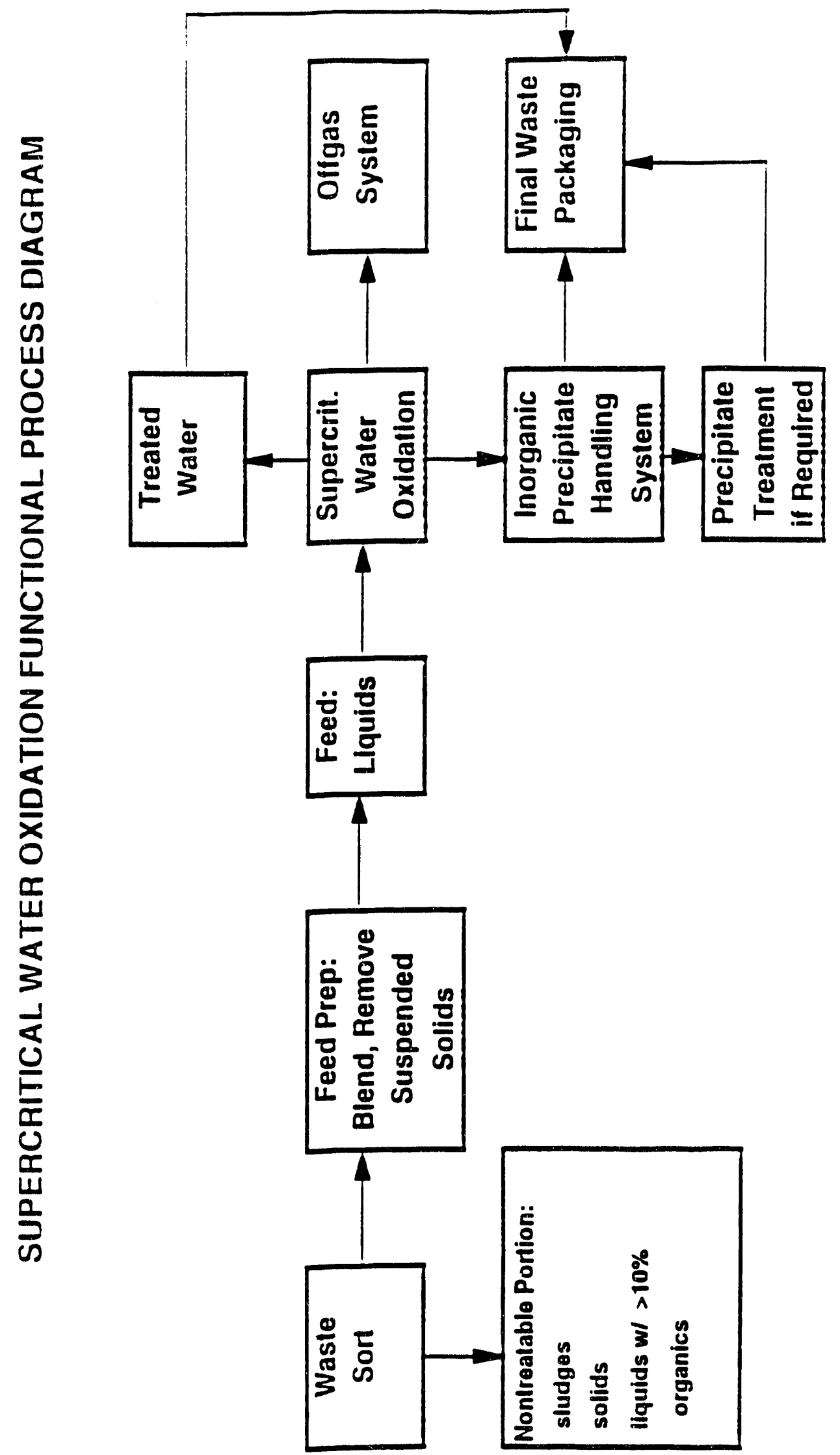




$$
\text { C- } 56
$$

Technology Name: Ultraviolet Photo-Oxidation

Maturity: $\quad$ Operational - Unique

\section{Description:}

Ultraviolet photo-oxidation (UVP) is a process that destroys or detoxifies hazardous chemicals in aqueous solutions utilizing UV radiation from various sources. UV radiation, ozone, and hydrogen peroxide combine to oxidize organic compounds including chlorinated hydrocarbons and aromatic compounds.

The UVP unit consists of a reactor module, air compressor/ozone generator module, and a hydrogen peroxide feed system. Offgas from the reactor passes through an ozone destruction (Decompozon) unit. The Decompozon unit destroys all gaseous volatile organic compounds stripped off in the reactor. UVP operation is based on the theory that adsorption of energy in the UV spectrum results in a molecule's elevation to a higher energy state, thus increasing the ease of bond cleavage and subsequent oxidation of the molecule.

Waste Applicability:

Aqueous Liquids:

High applicability to aqueous liquids.

Organic Liquids:

High applicability to organic liquids with $<10 \%$ organics.

Wet Solids:

Not applicable to solids.

Dry Homogeneous Solids:

Not applicable to solids.

Dry Heterogeneous Solids

Not applicable to solids.

(Small):

Dry Heterogeneous

Solids (Large):

Not applicable to solids.

\section{Advantages:}

UVP is skid-mounted, portable, and permits on-site treatment of a wide variety of liquid wastes. UVP is not a thermal technology, therefore it does not pose the risks or perception problems normally associated with thermal treatment. While UVP is effective at all concentrations, it does so without giving off any air emissions. The unit can be used as a stand alone, or combined with other treatment units in a system. 


\section{Disadvantages:}

UVP is not a very versatile technology. The inability of UV light to penetrate and destroy pollutants in soil or in turbid or opaque solutions is a limitation to this approach. UVP is only capable of treating clear liquid wastes, and the reaction rate is dependent upon the $\mathrm{pH}$ of the input solution. During the process, the catalyst is susceptible to degradation and some harmless organics can produce competing reactions. Maintenance of UVP units is required on a routine basis.

\section{Development Needs:}

UVP is a fully developed technology and is widely available in the commercial market. There has been some history of failure in the heater element of the Decompozon unit, however this was a minor problem. Other areas in need of development include improved efficiency of the light source with respect to bandwidth: decreased catalyst degradation; decreased competing organic reaction; less dependency on $\mathrm{pH}$ with respect to reaction rate; and a more in-depth look at large-scale operations/economics.

\section{Vendor List:}

\section{Artech Incorporated \\ DeGussa \\ ECOVA \\ Kerr McGee \\ Peroxidation Systems \\ Syntex Chemicals \\ Ultrox International}

\section{DOE Laboratories Involved in Technology:}

Sandia National Laboratory

Lawrence Livermore National Laboratory

DOE Kansas City Plant

\section{References:}

Craig E. Tyner, "Application of Solar Thermal Technology to the Destruction of Hazardous Wastes", Solar Energy Materials, vol. 21, 1990, pp. 113-129, Elsevier Science Publishers B.V., North-Holland.

Judith F. Kitchen, et al., "Cleanup of Spilled Chlorinated Organics with the LARC Process", Atlantic Research Corporation, Alexandria, VA 22312, 1984.

"The Superfund Innovative Technology Evaluation Program: Technology Profiles", US 


\section{C -58}

EPA, EPA/625/8-87/014, September 1987.

"Ultrox International Ultraviolet Radiation/Oxidation Technology", US EPA. EPA/540/A589/012, September 1990. 


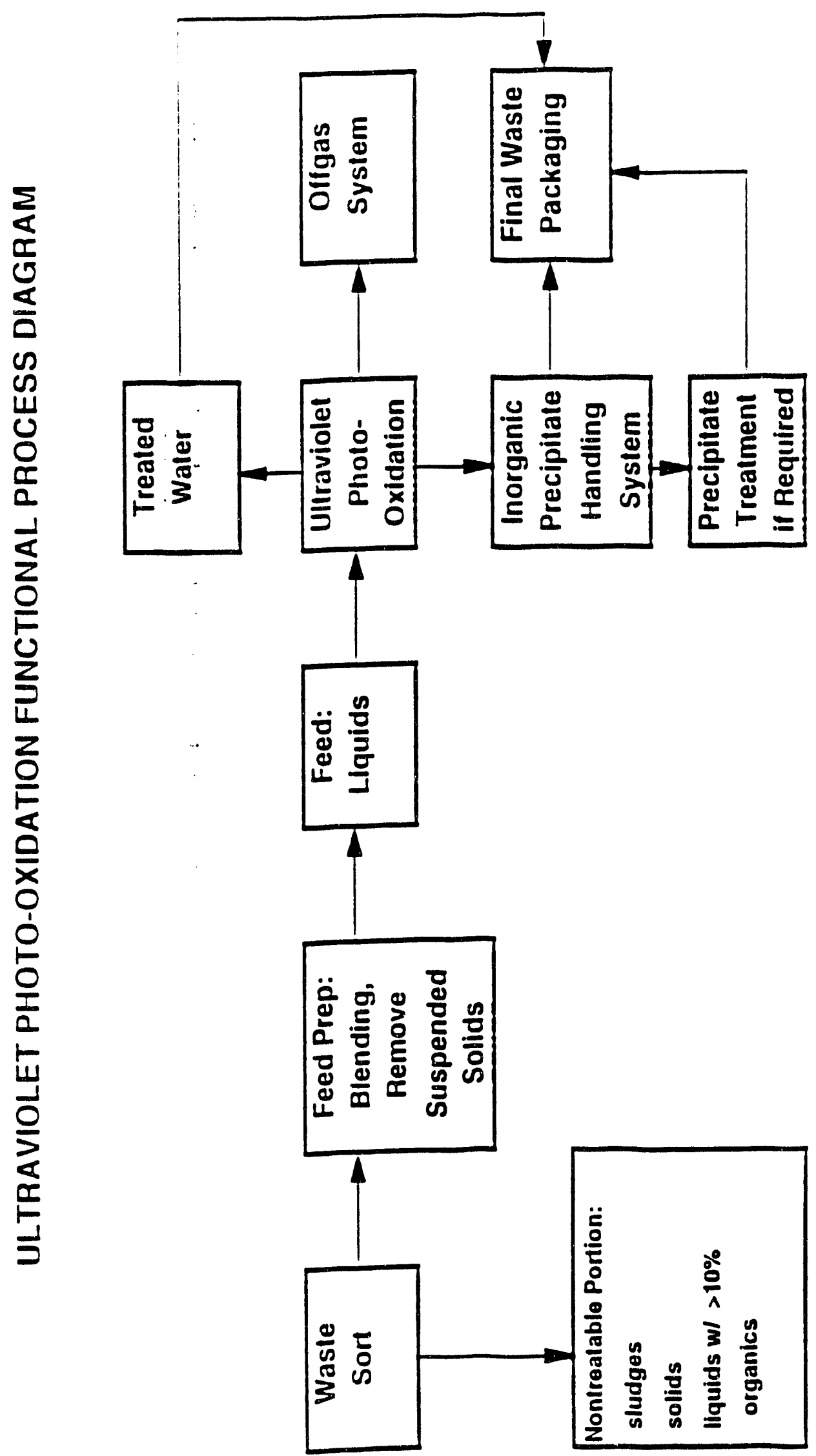


Technology Vame:

Maturity:

\section{Description:}

A horizontal reactor chamber in which liquid waste molecules are pyrolyzed by passing through a thermal plasma plume. The plume is generated by passing an electric charge through an atmospheric airstream which ionizes the gas molecules and generates temperatures up to $18,000^{\circ} \mathrm{F}$. The collinear electrodes of the plasma device act as a plugflow atomization zone for the liquid waste feed, and the pyrolysis chamber serves as a mixing zone where the atoms recombine to form $\mathrm{H}_{2}, \mathrm{CO}, \mathrm{HCl}$. and particulate $\mathrm{C}$. Residence times in the residence zone and recombination zone are 500 microseconds and one second, respectively. Temperature in the recombination zone is maintained at $1200^{\circ}$. $2400^{\circ} \mathrm{C}$. After offgas scrubbing, the residual gases are electrically ignited in a flare stack.

\section{Waste Applicability:}

Aqueous Liquids:

Low applicability to aqueous liquids.

Organic Liquids:

High applicability to organic liquids.

Wet Solids:

Not applicable to absorbed liquids or sludges with organics.

Dry Homogeneous

Not applicable to solids.

Solids:

Dry Heterogeneous

Solids (Small):

Dry Heterogeneous

Solids (Large):

\section{Advantages:}

The small equipment size required for this technology allows for portability; minimal setup is required after delivery to new site. The plasma pyrolysis reactor technology has a high throughput and can process highly toxic and refractory compounds, as well as wastes with low heating values. rapid on/off cycle times; high DREs; high destruction temperatures; produces a fuel gas for energy recovery. 


\section{Disadvantages:}

The technology can treat only liquids with light particulate loading. Plasma pyrolysis reactors are energy intensive to operate.

\section{Development Needs:}

Limited long term operational data: electrode life uncertainties, significantly affects peak electrical use (peak charge may increase); heating value limits of waste streams; power needs v.s. feed properties.

\section{Vendor List:}

Pyrolysis Systems Inc.

Westinghouse Research \& Development Center

\section{DOE Laboratories Involved in Technology:}

None

\section{References:}

Marc Breton et al., "Technical Resource Document: Treatment Technologies for Solvent Containing Wastes", U.S. Environmental Protection Agency, EPA/600/2-86/90, October 1986.

Harry Freeman, "Innovative Thermal Hazardous Organic Waste Treatment", Noyes Publications, Park Ridge, NJ, 1985.

Michael F. Joseph, Thomas G. Barton, "Waste Destruction by Plasma Arc Pyrolysis", Pyrolysis Systems Inc., Kingston, Ontario, Canada.

The Hazardous Waste Consultant, McCoy \& Associates, Vol. 4, Issue 3, May/June 1986.

Contact: E.S. Fox, Jr., Pyrolysis Systems, Inc., 61 Thorold Road, Welland, Ontario, L3B SPI, Canada, (416) 735-2401.

Contact: Westinghouse Plasma Systems, P.O. Box 350, Madison, P.A 15663, (412) 7225275 . 
C. 62

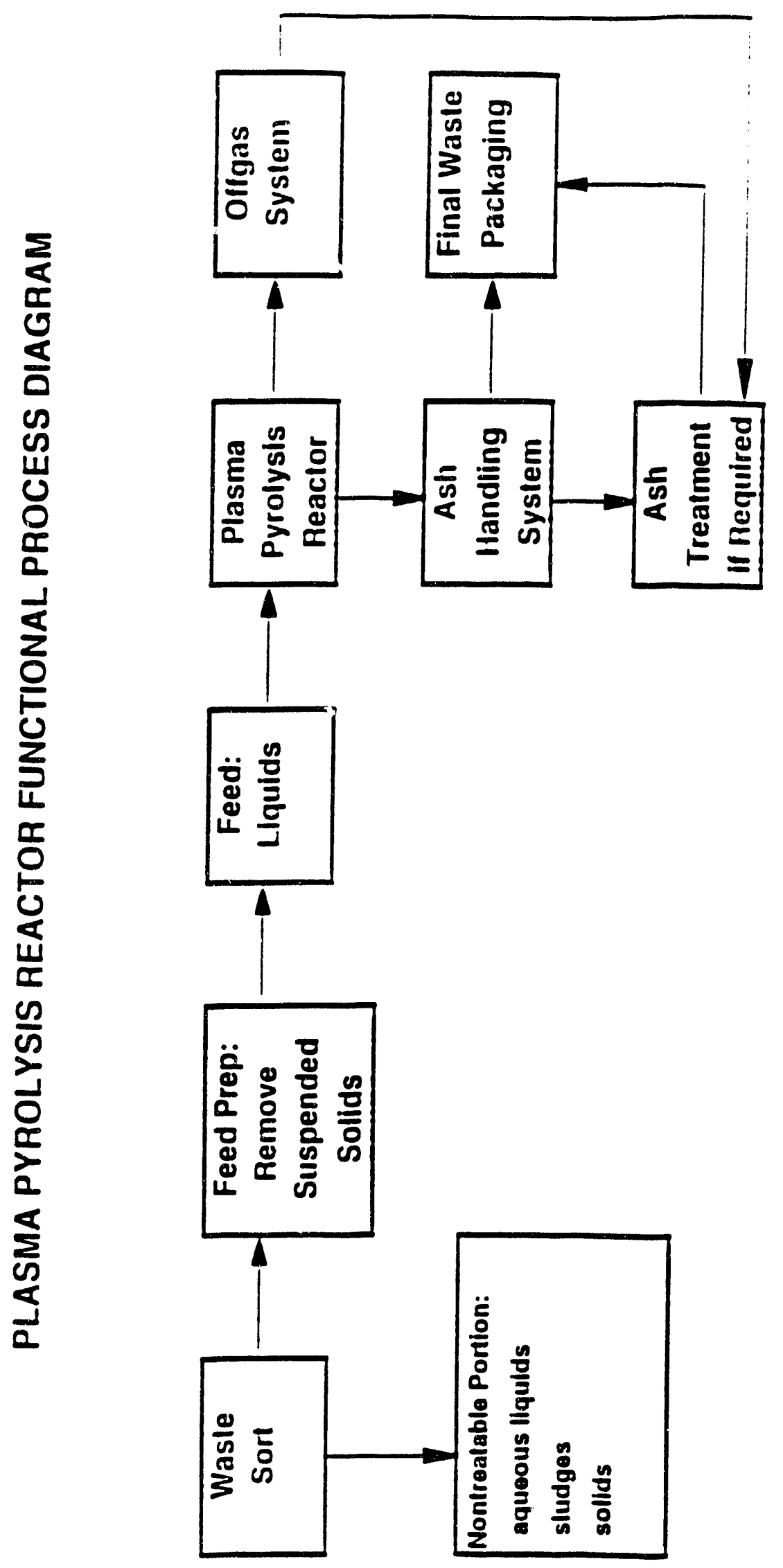


C -63

APPENDIX C3

MELTER TECHNOLOGIES 
Technology Name: Molten Salt Furnace

Maturity: $\quad$ Emerging-Pilot/Emerging-Demonstration

\section{Description:}

In the molten salt (MS) process, waste and air are contınuously introduced beneath the surface of a sodium carbonate $\left(\mathrm{Na}_{2} \mathrm{CO}_{3}\right)$ melt at a temperature of $750^{\circ}$ to $1000^{\circ} \mathrm{C}$. Supplemental fuel may be required if the waste is not sufficiently combustible. Rapid destruction of the waste results from the catalytic effect of the salt, and from the intimate contact of the waste with air and the hot molten salt, which provides rapid transfer of heat to the waste. The molten salt forms chemical complexes with toxic metals and radionuclides which reduces their thermodynamic activity and thus retains them in the salt. Sodium carbonate is used because it prevents emission of acidic gasses. such as $\mathrm{HCl}$ (ordinarily produced from organic chloride compounds) and $\mathrm{SO}_{2}$ (from organic sulfur compounds). Also. it is stable, nonvolatile, inexpensive, and nontoxic. The carbon and hydrogen of the waste are converted to $\mathrm{CO}_{2}$ and steam; halogens form their corresponding sodium halide salts; phosphorus, sulfur, arsenic, and silicon (from glass or ash in waste) form oxygenated salts; and the iron from metal contanners forms iron oxide. The ash is trapped in the melt. The melt is removed periodically or batch-wise to prevent excessive build-up of halide salts or ash. The ash can be separated from the salt in an aqueous separations process with the sulfates and chlorides scrubbed out and the carbonates recycled to the melt. The $\mathrm{CO}_{2}$ and water can be captured and stored in liquid form to be analyzed prior to release.

\section{Waste Applicability:}

Aqueous Liquids:

Organic Liquids

Wet Solids

Dry Homogeneous

Solids:

Dry Heterogeneous

Solids (Small)

Dry Heterogeneous

Solids (Large):
Low applicability to aqueous liquids.

High applicability to organic liquids.

Not applicable to solids.

Not applicable.

High applicability to combustıble dry solids only

Not applicable 


\section{Advantages:}

High waste destruction efficiency, high heat transfer rates: Liquid waste effluent is not produced. The molten salt combustor is versatile, handling a wide variety of wastes. Excellent temperature control may be maintained due to the thermal inertia of melt bed. Acid gases are not produced. nor are they emitted. The radioactive elements of heavy metals are retained in the salt. Potentially good public acceptance

\section{Disadvantages:}

High ash waste requires greater salt make-up than liquid wastes (e.g. solvents), and salt/ash separation is difficult. Feedstock must be size-reduced, as large forms. e.g. 55 gal-drum, cannot be accepted. The molten salt is corrosive to most metals. The system complexity is high because of salt recycling needs to make the process cost-effective.

\section{Development Needs:}

Performance of materials of construction over range of salt chemical compositions and temperatures. Develop process for treatment of spent melt, e.g. process to separate ash from salt; develop process to recover radioactive elements or heavy metals from salt.

\section{Vendor List:}

\section{Rockwell International}

DOE Laboratories Involved in Technology:

Lawrence Livermore National Laboratory

Los Alamos National Laboratory

Hanford (using zinc chloride salts)

\section{References:}

Marc Breton et al, "Technical Resource Document: Treatment Technologies for Solvent Containing Wastes", U.S. Environmental Protection Agency, EPA/600/2-86/095. October 1986

H.M. Freeman et al., "Thermal Destruction of Hazardous Waste A State-of-the-Art Review", Joumal of Hazardous Materials, Vol. 14, 1987, pp. 103-117.

Harry Freeman, Innovative Thermal Hazardous Organic Waste Treatment, Noyes Publications, Park Ridge, NJ, 1985. 


$$
\text { C. } 66
$$

R.L. Gay et al., "Destruction of Toxic Wastes L'sing Molten Salts". Technical Meeting of the American Insutute of Chemical Engineers. Anaheim. CA. April 1981.

J.G. Johanson et al., "Destruction of Hazardous Wastes by the Molten Salt Destruction Process", Seminar of the American Society of Testing Materials Committee D-27, Nashville, TN, March 1982

Contact: Richard L. Gay, Rocketdyne Division. Rockwell International Corp., 6633 Canoga Ave., Canoga Park, CA 91303, (818) 700-3505. 

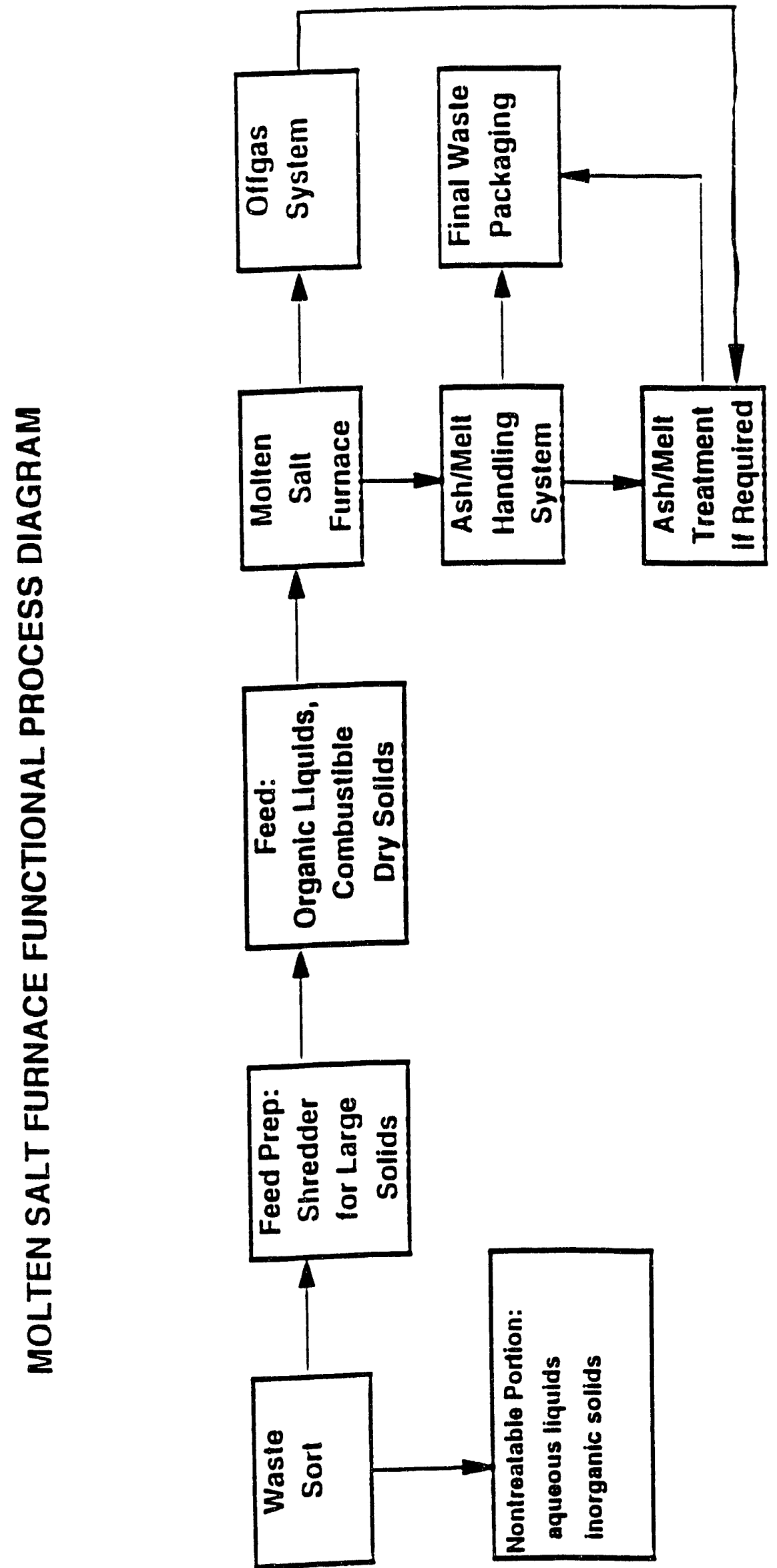
Technology Name: Joule Heated Melter

Maturity: Operational on Mixed High-Level Radioactive Waste

\section{Description:}

A refractory lined reactor in which a pool of glass is initially melted by auxiliary heating, then maintained in a molten state by joule heating (alternating electric current passing through the glass between submerged electrodes dissipates energy due to bulk glass resistivity). The technology described here is distinguished from the HighTemperature Joule Melter described later by its nominal operating temperature of $1200^{\circ} \mathrm{C}$ or less. This class of process equipment includes a broad range of designs. It is the base technology for vitrifying high-level radioactive waste at Savannah River's Defense Waste Processing Facility, the West Valley Vitrification Facility and the Hanford Waste Vitrification Plant. This general technology has been deployed internationally and operated under remote radioactive conditions for over six years (1985 to 1991) in the PAMELA plant at Mol, Belgium. High level mixed wastes are typically fed in a slurry form to facilitate transfer of waste to the process. Glass formers or premelted glass is mixed in with the waste to provide the silica and fluxes needed to melt at the operating temperature limit of $1200^{\circ} \mathrm{C}$.

For non-slurried waste applications, waste is introduced into the furnace above the molten glass pool along with the combustion air. Combustion is achieved by exposure to the radiant heat above the pool or by contact with the molten glass. Exhaust gases flow out the opposite end of the furnace. Solid products of combustion and noncombustible materials are encapsulated in the glass, which can be continuously removed or batch discharged to solidify into a nonleachable matrix. A feeding variation by one developer introduces the waste and air under the surface of the molten glass via a drop tube to confine most of the combustion below the surface of the pool, enhancing intermixing of the waste and combustion gases with the glass and attaining higher particulate retention. Typical mean glass residence times range from 24 to 48 hours. This assures homogeneity of the glass material being discharged even with variations in the waste stream.

\section{Waste Applicability:}

Aqueous liquids:

Medium applicability to aqueous liquids. The technology can and has been fed dilute liquid waste streams where evaporation and vitrification of the residue occurs. High level waste may have at least $40 \mathrm{wt} \%$ solids with the balance being liquid.

Organic liquids:

High applicability to organic liquids. Organics present at up to 100 grams/liter in high level waste have been destroyed with high destruction efficiencies (>99.99\%). For 
strictly organic hazardous wastes. destruction efficiencies in excess $99.999 \%$ have been demonstrated at .Mound and Pacific Northwest Laboratory.

Wet Solids:

Dry Homogeneous Solids:

Dry Heterogeneous

(Small and Large):
High applicability to wet solids. This report's definition of wet solids is consistent with the primary application of this technology, the processing of waste slurnes and sludges.

High applicability to dry homogeneous solids. Some size reduction may be required to facilitate the feeding of the unit but processing of dry solids is an adaptation of the conventional glass industry use of this technology.

This technology is judged not to be applicable to Solids heterogenous solids because of the presumed metal content. Metals will precipitate to the floor of the melter, not be dissolved, and ultimately lead to electrical shorting between the power electrodes.

\section{Advantages:}

This adaptation of the glass industry technology has been thoroughly tested for slurries and sludges typical of high-level, mixed wastes. The operating conditions for successfully producing a chemically durable product is well documented. The ability to destroy organics has been demonstrated in melters that employ plenum heaters. At the prescribed operating temperatures $\left(<1200^{\circ} \mathrm{C}\right)$, a broader spectrum of electrodes and glass contact refractory can be used. A long reliable operating life, in excess of two to five years, should be expected without failure. This technology has been designed for totally remote operation. For mixed wastes that pose a significant chemical or radioactive hazard during operations, these designs can be confidently employed. Use of joule heating minimizes possible safety issues regarding combustible gases for radioactive application.

\section{Disadvantages:}

The relatively low operating temperature of $1200^{\circ} \mathrm{C}$ limits the waste loading in the product glass. For high-level waste a loading of 25 to $35 \mathrm{wt} \%$ of wastes is typical. For contaminated soils or similar compositions, 60 to $80 \mathrm{wt} \%$ waste loading may be more typical. However, the relatively high density of the glass $(2.5$ to $2.8 \mathrm{gm} / \mathrm{cc})$ may result in high volume reduction. The operating temperature essentially precludes the opportunity to process high metal containing waste streams. Here, the metals can settle to the floor, collect and cause an electrical short between the power electrodes. The capital cost for these high-level waste melters is relatively high and operating life may be limited to several years. Process control necessitates feed characterization and periodic sampling and analysis of the glass stream. In general, the joule heated melter is more suitable to 
feed streams where there is a substantial amount of relatively homogeneous feed. The joule melter can be idled at a lower temperature, but must be drained of glass if a complete shutdown is required.

\section{Development Needs:}

The specifics of the waste stream need to be defined and an acceptable glass needs to be tailored for its processing. After laboratory development of these waste glasses. demonstration of the technology with the specific waste stream(s) is needed to quantify the specific throughput and to identify any unforeseen issues. Joule heated melters are available within the DOE Complex and industry, so that demonstrations can be performed without large capital investments. However, testing may require modification of melter feed systems.

\section{Vendor List:}

American Environmental Management Corp.

Frazier-Simplex Inc.

Penberthy Electromelt International, Inc.

Recomp, Inc.

Sorg Engineering

Toledo Engineering Co., Inc

\section{DOE Laboratories Involved in Technology:}

Pacific Northwest Laboratory

Savannah River Laboratory

Mound Laboratory

\section{References:}

Janke, 1990, D.S. Janke and C. C. Chapman, Characteristics of Fernalds K-65 Residue Before, During and After Vitrification, FMPC/SUB-035, Pacific Northwest Laboratory, Richland, WA.

Brouns, 1988, R. Brouns, A. A. Balasco, et. al., Bench Scale Glassification Test on Rocky Mountain Arsenal Basin F Material, AMXTH-TE-CR-88015, Pacific Northwest Laboratory, Richland, WA.

Klinger, 1989, Joule Heated Glass Furnace Processing of a Highly Aqueous Hazardous Waste Stream, L. M. Klingler, P. L. Abellera, March 17, 1989, MLM-3577, Mound Applied Technologies, Miamisburg, $\mathrm{OH}$.

Larson, 1983, Assessment of power reactor waste immobilization bv vitrification, D. E. 
Larson, et. al., August. 1983, EPRI-NP-3225, Pacific Northwest Laboratoryes. Richland. WA.

Klinger, 1985. Glass Furnace Project Final Report: An Evaluation of Operating Experience for Low-Level Nuclear Waste Processing, L. M. Klingler. K. M. Armstrong, February, 28, 1985. MLM-3229, Mound Laboratories, Miamisburg, OH.

Armstrong, 1985, Nitrate Waste Processing by means of a Joule-Heated Glass Furnace, K. M. Armstrong, L. M. Klingler, October 18, 1985, MLM-3304, Mound Laboratories, Miamisburg, $\mathrm{OH}$.

Klinger, 1988, Glass Furnace Processing of Rockv Flats Plant Wastes - an Evaluation, L.M. Klingler, P.L. Abellera, April 29, 1988, MLM-3493, Mound Laboratories, Miamisburg, $\mathrm{OH}$.

Wiese, 1988, Industrial Vitrification of High Level Liquid Waste with the PAMELA Plant in Belgium, Wiese, $\mathrm{H}$. and E. Ewest, Proceedings of the International Topical Meeting on Nuclear and Hazardous Waste Management, Spectrum '88, September, 1988, pp 75-77.

Barnes S.M., J.M. Pope and C. C. Chapman, Three Year's Progress of the West Valley Demonstration Project Vitrification System, March 1988, Waste Management '88, Tucson, Arizona, Waste Management '88 Proceedings

Brouns, R. A. and M. S. Hanson, 1984, "The Nuclear Waste Glass Melter--An Update of Technical Progress", Fuel Processing and Waste Management, Vol. 1, p. 101. American Nuclear Society, Inc., La Grange Park, Illinois.

Buelt, J. L. 1985, A Mobile Encapsulation and Volume Reduction System for West Low-Level Wastes. PNL-5533, Pacific Northwest Laboratory, Richland, Washington.

Chapman, C. C. and J. L. McElroy, 1989, Slurry-Fed Ceramic Melter - A Broadly Accepted System to Vitrify High-Level Waste, Proceedings of the 1989 Joint International Waste Management Conference, Kyoto, Japan, October 22-28, 1989, volume 2 pages 119 128.

Holton, L. K., Jr., J. E. Surma, R. P. Allen, R. A. Brouns, G. H. Bryan, M. L. Elliott, R. W. Goles, F. E. Haun, Y. B. Katayama, R. F. Klein, and R. D. Peters, 1989, Processing Summary Report: Fabrication of Cesium and Strontium Heat and Radiation Sources, PNL-6790, Pacific Northwest Laboratory, Richland, Washington. 
Holton, L. K., Jr., D. N Berger, W. J. Bjorklund. and R. D. Dierks, 1984, "Design Features of a Radioactive Liquid-Fed Ceramic Melter System", Iransactions of the American Nuclear Society, Vol. 46, p. 785. American Nuclear Society, Inc.. La Grange Park. Illinois.

McElroy, J. L., W. J. Bjorklund, and W. F. Bonner, 1982, "Waste Vitrification: A Historical Perspective", The Treatment and Handling of Radioactive Wastes, A. G. Blasewitz, J. M. Davis, and M. R. Smith, Editors, p. 171. Battelle Press, Richland, Washington. 


\section{C- 73}

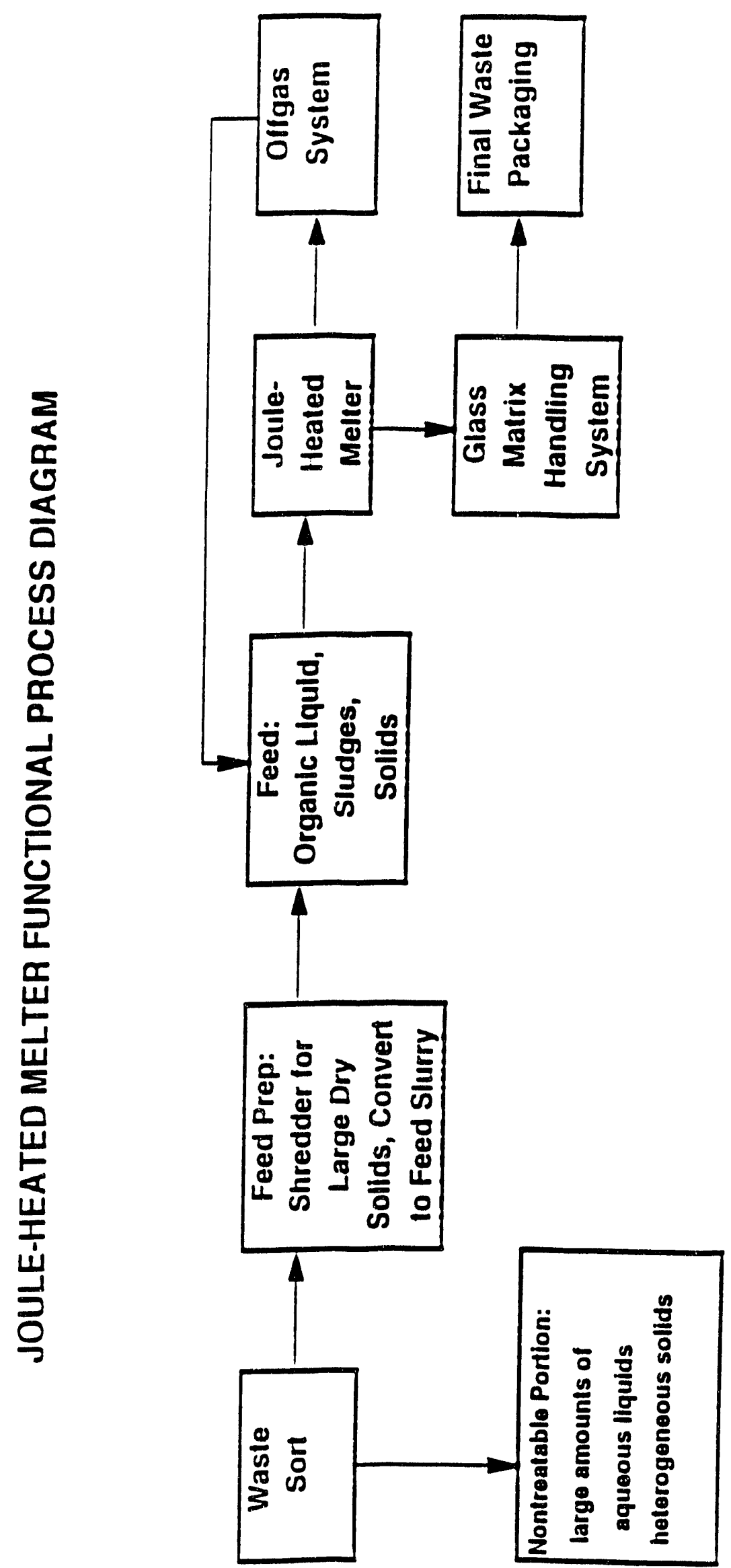


Technology Name: Plasma - Arc Furnace

Maturity: $\quad$ Emerging-Pilot

\section{Description:}

A plasma arc furnace uses the energy from a thermal plasma arc, generated by joule heating of a gaseous electrical conductor between two high voltage electrodes, to combust organics and melt inert waste components. The plasma arc is generated within the furnace primary chamber by a removable plasma torch. Two types of plasma torches are available; transferred and non-transferred arc. The transferred arc uses a conductive hearth for maintaining the voltage differential for arc generation. In the non-transferred plasma torch, the arc is generated and maintained within the torch body. Waste is introduced into the furnace into a molten bath of material, which could be inert waste or other material. The high temperature plasma zone and the molten bath (in excess of $3000^{\circ} \mathrm{F}$ ) combust (or pyrolyze) the organics and melt all other inert materials into the bath. Volatile organics are further treated in a secondary combustion chamber. Very small gas volumes are required for the plasma arc, resulting in low offgas volumes. Molten solid material can be removed continuously by overflow or poured by batch and forms a leach-resistant, vitrified (glassy) waste form. Furnace operation is similar to a dual chamber controlled air incinerator with the substitution of a plasma arc torch for a burner in the primary chamber. The plasma arc furnace can reprocess all of its byproducts such as flyash, filters and scrubber residues.

\section{Waste Applicability:}

Aqueous Liquids:

Organic Liquids:

Wet Solids:

Dry Homogeneous Solids:

Dry Heterogeneous

Solids (Small):

Dry Heterogeneous Solids (Large):
Medium applicability to aqueous liquids.

High applicability to organic liquids.

High applicability to absorbed liquids and sludges with organics.

High applicability.

High applicability.

High applicability. 


\section{75}

\section{Advantages:}

Solid byproduct is a vitrified "glassy" slag that is excellent for stabilization of toxic metals and radionuclides. Quiescent combustion in primary chamber results in reduced particulate emissions. Plasma energy assists carbon burnout. Reduced offgas volume decreases air pollution control equipment costs. Byproducts such as flyash, filters, and scrubber residue can be reprocessed through the furnace. The process requires minimal waste characterization and pretreatment and has been demonstrated on an industrial scale for metal production. The furnace can be shut down and restarted with little difficulty. It can operate with a skull to reduce reaction of the melt with the metal or refractory hearth. Use of an electrical plasma avoids possible safety issues regarding combustible gases for radioactive application. This is an emerging technology for a variety of waste types.

\section{Disadvantages:}

The non-transferred arc allows operation over a wide range of power settings and has relatively simple controls, however, operation, start up, and control of a transferred arc plasma furnace is more complex than conventional incineration. If high temperatures are maintained, this may lead to high $\mathrm{NO}_{x}$ levels and increased volatilization of heavy metals.

\section{Development Needs:}

Optimization of slag chemistry for metals stabilization; evaluation of variation in slag chemistry resulting from variations in the input stream; re-introduction of condensed volatile metals into slag phase; electrode life studies; DRE of hazardous organics; safety assessments for heterogeneous waste processing; determination of radionuclide partitioning in slag/metal phases.

\section{Vendor List:}

ABB

Plasma Energy Corp.

Retech Inc.

Westinghouse

\section{DOE Laboratories Involved in Technology:}

Idaho National Engineering Laboratory

Pacific Northwest Laboratories

Westinghouse Hanford Company 


\section{References:}

J.F. Goodwill, "Proceedings of the Fir:" International EPRF Plasma Symposıum", CMP Report No. 90-9, May 1990, Chapters 1, 13, 14, and 16.

S.L. Camacho, "The F1 Manual: Application of Plasma Technology", Plasma Energy Corp., Raleigh, N.C. 1988.

S.L. Camacho, "Lasma Heating", Handbook of Applied Thermal Systems, McGraw-Hill, 1988.

S.L. Camacho, "Industrial-Worthy Plasma Torches: State-of-the-Art", Pure and Applied Chemistry, Vol. 60, No. 5, pp. 619-632, 1988.

C.R. Brunner, "Incineration Systems-Selection and Design", Incinerator Consultants Incorporated, Reston, VA 1988.

J.A. Batdorf, private communication, September 1990, Haz Answers, Inc., Idaho Falls, ID.

R. D. Peters and W. A. Ross, "Plasma Melting of Non-Irradiated Fuel Assembly Hardware: Initial Testing and Evaluation", Radioactive Waste Management and the Nuclear Fuel Cycle, 1989, Vol. II(4), pp. 333-345. 
C. -7

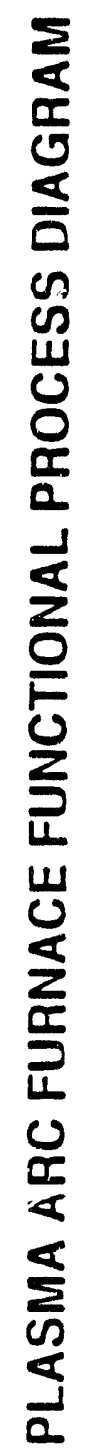

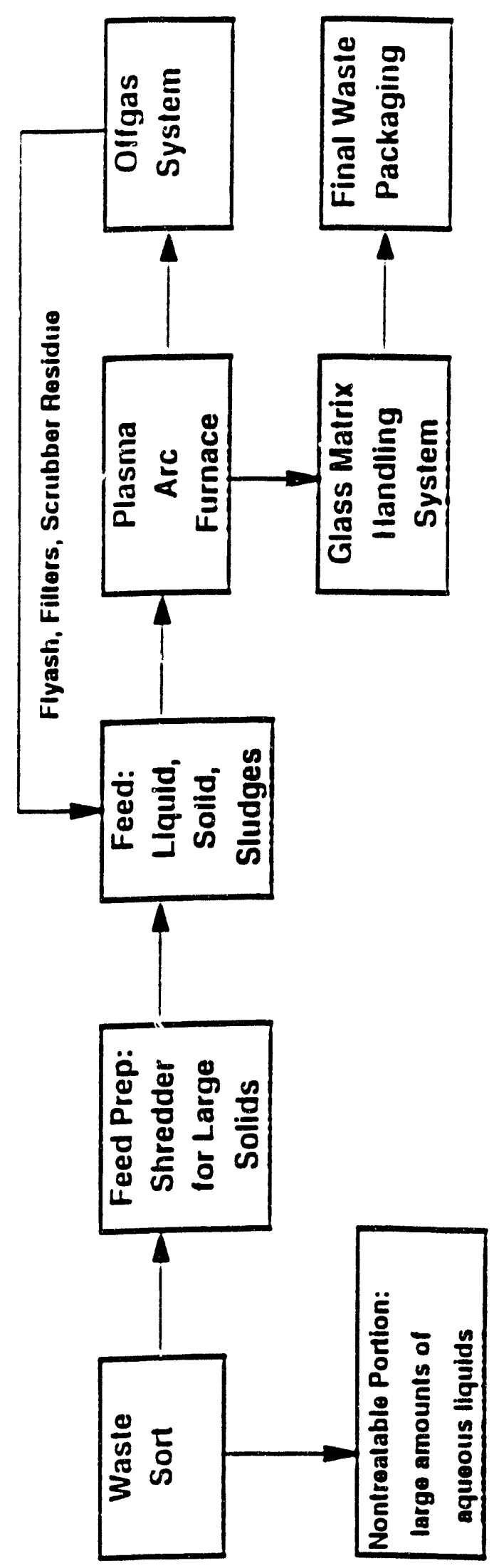




\section{C- 78}

Technology Name: Microwave Melter

Maturity: Demonstration

\section{Description:}

This process utilizes microwave energy for in-container solidification/stabilization of radioactively contaminated non-organic wastes such as incinerator ash, sludges, or soils. Waste moisture is removed in a belt-driven microwave dryer prior to treatment. The dry waste materials are vitrified inside a metal disposal container in either a batch or continuous feed mode. Melt temperatures range from $1800^{\circ}-2600^{\circ} \mathrm{F}$ and the resulting product is a glassy monolith that meets radioactive disposal criteria for liquid and particulate content. and RCRA LDR requirements for leaching of toxic hazardous constituents. The process results in volume reductions on the order of $80 \%$ with waste loadings on the order of $60 \%$.

\section{Waste Applicability:}

Aqueous Liquids: $\quad$ Medium applicability to aqueous liquids.

Organic Liquids: $\quad$ Medium applicability to organic liquids with a secondary combustion system added (not currently part of system).

Wet Solids:

High applicability to absorbed liquids and sludges with organics.

Dry Homogeneous

High applicability.

Solids:

Dry Heterogeneous

Not applicable to heterogeneous wastes.

Solids (Small):

Dry Heterogeneous

Not applicable.

Solids (Large):

\section{Advantages:}

Direct application of energy to the wastes - surrounding equipment remains relatively cool: process occurs inside disposal container, minimizing waste handling.

The waste form will meet applicable waste acceptance criteria for the disposal facilities; equipment is inexpensive and easy to maintain; process requires short heating time to achieve operational temperature (on the order of 30 minutes); heating can be instantaneously interrupted; heating is uniform in the waste material; energy can be selectively directed to the waste and not the equipment, preventing thermal cycling of the 


$$
\text { C-79 }
$$

equipment; the waste form is processed "in drum," reducing the material handling and generation of additional waste: "in-drum" processing eliminates the requirement of producing a pourable. low viscosity melt: waste volumes are reduced up to $80 \%$ compared to current cementation processes.

\section{Disadvantages:}

Applicable to dry or near-dry non-organic wastes only; waste must be relatively homogeneous fines: low throughput results in high unit operating costs; uneven melting of the wastes, especially near the bottom and sides: some oxidation of the metal waste container; melt-through of the container at hot spots.

\section{Development Needs:}

Evaluation of the process for other applications, i.e. destruction of hazardous wastes; leachability of the vitrified waste; develop dielectric property models; study container corrosion problems; control heat profiles in small heterogeneous wastes; perform volatility studies on liquid organics.

\section{Vendor List:}

Japanese manufacturers

\section{DOE Laboratories Involved in Technology:}

Rocky Flats Plant

Oak Ridge National Laboratory

Oak Ridge K-25 Plant

Los Alamos National Laboratory

\section{References:}

R.D. Petersen et al., "Application of Microwave Energy for Solidification of TRU Waste", American Nuclear Society 1987 Winter Meeting, Los Angeles, CA, November 1987.

Hirofumi Wshima et al., "Continuous Penetration Test Equipment Using Microwave Heating", RFP-TRANS-462, Translated from Toshiba Review, 39(7), pp. 611-614, 1984.

F. Komatsu et al., "Application of Microwave Treatment Technology to Radioactive Waste", Proceedings of the 1989 Incineration Conference, Knoxville, TN.

R.D. Petersen, "Microwave Vitrification of Rocky Flats TRU Sludge", American Nuclear Society 1989 Winter Meeting, San Francisco, CA, November 1989. 


\section{C -80}

Contact: Robert D. Peterson. EG\&G Rocky Flats. Rocky Flats Plant. Denver. CO (303) 966-4051.

Contact: Greg Sprenger. EG\&G Rocky Flats, Rocky Flats Plant. P.O. Box 464. Golden, CO 80402-464, (303) 955-3159 
C-81

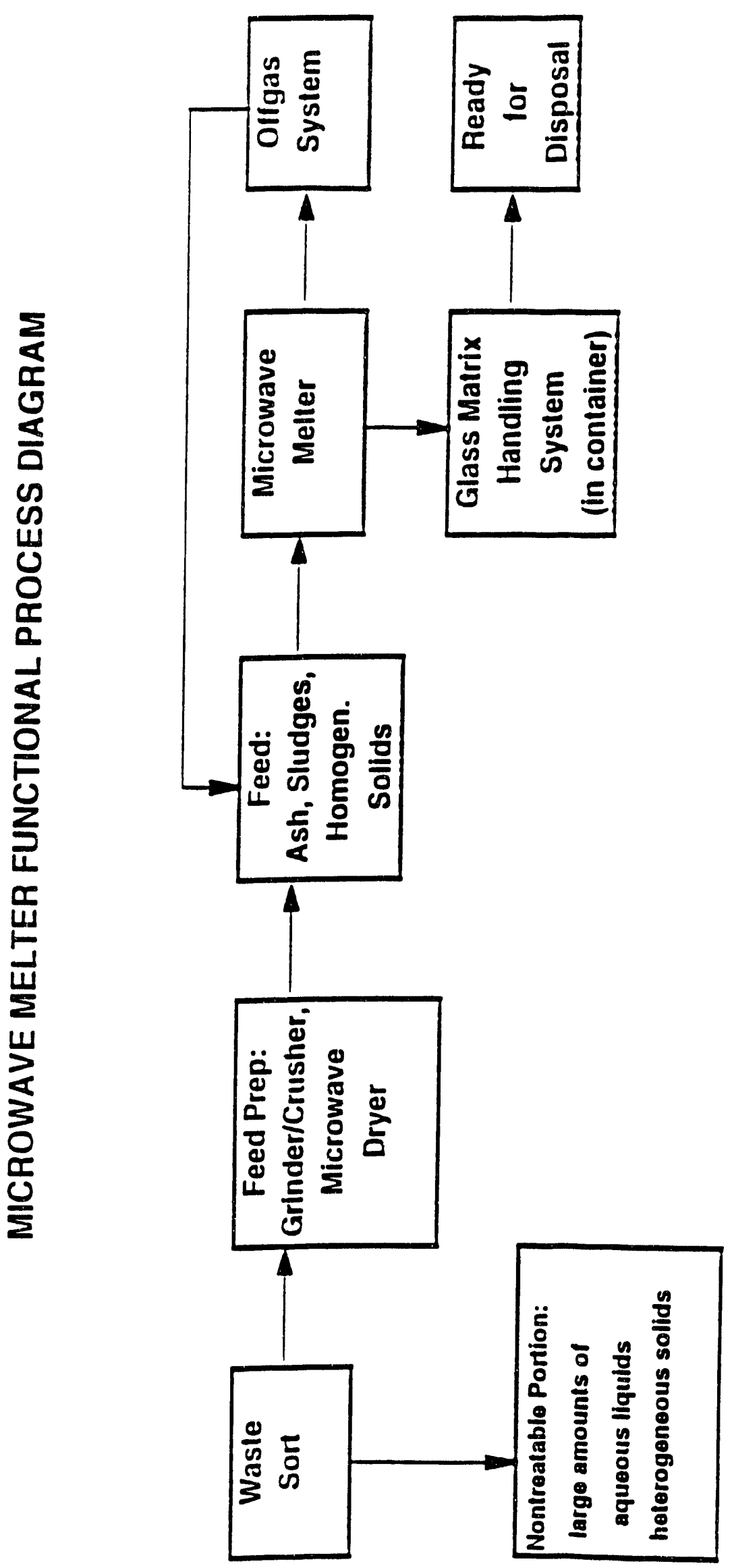




\section{C -82}

Technology Name: $\quad$ Slagging Kiln

Maturity: Operational - Unique

\section{Description:}

A slagging kiln is an incinerator designed to operate at sufficiently high temperatures so that the entire charge of waste material essentially melts into a "slag". Almost all slagging kilns are based on an improved rotary kiln incınerator design (see "Rotary Kiln" entry for details), requiring more attention to the refractory lining and the slag handling equipment. Other designs are possible, however, as evidenced in one particular application of a German-designed multi-chamber slagging kiln. Slagging kilns normally require a secondary combustion chamber to assure complete destruction of hazardous constituents. The primary chamber functions to combust solid waste to gases at temperatures of $2000^{\circ}$ to $2200^{\circ} \mathrm{F}$, thus leaving a melted slag residue of the noncombustible components (i.e. alumina and silica compounds, metal, glass). The slag melt progresses through the kiln into a water quench, where it solidifies and fractures into small pieces, and is then drawn from the process. Both primary and secondary chambers are generally supplied with auxiliary fuel systems which can be used for liquid waste incineration. An extensive offgas system is generally required to control the high volume of emissions. Slagging kilns are generally used in applications involving high calorific value type wastes.

Waste Applicability:

Aqueous Liquids

Organic Liquids:

Wet Solids: organics.

Dry Homogeneous Solids:

Dry Heterogeneous Solids (Small):

Dry Heterogeneous Solids (Large):
Medium applicability to aqueous liquids.

High applicability to organic liquids.

High applicability to absorbed liquids and sludges with

High applicability.

High applicability to heterogeneous wastes.

High applicability

\section{Advantages:}

Can handle a wide variety of solid, liquid and sludge waste types; can accept whole 
metal drums of waste without breaching or shredding; slag is removed continuously and does not interfere with waste oxidation: when operated at very high temperatures leads to more complete burning and better destruction of difficult to destroy compounds; reduced offgas particulate loading due to adsorption into the slag; lower excess air requirements.

\title{
Disadvantages:
}

High capital cost for installation; spherical or cylindrical objects may roll through the kiln before complete combustion; need to replace the refractory lining more often; higher temperatures increase probability of volatilizing heavy metals; not efficient for low calorific wastes; cannot be thermally cycled often (shutdown/startup cycle); feed composition must be tightly controlled; maintaining seals difficult; large volumes of air required for combustion give rise to large, costly, and difficult to operate offgas treatment systems.

\section{Development Needs:}

Better kiln seal design, slag chemistry, advanced offgas systems, stack monitoring and other real-time performance assurance capabilities; control of heavy metal emissions; combustion by-product formation; sub-micron particulate emissions.

\section{Vendor List:}

\author{
Allis Chalmers \\ Combustion Engineering Co. \\ Ford, Bacon, and Davis \\ Rollins Environmental Services \\ Von Roll, Ltd (Switzerland) \\ John Zink Co.
}

\section{DOE Laboratories Involved in Technology:}

\section{References:}

D.A. Tillman et al., "Rotary Incineration Systems for Solid Hazardous Wastes". Chemical Engineering Progress, July 1990.

P.W. Falcone and R.J. Buchanan, "Hazardous Waste Incineration by Slagging - Mode Rotary Kiln", 20th Annual Mid-Atlantic Industrial Waste Conference, Washington, D.C., June 1988.

N. Van de Voarde et al., "High Temperature Incineration of Radioactive Waste", Nuclear Science and Technology, Commission of the European Communities, 1986. 


\section{C-84}

N. Van de Voarde et al., "High Temperature Slagging Incineration -Recent Operating Experience", Spectrum '86. American Nuclear Society International Topic Meeting, Niagara Falls, NY, 1986. 


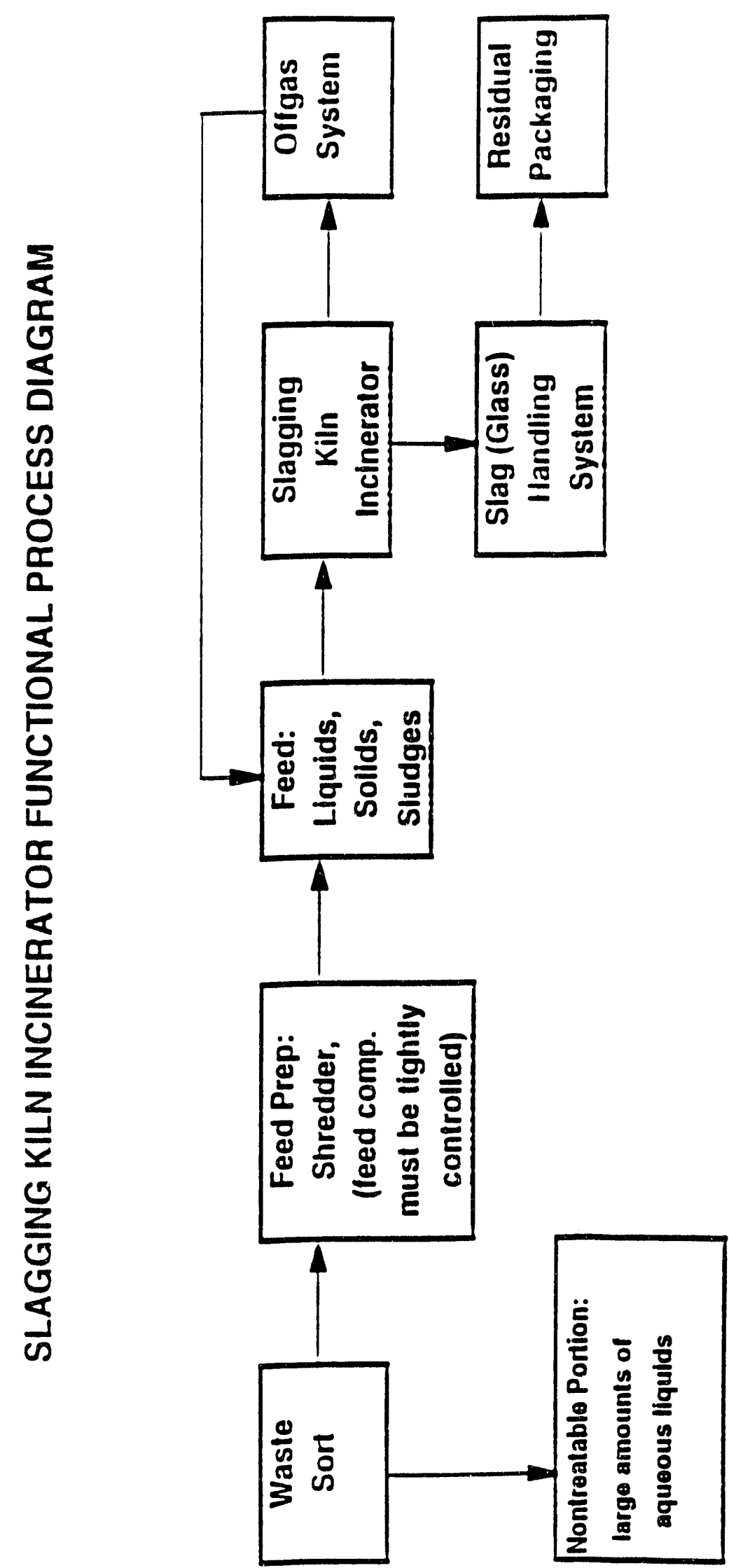


Technology Name: $\quad$ Electric Furnace Melter

Maturity: Operational - Conventional (has not been demonstrated on waste processing)

\section{Description:}

Electric furnaces have been used as smelters in the steel industry for several years. The electric furnace melter uses graphite electrodes to melt inorganic waste components into a glassy slag and pyrolyze or combust organic waste components. The electrodes may be submerged in the molten bath where the resistance to the electrical current passing between the electrodes creates the temperatures necessary to melt the material, or the electrodes may remain above the surface of the bath, creating an arc plasma zone of high temperatures. Temperatures of $1650^{\circ} \mathrm{C}$ are routinely maintained within the furnace chamber and higher temperatures are achievable. Waste can be fed to the furnace through chutes, hollow electrodes, or a series of doors which form an airlock. Depending on the type of feeding system used and the size of the waste, some size reduction may be necessary. It may also be beneficial to pretreat the waste with a fluxing agent, such as lime.

\section{Waste Applicability:}

Aqueous Liquids:

Medium applicability, although there is a concern of a steam explosion if liquids get below the melt surface.

Organic Liquids:

High applicability. The chamber temperatures are typically $550^{\circ} \mathrm{C}$ higher than conventional incinerators.

Wet Solids:

High applicability.

Dry Homogeneous

High applicability.

Solids:

Dry Heterogeneous

Solids (Small):

High applicability.

Dry Heterogeneous

High applicability.

Solids (Large):

\section{Advantages:}

This technology can handle a wide variety of waste streams, such as organics, inorganics, and bulk metals. As with all melter technologies, a leach-resistant final waste 


\section{C -87}

form is generated. In addition. the high temperatures should provide excellent destruction of organics. As with all electrically-heated systems. the offgas volume is reduced. as are the associated pollution control equipment sizes.

\section{Disadvantages:}

The high temperatures result in a high volatilization of toxic, heavy metals present in the waste stream, especially in a reducing environment. There is a heavy consumption of electrodes, especially in an oxidizing environment. If melting bulk metals. there is a possibility of steam explosions if liquids get below the surface.

\section{Development Needs:}

Testing with various types of waste feed is needed to gain experience, verify applicability, and identify potential problems. Operational and physical parameters must be optimized and methods utilized to keep the heavy metals from volatilizing from the melt.

\section{Vendors:}

Electropyrolysis Inc. Heat Engineering Corp.

Koch Process Systems

Lectromelt

Mannesmann Demag Corp.

Whiting Corporation

DOE Laboratories Involved in Technology:

Idaho National Engineering Laboratory

\section{References:}

"Metalcaster's Reference and Guide", First Edition, E. L. Kotzin, Editor, American Foundrymen's Society, Des Plaines, IL, August 1972. 
C. 88

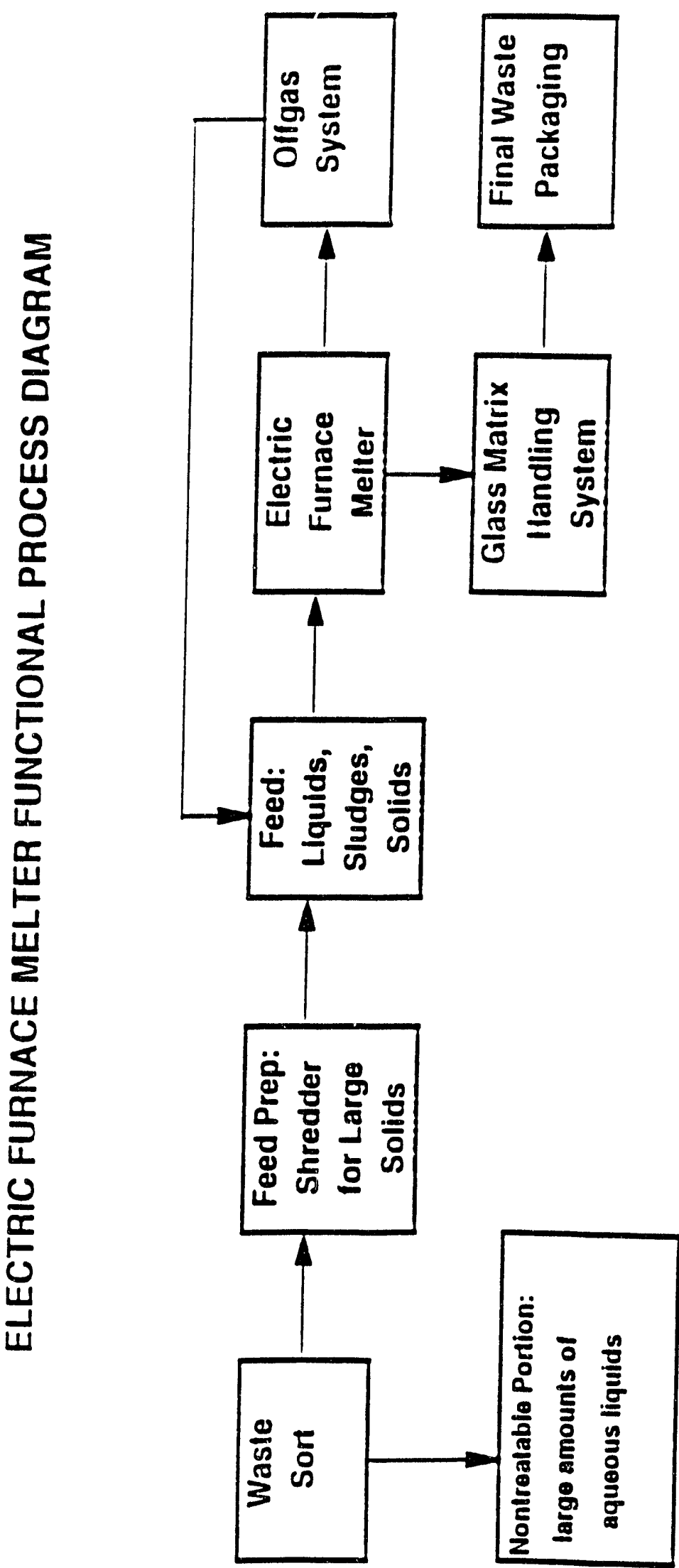


Technology Name:

Maturity:
Fuel-Fired Melter

Operational - Conventional (not demonstrated for waste processing)

\section{Description:}

The fossil fuel hearth melting technology is a thermal smelting technology consisting of a molten slag bath into which metal ore, blast funace slag, and other waste materials are introduced. The specific process variation addressed here is an adaptation of a proprietary commercial metal smelting technology, known as "Sirosmelt." The sirosmelt process utilizes a lance through which air and fuel can be injected under the surface of the slag bath. This injection of air fuel mixture creates high turbulence within the bath, providing good mixing and combustion of the waste. The system is flexible in producing an oxidizing or reducing environment, depending on the waste being processed. Operational temperatures of the molten bath of as much as $1600^{\circ} \mathrm{C}$ destroy the organics and melt the inert fractions into a vitrified slag product. Fluxing agents can be introduced into the bath through the lance while larger particle waste forms are fed through an auxiliary feed port. The resulting slag of melted inert material is removed and cast into 1 to 2 ton blocks.

\section{Waste Applicability:}

Aqueous Liquids: Medium applicability.

Organic Liquids: High applicability.

Wet Solids:

High applicability.

Dry Solids:

High applicability.

Dry Heterogenous

Solids (Small

and Large):

Low applicability to heterogeneous solids due to poor mixing with these feed materials. Lance may enhance mixing and increase applicability.

\section{Advantages:}

Lance injection of air creates excellent waste/bath mixing for maximum combustion, relatively simple operating concept with few moving parts, high temperatures resulting in high waste destruction efficiencies.

\section{Disadvantages:}

High temperatures within the system will volatilize metals and will generate $\mathrm{NO}_{\mathrm{x}}$, the 


\section{C -90}

high turbulence will cause high particulate carryover, and contamination control problems in a non-sealed fumace configuration.

\section{Development Needs:}

The primary need is to develop and demonstrate the operability of the technology as a waste treatment process. The Sirosmelt process has had very limited testing. As with other melting technologies, effects of heterogeneous waste streams on slag chemistry and process operations. as well as the fate of heavy metals and radionuclides, need further investigation.

\section{Vendor List:}

Ausmelt Pty, Ltd. (Australia)

General Glass Equipment Co.

Surface Combustion, Inc.

Toledo Engineering Co.

DOE Laboratories Involved in Technology:

None

\section{References:}

SAIC, "An Assessment of Incineration and Melting Treatment Technologies for Application to the RWMC Buried Waste", 1991. 


\section{C-91}

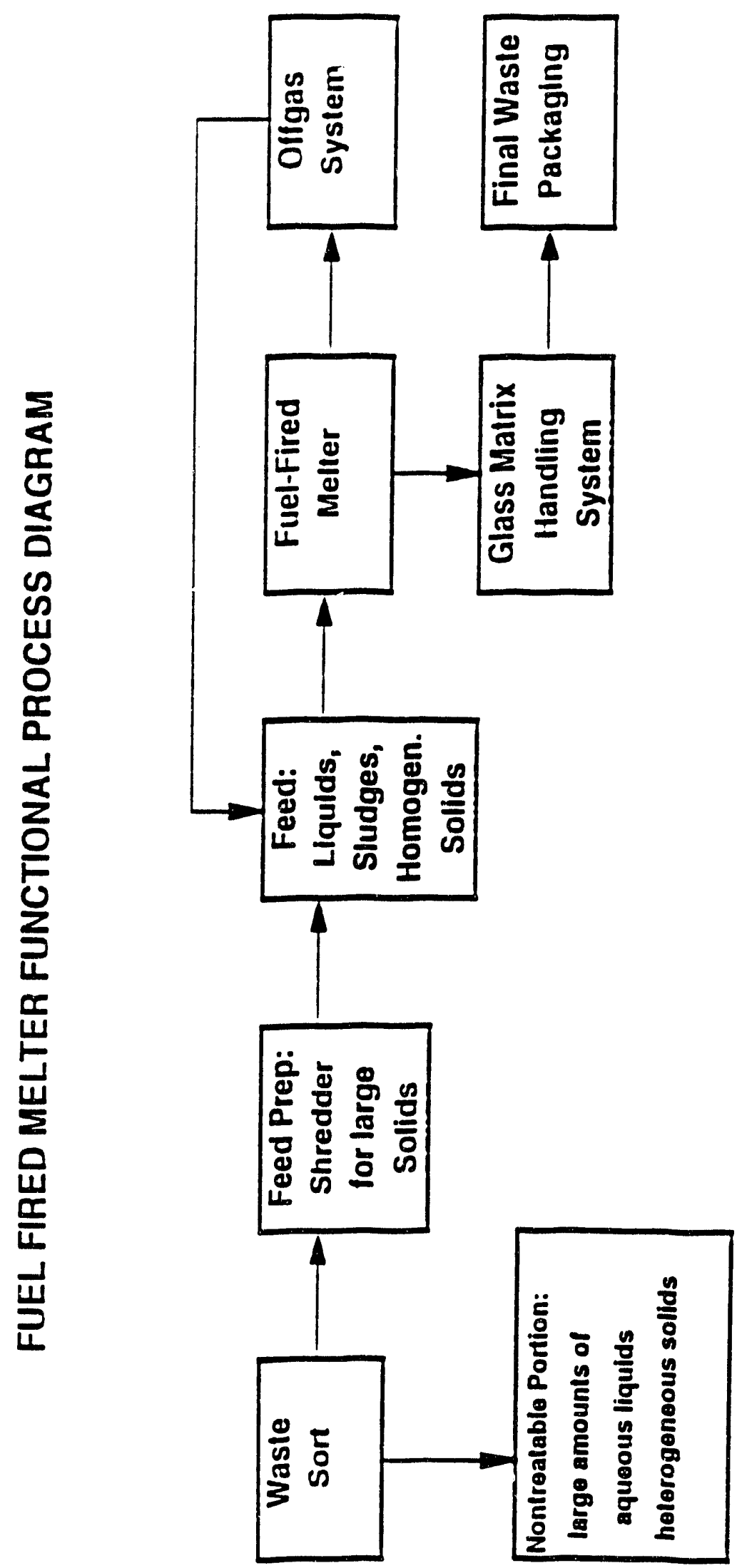


Technology Name:

Maturity:

Description:
High Temperature Joule Melter

Emerging - Pilot Scale

The high temperature joule heated melter can take many different forms. A specific design is directed toward the overall operational production objectives. This generalized technology is the foundation for nearly all high quality glass produced in the glass industry. The unit has a processing chamber which contains the molten glass and is lined by refractory. This versatile device can process a broad spectrum of wastes. Organic liquids, wet solids, dry solids, and heterogeneous solids can all be fed to this generalized process if the appropriate off gas treatment system is connected. The material is fed through a central location. If the waste contains combustible solids or organics, oxidation air is directed into the pile. After the material heats, combusts and oxidizes, it settles to the molten glass surface, where it melts and is homogenized with the balance of the material in the molten pool. In this arrangement, top entering electrodes are immersed in the molten pool and provide the joule heating. This allows renewal of the consumable electrodes which are usually either graphite or molybdenum. Operating temperatures in excess of $3000^{\circ} \mathrm{F}$ can be sustained using conventional materials. The joule heating induces natural convection around the electrodes resulting in good mixing and nearly uniform temperatures within the majority of the bulk glass. The high temperature allows metals such as iron and stainless steel to be included in the waste. Metals settle into the pool, melt and collect at the bottom. These molten materials can then be oxidized and incorporated into the bulk glass before being discharged into the waste box or a pos، :reatment system. Separation of about two to three feet between the end of the power electrodes and the molten metal avoids significant electrical shorting.

\section{Waste Applicability:}

Aqueous Liquids:

Medium applicability to aqueous liquids. Direct aqueous liquid feeding onto the pool can consolidate unit operations and may be attractive for certain waste streams.

Organic Liquids:

High applicability to organic liquids. Demonstrated destruction efficiencies in excess of $99.999 \%$ have been demonstrated at Mound laboratory and Pacific Northwest Laboratory.

Wet Solids:

High applicability to wet solids.

Dry Solids:

High applicability to dry solids because it can oxidize and melt the feed material into a molten pool within the same device. 
Dry Heterogenous

Solids (Small and Large):
High applicability. This technology can accommodate metals contained in the waste. The collection of molten metals at the bottom of the molten pool may be oxidized in place or tapped off periodically.

\section{Advantages:}

With the high temperature capability of this technology, metals that may be found in the waste feed can be melted, collected at the bottom, and oxidized. High waste loading can be realized at higher temperatures so 80 to $100 \mathrm{wt} \%$ of the waste may be incorporated into a chemically durable material before being discharged for disposal. The large inventory of molten material allows high variations in the instantaneous composition being fed. The large molten pool which may represent 4 to 5 days of feeding, can be used to average the waste composition over time and can allow large variations over significantly long periods of time without adversely impacting the quality of the discharged material. The ability to oxidize feed materials directly as indicated or process slurries, solutions, and sludges, without pretreatment allows a very broad range of material to be considered for processing. The configuration is readily adaptable to radioactive operation, because all key replaceable systems can be accessed and replaced from the top.

\section{Disadvantages:}

This device is best suited for long term, continuous operation. Therefore, rapid shut down and intermittent operation are not recommended. High temperatures within the system will volatilize heavy metals and generate high $\mathrm{NO}_{x}$.

\section{Development Needs:}

The key development need is the demonstration of the different waste streams in a unit of this style. This will allow measurement of instantaneous and specific processing rates to be defined and the identification of phase separation, if any. Tailoring of acceptable glasses may also be required for acceptance. Effects of heterogeneous waste streams on slag chemistry and process operations, as well as the fate of heavy metals and radionuclides, and $\mathrm{NO}_{x}$ production need further study.

\section{Vendor List:}

American Environmental Management Corp.

Frazier-Simplex Inc.

Penberthy Electromelt International, Inc.

Recomp, Inc.

Sorg Engineering 
Toledo Engineering Co.. Inc

DOE Laboratories Involved in Technology:

Pacific Northwest Laboratory

Mound Laboratory

\section{References:}

Armstrong, 1985, Nitrate Waste Processing by means of a Joule-Heated Glass Furnace, K. M. Armstrong, L. M. Klingler, October 18, 1985, MLM-3304, Mound Laboratories, Miamisburg, $\mathrm{OH}$.

Brouns, 1988, R. Brouns, A. A. Balasco, et. al., Bench Scale Glassification Test on Rocky Mountain Arsenal Basin F Material, AMXTH-TE-CR-88015, Pacific Northwest Laboratory, Richland, WA.

Chapman, 1991, C. C. Chapman, Evaluation of Vitrifying Municipal Incinerator Ash, Proceedings of the Fifth International Symposium on Ceramics in Nuclear and Hazardous Waste Management, American Ceramic Society, April 29 .- MaY 3, 1991.

Janke, 1990, D.S. Janke and C. C. Chapman, Characteristics of Fernalds K-65 Residue Before, During and After Vitrification, FMPC/SUB-035, Pacific Northwest Laboratory, Richland, WA.

Klinger, 1989, Joule Heated Glass Furnace Processing of a Highly Aqueous Hazardous Waste Stream, L. M. Klingler, P. L. Abellera, March 17, 1989, MLM-3577, Mound Applied Technologies, Miamisburg, $\mathrm{OH}$.

Klinger, 1988, Glass Furnace Processing of Rocky Flats Plant Wastes - an Evaluation, L.M. Klingler, P.L. Abellera, April 29, 1988, MLM-3493, Mound Laboratories, Miamisburg, $\mathrm{OH}$.

Klinger, 1985, Glass Furnace Project Final Report: An Evaluation of Operating Experience for Low-Level Nuclear Waste Processing, L. M. Klingler, K. M. Armstrong, February, 28, 1985, MLM-3229, Mound Laboratories, Miamisburg, OH.

Larson, 1983, Assessment of power reactor waste immobilization by vitrification, D. E. Larson, et. al., August, 1983, EPRI-NP-3225, Pacific Northwest Laboratories, Richland, WA.

Moore, 1989, All Electric Furnace Works Well for Gallo Glass, R. D. Moore, R. E Davis, Glass Industry, March, 1989, pp 10-15. 


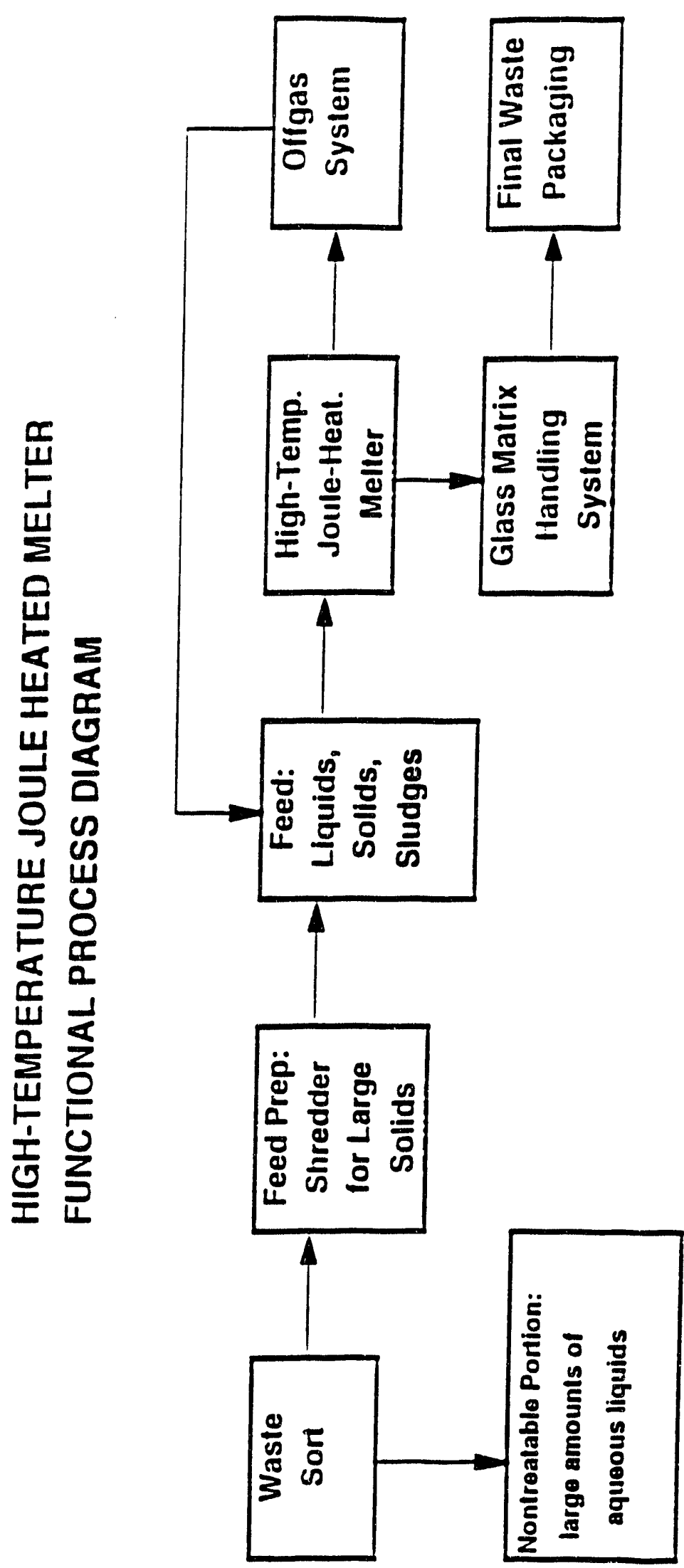


Technology Name: In-Can Resistance Melter

Maturity: Developmental

\section{Description:}

An alloy canister or can is used as both the melting crucible and the disposal container. The can is placed inside a resistance-heated furnace and heated up to $1050^{\circ}$ $1070^{\circ} \mathrm{C}$. Waste and glass frit are added simultaneously in the desired proportions by gravity feed through a drop tube. The tube can be submerged below the melt surface to increase the absorption of inorganic matter into the melt. If the waste is to be combusted as well as vitrified, oxygen is also added through the drop tube. As the waste and glass frit are added to the melter, the level in the can will rise. When the can is full, the waste and frit feed is diverted into a second in-can melter while the filled can in the first melter is cooled, removed from the furnace, and capped before transportation to a disposal facility. The critical process parameters are temperature, rate of waste/frit addition, the ratio of frit to waste, and, for waste combustion, the amount of oxygen in the system.

\section{Waste Applicability:}

Aqueous Liquids:

Organic Liquids:

Wet Solids:

Dry Homogeneous

Solids:

Dry Heterogeneous

Solids (Small):

Dry Heterogeneous

Solids (Large):
Low applicability because of heat input constraints, treatment via calcination or evaporation may be desirable for large quantities of aqueous liquid waste with the remaining residue treated by in-can melting.

Low applicability.

Medium applicability.

Medium applicability.

Low applicability. Poor mixing of melt is a concern.

Not applicable.

\section{Advantages:}

This process is fairly simple and does not require transfer of the molten material from vessel to vessel. With the exception of the volatile matter that becomes part of the offgas, all the waste material is fed to the final disposal container. Consequently, the melter is not degraded by the corrosiveness of the melt, and the furnace interior should not be 
contaminated to the degree that other melters are. These characteristics enhance the remote operability of the melter.

\section{Disadvantages:}

The in-can melter has a slower processing rate than other melters. The maximum melting rate is dependent on the can diameter, which is determined by the heat load which the alloy canister can handle. In short, the processing temperature and time are limited by the durability of the canister alloy. At operating temperature, the alloy canister can be subjected to a severe environment. A corrosive molten glass and high temperature oxidation will degrade the canister unless an expensive alloy is used. In addition, because the alloy can has a higher thermal expansion than the glass melt, the can contraction from cooling would normally be greater than the glass. As a result, after the can and glass are cooled, the hardened glass will keep the can in an expanded condition with severe mechanical stresses. There can also be some control problems with the in-can melter. The rising molten glass level must be continuously monitored, which is difficult at operating temperatures. The glass frit-to-waste ratio can also be difficult to control if the waste is added directly from the discharge of another waste treatment unit such as a calciner. This method of feed addition can also result in poor blending of the waste and the glass frit.

\section{Development Needs:}

Improvements in heat and mass transfer are needed to reduce the melt time. Longer term testing is needed to identify and solve operational problems. Application to radioactive waste must be verified and the offgas characterized.

\section{Vendor List:}

Not commercially available.

\section{DOE Laboratories Involved in Technology:}

Pacific Northwest Laboratory

\section{References:}

H. T. Blair, "In-Can Melting Process and Equipment Development from 1974 to 1978", PNL-2925 UC-70, prepared by Pacific Northwest Laboratory for the U.S. DOE under contract EY-76-C-06-1830, August 1979.

J. L. Buelt, "The Feasibility of Incinerating and Vitrifying Organic Resins in a Single Step", The Handling and Treatment of Radioactive Wastes, edited by A. G. Blasewitz, J. M. Davis, and M. R. Smith. 
C-98

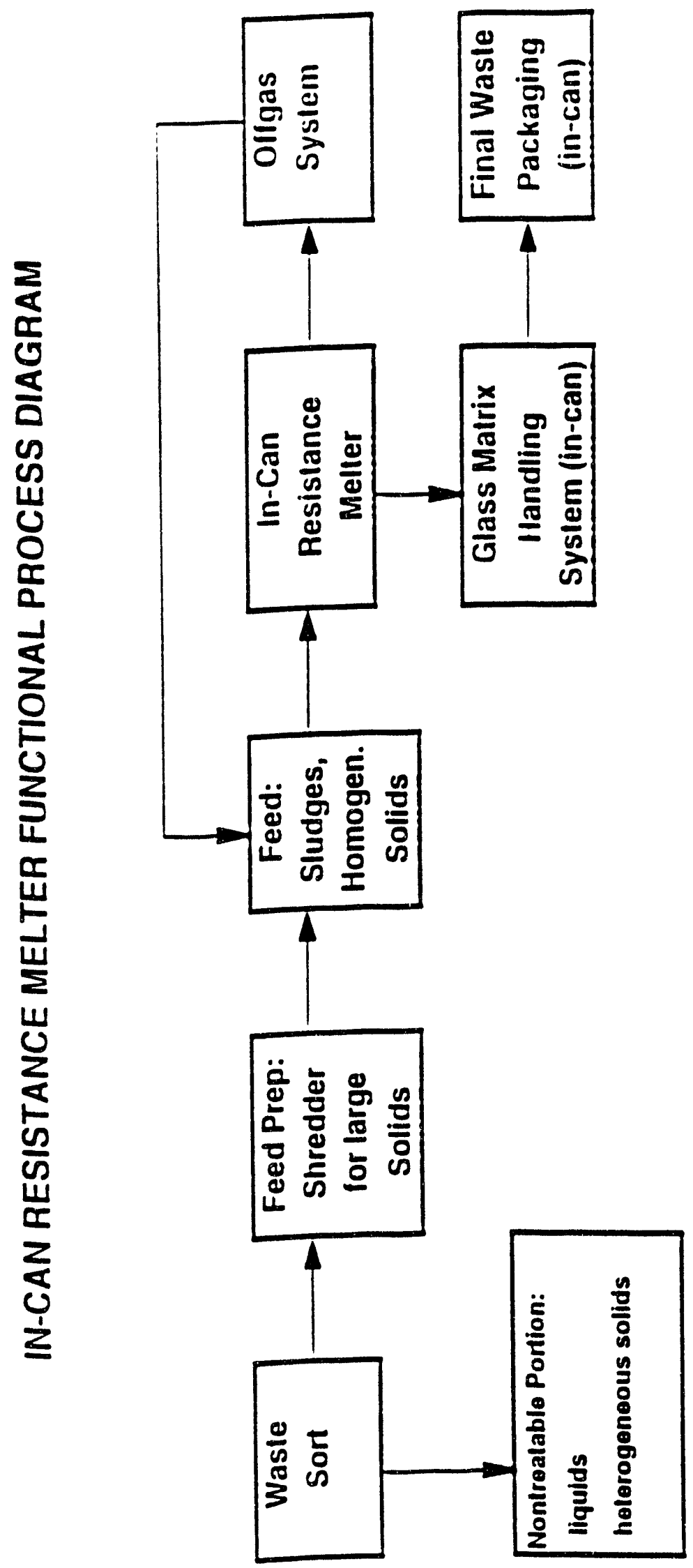


Technology Name: $\quad$ Stirred Joule Melter

Maturity: Emerging - Pilot

\section{Description:}

Stirred joule melters are joule-heated melters in which the molten material is agitated by a stirrer. Depending on the type of waste feed, different stirrers can be utilized to optimize the process. The waste can be fed in a dry form or in an aqueous slurry; however, a lower throughput results from an aqueous feed. A two-zone melter is used with the top zone highly mixed by the stirrer. The bottom zone is less turbulent so that gas bubbles can separate and rise out of the zone, resulting in a dense glass. Electric resistant heaters are used to pyrolyze organic materials and provide startup heat until electrically conductive temperatures are reached so that joule heating can be established.

\section{Waste Applicability:}

Aqueous Liquids:

Organic Liquids:

Wet Solids:

Dry Solids:

Heterogenous Solids:
Low applicability for aqueous liquids.

High applicability.

High applicability.

High applicability.

Not applicable because of potential damage to the stirrer by large solid objects.

\section{Advantages:}

Because the stirrer increases efficiency in heat distribution, stir melters have a high throughput rate for their size. Throughput rates with the stirrer operating have been eight times greater than those without the stirrer operating. The greater efficiency in heat distribution also permits operation of the stir-melter at lower temperatures, thus allowing increased flexibility in selection of materials for melter components and increased contaminant incorporation into the waste glass. The smaller size and lower operating temperatures also reduce costs by reducing heat losses.

\section{Disadvantages:}

Because this technology is basically a variation of high temperature joule melters, there are the same types of disadvantages for the stirred joule melter as for the high temperature joule melter. There is concern about damaging the stirrer if large metallic objects are added to the melter. There is also a concern with heavy metal carryover from 


\section{C- 100}

volatilization because of the high temperature. long residence time, and potentially reducing environment. As with other vitrifiers, chloride and sulfate salts in the waste are not tolerated very well.

\section{Development Needs:}

More work is needed to demonstrate this type of unit on various types of waste streams. In conjunction with this work, different types of glasses can be tested and the chemistry verified. Characterization of the offgas is needed, and when appropriate, efforts to minimize reduction of metal oxides and thereby minimize volatilization of metals would be beneficial. If organics are to be processed in this type of melter, the unit must be mated to a secondary combustion chamber.

\section{Vendor List:}

Glasstech

DOE Laboratories Involved in Technology:

Savannah River Site

\section{References:}

R. S. Richards and J. W. Lacksonen, "Stir-Melter Vitrification of Simulated Radioactive Waste, Fiberglass Scrap, and Municipal Waste Combustor Flyash", presented at the 93rd Annual Meeting of the American Chemical Society, Cincinnati, OH, April/May 1991. 
C-101

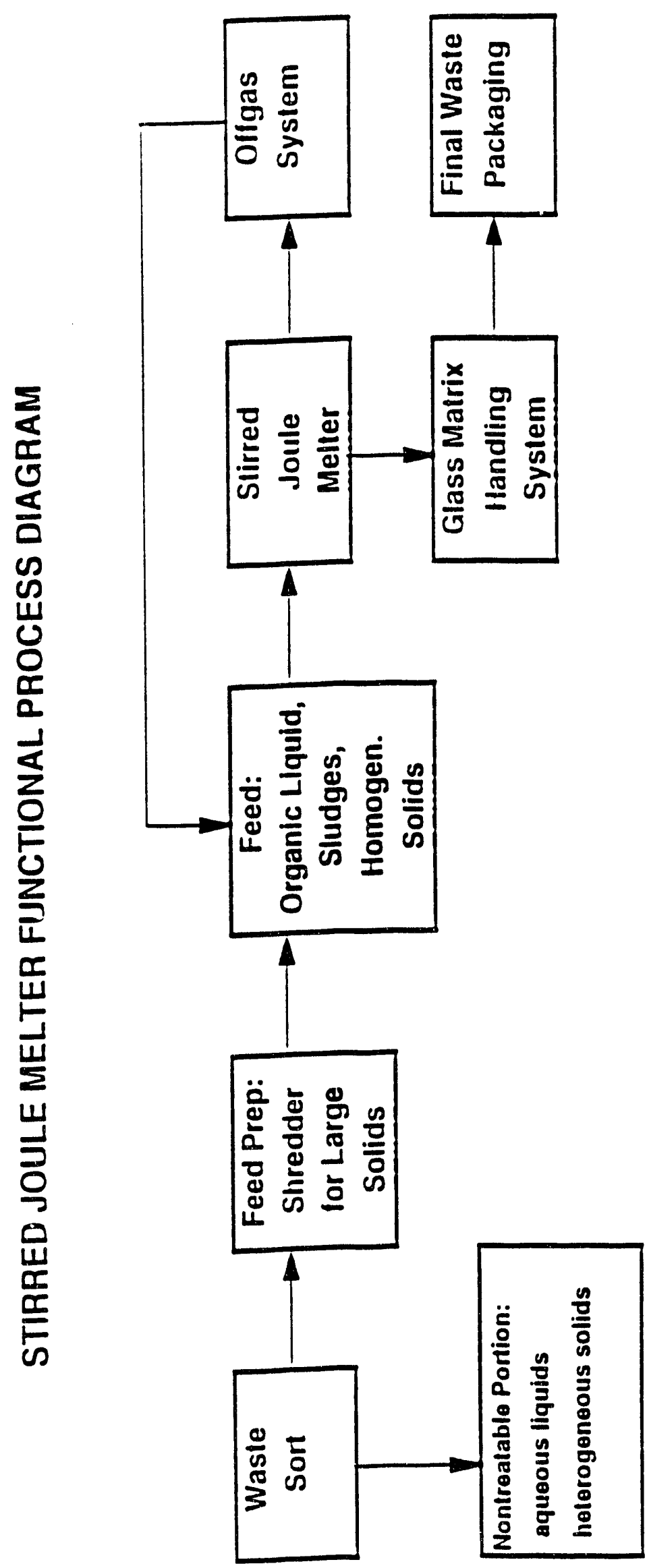




\section{C-102}

Technology Name: $\quad$ Induction Melter

Maturity: Operational-Conventional

\section{Description:}

An induction melter consists of a refractory-lined crucible with an electrical induction coil encircling the crucible for a heat source. A high frequency power supply provides the electrical input and a cooling water system is needed to cool the induction coil and the power supply. An induction melter can be used to melt metals or vitrify inorganic materials such as incinerator ash in order to volume reduce the waste and obtain a more stable final waste form. Waste material is placed in the crucible and the power supply is turned on. The material in the crucible begins to melt, forming a molten mass which flows down into the bottom of the crucible, filling the void spaces between the unmelted waste. Once the waste in the crucible is melted, additional waste material is slowly added to the crucible and allowed to melt before the next batch of material is added. When vitrifying inorganic material, an additive may be used to lower the melting point of the waste material. When melting metals, a slag coagulant is added to the top of the molten mass to aid in slag removal. Once the waste is completely melted and at the desired temperature, the melter is tilted so that the molten mass can be poured into a refractorylined mold.

\section{Waste Applicability:}

Aqueous Liquids:

Organic Liquids:

Wet Solids:

Dry Homogeneous solids:

Dry Heterogeneous Solids (Small):

Dry Heterogeneous Solids (Large):
Low applicability, with only small amounts of moisture present in the waste. If moisture is added after the melting begins, steam explosions can occur. Even trace quantities of moisture can cause splattering of the molten matter.

Low applicability. In metal melting operations, it is undesirable to enhance contact between the waste and oxygen, or more slag will be formed.

Low applicability; can only be charged before the system is heated up.

Low applicability.

Medium applicability (metals only).

Medium applicability (metals only). 


\section{Advantages:}

This technology is used commercially in the foundry industry and is well understood. It provides high density of final waste form, which results in a good volume reduction ratio. The final waste form is highly resistant to leaching. The only waste pretreatment necessary is size reduction of large components to fit in the melter.

\section{Disadvantages:}

A slag bridge can form when melting metals that can result in an insulating effect, which will lead to higher temperatures in the melt, which can damage the refractory lining. The slag bridge can also prevent the release of smoke and gases, resulting in a pressure buildup and a possible eruption of the molten material if the pressure breaks the bridge. Moisture can cause steam explosions. High frequency power supply can result in generation of a large amount of electrical "noise" throughout the electrical distribution system. The temperature of the molten mass must be carefully controlled to ensure proper transfer of material into the mold.

\section{Development Needs:}

Efforts to verify treatment of various types of wastes are needed. Incorporation of a nuclear-grade offgas treatment system and possibly a secondary combustion chamber may be needed as well. Improvements in monitoring the process, including the melt temperature, would be beneficial. Characterization of offgas is necessary, and improvements in offgas monitoring would be beneficial.

\section{Vendors:}

ABB Industrial Systems

Ajax Magnethermic Corp.

Inductotherm Corp

Industrial Furnace Systems

Leco Corporation

Omega

Pillar Industries

Radyne Corporation

\section{DOE Laboratories Involved in Technology:}

Hanford

Idaho National Engineering Laboratory 


\section{References:}

K. Katoh, S. Fujisaki. and K. Hirayama, "Solidification Tests of Radioactive Incineration Ash with Induction Heat Melting Process", presented at the Internation Conference on Incineration of Hazardous, Radioactive, and Mixed Waste, San Francisco, California, May 1988.

M. M. Larsen and J. A. Logan, "Sizing and Melting Development Aritivities Using Noncontaminated Metal and the Waste Experimental Reduction Facility", prepared by EG\&G Idaho for the U. S. DOE, EGG-2319, May 1984.

R. L. Gillins and R. Y. Maughan, "Progress Report on Metal Sizing and Melting Activities at the Waste Experimental Reduction Facility", prepared for the U.S. DOE, EGG-2434, November 1985. 
C-105

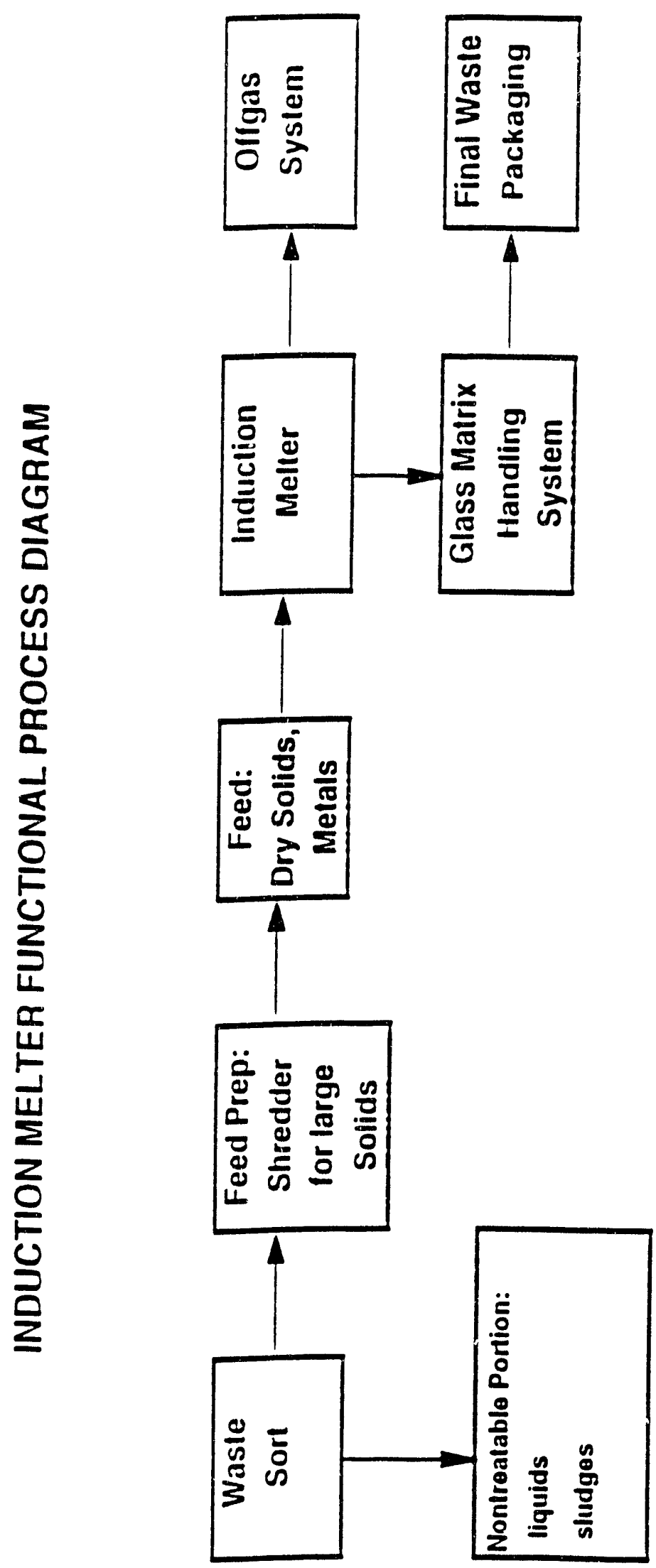




\section{APPENDIX D}

Additional Thermal Treatment Technologies

1 Information contained in Appendix D was obtained from the following document: Geimer, R., Hertzler, T., Gillins, R., Anderson, G., A ssessment of Incineration and Melting Treatment Technologies for RWMC Buried Waste, EG\&G-WDT-1035, EG\&G idaho, inc., February 1992. 
D-3

TABLE OF CONTENTS

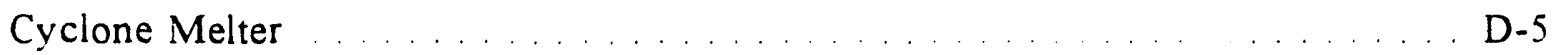

Graphite Electrode Hearth Melter . . . . . . . . . . . . . . . . . . . . . D-7

Fossil Fueled Shaft Furnace (Cupola) $\quad \ldots \ldots \ldots \ldots \ldots$

Plasma Torch Fired Shaft Furnace . . . . . . . . . . . . . . . . . D-11

Graphite Electrode Shaft Furnace . . . . . . . . . . . . . . . D-13 


\section{CYCLONE MELTER}

\section{Technology Description}

A cyclone melting system utilizes cyclonic flow patterns to create high turbulence, which produces good mixing and heat transfer, enhancing combustion of organics and promoting melting, agglomeration, and separation of inorganics. Preheated combustion air $\left(800-1100^{\circ} \mathrm{F}\right)$, fuel (natural gas, fuel oil, or powdered coal) and the waste is injected tangentially into a cyclone barrel. Temperatures within the combustion chamber can reach $3000^{\circ} \mathrm{F}$. At this operating temperature the inorganic components of the feed material are melted and transported to the outer wall of the cylinder. The slag formed is tapped from the bottom of the chamber and quenched in a water bath. The resulting residue composition and quality is dependent on the waste feed composition and the addition of any glass making constituents. The organics are oxidized either within the primary chamber or in a secondary chamber with a separate burner.

\section{Past/Current Applications}

Original development centered around the combustion of crushed coal in electrical generating facilities. Past waste applications of the cyclone furnace/melting technology have been for the incineration of sewage sludge, liquid waste destruction, and the combustion of high inorganic (ash) coal. Current applications for incineration/vitrification of municipal solid waste (MSW) ash, incinerator ash, soils with particle size reduction, asbestos, and waste insulation fiberglass are being studied and are in various stages of development.

\section{Advantages}

The Cyclone melter is capable of achieving high destruction and removal efficiencies of organics mainly due to the high turbulence/mixing of the waste with the fuel/air mixture. This turbulence and mixing also promotes rapid heat transfer, allowing for the melting of inerts in a short residence time. The resulting slag residue is a glass-like material that should prove leach resistant.

\section{Disadvantages}

Chemistry of the residual solid product is difficult to control due to up-front estimation of waste feed characteristics, prefeeding estimated quantities of chemistry control additives, and short residence time effecting waste mixing and homogeneity. Other disadvantages include: restricted waste feed particle size, little control of fate of bulk metals, high temperatures and turbulence in the system generates thermal $\mathrm{NO}_{\mathrm{x}}$, and 
high temperatures also volatizes some heavy metals (e.g., $\mathrm{Cd} . \mathrm{Pb}, \mathrm{Cr}$ ) which are transported into the off-gas system.

\section{Research Needs}

Research is needed to better define the slag characteristics resulting from the processing of various waste streams. Physical characteristics and chemical leaching characteristics are dependent on the types of waste processed and additives that may be added. Advanced testing needs to be performed on various anticipated waste compositions.

\section{Process Data}

Status: Emerging-pilot

RCRA Handling Code: T18

Thermal Capacity Range: Low-- $0.70 \mathrm{MMBtu} / \mathrm{hr}$

High-- $425 \mathrm{MMBtu} / \mathrm{hr}$

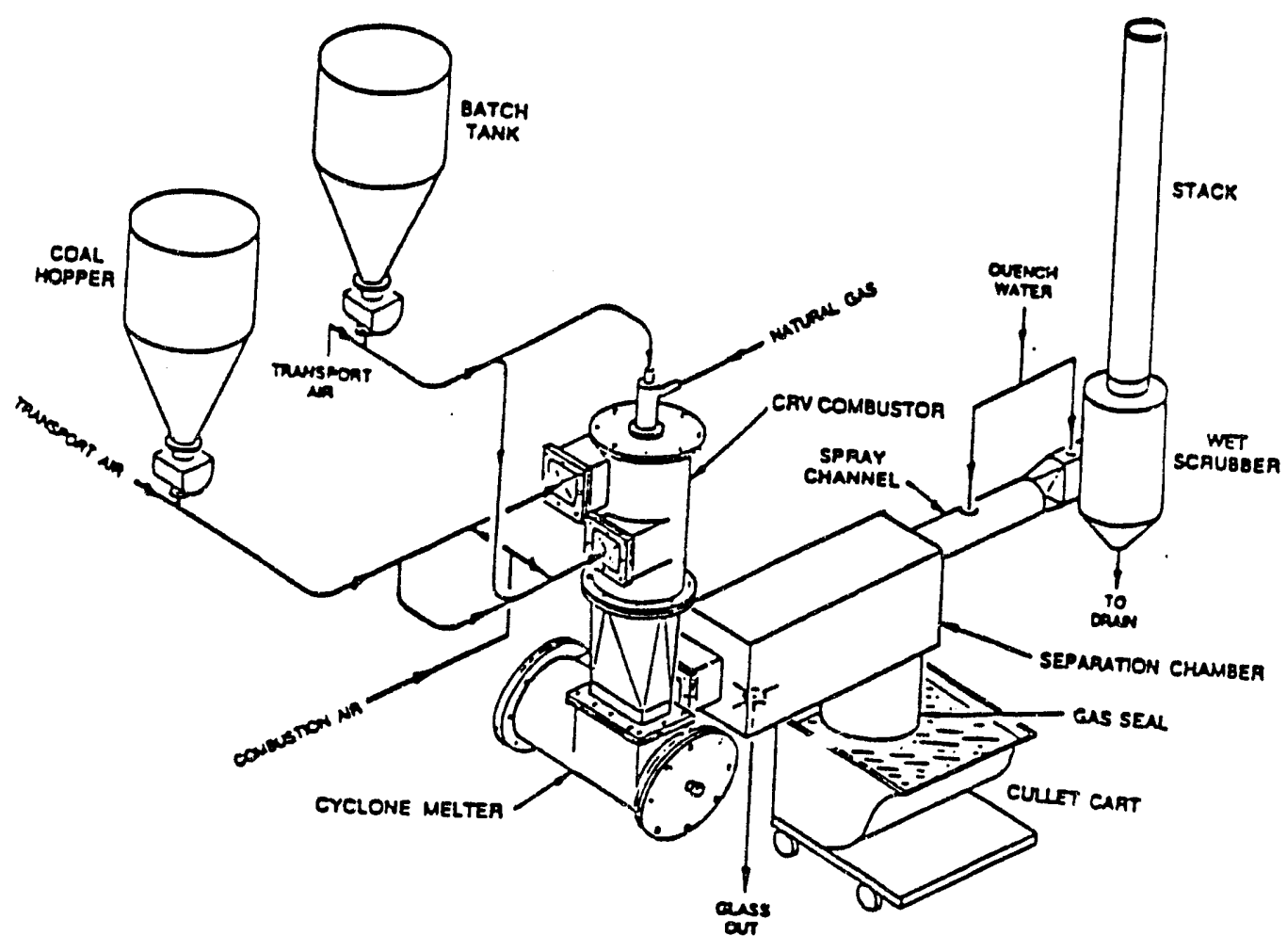

Fig. D.1. Cyclone Melter. 
D-7

\section{GRAPHITE ELECTRODE HEARTH MELTER}

\section{Technology Description}

The graphite electrode hearth melter technology encompasses a variety of electrically powered furnaces/melters. These furnaces use electrical energy transferred through graphite electrodes to melt raw materials (ore, slag waste, scrap, etc.) charged into a molten bath. The electrodes may be submerged in the molten bath where the resistance to the electrical current passing between the electrodes creates the temperatures necessary to melt the material, or they may remain above the surface of the bath creating an arc plasma zone of high temperature. Temperatures up to $30000 \mathrm{~F}$ are routinely maintained within the furnace chamber with even higher temperatures achievable. The high temperatures of the molten bath quickly destroy the organic components while melting the inert material into a glassy slag. A closed-furnace (sealed) system design would provide better offgas contamination control when dealing with radioactive and hazardous waste. Material feed for the closed furnace arrangement can be provided through feed handling chutes, hollow electrodes, or a series of air-lock doors. Material with grain sizes

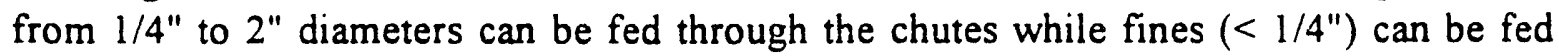
through the electrodes. Larger containers and objects can be fed through the air-lock door system.

\section{Past/Current Applications}

The electric-arc melting technology has been used in the steel industry for many years. Applications have focused on secondary smelting and metals recovery form steel making dusts and scrap iron. Current steel applications for sealed systems are for pig-iron smelting in a reducing atmosphere. New applications in the waste processing area are being demonstrated. An Arc Pyrolysis unit using a direct current electric arc furnace has been designed specifically for the treatment of solid hazardous waste. Limited data on this process is available at this time.

\section{Advantages}

Electric-arc furnaces can handle a wide variety of waste forms and sizes, depending on whether an open or closed system is used. The use of electrical energy rather than a fossil fuel for melting and combustion of the waste material significantly reduces the volumes of offgas and associated pollution control equipment requirements. Additionally the slag residue produced is a vitrified material that is likely to be a very stable waste form. 


\section{D-8}

\section{Disadvantages}

The high operating temperatures of the system volatilize heavy metals such as cadmium, lead, and chromium. Electrode consumption is high, particulariy in an oxidizing environment. The potential for accidental feed of water below the molten surface of the melt could cause a stream explosion. Additionally high turbulence causing offgas control difficulties may result from the introduction of high combustible waste streams.

\section{Research Needs}

Optimization of slag chemistry for heavy metals stabilization; evaluation of variations in slag chemistry resulting from variations in the input waste; reintroduction of condensed volatile metals into the slag phase. Additional testing and evaluation of technology performance on anticipated waste composition must be performed.

\section{Process Data}

Status: Emerging-pilot scale

RCRA Handling Code: T18

Thermal Capacity Range: Low Range-- $0.2 \mathrm{MMBtu} / \mathrm{hr}$

\section{High Range-- $164 \mathrm{MMBtu} / \mathrm{hr}$}

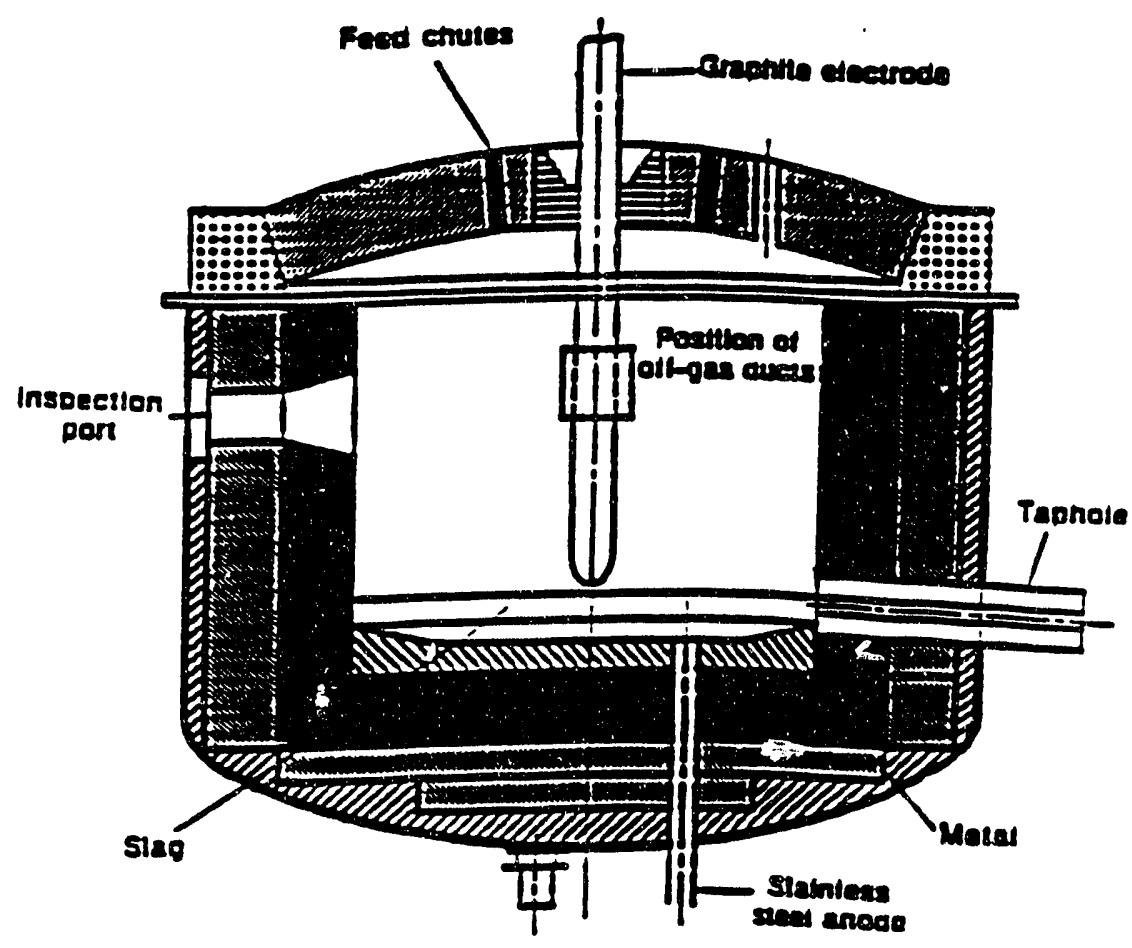

Fig. D.2. Graphite Electrode Hearth Melter 


\section{Fossil Fueled Shaft Fumace (Cupola)}

\section{Technology Description}

The traditional cupola is a vertical cylindrical water-cooled shaft furnace commercially used in the foundry industry. The process feed material, typically consisting of scrap iron and steel along with coke and limestone, is fed into the furnace from the top, and the combustion (blast) air is introduced through tuyeres at the base of the vessel. The combustion of the coke and the counter current flow of the product gases through the charge material supply the heat necessary to melt the iron. The cupola furnace is operated in a reducing atmosphere to promote the reduction of metallic oxides associated with the iron scrap charge. The primary product gases are carbon monoxide (CO) and hydrogen $\left(\mathrm{H}_{2}\right)$. Limestone is the primary fluxing agent added to slag the coke ash and other non-combustibles. Metal and slag are tapped from the bottom of the furnace and the $\mathrm{CO}$ and $\mathrm{H}_{2}$ are fed into an air enriched afterburner to complete combustion of the $\mathrm{CO}, \mathrm{H}_{2}$, and any volatilize. Conventional cupola furnaces operate with a metal to coke weight ratio of approximately $10: 1$ with $90 \%$ of the coke is consumed in heating and $10 \%$ added as carbon to the metal.

Variations of the basic cupola "cold-blast" (no waste heat recovery) furnace have been developed over the years. A hot-blast cupola furnace was developed to recover the sensible heat in the exhaust gases and increase the blast temperatures to $4000 \mathrm{C}$. Additional developments have centered around the use of auxiliary fuels such as natural gas, oil, anthracite coal and plasma arc (electrical) to minimize the quantity of coke needed as well as increase the productivity while decreasing the environmental impact of off gas products.

\section{Past/Current Applications}

The cupola (shaft) furnace is a very mature secondary smelting foundry technology. New areas of application are focusing on the waste treatment potential of these furnaces. With the addition of plasma torches and other auxiliary sources of heat energy, the cupola furnace may have potential waste processing applications.

\section{Advantages}

Shaft furnace smelting is a mature technology and considerable experience in adapting auxiliary heat sources (e.g., plasma arc) to enhance system flexibility have been tested and verified in the foundry industry. This experience will influence future development, however the technology is limited by the lack of development for waste treatment. 


\section{Disadvantages}

Conventional fossil fuel-fired cupola furnaces have significant gas velocities which prevent the charging of fine material. Fines and small particles are easily entrained and carried into the pollution control equipment. Bridging and freezing of the charge material can occur. Non-homogeneity of feed material can cause slag chemistry control problems and temperature excursions within the furnace.

\section{Process Data}

Status: Emerging technology

RCRA Handling Code: T18

Thermal Capacity Range: Low-- $4 \mathrm{MMBtu} / \mathrm{hr}$

High-- $250 \mathrm{MMBtu} / \mathrm{hr}$

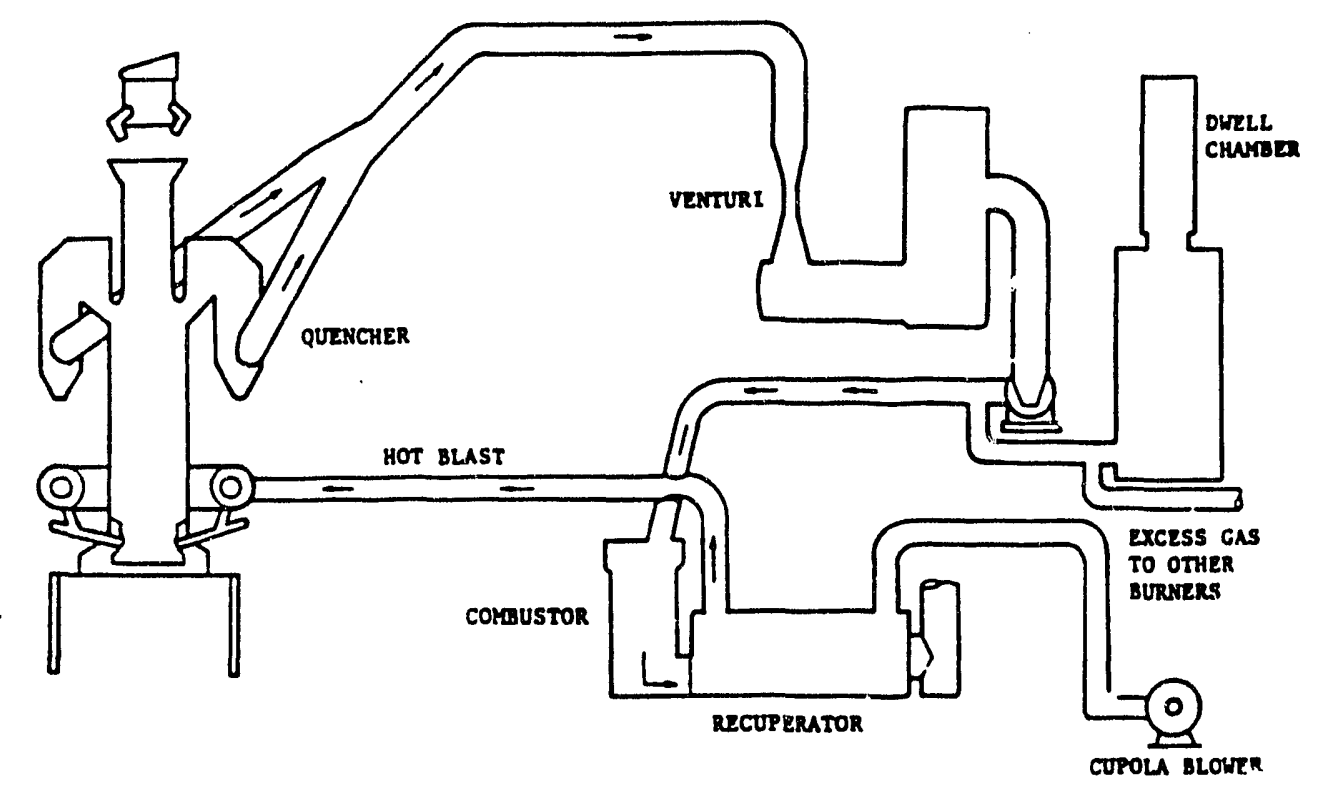

Fig. D.3. Fossil Fuel Shaft Fumace. 


\section{Plasma Torch Fired Shaft Fumace ${ }^{d}$}

\section{Technology Description}

The plasma-fired cupola operates in much the same way as the conventional fossil fuel-fired cupola except it utilizes plasma torches as an auxiliary source of thermal energy. The plasma torches are symmetrically located at the base of the vessel in the areas of the tuyeres. The plasma torches superheat the blast air up to $10000 \mathrm{C}$. This heat source decreases the amount of coke necessary in the feed, which greatly reduces the volume of offgas generation. The decrease in offgas generation reduces the gas velocities within the furnace allowing finer material to be charged and processed. Process gases (e.g., $\mathrm{CO}, \mathrm{H}_{2}$ ) from the top of the furnace are recycled through the plasma torches additionally reducing offgas volumes. The product gases not recycled are fully oxidized in an air enriched afterburner as in the conventional cupola.

\section{Past/Current Applications}

Plasma-fired cupola furnaces have been commercially applied int he foundry industry. Plants applying this technology both in the U.S. (General Motors) and abroad (Peugeot) have verified the benefits of using plasma arc fired cupolas in foundry applications. Westinghouse Electric is presently involved in extending the application of this technology to hazardous waste treatment. Limited information is currently available on the testing of this pilot scale system.

\section{Advantages}

The plasma-fired cupola has a number of advantages over the conventional coke fired cupola. The reduction of coke use reduces cost, decrease offgas generation and particulate emission by reducing superficial velocities within the furnace. The auxiliary heat source provided by the plasma allows flexibility in waste input characteristics and melt temperatures can be controlled rapidly reducing bridging problems.

\section{Disadvantages}

As with conventional cupola furnaces the "bridging" of the charge material can occur. Residual solid product chemical and physical characteristics is very difficult. Slag shemistry is only controllable based on initial feed characteristics, waste density and waste mixtures. Estimation of feed parameters, fluxing additives, and non-homogeneity of waste will cause final waste form variations. Additionally channeling of offgas through the charge material causes variation in bed temperatures and other operational parameters. 


\section{D-12}

\section{Research Needs}

Continued testing and development for waste treatment applications is necessary. Characteristics and mixes of charge material variations and resulting slag chemistry needs further study.

\section{Process Data}

Status: Emerging-bench scale

RCRA Handling Code: T18

Thermal Capacity Range: Low-- $4 \mathrm{MMBtu} / \mathrm{hr}$

High-- $41 \mathrm{MMBtw} / \mathrm{hr}$

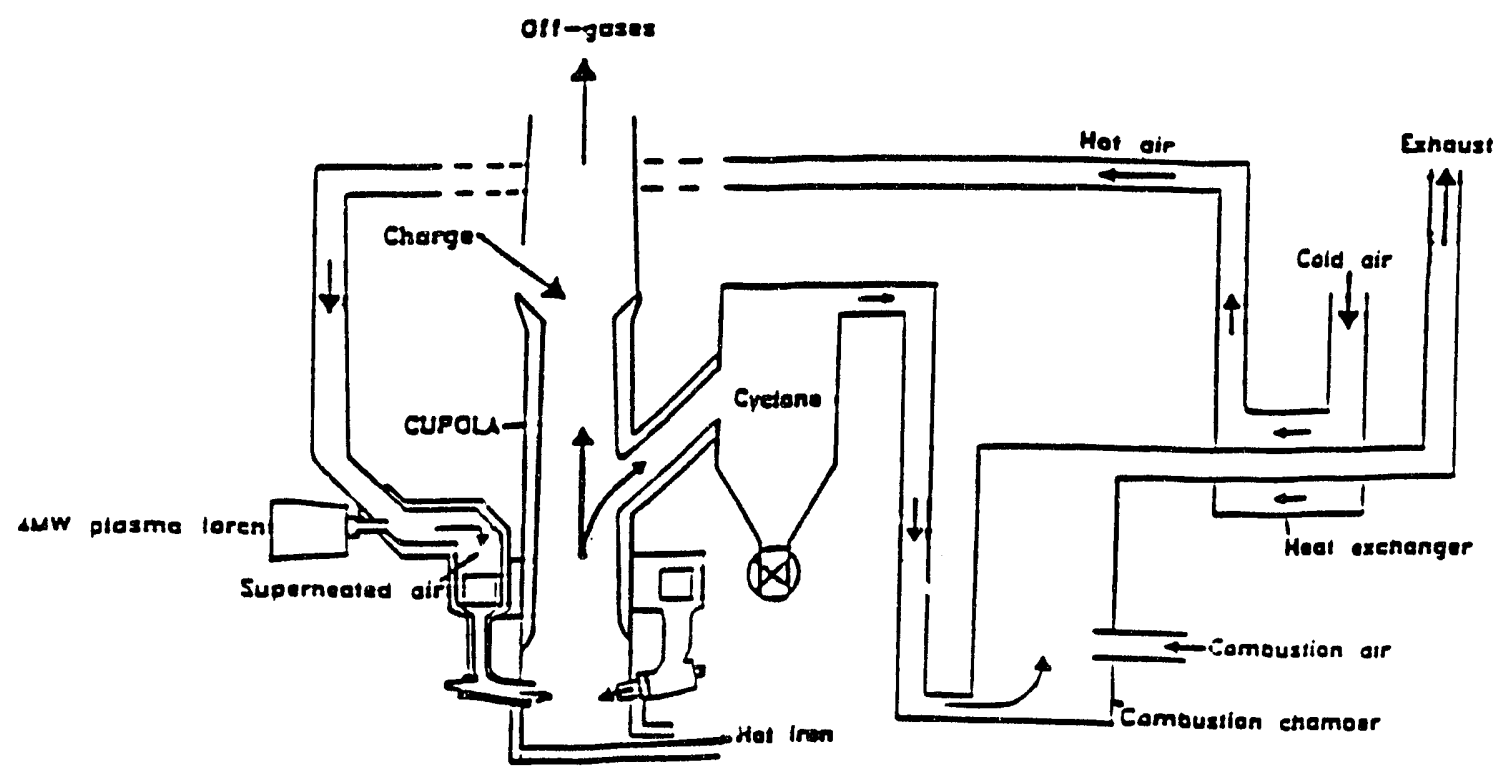

Fig. D.4. Plasma Torch-Fired Shaft Fumace. 


\section{D-13}

\section{Graphite Electrode Shaft Fumace}

\section{Technology Description}

The graphite electrode shaft furnace technology focuses around the use of electrical energy rather than fossil fuels, transmitted through an electric arc to pyrolyze hydrocarbons into partially oxidized gaseous components $\left(\mathrm{CO}, \mathrm{H}_{2}\right.$, tars. gums. etc) which are subsequently fully oxidized in an air rich afterburner. The pyrolyzing concept of incineration utilizes a starved air environment in the primary chamber to obtain the partially oxidized effluent.

A variation to the typical pyrolysis is known as the Skygas process. The skygas process depends on an electric arc initiating the dissociation and activation of water within the reactor and the feed to create gaseous radicals of $\mathrm{H}_{2}$ and $\mathrm{OH}$. The gaseous radicals pass up through the waste initiating a chain reaction and propagation of additional free radicals and non-radicals. The large hydrocarbon molecules are thus broken down into partially oxidized gaseous components. Predominate gas products form the skygas process are the same as the basic process and consist primarily of $\mathrm{CO}$, and $\mathrm{H}_{2}$.

The gases exiting the primary chamber are again subjected to an electric arc and passed through a coke bed for additional refining and breakdown of tars and gums.

\section{Past/Current Applications}

Controlled air pyrolysis using fossil fuels as the heat source have been used as a waste treatment process for many years. The use of a controlled air electric arc processing a waste treatment application is new. Limited data is currently available on the application of this technology to waste treatment.

\section{Advantages}

The use of an electric arc rather than fossil fuels to pyrolyze and/or initiate radical chain reaction chemistry will reduce the offgas volume generation which will reduce pollution control handing requirements. Multiple sets of reactor units in the skygas process would further reduce carbon dioxide and tars/gums resulting in a higher quality of gas product for reuse.

\section{Disadvantages}

As with other shaft furnace technologies bridging of the charged material within the shaft is a problem, especially if high percentages of low melting materials (e.g., glass) exist within the feed material. The resulting residue from the primary reactor of the Skygas process is a non-vitrified ash. Limited feed handling capabilities were noted in testing of chopped tire feed and high moisture content sludgc. 


\section{Research Needs}

Limited data exists on the application of this technology on waste streams of mixed composition. Additional testing and documentation of process data, operational parameters and waste acceptability needs to be performed. Final waste form (ash) stabilization not well addressed in the Skygas process.

\section{Process Data}

Status: Emerging technology

RCRA Handling Code: T18

Thermal Capacity Range: Low-- 4 MMBtu/hr

High-- $41 \mathrm{MMBt} / \mathrm{hr}$

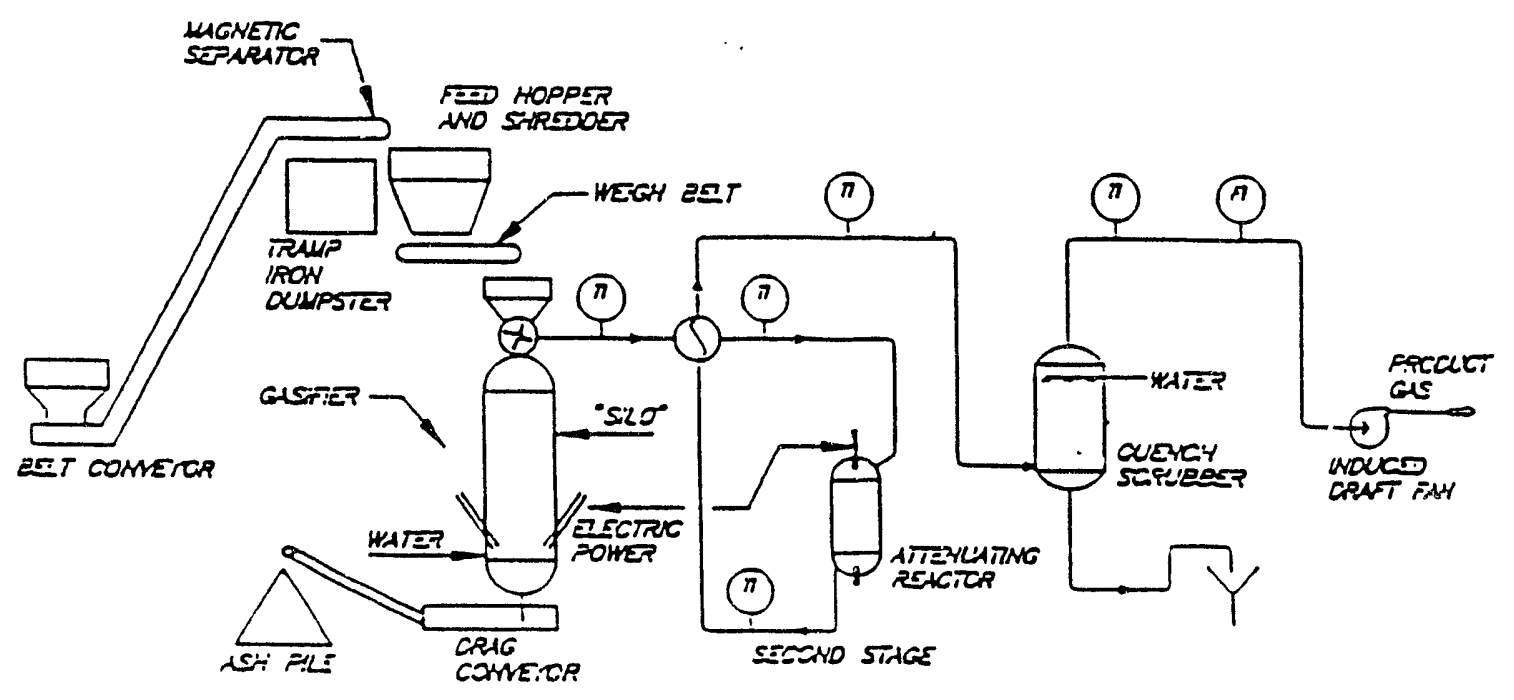

Fig. D.5. Graphite Electrode Shaft Fumace. 


\title{
APPENDIX E
}

\author{
Additional Furnace Technologies!
}

1 Information contained in Appendix $\mathrm{E}$ was obtained from the following document: Batdorf, J., Gillins, R., Anderson, G., A ssessment of Selected Fumace Technologies for $R W M C W$ aste, EGG-WTD-10036, EG\&G Idaho, Inc., March 1992. 


\subsection{MOLTEN METAL BATH TECHNOLOGX}

The term molten metal bath refers to a treatment approach that utilizes a pool of molten metal as the medium to transfer heat to waste materials to break down the organics and vitrify the inorganics into a slag material. The slag is drawn off the top of the melt and the bath is maintained at a relatively constant level by tapping off or adding metal, as required. Steel is typically used as the bath material, but any of a variety of metals could be used to tailor the process to meet specific treatment requirements.

\subsection{DEVELOPMENT HISTORY}

Development of the technology is relatively recent. U.S. Steel (U.S.S.) developed a molten metal bath technology between 1982 and 1986 termed the catalytic extraction process (CEP)(Reference 1). A technology innovation group at U.S.S. developed the process looking for ways to use the stored energy in the molten steel and slag in the steel plant's processing units. The group concluded that they could use the molten metal as a solvent and run high temperature chemical reactions on waste materials and byproducts. U.S.S. received broad patent coverage for the technique. However, U.S.S. opted not to pursue it, and transferred the rights in 1989 to a new development company, Molten Metal Technology (MMT) of Cambridge, Massachusetts, via the Massachusetts Institute of Technology (MIT) (Reference 1).

MMT subsequently formed alliances with a variety of commercial companies to help market the technology. The technical entities that have agreements in place with MMT include L'Air Liquide of France, DuPont, and Rollins Environmental Services of the United States. The CEP is illustrated in Figure E.1.

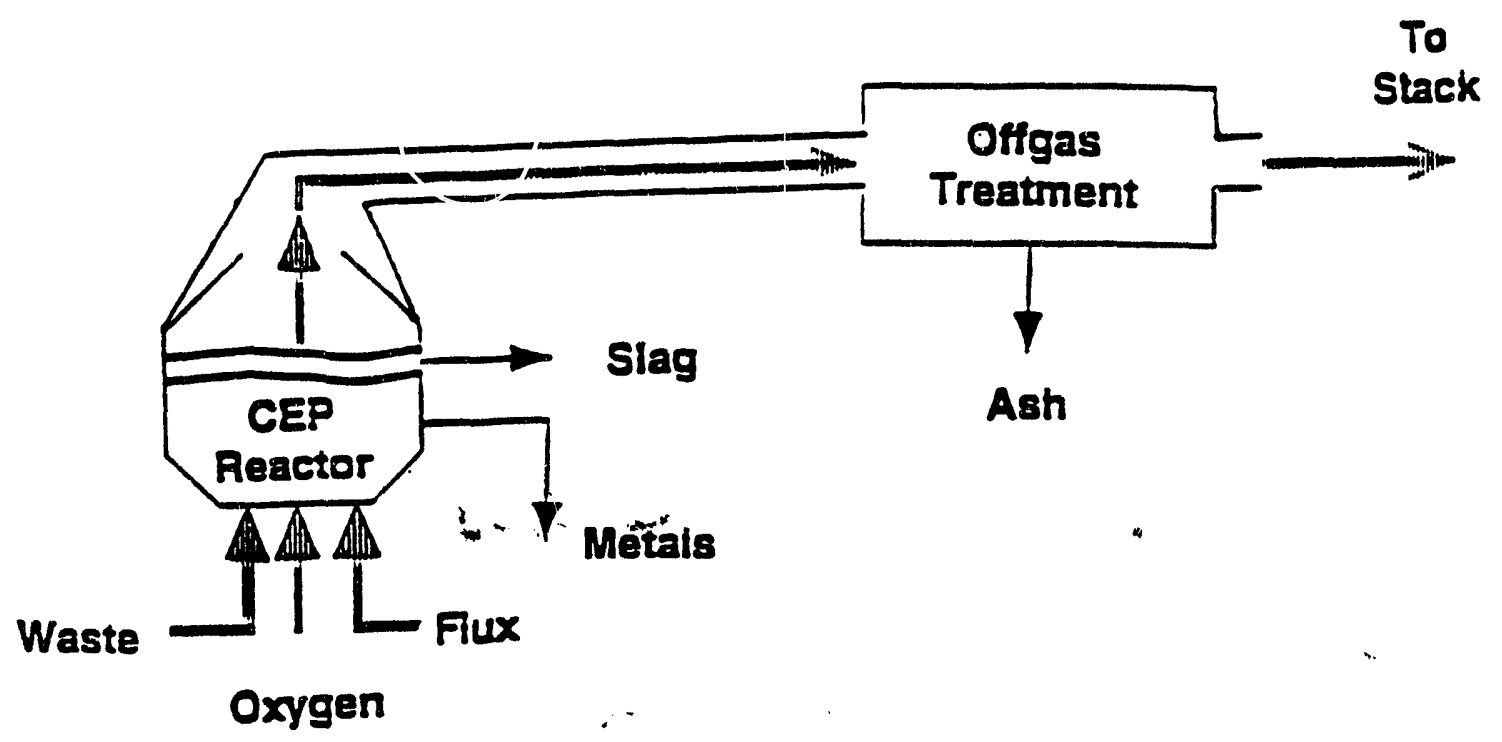

Fig. E.1. Simpiified Flow Diagram for Catalytic Extraction Procesš. 
A separate molten metal bath project was initiated in 1986 as a joint

German/Swedish KFA-KTH) investigation (Reference 2 and 3 ). The project

examined various metal industry processes for use in the destruction of hazardous wastes. This investigation leaned toward adapting the iron bath coal gasification process. rather than the scrap metal conversion process that MMT is pursuing, though the processes are very similar. This project was reported as a paper study and is currently in the pilot demonstration stage.

Applicable waste treatment data on this process are extremely limited. MMT is treating the details of its process as proprietary, making assessment of the technology highly speculative. However, some general conclusions can be drawn.

\subsection{PROCESS DESCRIPTION}

\subsubsection{Cument Waste Applications}

The application for which the technology was originally intended was introduction of chemical energy into a scrap steel converter to increase the capacity for scrap steel processing. This was accomplished by adding carbon from various waste forms, such as waste oil and tires, to reduce the iron oxide and produce iron and carbon monoxide. MMT has subsequently applied the process to a wide variety of chemical byproducts and industrial waste materials. The technology primarily aimed at the resource recovery market, where valuable materials can be recovered from a waste or byproduct stream within an existing commercial process, thereby avoiding RCRA regulations (Reference 4). Examples include the recovery of valuable metals such as nickel from a nickel contaminated organic stream, recovery of cobalt from spent catalysts, or generation of synthesis gas from hydrocarbon bearing wastes. Some work has also been done on waste processing to demonstrate destruction of organics such as PCBs.

The preferred means of feeding is by injecting liquid, gas, or fluidized solid waste into the bottom of the metal bath along with reagent gases and fluxes. However, the vendor reports that large solids such as whole PCB transformers were fed over the bath from a conveyer system.

\subsubsection{Theory of Operation}

Catalytic extraction processing utilizes standard "off the shelf" equipment from the steel processing industry. The process vessel is a steel converter,which is an enclosed, airtight cylinder with dimensions that can vary widely to yield the combination of surface area and retention time required for specific wiste characteristics.

To initiate the process, the metal catalyst, which is typically steel, is melted in the reactor by one of three standard methods; induction heating, electric arc, or plasma arc. Of the three methods, plasma arc is least used. Temperatures in the $2500-3500^{\circ} \mathrm{F}$ range are used, with $3000^{\circ} \mathrm{F}$ most typical. A reducing atmosphere is maintained in the reactor

Waste material in the form of gas, liquid, sludge, or solid is introduced into the molten metal bath beneath the surface, generally utilizing a pneumatic transport

$$
\text { Page } 5-2
$$


approach for the solids. Because of rapid heat transfer from the molten steel to the waste, the waste material dissociates into its elemental constituents. The dissociated atoms become evenly distributed throughout the bath by the natural convection currents present. Oxygen is injected into the bath to strip the carbon absorbed by the steel. This reaction forms carbon monoxide.

The molten inorganic material (slag) introduced by the waste nises to the top of the bath and is eventually skimmed or tapped off. The slag acts as an insulator to increase the bath's thermal efficiency and as a primary scrubber to remove such materials as volatile heavy metals, phosphates, and sulphur. Other reactants may be added to the bath to optimize slag chemistry. Typically, the slag is cast into shapes for ease of handling, though it can be quenched and collected in a water bath where the thermal shock creates a relatively small aggregate waste form. The metal components are heavier than the slag, collect in the metal bath and are tapped separately from the slag. If the metals are mixed, subsequent processing would be necessary for separation and recovery of the metals of interest (Reference 1).

The CEP design does not provide for secondary combustion of organics because MMT believes complete organic destruction will occur in the bath and in the high temperature reactor space above it. The KFA-KTH pilot plant will have either oxygen injection in the reactor above the bath or a separate secondary combustion chamber (Reference 2). The CEP unit could be provided with a secondary chamber as well.

\subsubsection{Material and Energy Balances}

Figure E.2. is a graphical representation of the mass flow for a molten bath furnace treating $1000 \mathrm{lb} / \mathrm{hr}$ of an inert waste. In this case, the waste contains no combustible material, however, some offgas is generated from the vaporization of moisture in the feed. The only gases entering the furnace are from air leaks and purges on the feed system. Electrical energy is supplied through submerged electrodes or induction heating. This process results in a minimum offgas volume. During processing of an actual waste, the offgas flow is likely to be higher because of small amounts of organic materials in the feed. Also, decomposition of inorganic materials such as nitrates and carbonates will release gases.

Figure E.3. is a graphical representation of the energy flow for the molten metal bath process shown in Figure E.2. Approximately $77 \%$ of the electrical energy input is used to melt the solid inert material. The remaining energy is lost as heat through the furnace walls and as hot offgas.

Treatment of a waste with even a small organic content will dramatically alter the material and energy balances. Waste with only $8 \%$ carbon, resulting in a heating value of $1120 \mathrm{Btw} / \mathrm{lb}$, would release energy equivalent to the electrical input shown in Figure E.3. Complete combustion of this waste would result in 10 times the offgas volume. Thus, although this is a low volume offgas process, the offgas flow rate can easily be dominated by a small amount of combustible material in the feed. 


\subsection{TECHNOLOGY ANALYSIS}

\subsubsection{Advantages}

The CEP operates at high temperatures and with sufficient residence time within the bath to achieve highly erficient destruction of organics. The high energy density of the molten metal allows shorter residence times for complete destruction. The high temperature operation results in vitrification of inorganic solids and produces a slag that is likely to be a highly stable and leach resistant waste form. Operation of the technology in a reducing mode minimizes the high $\mathrm{NO}_{x}$ that would otherwise be generated by the high temperatures. The technology has a long history of the building and operation of large scrap steel converts. The use of oxygen injection instead of air results in low volumes of offgas emissions and the introduction of waste below the surface of the bath results in high particulate retention and thus low offgas carryover. The large thermal mass of the metal bath results in a more stable and uniform temperature environment than open flames and a greater likelihood of complete organic destruction. Nonflame combustion ensures that the offgas is free of contamination from products of incomplete fuel combustion.

CEP reactor vessels are simple and compact. As in most vitrification devices, the fly ash may be returned to the reactor for reprocessing. Radiologically contaminated metal could be used for the bath, providing a method of decontamination, since radionuclides tend to migrate to the slag and volume reduction by eliminating void spaces.

\subsubsection{Disadvantages}

The high operating temperatures of the CEP will result in relatively high volatilization of heavy metals and radionuclides into the offgas stream, requiring special attention for the removal of these constituents in the offgas treatment system.

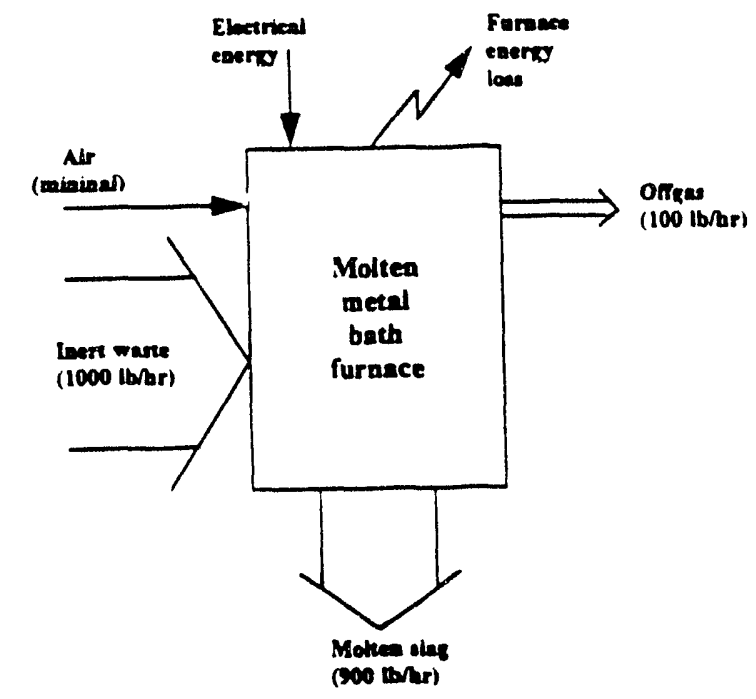

F1 r. E.2. Graphical Representation of Mass Flows for a Simplified Molten Metal Bath Process with Inert Feed (HHV $=0.0$ Btw/lb). 


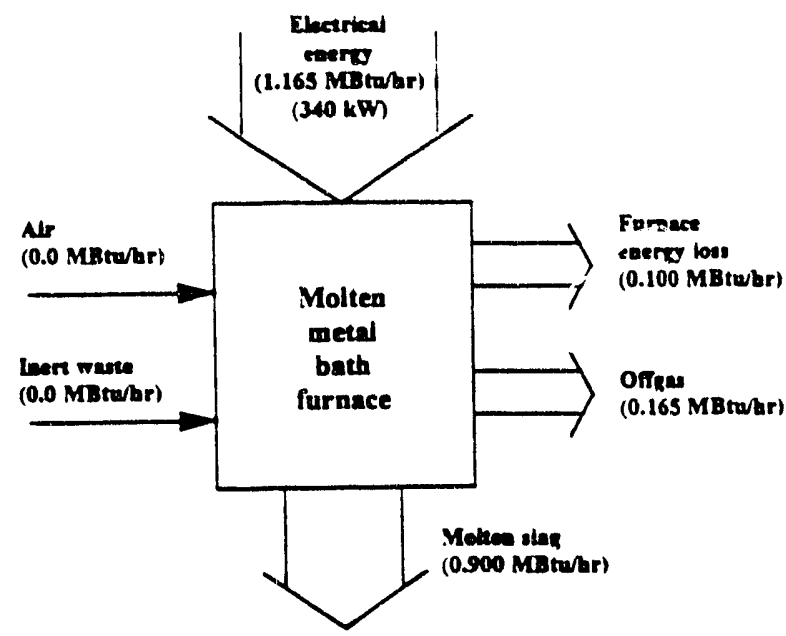

Fig. E.3. Graphical Representation of Energy Flows for a Simplified Molten Metal Bath Process with Inert Feed (HHV =0.0 Btw/lb).

Solid waste must be size reduced extensively for subsurface injection, or else dropped into the bath from above, which may reduce the effectiveness of the process to completely treat the waste (i.e. the waste may volatilize and be carried directly into the offgas without complete destruction). Introduction of significant quantities of noncombustible liquids or wet solids directly into the metal bat'h has the potenitial of causing a steam explosion. Slag chemistry is dependent on waste characteristics and may be difficult to optimize with a heterogeneous waste feed. If the metal in the bath is not radioactively contaminated to start with, it will be considered contaminated after exposure to mixed waste.

\subsubsection{State of Development}

The development work performed at U.S.S. between 1982 and 1986 verified the principles of operation and could be considered bench scale development, though feed rates of up to 22,000 tons/year were demonstrated on a variety of carbon-containing streams. The German/Swedish effort is in the pilot demonstration stage, but no data are available on demonstration results.

MMT claims their technology is commercially available and has developed designs for facilities ranging in capaci.y from 5,000 to 100,000 tons/year. However, no commercial units have been constructed to date. Realistically, the technology will require actual waste processing at pilot scale before it can be considered commercially available. 


\subsubsection{Research, Development, or Demnnstration Needs}

Primary research needs to demonstrate the technology's effectiveness in hazardous waste destruction. Other needs include the following: investigation of partitioning of radionuclides and heavy metals in the metal bath and slag; determination of slag chemistry sensitivity to variations in waste content: and, leachability characteristics of the slag. The technology has not been demonstrated for soil applications.

\subsection{POTENTIAL FOR INEL APPLICATIONS}

The potential application of this technology to the MNEL buried wastes is difficult to assess given the state of development. If the technology proves to be effective at processing large solid wastes without extensive pretreatment by introduction into the metal bath from above the surface, then it is likely that most buried wastes could be processed. However, the technology has been demonstrated to be most effective when the waste is gaseous, liquid, or fluidized solid fines and is injected under the bath. Extensive pretreatment of most buried wastes would be required to yield solid fines capable of fluidization in order to pneumatically transport the solids for introduction into the molten metal bath beneath the surfaces.

\subsection{REFERENCES}

1. Smith, Jeffrey D., "Molten Metal Technology", EI Digest, pp. 8-13, July 1991.

2. Axelsson, Carl-Lennart, "KFA-KTH Joint Investigation on a Process for Hazardous Waste Destruction in an Iron Melt", Stockholm, Sweden, May 1988.

3. Zimmer, Erich, "Treatment of Hazardous Wastes in an Iron Melt", KFA Julich GMbH, Julich, Germany, September 1988.

4. Yates, Ian C. and Johnston, James E., "Resource Recovery With Catalytic Extraction Processing", Environmental Waste Management, pp. 30-31, May 1991. 


\begin{abstract}
APPENDIX F
Mixed Waste Integrated Program Technology Needs Statement and Call for Proposals FY94'
\end{abstract}

1 Information contained in Appendix F was obtained from the following document: Mixed Waste Integrated Program Technology Needs Statement and Call for Proposals, Mixed Waste Integrated Program, FY-94. 


\section{WASTE DESTRUCTION/STABILIZATION}

\section{BACKGROUND INFORMATION}

The Waste Destruction/Stabilization TSG is identifying and evaluating innovative technologies that fill key waste treatment needs i $r$ offer significant improvements over baseline technologies for waste destruction, recovery, or stabilization. The TSG provides guidance to the MWIP and industry so that technology development can be effectively focused on DOE identified needs. Specifications and criteria used to identify technology needs and evaluate proposed technologies for meeting those needs are listed in the last section of this report. New and/or developing technologies will be compared with existing technology by using accepted standards.

With the assistance of members, consultants, and experts in the field, the TSG is compiling a list of current and emerging technologies for addressing applicable waste streams. Current technologies will comprise those that are presently industrial use and will serve as baseline methods. Emerging technologies will comprise those that are still under development, but have shown promise for addressing needs and concerns.

A baseline technology inventory for mixed waste destruction, reduction, or stabilization will be generated for input from the MWTP waste treatment plant flow sheets. Additional baseline technologies extracted from DOE, EPA, commercial, and foreign experience on similar waste will be evaluated to ascertain the current best state-of-the-art technology. Technology needs are then evaluated based on either a technology hole in the flow sheets or a baseline technology for wh:ch significant concerns about performance, economics, or permitting are a major concern.

Technology development activities that may pertain to mixed waste from all available sources will be evaluated and those that meet the needs criteria will be recommended for support. Proposals for additional new and innovative technologies that may offer significant improvements over the baseline will be solicited.

The use of thermal treatment technologies for waste destruction and stabilization is being investigated. Innovated technologies, loosely defined as those technologies that are not currently being used on a large scale to treat wastes and/or significant extensions of current technology beyond its demonstrated capabilities must be developed, and issues regarding full-scale operation must be resolved. Development of the following processes is currently in progress: metal-melting technologies, and plasma-arc incineration. Metal-melting technologies are basically adapted from the metals industry (e.g., induction furnaces and plasma-arc melters). Although the operating principles for these processes are not new, there is only limited operational experience in the waste management area. In addition, new concepts in melting processes should be researched as waste management tools (e.g., the microwave melter).

Melter technologies hold the promise of being highly effective for waste treatment because the residue may require little or no additional treatment prior to disposal. The treated waste form may be physically and chemically stable enough to pass regulatory 
standards. Because of the high temperature of melting operations. melters can be used to remove or destroy regulated organics. Process modifications will be required to ensure the destruction of organic material during the metal-melting process. Consistency and reproducibility of treated waste treatment processes is required for regulatory approval.

Melters are ideally suited for inorganic waste streams such as inorganic oxides and elemental metals. Furthermore, the chemistry in the melt can be reducirig or oxidizing depending on the type of waste form desired. When processing oxides, the final waste form will be a glass or a ceramic, primarily depending on the rate of cooling. When processing metals, the melt will form a top layer of siag and a bottom layer of molten metal. The slag can then be separated from the molten metal, allowing for the recycle of the molten metal. Depending on operating parameters, it is possible to oxidize the majority of the radionuclides in the waste so the radionuclides become part of the slag, resulting in a decontaminated molten metal.

The baseline technologies for organic destruction and volume reduction for all the waste streams except aqueous waste and metals are various forms of incineration. Alternative processes need to be evaluated and developed as a potentially more effective method of treatment, a more economical method, particularly for small volume waste streams, and, because of the permitting concerns for incineration, as a potential fall-back process. Currently the state of the art for alternatives to incineration is being evaluated to expand DOE options on waste treatment. A preliminary list of technology development options is included in section entitied "Alternatives to Incineration."

Research and development are needed in the waste destruction area. A primary need in the area of waste destruction and stabilization is to develop thermal treatment technologies that are capable of treating a wide variety of DOE mixed wastes. Ideally, these technologies will minimize the need for waste characterization, handling, sorting, and pretreatment. These technologies will destroy or stabilize the hazardous constituents so that all applicable DOE orders and regulatory requirements are met. Generally, these needs can be classified as requiring more operational experience, better materials of construction, improved materials handling techniques, less waste pretreatment, control of the chemistry in the process, and detailed analysis of the resulting residue and off-gas to determine the constituents that are in the process effluent streams. A secondary consideration is to produce an enhanced final waste form that will pass EPA leach tests and meet the Land Disposal Restrictions. The technologies must be acceptable to the general public and must be permitable by appropriate regulatory agencies. Additionally, it is desirable to minimize the generation of secondary wastes and to minimize pollutant releases to the offgas.

Ultimately, technologies that meet these criteria and that are selected for funding will be demonstrated from their current level of development through pilot-scale tests. When the technology has been successfully demonstrated as a single unit, the process will be incorporated into a pilot-plant system to simulate performance within the context of the prototypical treatment scheme. This phase of the work will be conducted in conjunction with Office of Waste Management staff. Initial testing 


\section{F -5}

should be conducted on a wide variety of waste types to demonstrate the versatility of the technology. Further testing will be used to identify and solve problems associated with the technology and to characterize secondary wastes and effluents. Testing in out years will determine important parameters such as equipment configuration, capital and operating costs, and operational variables.

The following needs are listed in priority order. Principal investigators should refer to the evaluation criteria in the last section of this document for guidance on information that is of interest to the MWIP. Each TTP directed to development and demonstration of technology hardware or processes must also include a simple process flow diagram illustrating how the technology fits into the baseline (Mixed Waste Treaiment Project) flow diagram. This simplified flow diagram should clearly identify:

- technology location in the prototype process flow

- generic waste streams that are highly applicable for the technology and required pretreatment

- input waste pretreatment requirements

- input/output waste streams

- solid wastes and byproducts

- liquid wastes and byproducts

- consumable materials (e.g., catalysts, filters, electrodes)

- . process volume ratio (effluent volume divided by influent volume)

- byproduct/effluent treatment requirements

- decontamination/decommissioning and disposal requirements

- potential for process automation

\section{SPECIFIC NEEDS}

\section{Metals processing}

Metal recovery and recycle for use within the DOE complex is a treatment objective for mixed waste processing. A determination of the ability to substantially partition the radionuclides and possible the heavy metals into the slag phase needs to be accomplished. A technology status review for this process is currently in progress. A technology development program to measure actual partition coefficients and methods for enhancing those coefficients is needed but standards for acceptable levels of contaminants for recycled metals will be need as guidance from DOE.

RDDT\&E on melter technologies (e.g., induction) that can be used to treat inorganic mixed wastes is needed. These melters will be used to decontaminate, volume reduce, and/or stabilize ferrous and nonferrous metals, oxides, noncombustible solids, sludge and potentially small amounts of organic. This RRDT\&E work will involve engineering studies and technology demonstrations to bring the technology demonstrations to implementation on a full-scale basis. This work may be conducted in any or all of three phases, depending on the development status of the technology, and will consist of all or some of the following tasks: 
Phase 1 -- Demonstrate the technology's vability and determine the technology's capabilities

- Periorm proof of principle tests including preliminary mass balances

- Demonstrate the technology on a wide variety of inert wastes to determine the ability to destroy or stabilize hazardous constituents and organics (if present)

- Determine waste loading that can be used

- Determine characteristics of residues and additional treatment requirements of residue

- Investigate the possibility of decontaminating metals for recycling

- Determine characteristics of offgas and the types of pollutants in offgas to be treated

- Determine partitioning of radionuclides and toxic metals in the metal, slag, and offgas.

- Identify problems with technology and investigate potential solutions to problems

Phase 2 -- Establish Operational Parameters

- Evaluate system thermodynamics

- Determine melt chemistry and the need to use additives

- Through long term testing, optimize operational parameters (e.g., temperature, redox state)

- Determine throughput capabilities

- Determine quantity of secondary wastes produced

- Demonstrate a consistent product over a long term operations

- Identify limitations to technology

- Test and verify solutions to operational problems previously identified

- Establish oxidation conditions to completely convert metals to oxides

Phase 3 -- Determine Conceptual Design Requirements for use in Pilot Plant Tests

- Identify and demonstrate materials of construction to maximize component life

- Develop pilot-scale configuration of system including subsystems and components such as waste feeding, residuals removal and handling, and pretreatment requirements

- Estimate life-cycle costs

Deliverables: a. Test plan and technology development approach including preliminary data on comparison of proposed process with available alternatives

b. Results of laboratory-scale test including radionuclide data for selected waste stream(s) as appropriate. 


\section{F-7}

c. Plans for pilot-scale testing including assessment of the potential use of Pacific Northwest National Laboratory pilot-plant.

d. Results of pilot-scale tests.

EM-30's earliest schedule for development of prototypical treatment and Federal Facility Compliance Agreement-based regulatory drivers require that deliverable " $a$ " be drafted by early FY94. Deliverable "b" should be nearing completion by the end of FY94, and "c" must be in progress early in FY95 and continued as appropriate. Preliminary resulte for deliverable " $d$ " must be available by the end of FY95 and will continue as necessary.

\section{Flexible thermal treatment technologies}

Research. development, demonstration, testing, and evaluation (RDDT\&E) of emerging versatile thermal technologies that can treat a wide variety of DOE waste streams is needed to simplify waste processing, simplify permitting requirements, and lower life cycle costs. Processes that are capable of handling heterogeneous raw waste such as mixes of metals, inerts, and organics are of interest. This work will involve engineering studies and technology demonstrations to bring the technology to implementation on a full-scale basis. Development of a plasma-based process is currently in progress; other robust thermal treatment technologies should be considered $f r$ inclusion in this development effort. Experience using flexible thermal treatment technologies should be compared and "lessons learned" from waste processing should be applied to mixed waste treatment. One alternative -rocess is the glass melter; this technology is being developed under the Final Waste Forms technical area. The two processes will be compared as to their effectiveness and the advantages and disadvantages of each.

Phase 1 --Demonstrate the technology's viability and determine the technology's capabilities

- Perform proof of principle test including preliminary mass balances

- Demonstrate the technology on a wide variety of waste types to determine the range of wastes that can be treated

- Determıne ability to destroy and/or stabilize hazardous constituents

- Determine characteristics of residues and additional treatment requirements of residues (an enhanced final residue which does not require additional treatment is most desirable)

- Investigate feasibility of recycling residues through process if additional treatment is required

- Determine characteristics of offgas and the types of pollutants in offgas to be treated

- Determine partitioning of radionuclides and toxic metals 


$$
\text { F-8 }
$$

- Identify problems with technology and investigate potential solutions to problems

- Demonstrate ability to destroy large quantities of combustibles

Phase 2 -- Establish Operational Parameters

- Evaluate systems thermodynamics

- Investigate process chemistry and the need for additives

- Through long-term testing, optimize operational parameters (e.g., temperature, pressures)

- Determine throughout capabilities

- Determine quantity of secondary wastes produced

- Demonstrate a consistent product over long term operations

- Identify limitations to technology

- Test and verify solutions to operational problems previously identified

Phase 3 -- Determine Conceptual Design Requirements for use in Pilot Plant Tests

- Identify and demonstrate materials of construction to maximize component life

- Develop pilot-scale configuration of system including subsystems and components such as waste feeding, residuals removal and handling, and pretreatment requirements

- Estimate life-cycle costs

Deliverables: $\quad$ a. Test plan and technology development approach including preliminary data on comparison of proposed process to baseline.

b. Results of laboratory-scale tests including radionuclide data for selected waste stream(s) as appropriate.

c. Plans for pilot-scale testing including assessment of the potential use of Office of Waste Management pilot-plant.

d. Results of pilot-scale tests.

EM-30's earliest schedule for development of prototypical treatment requires that deliverable " $a$ " be drafted by early FY94. Deliverable "b" should be nearing completion by the end of FY94, and "c" must be in progress early in FY95 and continued as appropriate. Preliminary results for deliverable " $\mathrm{d}$ " must be available by the end of FY95 and will continue as necessary.

\section{Sampling and characterization of thermal treatment emissions}

A consistent methodology for monitoring combustion processes should be developed and implemented for all experiments conducted using thermal treatment under the MWIP. This methodology will ensure that data are comparable and that alternative processes can be directly compared as to performance, risk and life-cycle 
cost. Commercial capability in this regard should be surveyed and utilized as appropriate.

Emissions of metals and organics (i.e., products of incomplete combustion) from incinerators are of public concern and can prevent this technology from being permitted. An aggressive program to understand the mechanisms involved in the metal emission process and in devising methods to reduce those emission to regulatory and publicly acceptable levels is needed. An initial program to model the emission process and to verify that model should be a primary objective for FY94.

\section{Altematives to Incineration}

The MWIP is interested in proposals on alternatives to incineration such as wet air oxidation (catalyzed and non-catalyzed), calcination, supercritical water oxidation, steam reforming, metal and glass melting, and microwave processing. Non-thermal treatment technologies of interest include: biotreatment, electrochemical oxidation, electron beam and other radiolytic methods, silent discharge plasma and other ozonation methods, corona discharge, UV mediated oxidation, sonochemical destruction, and supercritical $\mathrm{CO}_{2}$ extraction. Waste streams that are considered candidates for these technologies are: nitrates, chlorides, radioactively contaminated metals, tritium contaminated mixed wastes, PCB contaminated materials, ion exchange resins, fluid organics, aqueous waste contaminated with organics, and plastics and other room trash (including cellulose). This is a broad category of need that is not as strongly linked to the implementation of the MWTP flowsheet as other areas. Principal investigators ideas are of interest to the MWIP.

An example of the need for alternatives to incineration is the need to consider technologies to replace wet air oxidation. The aqueous waste treatment streams baseline treatment technology for MWTP is a conventional wet air oxidation process. This process suffers the disadvantages of high pressure, low organic feed concentration capabilities, limited waste stream acceptability and lack of predictability, and typically not meeting EPA treatment standards. More robust and effective technologies need to be explored to replace a baseline technology for which major concerns as to performance and permitting are issues. Significant effort to find mature technology improvements or replacements for the wet air oxidation process are needed. Catalyzed wet air oxidation is a mature technology that may better meet the MWTP needs. Commercial availability should be pursued and the state-of-the-art assessed to determine if additional development is required.

The proposed technology should be clearly identified as to why it is an alternative to incineration. That is, is it an altemative because it will address a waste stream that is not amenable to treatment by incineration or is it an alternative to the process of incineration. An example of the waste-stream specific alternative is the treatment of vermiculite which does not burn. TTPs should discuss the improvement of proposed technology over baseline technology (i.e., incineration and wet air oxidation). An alternative process may be more applicable to small problem waste streams; the process need not handle a wide range of waste streams to be of interest to the MWIP. 


\section{F-10}

Desirable advantages for prospective alternatives to incineration are: handle wastes not handled by incineration or handle a wide range of wastes equal to those handled in incineration: technically surpass incineration capabilities. produce more benign wastes, smaller volumes, or no secondary waste; reduce or eiminate fugitive emissions; and operate at lower risk.

This RDDT\&E work will involve engineering studies and technology demonstrations to bring the technology to implementation on a full-scale basis. This work may be conducted in any or all of three phases, depending on the development status of the technology, and will consist of all or some of the following tasks:

Phase 1 -- Demonstrate the technology's viability and determine the technology's capabilities

- Perform proof of principle tests including preliminary mass balances

- Demonstrate the technology on a wide variety of waste types to determine the range of wastes that can be treated

- Determine ability to destroy and/or stabilize hazardous constituents

- Determine characteristics of residues and additional treatment requirements of residues

- Investigate potential to purify water so it can be recycled or meet regulatory requirement for release to the environment

- Determine characteristics of offgas and the types of pollutants in offgas to be treated

- Identify problems with technology and investigate potential solutions to problems

Phase 2 -- Establish Operational Parameters

- Investigate process chemistry and the need for additives

- Through long-term testing, optimize operational parameters (e.g., temperature, pressures)

- Determine throughout capabilities

- Determine quantity of secondary-wastes produced

- Demonstrate a consistent product over long term operations

- Identify limitations to technology

- Test and verify solutions to operational problems previously identified

Phase 3 -- Determine Conceptual Design Kequirements for use in Pilot Plant Tests

- Identify and demonstrate materials of construction to maximize component life

- Develop pilot-scale configuration of system including subsystems and components such as waste feeding, residuals removal and handling, and pretreatment requirements

- Estimate life-cycle costs 


\section{$\mathrm{F}-11$}

Deliverables:

a. Test plan and technology development approach including preliminary data on comparison of proposed alternative process with available technology.

b. Results of laboratory-scale tests including radionuclide data for selected waste stream(s) as appropriate.

c. Plans for pilot-scale testing including assessment of the potential use of Lawrence Livermore National Laboratory pilot-plant.

d. Results of pilot-scale tests.

EM-30's earliest schedule for development of prototypical treatment requires that deliverable "a" drafted by the end of FY94. Deliverable " $b$ " should be nearing completion by the end of FY95, and "c" must be in progress early in FY95 and continued as appropriate. Preliminary results for deliverable " $d$ " must be availability by the end of FY96 and will continue as necessary. 


\section{INTERNAL DISTREUTION}
1. T. Abraham
2. P. Backus
3. M. Baker
4-8. J. Berry
9. G. Bloom
10. C. Brown
11. A. Croff
12. T. Conley
13. R. Genung
14. B. Hightower
15. D. Hutchins

16. G. Kamp

17. T. Malinauskas

18. L. Mezga

19. J. Perona

20. M. Savage

21. P. Taylor

22. Central Research Library

23. Document Reference Center

24. ORNL Patent Section

25-26. ORNL Laboratory Records

27. ORNL Laboratory Records, RC

\section{EXTERNAL DISTRIBUTION}

28. N. Askew, Westinghouse Savannah River Co., P.O. Box 616, Aiken, SC 29802

29. C. Baldwin, EG\&G Rocky Flats, P.O. Box 464, Highway 93 \& Cactus, Bldg. 881, Golden, CO 80402-0464

30. M. Ballestri, BDM Federal, 20251 Century Blvd., 4th Floor, Germantown, MD 20874

31. J. Bassi, EM-351, U.S. Department of Energy, 12850 Middlebrook Road, Germantown, MD 20874

32. J. Batdorf, SAIC, 545 Shoup Ave., P.O. Box 50697, Idaho Falls, ID 83405-0697

33. S. Bates, EG\&G Idaho, Inc., P.O. Box 1625, MS-3930, Idaho Falls, ID 83415-3930

34. T. Bergsman, Battelle Pacific Northwest Laboratory, Battelle Boulevard, MS P7-41, Richland, WA 99352

35. L. Borduin, Los Alamos National Laboratory, One Bikini Road, MS K557, Los Alamos, NM 87545

36. M. Brooks, Waste Policy Institute, 555 Quince Orchard Blvd., Suite 600, Gaithersburg, MD 20879

37. H. Burns, Westinghouse Savannah River Co., P.O. Box 616, Bldg. 704-61s, Aiken, SC 29808

38. G. Bryan, Pacific Northwest Lab, Battelle, Blvd., Richland, VA 99352

39. P. Castel, U.S. DOE/HQ, WINCO, 20201 Century Blvd., Rm. 408, Germantown, MD 20874

40. D. Chaiko, Argonne National Lab, CMT/Bldg. 205, 9700 S. Cass Ave., Argonne, IL 60439

41. C. Collier, BDM Federal, 20251 Century Blvd., 4th Floor, Germantown, MD 20874

42. C. Cooley, U.S. Department of Energy, EM-50, Trevion II, Washington, D.C. 20585-0002

43. T. Cooper, Westinghouse Hanford Corp., 2355 Stevens Dr., MS N3-12, Richland, WA 99352 
44. A. Corstillo, FERMCO, 25 Merchant St., 3rd Floor Technology, Springdale, OH 45246

45. S. Couture, Lawrence Livermore National Lab, P.O. Box 808, L-591, Livermore, CA 94551

46. G. Coyle, EM-541, U.S. Department of Energy, 12800 Middlebrook Road, Trevion II, Germantown, MD 20874-1290

47. P. Coyle, EM-55, U.S. Department of Energy, 19901 Germantown Road, Germantown, MD 20874

48. J. Cunnane, Argonne National Lab, 9700 South Cass Ave., Bldg, 205, Argonne, IL 60439

49. J. Dalton, SAIC, 545 Shoup Ave., P.O. Box 50697, Idaho Falls, ID 83405-0697

50. J. Dancz, SAIC, Quince Diamond Executive Center, 555 Quince Orchard Rd., Suite 500, Gaithersburg, MD 20878-4137

51. R. Darnell, EG\&G Idaho, Inc., P.O Box 1625, MS-3950, Idaho Falls, ID 834153950

52. L. Dewitt, SAIC, 545 Shoup Ave., P.O. Box 50697, Idaho Falls, ID 83405-0697

53. S. Domotor, U.S. DOE, EM-351, Trevion II, Washington, D.C. 20585

54. P. Erickson, EPA-RREL, 5995 Center Hill Ave., Cincinnati, OH 45224

55. J. Fannon, U.S. DOE, HQ/EM-50, 20201 Century Blvd., Bellmeade Bldg. II, Rm. 402, Germantown, MD 20874

56. G. Fitzgibbon, WHC, P.O. Box 1970, MS H6-07, Richland, WA 99352

57. C. Frank, EM-50, U.S. Department of Energy, Forrestal Office Building, Washington, DC 20585

58. E. Franz, Brookhaven National Lab, Environmental \& Waste Technology Center, North Railroad St., Bldg. 830, Upton, NY 11973

59. N. French, Sandia National Laboratory-Livermore, 7011 East Avenue, Livermore, CA 94550

60. M. Fuhrmann, Brookhaven National Laboratory, Building 703, Upton, NY 11973

61. A. Gatuchette, US EPA, Risk Reduction Engineering Lab, 26 W. Martin Luther King Blvd., Cincinnati, OH 45268

62. R. Gehrke, EG\&G Idaho, Inc., 2151 N Blvd., MS-7111, P.O. Box 1625, Idaho Falls, ID 83415

63. R. Geimer, SAIC, 545 Shoup Ave., P.O. Box 50697, Idaho Falls, ID 83405-0697

64. R. Gillins, SAIC, 545 Shoup Ave., P.O. Box 50697, Idaho Falls, ID 83405-0697

65. K. Hain, EM-55, U.S. Department of Energy, 1000 Independence Ave., SW, Washington, DC 20585

66. T. Harris, SAIC, 545 Shoup Ave., P.O. Box 50697, Idaho Falls, ID 83405-0697

67. P. Hart, U.S. Department of Energy, EM-542, Trevion II, 19901 Germantown Rd., Germantown, MD 20874-0002

68. J. Helt, Argonne National Laboratory, 9700 S. Cass Avenue, Bldg. 205, Argonne, IL 60439

69. D. Helton, Westinghouse Savannah River Co., P.O. Box 616, Bldg. 773-41 A., Rm. 228, Aiken, SC 29802

70. B. Hickman, Lawrence Livermore National Lab, 7000 E. Ave., Livermore, CA 94550

71. D. Hjeresen, AET, MS-P641, Bikini Road, Los Alamos, NM 87545

72. J. Hunter, Westinghouse Hanford Co., P.O. Box 1970, MS L531, Bldg. 3766, Rm. 14, Richland, WA 99352

73. D. Isbell, EM-40, U.S. Department of Energy, 12800 Middlebrook Road, Trevion II, Germantown, MD 20874 
74. P. Jones, BDM Federal, 20251 Century Blvd., 4th Floor, Germantown, MD 20874

75. P. Kalb, Brookhaven National Lab, Environmental \& Waste Technology Center, North Railroad Street, Bldg. 830, Upton, NY 11973

76. T. Kan, Lawrence Livermore National Lab., P.O. Box 808, L-467, Livermore, CA 94550

77. B. Kitchen, Savannah River Laboratory, Westinghouse Savannah River Co., P.O. Box 616, Aiken, SC 29802

78. K Kostelnik, EG\&G Idaho, Inc., P.O. Box 1625, MS-3930, Idaho Falls, ID 834153930

79. D. Kried, Battelle Pacific NW Lab, Battelle Blvd., Richland, WA 99352

80. O. Kruger, Westinghouse Hanford Company, 2355 Stevens Dr., Richland, WA 99352

81. M. Lankford, EM-552, U.S. Department of Energy, 12800 Middlebrook Road, Trevion II, Germantown, MD 20874

82. M. Larsen, SAIC, 545 Shoup Ave., P.O. Box 50697, Idaho Falls, ID 83405-0697

83. G. Leatherman, SAIC, Quince Diamond Executive Center, 555 Quince Orchard Rd., Suite 500, Gaithersburg, MD 20878-0697

84. S. Lein, EM-54, U.S. Department of Energy, 12800 Middlebrook Road, Trevion II, Germantown, MD 20874-1290

85. J. Lippold, BDM Federal, 20251 Century Blvd., 4th Floor, Germantown, MD 20874

86. P. Lurk, EM-552, U.S. Department of Energy, 12800 Middlebrook Road, Trevion II, Germantown, MD 20874

87. J. Mayberry, SAIC, P.O. Box 50697, Idaho Falls, ID 83405-0697

88. W. McCulla, Los Alamos National Laboratory, SM 30 Warehouse, Bikini Road, MS J-563, Ios Alamos, NM 87545

89. J. McFee, IT Corporation; 5301 Central Ave., NE, Albuquerque, NM 87108

90. K. Merrill, EG\&G Idaho, Inc., 2151 N Blvd., MS-3930, P.O. Box 1625, Idaho Falls, ID 83415

91. R. Moats, BDM International, 12850 Middlebrook Road, Suite 300, Germantown, MD 20874

92. J. Moore, U.S. Department of Energy, P.O. Box 2001, Oak Ridge, TN 37830-8620

93. D. Musgrave, Lawrence Livermore National Laboratory, 7000 East Avenue, P.O. Box 808, L-440, Livermore, CA 94550

94. T. Myrick, SAIC, P.O. Box 2501, Oak Ridge, TN 37831

95. R. Nakaoka, Los Alamos National Laboratory, P.O. Box 1663, MS-6517, Los Alamos, NM 87545

96. M. Nawar, Office of Radiation Programs, Environmental Protection Agency, 401 M St. SW, ANR-461, Washington, DC 20460

97. G. Ordaz, EM-541, U.S. Department of Energy, 12800 Middlebrook Road, Trevion II, Germantown, MD 20874

98. C. Owens, EG\&G Idaho, P.O. Box 1625, Idaho Falls, ID 83415-3960

99. R. Peters, Battelle-Pacific Northwest Lab, P.O. Box 999, MS P7-41, Richland, WA 99352

100. W. Phillips, Roy F. Weston Office of Technology Services, 12850 Middlebrook Road, Germantown, MD 20874

101. W. Pitt, Texas A\&M University, Department of Nuclear Engineering, College Station, TX 77843

102. B. Place, Westinghouse Hanford Co., Solids \& Liquids Waste Remediation, P.O. Box 1970, MS H5-33, Richland, WA 99352 
103. W. R.oss, Battelle-Pacific Northwest Lab, P.O. Box 999, MS P7-41, Richland, WA 99352

104. R. Schumacker, Westinghouse Savannah River Co., SRTC, P.O. Box 616, Bldg. 773-42A, Aiken, SC 29808

105. B. Schutte, EM-54, U.S. Department of Energy, 12800 Middlebrook Road, Trevion II, Germantown, MD 20874-1290

106. B. Schwinkendorf, BDM Federal, 1801 Randolph Rd., SE, Argonne, IL 60439

107. G. Sevigny, Battelle-Pacific Northwest Lab, P.O. Box 999, MSIN P7-42A, Aiken, SC 29808

108. M. Shupe, EM-541, U.S. Department of Energy, Trevion II, Room 440, 19901 Germantown Road, Germantown, MD 20874-1290

109. D. Singh, Argonne National Lab, 9700 South Cass Ave., Bldg. 212, Rm. G-233, Argonne, II 60439

110. D. Skrincosky, Strategic Technology International, 20 Avon Meadow Ln., Suite 220, Avon, CT 06001

111. S. Slate, Battelle Pacific Northwest Laboratory, 902 Battelle Blvd., P.O. Box 999, KI-25, Richland, WA 99352

112. S. Stein, Battelle, Seattle Research Center, 4000 NE 41st, Seattle, WA 98105-5428

113. E. Steverson, SAIC, 545 Shoup Ave., P.O. Box 50697, Idaho Falls, ID 83405-0697

114. P. Sydenticker, BDM Federal, 20251 Century Blvd., 4th Floor, Germantown, MD 20874

115. H. Turner, ARCO, 2300 W. Plano Parkway, Plano TX, 75075-8499

116. T. Timmerman, Mason \& Hanger, Bldg. 11-2, P.O. Box 50697, Idaho Falls, ID 83405-0697

117. T. Uhlmeyer, MD-Ferguson Co., 7295 Highway 94 South, St Charles, MO 63304

118. J. Vavruska, Equinox, Ltd., 872 Don Cubero Ave., Santa Fe, NM 87501

119. C. Ward, Westinghouse Savannah River, Building 773-A, D-1134, Aiken, SC 29808

120. S. Warren, EM-442, U.S. Department of Energy, 12800 Middlebrook Road, Trevion II, Germantown, MD 20874-1290

121. J. Witzeman, P.O. Box 398704, 7400 Williey Road, Fernald, OH 45030

122. S. Wolf, U.S. Department of Energy, Trevion II, 19901 Germantown Road, Germantown, MD 20874

123. W. Wolfe, SAIC, 545 Shoup Ave., P.O. Box 50697, Idaho Falls, ID 83405-0697

124-125. A. Wollerman, Trevion I, 12850 Middlebrook Road, Suite 400, Room 721, Germantown, MD 20874

126. M. Zenkowich, EM-323, U.S. Department of Energy, 12800 Middlebrook Road, Germantown, MD 20874

127. Office of Assistant Manager, Energy Research and Development, DOE-OR, P.O. Box 2001, Oak Ridge, TN, 37831

128-129. Office of Scientific and Technical Information, P.O. Box 62, Oak Ridge, TN 37831 

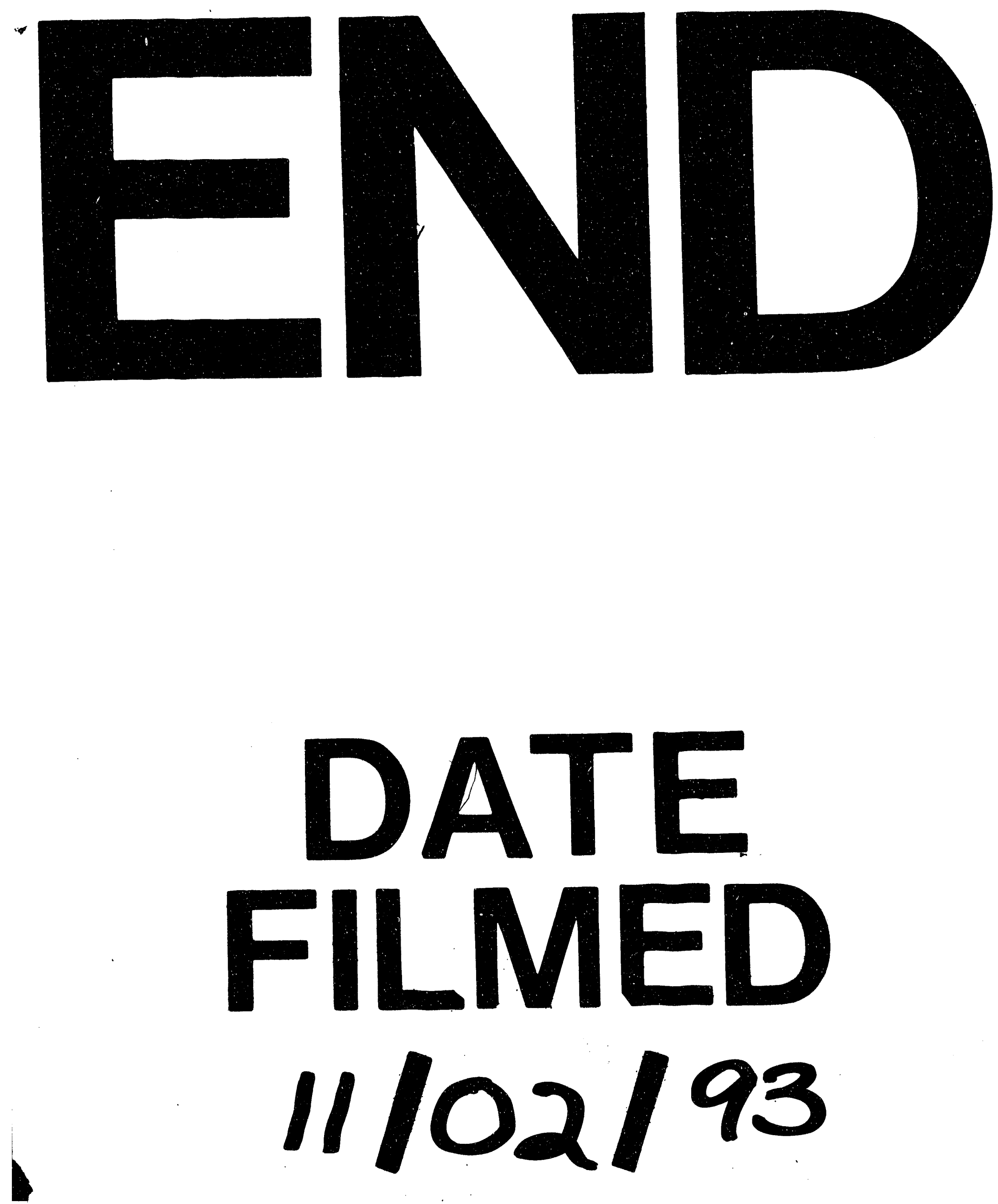
